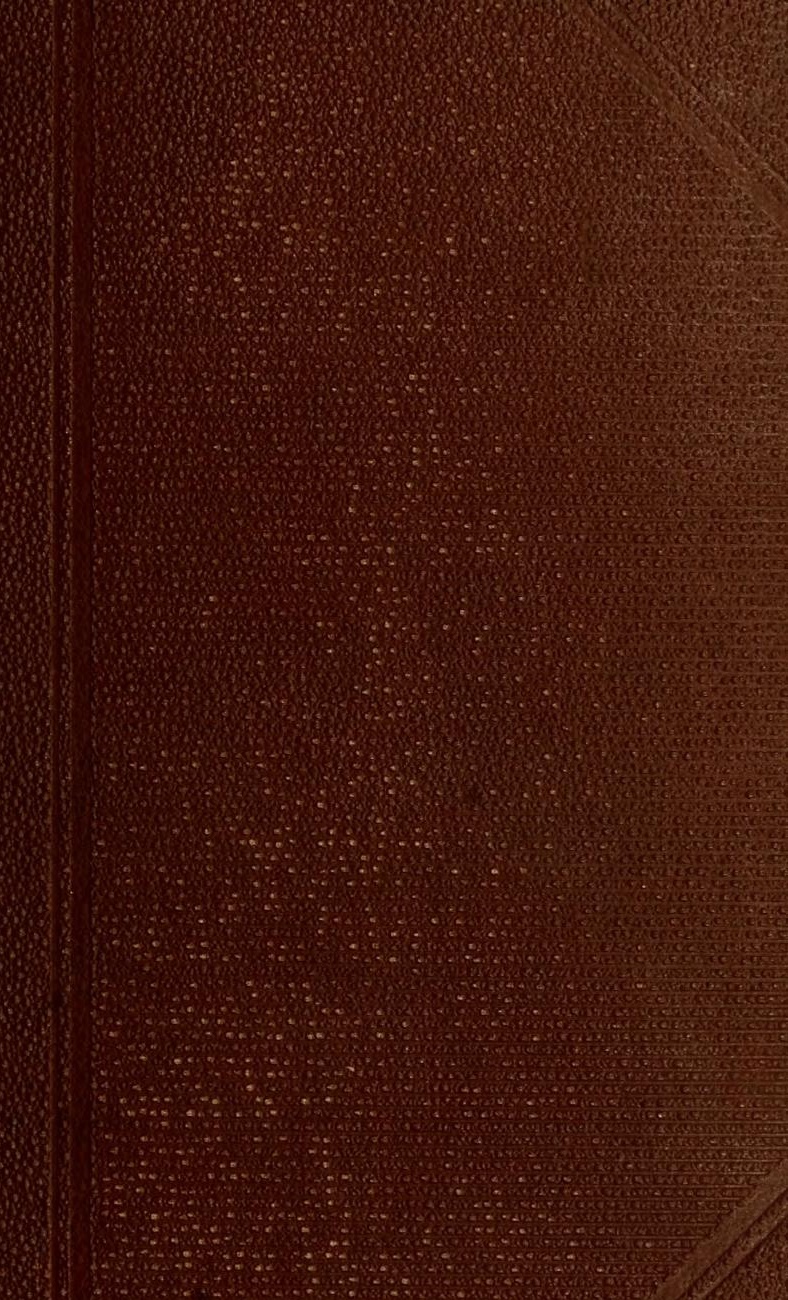




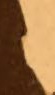








\title{
COMPARATIVE ZOOLOGY,
}

\author{
STRUCTURAL AND SYSTEMATIC.
}

FOR USE IN SCHOOLS AND COLLEGES.

\section{By JAMES ORTON, Pн.D.,}

PROTESSOR OF NATULAL HISTORY IN VASGAR COLLEGE: CORLESPONIING MEMBER OF THE ACADEMX OF NATURAY, SOIENOES, PHLADFLPHIA, ANID OF THE LYOREM OF NATURAL HISTORY, NICW YORK; AUTHOR OF "THE ANDES AND THE AMAZON," ETE.

"The education of a naturalist now consists chiefly in leurning how to compare."-AGAssiz.

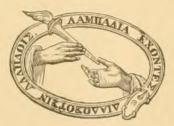

\section{NEW YORK:}

HARPER \& BROTHERS, PUBLISHERS, F R A N K L I S Q UA RE.

1880 . 
Entered according to Act of Congress, in the year 1876, by HARPER \& BROTHERS,

In the Office of the Librarian of Congress, at Washington. 


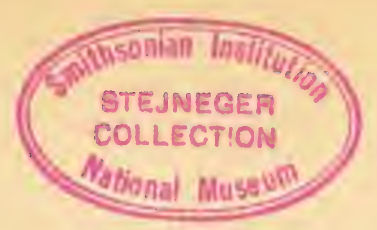

\section{PREFACE.}

True distinctive character of this work consists in the treatnent of the whole Animal Kringdon as a mit; in the comprative study of the development and rariations of organs and their functions, from the simplest to the most complex state; in withlolding Systematic Zoolugy until the stuelent has mastered those structural aflinitics njon which true clinsitication is founded; and in heing titted for Iligh Schools and Mixed Schools by its langratge and illustrations, yet enoing far enongh to constitute a consplete grammar of the science for the moler-graduate comse of any College.

It is derigned sulely as a mamual for instruction. It is not a work of reference, nor a treatise. So far as a book is encelolupediace, it is mutit for a text-book. This is prepared on the principle of " just enongh, and no more." It aims to present clearly, and in a somewhat new form, the established facts and prineiples of Zoology. All theoretical and debatable points, and erery fact or statenent, howerer valuahle, which is not ahsolutely necessary to a clear and aleynate conception of the learling principles, are onitted. It is written in the light of the nust recent phatse of the science, but not in the interest of any particular theory. To have given an exhantive surrey of animal life wonld not only have heen mudesirable, but imposible. Even Curier's great wirk must be supplemented by nusemms, 


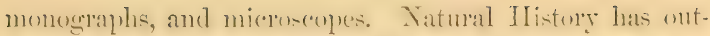
grown the limits of a single houk. Trial has proved the folly of giving the student so many things to learn that lie has no time to molerstand, and the error of condemming the student to expend his strength mon the details of classification, which may change in the comming decarle, instead of mpon structure, which is permanent. Of course, specialists will miss many things, and find abmolant rom for eriticism in what they regard as defieiencies: lut the work should be judged by what it dres contain, rather than lyy what it does not.

What is claimed, in the language of inventors, is the selection and arangement of escential principles and typical illustrations from the stand-point of the teacher. The synthetic method is employed, as heing the most natmal : to begin with complex Man, instead of the simplest forms, would give a false idea. Man is not a molel, but a mon. strosity, the most modified of Tertehrates. But these ontlines must be filled up, on the part of the teacher, by lectmes, and hy the exhibition of specimens, and. on the part of the student, by observation (noting, ahove all, the characteristic hal,its of animals), and by personal work with the knife and microserye. No text-bork ean take the plare of nature, or supersede oral instruction from a (onilpetent teacher.

Suggestions and corrections from naturalists and teachers will be thankfully received.

In a work of this character, which is but a compend of the sabors of all naturalists, it would be superfluous to make arkinowledgments. The works referred to on lage 385 have been specially consulted. 


\section{CONTENTS.}

INT'RODUCTION.

TAGF

Definition of Zoology, and its Place among the Sciences................. 11

Historical Sketch .................................................... 14

\section{PART I.-STRUCTURAL ZOOLOGY.}

CHAPTER I.

MrNerals and Organized Bomies distixguished.

CHAPTER II.

Plants and Anmals distingdisired.

CHAPTER III.

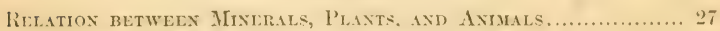

CHAPTER IV.

Nitcre of Life

CHAPTER V.

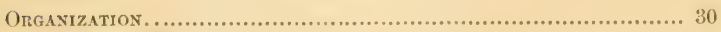

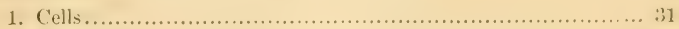

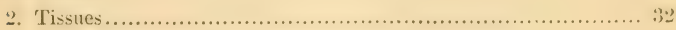

3. Organs, and their Functions.................................... 41

CHAP'TER VI.

Netnitios. 4

CHAPTER VII.

Trie Food of Aximals. 46 
How ANmat: Lit

1. The Prehention of Fund . . ................................. 4 !

2 . The Ilouths of Aumals....................................... it

3. The Teeth of Animals........................................ 62

4. Deglutition, or how Animals swallow.......................... it

CHAPTER IX.

The Alimextmix Caxal.

CHAPTER X.

How Animals Drgest.

CHAPTER XI.

The Aesonbent Sistem. $9: 3$

CHAPTER XII.

The Bloed of ANmills. 96

CHAPTER XIII.

The Circulation of the Blood. 102

CHAPTER XIV.

How Axmals Breathe. 110

CIIAPTER XV.

Secretios and Exeretion.

CHAP'TER XVI.

The Skin and Sreleton. 125

\section{CHAP'IER XVII.}

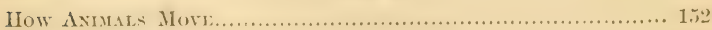

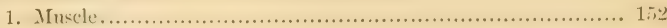

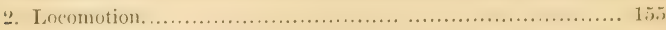

('ILAPTER XVIII.

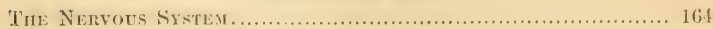

1. The Senses...................................................... 173

2. Instinct and Intelligence...................................... 181

3. The Voices of Animals ........................................ 18ז 
REProdectioN.

CHAP'TER XX.

DeVElotyext. $19 \%$

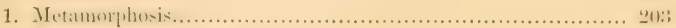

2. Alternate fieneration..........................................

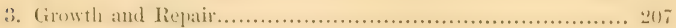

4. I.ikeness and Variation....................................... $2(19)$

5. Homology; Analogy, and Correlation............................. 211

6. Relations of Number, Size, Form, and Rank................... 214

7. Thie Struggle for Life....................................... 219

\section{PART II.-SYSTEMATIC ZOOLOGY.}

\section{CHAPTER XXI.}

The Classification of Animals................................... 223

Protozoans................................................... $2: 31$

Colenterates........................................................ 28

Echinoderms...................................................... 247

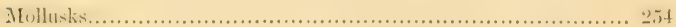

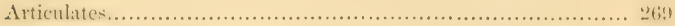

Vertebrates. ....................................................... 295

CHAPTER XXII.

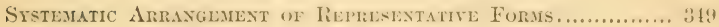

\section{CHAI'TER XXIII.}

The Distribution of Aximals. 



\section{INTROD U C T IO I.}

1. Definition of Zoology, and its Place among the Sciences.-The province of - Tutural Kistory is to describe, compare, and classify natural oljects. These objects have been divided inte the "organic" and the "inorganic," or these which are, and those which are not, the prolucts of life. Bioln!y!y is the science of the former, and Mineralongy the sciener of the latter. Biolery arain separates into liotemy, or the Xitural IIistory of IPlants, and Zooloygy, or the Natural IListory of Animals; while Mineralegy divieles into Mimorelog!! froprer, the science of mineral species, and Lithole!g!!, the science of mineral aggregates or rocks. Gomlongy is that comprehensive knowlerge of the earth's structure and developmont which rests on the whole doctrine of Natural IIistory.

If we examine a piece of chalk, and determine its physical and chemical characters, its morle of ocemrence aml its uses, so as to distinguish it from all other forms of matter, we hate its Mineralogy. But chalk oceurs in vast natural berls: the examination of these mases-their origin, structure, position, and relation to other rocks-is the work of the Lithologist. Futher, we oherve that while chalk and marble are ehemically alike, they widely differ in another respect. Cirindine a piece of chalk so thin that we ean see through it, and putting it muler a microscope, we find imberled in it immunerable lunlies, abont the humberth of an inch in cliameter, having : well-elefinert, symmetrical shape, and chambereel like a Nautilus. We can mot say these are anceiclental agrelegations, not are they arystals: if the oyster-shell is formerl by an oyster, these also) must be the produets of life. Indeed, the dredge brings up similar microscopic slieletons from the bottom of the Atlantic. so we conchule that chalk is but the dried mul of an ancient 
sea, the cemetery of countless animalenles that liverl and died lone aco. The eonsideration of their fossil remains belones 16) P'aleontoleng, or that part of Jiology which deseribes the relices of extince forms of life. 'T'o stmely the stratieraphical poxition of the chalk-bed, and by the aid of its l'aleontolegy to determine its age and part in the world's history, is the business of Geology.

Of all the sciences, Zoology is the most extensive. Its fielil is a world of varied forms-hundreds of thous:mels in number. To retermine their origin and development, their structure, habits, distribution, and mutual relations, is the work of the Zoologist. But so many and far-reaching are the aspects under which the animal ereation maty be contemplaterl, that the general science is beyond the gratsp of any single persun. Special departments hare, therefore, arisen; and Zoolengy, in its comprehensive sense, is the combinerl result of the labors of many workers, each in his own line of research.

Structural Zoology treats of the organization of animals. There are two main branches: A futomy, which consiclers the constitution ant construction of the animal frame; and P/y,siology, which is the study of the apparatus in atetion. The former is separated into E'mbryolongy, or an aceount of the snecessive molifications through which an animal passes in its ilevelopment from the exy to the adult state; and $1 / 0$ r $^{-}$ jtholo!y!/, which includes all inquiries concerning the form of mature animals, or the form and arrangement of their oreans. The microscopical examination of any part, especially the tissues, belongs to II istology. Compuntere Zoology is the (omparison of the anstomy and physiolosy of all animals, cxisting amblextinct, to diseover the fundamental likeness umlemeath the superficial differences, and to trace the adaptation of orwans to the habits and spleres of life. It is this compraraive science which has led to such grand generalizations as the unity of structure amidst the diversity of form in the animal ereation, and by resealing the deagrees of affinity between species has enabled us to classify them in natural groups, and thus laicl the fomblation of Systematic Zoology. When the stuly of structure is limited to a particular class or species of animals, or to a particular orgam or prat, monographic sciences are created, as Uinithotomy, or anatomy of birds; 


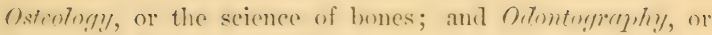
the natural history of teeth.

Systematic Zoology is the chissifieation of animals, or the stmely of animals, as to their kimls, wiving to each a distinctive name amb description. The systematic knowledge of the ser eral clisses, as Insects, lieptiles, am birrls, hats given rise to

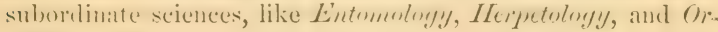
nitholu!!!!. :*

Distributive Zoology is the knowlerlere of the suecessive appeamance of animals in the order of time (Paleontology in part), and of the geographical and physieal distribution of animals, living or extinct, over the surface of the earth.

Theoretical Zoology includes those provisional modes of gromping facts, and interpreting them, which still stam wating at the sate of science. They maly be true, but we can not sily that they are true. 'The evidence is incomplete. Such are the theories which attempt to explain the origin of life and the origin of species.

fuppose we wish to understand all about the Horse. Our first oloject is to stuly its structure. The whole body is inclesed within a hille, a skin coverenl with hair; and if this hicle be taken off, we find a wreat mass of flesh or muscle, the sulstance which, by its pow of contraction, enables the animal to move. On removing this, we have a series of bones, bomml together with ligaments, and forming the skeleton. I'ursuing our researches, we find within this frame-work two main cavities: one, heginning in the skull and rumning through the spine, containing the brain and spinal marrow; the other, commencing with the mouth, contains the gullet, stomach, intestines, and the rest of the apparatus for digestion, and also the heart and lungs. Examinations of this character would wive us the Amutomy of the IIorse, or, more precisely, II ipprotomy. The stuly of the bones alone would be its.

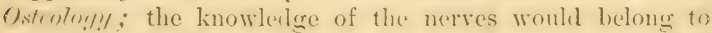
Timetomi!. If we examinerl, unter the microseope, the minute structure of the latir, skin, tlesh, blook, and bone, we would leam its IVistolog!\%. The consiuleration of the manifold changes molergone in developing from the eque to the full-

* Numbers like this refer to the Notes at the end of the volume. 
grewn amimal, would be the Evintrigelogy of the ILorse; and

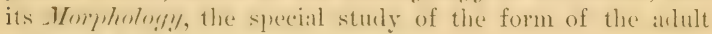
animal and of its internal organs.

Thus far we have been looking, as it were, at a steamengine, with the fires out, and nothing in the boiler: but the borly of the living IIorse is a beatutifuly forment, actire machine, and every part has its different work to do in the working of that machine, which is what we call its life. The seience of such operations as the grinding of the for in the complex mill of the mouth; its cligestion in the laboratory of the stomach; the pumping of the bloon through a vast system of pipes over the whole bouly; its purification in the lumes; the process of growth, waste, and repair ; and that wombens telegriph, the brain, receiving impressons, and semeling messages to the muscles, by which the animal is entowed with voluntary locomotion-this is Ply!siolongy. But IIorsers are not the only living ereatures in the world; and if we complare the structures of various animals, as the IIorse, Zebra, Dow, Monkey, Eagle, and Codtish, we shall find more or less resemblances and differences, enomgh to enable us to (dasify them, sml give to each a deseription which will distingmish it from all others. This is the work of systemutir Zomlongy. Inrever, the Horses now living are not the only kinds that have ever lived for the examination of the earth's crust-the great hurial-gromul of past ages-reveals the bones of numerous horse-like animals: the sturly of this pre-atamite race belongs to I'uleontolor!!. The chronological and geographical distribution of species is the department of Distributice Zoolo:!! Fyeenlations abont the origin of the molern IIorse, whether hy special creation, or by development from some allierl form now extinct, are kelt aloof from demonstrative science, under the head of Theoretical Zoology.

2. History.-The treek philosopher Aristotle (r.c. :38432\%) is cille." the "Father of Zeologr." Certinly, he is the only great representative in aneient times, though his frepuent allusions to familiar works on anatomy show that something had been done before him. His "Ilistory of Animals," in nine books, displays a womderful knowledge of external and internal structure, habits, instinets, and uses. Ilis descrip)tions are incomplete, but generally exact, so far as they go. 
Alexander, it is said, gave him nine hundrerd talents to colleet. materials, and put at his disposil several thous:mel men, for hunting specimens and procuring information.

The Romans aceomplished little in natural science, though their military expeditions furnished unrivaled opportunities. Nearly three centuries and at half after Aristotle, Pliny (A.1). 2:3-79) wrote his "Natural IIistory." He wats al voluminons compiler, not an observer: he alded hardly one new fact. He states that his work was extrated from over two thousand volumes, most of which are now lost.

During the Mirlule Ages, Natural IIistory was studien in the hook of the ancients; and at the close of the fifteenth century it was found where Pliny had left it, with the addition of many vague hypotheses and silly fancies. Allertus Magnus, of the thirteenth century, and Commol Gesmere and Aldrovandus, of the sixteenth, were yoluminous writers, not naturalists. In the latter half of the sixteenth century, men began to observe nature for themselves. The earliest noteworthy researches were made on Fishes, by Rindelet (1507$1566)$ and beton (1517-1564), of France, and silviani (1514$1572)$, of Italy. They were followed by valuable olservations upon Insects, hy Reeli (1626-1698), of Italy, and swammerdam (16:3-1850), of Ifollame; and toward the end of the same century, the Dutch naturalist, Leeuwenhoeck (163:1723), opened a new world of life by the use of the mieroscope.

But there was no real alvance of Srstematic Zoology till the arlvent of the illustrious John Ray $(1628-1705)$, of Lnglant. IIis "Synopsis," published in 1693, contained the first attempt to classify animals aceorling to structure. Ray was the forerunner of "the immortal swede, Limmans (i 50 1625), "the great framer of precise ami definite illeas of natwral objects, and terse teacher of the briefest and clearest expressions of their differences." ITis chief merit was $\vdots$ d defin. ing generie groups, and inventing specitic names." senreely less important, howerer, was the impulse which he gave to the pursuit of Natural IFistory. The spirit of infuiry, which his genins infusen among the great, produced vorages of research, which leal to the formation of national museums. The first expedition was sent forth by (ieorge III. of England, in 
1765. Jin:tumur (16:3-1755) marle the earliest zonlogical collection in France; and the Wrest Indian collections of sir Il:ms sluane $(1660-1752)$ were the nucleus of the British Mus.rm. The aceumulation of specimens suggested comparisons, which eventually resulted in the highest alvance of the science.

The brilliant style of Buffon (1707-17Ss) mate Zoology popular not only in France, but throughout Europe. While the genius of Linnepus led to classification, that of Buffon lay in deseription. Ie was the first to call attention to the subjeet of Distribution. Lamarek (1745-1829), of P'aris, was the next great light. The publication of his "Animaux saus Tertibres," in 1:01, was an ejoch in the history of the lower animals. Ife was also the first prominent advocate of the transmutation of species.

But the brightest luminary in Zoology was George Cuvier (1769-18:32), a German, born on French soil. before his time, "there was 110 great principle of classification. Facts were accumulaterl, and more or less systematized, but they were not yet arranged aceording to law; the principle was still wanting by which to generalize them and give meaning and ritality to the whole." It was Cuvier who found the key. Ile was the first to so interpret structure as to be able from the inspection of one bone to reconstruct the entire animal, and assign its position. II anatomical investigations revealed the natural affinities of amimals, and let to the grand generalization, that the most comprehensive groups in the lingtom were baserl, not on special characters, but on different plans of structure. Palissy had long ago (1580) asserted that petrifier shells were of animal origin; but the publication of Cuvier's "Memoir on Fossil Elephants," in 1800, was the beginning of those profound researches on the remains of ancient life which ereated Paleontology. The disenvery of the true relation between all animals, living and extinct, opened a boumdless tield of inquiry; and from that day the arlvance of thology has been umparalleled. Special stullies of particular parts or classes of animals have so rapidly developerl, that the history of Zoolony luring the last fifty years is the history of many sciences. ${ }^{3}$ 


\section{PART I.}

\section{STRUCTURAL ZOOLOGY.}


The first thing to be determined about a new specimen is not its name, but its most prominent character. Until you know an animal, care not for its name. - AGAssiz.

The great benefit which a scientific education bestows, whether as training or as knowledge, is dependent upon the extent to which the mind of the student is brought into immediate contact with facts-upon the degree to which he learns the habit of appealing directly to Nature.-HuxLex. 


\section{COMPARATIVE Z0OLOGY.}

\section{CHAPTER I.}

AINERALS AND ORGANIZED BODIES DISTINGCINHED.

Nature may be separated into two great lingdomsthat of mere dead matter, and that of matter under the influence of life." These differ in the following points:

(1) Composition.--Fewer elements are used in the organic world than in the mineral. Over sixty are found in the latter, while four or five make up the former. Organic Inclies have a striking miformity of composition: the majority being ternary compounds, consisting of carbon, hydrogen, and oxygen; or quaternary, adding nitrogen; while a few only contain also sulphur or iron. But minerals exhibit a greater variety in their constitution, being made of one element alone, or two or more. In organic substances each ingredient is equally united with all the rest, while mineral compounds can be resolved into binary combinations. Thus, fibrine, which is compused of carbon, hydrogen, oxygen, and nitrogen, is called a quaternary compound; and carbonate of ammonia, made of the same materials, is eonsidered a binary union of two other binary compounds, carbonic acid and ammonia. Jint this distinction is shaken by the probability that binary principles exist in living bodies. It is true, howerer, that the constitution of organic substances is more complex than that of minerals; for, though composed of few elements, 
a large number of atoms of those elements enter into combination. 'Thus, one molecule of fibrine contains 216 atoms of carbon, 169 of hydrogen, 68 of oxygen, 27 of nitrogen, and 2 of sulphur. Organic molecules are therefore larger than the molecules of minerals. Furthermore, combinations formed under the influence of life are invariably characterized by the presence of carbon and water. An animal always contains a mixture of solids, liquids, and gases.

(2) Structure - A mineral is homogeneons, while an organized body is heterogeneous; $i$. e., it is composed of different parts, called tissues and organs, having peculiar uses and definite relations to one another. The tissnes and organs, again, are heterogeneous, consisting mainly of microscopic cells, a structure developed only by vital action. All the parts of an organism are mutually dependent, and reciprocally means and ends, while each part of a mineral exists for itself. The smallest fragment of marble is as much marble as a mountain-mass; but the fragment of a plant or animal is not an individual. The particles of a mineral are held together by colesion; the exact nature of the force, commonly called "life," which presides orer an organized body remains to be discovered.

(3) Size and Shape. - Living bodies gradnally acquire determinate dimensions; so do minerals in their perfect or crystal condition. But mnerystallized, inorganic bodies have an indefinite bulk. Most minerals are amorphous; crystals lave regular forms, bounded, as a rule, by plane surfaces and straight lines; plants and animals are circumscribed by curved surfaces, but never assume accurate geometrical forms.

(4) Phenomena.-Minerals remain internally at rest, and increase by external additions. In contrast, organisms are all in motion: they are constantly in a state of composition and decomposition, incorporating foreign particles and 
giving out their own. Organized bodies, moreover, pass through a cycle of changes-growth, development, and reproduction. Of more complex constitution, they are more unstable, and are more liable to decomposition than most inorganic compounds. The action of heat is invariably destructive. $\Lambda$ the end of a certain period, fixed for each species, living bodies infallibly perish.

\section{CHAPTER II.}

\section{PLANTS AND ANDIALS DISTINGUISHED.}

IT may seem an easy matter to draw a line betreen plants and animals. Who can not tell a Cow from a Cabbage? Who would confound a Coral with a Mushroom? Tet it is impossible to assign any absolute, distinctive character which will divide the one mode of life from the other. The diffienlty of defining an animal increases with our knowledge of its nature. Linnæus defined it in three words; a century later, Owen declared that a definition of plants which would exchde all animals, or of animals which wonld not let in a single plant, was impossible. Each different character used in drawing the boundary will bisect the debatable ground in a different latitude of the organic world. Between the higher animals and higher plants the difference is apparent; but when we reflect how many characters the two have in common, and especially when we descend to the lower and minuter forms, we discorer that the two "kingdoms" tonch, and eren dissolve into, each other. This borderland has been as hotly contested anong naturalists as many a disputed frontier between adjacent nations. Its inhabitants have been taken and retaken several times by 
botanists and zoologists; for they have characters that lead on the one side to plants, and on the other to animals. To solve the difficulty, some eminent naturalists, as Iiackel and Owen, propwe a fourth "kinglom," to receive those living beings which are organic, but not distinctively regetal or animal. But a greater difficulty arises in attempting to fix its precise limits.

The drift of modern research points to this: that there are but two kingloms of nature, the mineral and the organized, and these closely linked together; that the latter must be taken as one whole, from which two great branches rise and direrge. "There is at bottom but one life, which is the whole life of some creatures, and the common basis of the life of all; a life of simplest moring and feeling, of feeding and breathing, of producing its kind and lasting its day; a life which, so far as we at present know, has no need of such parts as we call organs. Lpon this general foundation are built up the manifold special characters of animal and regetable existence; but the tendency, the endeavor, so to speak, of the plant is one, of the animal is another, and the mlikeness between them widens the higher the building is carried rp. As we pass along the series of either [branch] from low to high, the plant becomes more vegetative, the animal more animal."

In general, we may say that a rooted organism, retaining carbon and exhaling oxygen, feeding on mineral matter. by alsorption, and having celluluse tissues, is a plant; that an irritable or locomotive organism, retaining oxycren and exhaling carlonic acid, feeding on organic matter by a mouth and stomach, and having albuminons tissnes, is an animal. But Nature knows no such line of demarkation; for it is bridged at numerous points.

(1) Origin.-Both branches of the tree of life start alike: the lowest of plants and animals, as I'rotococeus and Gregurina, consist of a single cell. In fact, the crocle of life in 
all living beings, high or low, begins in a small round det of matter-in plants called an orule, in animals, an orum. This cell, or dot, contains a fluid, called protoplasm, identical in composition and in function. In the very simplest forms the protoplasm is not inclused by a membrane; but generally there is a cell-wall. In plants, with few exceptions, this wall is of celluluse, or something akin to starch; in animals, with few exceptions, the wall is a pellicle of firmer protoplasm, i. e., albuminous.

(2) Composition.-Morlern revearch has broken down the partition between plants and animals, so far as chemical nature is concerned. The vegetable fabric and secretions may be ternary or binary compounds; but the essential living parts of plants, like animals, are quaternary, consisting of four elements-carbon, hydrogen, oxygen, and nitrogen. Cellulose (woody fibre), starch, and chlorophyl (green coloring matter) are eminently regetable products, lut not distinctive; for celluluse is wanting in some plants, as Fungi, and present in some animals, as Tunicates; starch, under the name of glycugen, is fomd in the liver and brains of Mammals, and chlorophyl gives color to the fresh-water Polyp. Still, it holds good, generally, that plants consist mainly of celluluse, dextrine, and starch; while animals are mainly made up of albmmen, fibrine, and gelatine; that nitrogen is more abundant in animal tissnes, while in plants carbon is predominant.

(3) Form. - No outline can he drawn which shall be common to all animals or all plants. The lowest members of hoth have no fixed shape. The seeds of Confervir cain hardly be distinguished from animalcules; the compound animals, Sea-mat and Sea-moss (Polyzoa), are often taken for sea-weeds; the trees mimic the lnanching ('oral, and the Coral buds and blessoms like the Rose. The ideal form of a plant-- trunk, hranches, twies, special organs - is a form natural to all living matter enjoring rapid 
growth. Ascending the scale of animal creation, we find the primitive form gradually obseured by new and powerful molding influences.

(4) Structure. - I plant is the multiplication of the unit - a cell with a cellulose wall. Some simple animals have a similar cellular structure, and all animal tissues, while forming, are cellular. But this character, which is permanent in plants, is generally transitory in animals. Their tissues are composed of little plates, or lamine, intersecting each other in such a way as to constitute spongy masses, or membranes, which are not made up of cells independent of each other, as in regetables. Excepting the very lowest forms, animals are more composite than plants, $i$. e., their organs are more complex and numerous, and more specially deroted to particular purposes. Repetition of similar parts is a characteristic of plants ; of animals, it is differentiation. Most animals, moreorer, have fore-and-aft polarity; in contrast, plants are up-and-down structures, though, in this respect, they are imitated by radiated animals, like the Star-fish.

(5) Physiology.-In their modes of nutrition, plants and animals stand widest apart. Yet "the difference" (says Owen) " is, at most, one of form and proportion of the internal cavities, and of their external openings: they are the same as to function." As a rule, plants absorb and assimilate food by the external surface, which is therefore greatly extended by leaves and roots. As a rule, animals receive nourishment through a mouth into an internal permanent or temporary stomach. But there are certain molds which scem to swallow their food, ${ }^{7}$ and Tapeworms have neither mouth nor stomach.

$\Lambda$ plant in the seed and an animal in the egg exist in similar conditions: in both cases a mass of organic matter accompanies the germ. When this supply of food is exJiansted, both seek nourishment from without. But here 
analogy ends: the plant feeds on mineral matter, the animal on organic. The former only has the power to conrert the inorganic elements (carbon, oxygen, hydrogen, and nitrogen) into organic substance; the latter is dependent mpon the organic substance thus prepared. But the Fungi also live on organic compounds (in a state of decomposition); and it is probable that some animals have the power of elaborating tissue directly from the mineral kingdom. The materials of nutrition are absorbed by all living bodies in a fluid state: the food of plants is gaseous or liquid; that of animals is received in a form more or less solid, but afterward dissolved. While the absorbents of plants (roots and leaves) are external, those of animals are distributed along the walls of a digestive cavity. Plants exhale less water, and animals more water, than they imbibe.

In general, plants receive nourishment to grow, animals to repair waste. The fabric of the former, once completed, remains unchanged; while the tissues of the latter require constant renewal. Plants are continually receiving additional members; animals are born perfect. In other words: in the nutrition of the former, addition is the prominent idea; in the latter, substitution. In the former, the result is a straggling outline, with almost unlimited growth; in the latter, a finished, compact form.

Plants decompose, and animals recompose, carbonic acid; the one yielding the oxygen and fixing the carbon, the other exhaling carbonic acid and retaining some oxygren. Animals, therefore, inspire what plants set free: the food of the former undergoes oxidation; that of the latter, deoxidation. This chenical antagonism, howerer, will not serve as a rigorous definition. Mushrooms and leafless j'arasites, all plants in the dark, germinating seeds and opening flowers, give off carbonic acid. ${ }^{\circ}$ Erery plant begins life as an animal-a consumer, not producer: not till 
the young shoot rises above the soil, and unfulds itself to the light of the sum, at the tonch of whose mystic rays (hloryphyl is created, does real, constructive regetation begin; then its mode of life is reversed - carbon is retained and oxygen set free.

Most plants, and many animals, multiply by budding and division; on both we practice grafting; in both the cycle of life comes round again to the orule or orum. Do ammuals flower but to die? Insects lay their egrgs in their old age. But in all cases of true ovulation, the animal embryo absorbs its yolk from the inside, while that of a seed is itself surrounded by the albumeu.

Animals generally possess sensation, conscionsness, and volition. Tet volition is wanting in some lower forms; and many plants show excitability, if not sensibility. For aught we lnow, irritability is the birthright of all living matter. In plants, the protoplasm is scattered and buried in rigid structures: feeling is, therefore, dull. In animals, the protoplasm is concentrated into special organs, and so feeling, like electricity rammed into Leyden jars, goes off with a flash. ${ }^{10}$

The self-motion of animals and the rooted state of plants is a very general distinction; but it fails where we need it most. It is a characteristic of living things to more. The protoplarm of all organisms is mucasingly active." Besides this internal morement, myriads of plants, as well as animals, are locomotive. Rambling Diatoms, writhing () seillaria, and the awile spores of Cryptogams crowd om waters, their instruments of motion (cilia) being of the very same character as in microscopic animals; while Sponges, Corals, Oysters, and Barnacles are stationary. $\Lambda$ contractile resicle is not exclusirely an animal property, for the fresh-water Tolrox and Gonimm have it. The act of muscular contraction in the highest animal is due to the same kind of change in the form of the cells of 
the ultimate fibrillis, as that which produces the sensible motions of plants. The ciliary morements of animalenle: and of microscopic plants are precisely similar, and in neither case indicate conscionsness or self-determining power.

Plants, as well as animals, need a season of repose. Both have their epidemics. On both, narcotic and acrid poisons produce analogous results. Both have circulatory systems. Are some animals warm-blooded! In cermination and flowering, plants evolve heat - the stamens of the Arum, e. $y$., showing a rise of $20^{\circ}$. In a sense, an Oak has just as much heat as an Elephant, only the miserly tree locks up the sunlight in solid carbon.

At present, any boundary of the Animal Kingdom is arbitrary. "Probably life is essentially the same in the two kingdoms; and to regetable life, faculties are superadded in the lower animals, some of which are, here and there, not indistinctly foreshadowed in plants." "It must he said that there are organisms which at one period of their life exhibit an aggregate of phenomena such as to justify us in speaking of them as animals, while at another they appear to be as distinctly vegretable."1:

\section{CHAPTER III.}

RELATION BETWENN MINERALS, PLANTS, AND ANTMLAL.

Tinere are no independent members of ereation: all things tonch upon one another. The matter of the living world is identical with that of the inorganic. The plant, feeding on the minerals, carbonic acil, water, and anmonia, builds them up into (omplex, organic compouml. as starch, sugar, gum, celluluse', allumen, fibrine; casceinc; 
and gluten. When the plant is eaten by the animal, the ternary products, as starch, sugar, gum, and cellulose, are simply carried by the blood to the lungs, and decomposed ly oxidation back to carbonic acid and water, in which process heat is generated. The other vegetable products, as albumen, etc., containing nitrogen, go to sustain the animal, forming blood, muscle, cartilage, etc. These, griring way to fresh material (for there is constant renewal), are resolved into carbonic acid, water, and ammonia, and returned to the earth and air through the kidneys. Both plant and animal end their life by going back to the mineral world: and thus the circle is complete-from dust to dust. Carbonate of ammonia and water, a blade of grass and a horse, are but the same elements differently combined and arranged. Plants compress the forees of inorganic nature into chemical compounds; animals liberate them. Plants produce; animals consmme. The work of plants is synthesis, a building-np; the work of animals is analysis, or destruction. The tendeney in plants is deoxidation; the tendency in animals is oxidation. Withont plants, animals would perish; without animals, plants had no need to be. ${ }^{13}$

\section{CHAPTER IV.}

LIFE.

As impenetrable veil hides the nature of life. TVe know nothing of it except by the phenomena it manifests; and as these nanifestations differ from those of any known physical force, they have been attributed to " "special principle." But the existence of this assumel canse has never been demonstrated. The biologist can 
take no cognizance of an independent principle whose mysterious mion with the body causes it to live, and whose separation leaves it to die. In the modern view, life is a system of functions, or the sum total of living phenomena. Many of these phenomena are evidently manifestations of the common force of nature, acting either mechanically, chemically, electrically, or osmotically.

Still, the combination of elements into organic cells, the arrangement of these cells into tissues, the gromping of these tissnes into organs, and the marshaling of these organs into plans of structure, call for some further shaping, controlling power to effect such wonderful co-ordination. Moreover, the manifestation of feeling and conscionsuess is a mystery which no physical hypothesis has cleared np. The simplest vital phenomenon has in it something over and above the known forces of the laboratory. ${ }^{14}$

Life is exhibited only under certain conditions. One condition is the presence of a physical basis called protoplusm. This substance is found in all living bodies, and, so far as we know, is identical in all - a viscid, transparent, homogeneous, minutely granular, albuminoid matter. Life is inseparable from this protoplasm ; but it is dormant unless excited by some external stimulants, such as heat, light, electricity, food, water, and oxygen. 'Thus, a certain temperature is essential to growth and motion; taste is induced by chemical action, and sight by luminous vibrations.

The essential manifestations of animal life may be reduced to three: contractility, or the property possessed by certain parts of the body, especially the muscular fibres, of shortening themselves; sensibility, or the pecnliar power, contined to nerrous matter, of receiving and transmitting impressions; and the power of assimiluting food. All 
animals move, feel, and grow. But some of the lowest forms are without the slightest trace of organs; they seem to be as perfectly homogeneous and structureless as a drop of jelly. They conld not be more simple. They are devoid of muscles, nerres, and stomach; yet they have all the fundamental attributes of life-moving, feeling, and eating. It has been supposed that the muscular and nervous matter is diffused in a molecular form; but all we can say is, that the highest power of the microscope reveals no organized structure whatever, $i$.e., there are no parts set apart for a particular purpose; but a fragment is as good as the whole to perform all the functions of life. The animal series, therefore, begins with forms that feel without nerves, move without muscles, and digest withont a stomach: in other words, life is the curse of oryanization, not the result of it. Animals do not live because they are organized, but are organized because they are alive.

\section{CHAPTER V.}

ORG A I Z A TION.

WE have seen that the simplest life is a formless speck of protoplasm, without distinctions of structure, and therefore without distinctions of function, all parts serving all purposes - month, stomach, limb, and lung-indiscriminately. There is no separate digestive cavity, no separate respiratory, muscular, or nerrous systems. Erery part will successively feed, feel, move, and breathe. Just as in the earliest state of society, all do every thing, each does all. Every man is his own tailor, architect, and lawyer. But in the progress of social development the principle of the division of labor emerges. First comes a distinction 
between the governing and governed classes; then follow and multiply the varions civil, military, ecclesiastical, and industrial occupations.

In like manner, as we adrance in the animal series, we find the body more and more heterogeneous and complex by a process of differentiation, $i$.e., setting apart certain portions of the body for special duty. In the lowest forms, the work of life is earried on by very simple apparatus. ${ }^{15}$ But in the higher organisms, every function is performed by a special organ. For example, contractility, at first the property of the entire animal, becomes centred in muscular tissue; respiration, which in simple beings is effected by the whole surface, is specialized in lungs or gills; sensibility, from being common to the whole organism, is handed over to the nerres. An animal, then, whose body, instead of being uniform throughout, is made up of different parts for the performance of particular functions, is said to be orgunized. And the term is as applicable to the slightly differentiated cell as to complex Man. (Organization is expressed by single cells, or by their combination into tissues and organs.

1. Cells. $-\Lambda$ eell is the simplest form of organized life. In general, it is a microscopic globule, consisting of a delicate membrane inclosing a minute portion of protoplasm. The very simplest kinds are without granules or signs of circulation; but usually the protoplasm is granular, and contains a defined separate mass called the nucleus, within which are sometimes seen one or two, rarely more, dark, round specks, named mucleoti. The enreloping membrane is

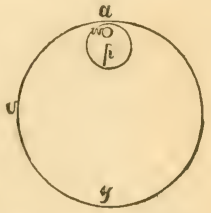

Fra. 1.-Parts of a Cell : $a, v, l$, cell-wall; $p$, nucleus; $u$, nucleolus. extremely thin and transparent, structureless and minutely perforated: it is only an excretion of dead matter acting as a boundary to the cell-contents. ${ }^{16}$ The nucleus is gen- 
erally attached to the inside of the membrane, and is the centre of activity.

Cells vary greatly in size, but are generally invisible to the naked eye, ranging from $\frac{1}{500}$ to $\frac{1}{1000}$ of an inch in diameter. Abont 4000 of the smallest would be necessary to cover the dot of this letter $i$. The natural form of isolated cells is spherical; but when they crowd each other, as seen in bone, cartilage, and muscle, their outlines become angular, either hexagronal or irregular.

Within the narrow boundary of a simple circle, the cell-membrane, are exhibited all the essential phenomena of life-growth, development, and reproduction. The physiology of these minute organisms is of peculiar interest, since all animal structure is but the multiplication of the cell as a unit, and the whole life of an animal is that of the cells which compose it: in them and by them all its vital processes are carried on. ${ }^{17}$

The structure of the cell is well illustrated by an egr, in which the shell represents the outer membrane, the white the cell-contents, the yolk the nucleus, and the germinal spot of the yolk the nucleolus. It is also seen in blood-corpuscles, by diluting with a weak solution of salt or sugar a drop of blood from a Frog, and placing it under the mieroscope. (See Figs. 62 and 158.)

2. Tissues.--There are organisms of the lowest grade (as Gregarina) which consist of a single cell, living for and by itself. In this case, the animal and cell are identical: the Gregarina has as much individuality as the Elephant. But all animals, save these unicellular beings, are mainly agreregations of eells. For the rarious parts of a body are not only separable by the knife, into bones, muscles, nerres, etc., but these are susceptible of a finer analysis by the microscope, which shows that they arise from the development and union of cells. These cellular falries, called tissues, differ from one another both chemically 
and structurally, but agree in being permeable to liquids - a property which secures that flexibility of the organs so essential to animal life. Every part of the human loody, for example, is moist: even the hairs, nails, and cuticle contain water. The contents as well as the shape of the cells are usually modified according to the tissue which they form: thus, we fiud cells containing earthy matter, iron, fat, mucus, etc.

In plants, the cell always retains the characters of the cell; but in animals (after the embryonic period) the cell usually undergoes such modifications that the cellular form disappears. The cells are connected together or enveloped by an intercellular substance (blustema), which may be watery, soft, and gelatinous, firmer and tenacions, still more solid and hyaline, or hard and opaque. In the fluids of the body, as the blood, the cells are separate; but in the solid tissues they coalesce, being simply comnected together, as in the epidermis, or mited into fibres and tubes.

In the lowest forms of life, and in all the higher animals in their embryonic state, the cells of which they are composed are not transformed into tissues: definite tissues make their first appearance in the Polyps, and they differ from one another more and more widely as we ascend the scale of being. In other words, the bodies of the lower and immature animals are more miform in composition than the higher, adult forms. In the latter only are all the following tissues found represented:

(1) Epithelial Tissue.-This is the simplest form of cellnlar structure. It covers all the free surfaces of the body, internal and external, so that an animal may be said to be contained between the walls of a double bag. That which is internal, lining the moutl, windpipe, lungs, blood-ressels, gullet, stomach, intestines-in fact, every cavity and canal -is called epithelium. It is a very delicate slin, formed of 
flat or eylindrical cells, and in some parts (as in the windpipe of air-breathing animals, and along the gills of the

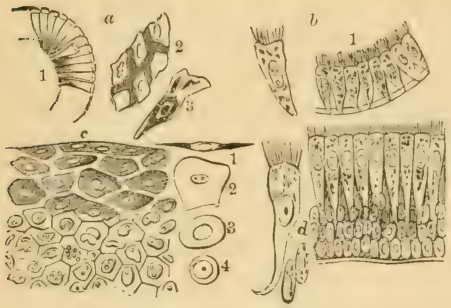

Fig. 2.-Various kinds of Epithelium Cells: $a$, columnar, from small intestine; 3 , a single cell, showing nucleus; $b$, ciliated, from one of the small airtubes; $d$, the same, from the windpipe, with single cell magnified abont 200 times; $c$, squamous, from eyelicl of a calf, showiug changes of form, from the deep to superficial cells, 1 being the scurf.

Oyster) is corered with cilia, or minute hairs, about $\frac{1}{6000}$ of an inch long, which are incessantly moring.

Continuous with this inner lining of the body (as seen on the lip), and covering the ontside. is the epidermis, or cuticle. It is the onter layer of the "skin," which we can remove by a blister, and in Man varies in thickness from $\frac{1}{x \cup 0}$ of an inch on the cheek to $\frac{1}{10}$ on the sole of the foot. It is constantly wearing off at the surface, and as constantly growing in the deeper portion; and in the process of growth and passage ontward, the cells change from the spherical form to dead horny scales (seen in scurf and dandruff). In the lower layer of the cuticle we find the pigment cells, characteristic of colored races. Neither the epidermis nor the corresponding tissue within (epithelium) has any blood-ressels or nerres. The epithelial tissue, then. is simply a superficial covering, bloodless and insensible protecting the more delicate parts underneath. Hairs, homs, huofs, nails, claws, corns, beaks, scales, tortoiseshell, the wings of Insects, etc., are modifications of the epidermis.

(2) Connective Tissue.-This is the most extensire tissue in animals, as it is the great connecting medium by which the different parts are held together. Could it be taken ont entire, it would be a complete mold of all the organs. 
It surrounds the bones, muscles, blood-ressels, nerres, and glands, and is the substance of the ligaments, tendons, "true skin," mucous membranes, etc. It varies in character, being soft, tender, and elastic, or dense, tongh, and generally unrielding. In the former state, it consists of innumerable fine white and yellow filres, which interlace in all directions, learing irregular spaces, and form-

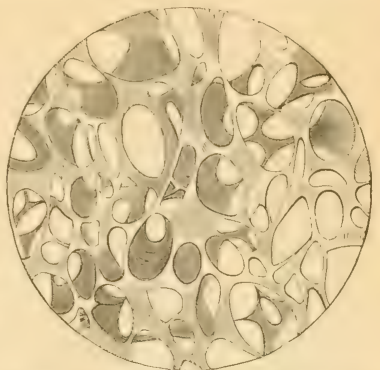
ing a loose, spongy, moist Fic. 3.-Counective Tivisue, showing areolar web. In the latter, the structure, $\times 25$.

fibres are condensed into sheets or parallel cords, haring

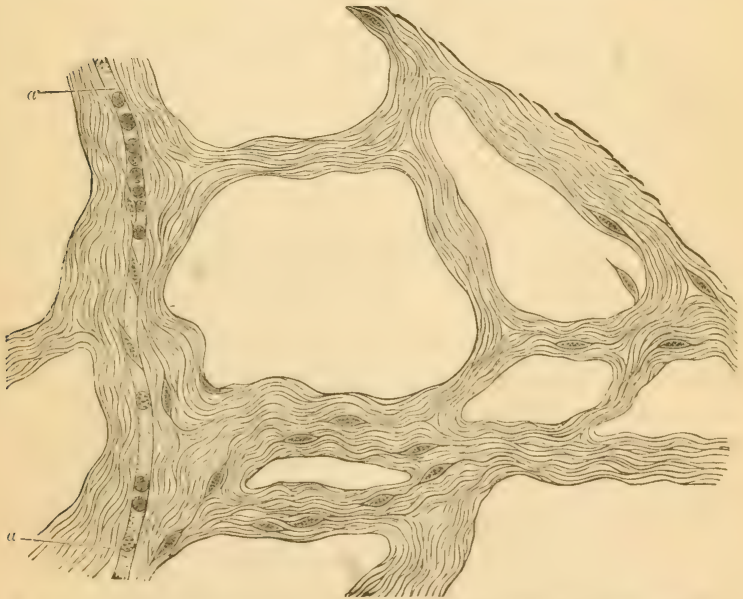

Fra. 4.-Connective Tissue from human peritoneum; highly magnitied; $a$, containing blood-ressel. 
a wary, glistening appearance. Connectire tissne is not rery sen-itive. It contains gelatine - the matter which tans when hide is made into leather. ${ }^{18}$

(3) Adipose Tissue. - This is simply an aggregation of large (ells (averaging $\frac{1}{50}$ inch in diameter) tilled with

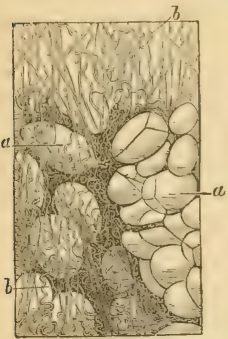

Frf. 5.-1hiture Tissue, $a$; with fibres of commective tissue, $b$. fat. They are distributed throngh the connective tissue (as in the "blubber" of Whales), or united into distinct masses (as about the kidneys in Rulminants). The marrow of bones is a good example. Globules of fat oceur in many Molluses and Insects; but true adipose tissue is found only in back-boned animals, particularly the herbivorons. In the average Man, it constitutes about $\frac{1}{20}$ part of his weight, and a single Whale has yielded 120 tums of oil. The fiut of animals has the different names of oil, lard, tallow, snet, spermaceti, ete. It is a reserve of nutriment in excess of consumption, serving also as a packing material, and as a protection against cold.

(4) Cartilaginous Tissue. - This is a deep-seated structure, better known as "gristle," which is dense, elastic, bluish white, and translucent, composed of cells imbedded in a granular or hyaline substance. It is found where strength, elasticity, and insensibility are wanted, as at the joints. It also takes the place of bones in the embryo. When cartilage is mixed with connective tissue, as in the ear, it is called fibro-cartilage.

(5) Osseous Tissue.-This hard, oparne tissue, called "bone," differs from the

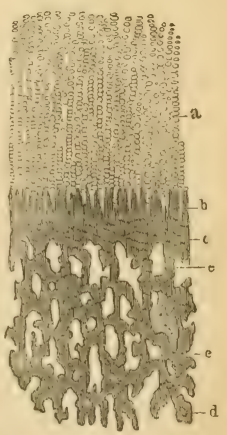

Fta. 6. - Oscifying (artilage, $\times 10 ; \quad$, cartilase cells, passing into compact bone, $c$, and then spongy boue, $e$. 
former in having the intercellular spaces or meshes filled with phosphate of lime and other earths, insteat of a liyaline substance. It may be called petrified cartilage-the quantity of earthy matter, and therefore the brittleness of the bone, increasing with the age of the animal. If a chicken-bone be left in dilute muriatic acid several days, it may be tied into a knot, since the acid has dissolved the lime, learing nothing but cartilage and connective tissue. If a bone be burned, it becomes light, porous, and brittle, the lime alone remaining. ${ }^{19}$

Bone is a very rascu-

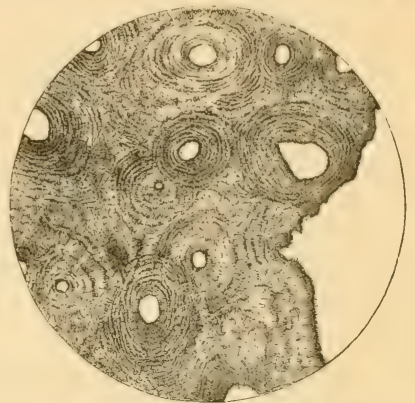

Fis. 7.-Transverse section of a Bone (Human Femur), $\times 50$, showing Haversian canals. lar tissue, that is, it is traversed by minute blood-ressels and nerves, which pass through a net-work of tuhes, called

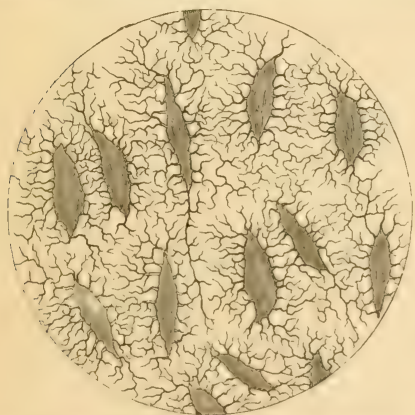

Fro. 8.-Frontal Bone of Human Skull under the microscope, showing lacunæ and canaliculi.

Haversian canals. The canals a verage $\frac{1}{1000}$ of an inch, being finest near the surface of the bone, and larger further in, where they form a cancellated or spongy structure, and finally merge (in the long bones) into the central cavity, containing the marrow. Under the microscope, each canal appears to be the centre of a multitude of lamina, or plates, arranged around it. 
Lying between these plates are little carities, called lacunce, from which radiate exceedingly fine pores, or canaliculi. The form of the lacune differs in the bones of different animals, being angular in Fishes, and oral in other animals. The size is related, not to the size of the animal, but to the size of the blood-corpuscles, and is therefore greatest in Reptiles.

True bone is found only in Vertebrates, or back-boned animals.

(6) Dental Tissue.-Like bone, a tooth is a combination of earthy and animal matter. It may be called petrified epithelium. In the higher animals, it consists of three parts: dentine, forming the body of the tooth, and always present; enamel, capping the crown; and cement, covering the fangs (Fig. 29). The last is true bone, or osseons tissue. Dentine resembles bone, but differs in having neither

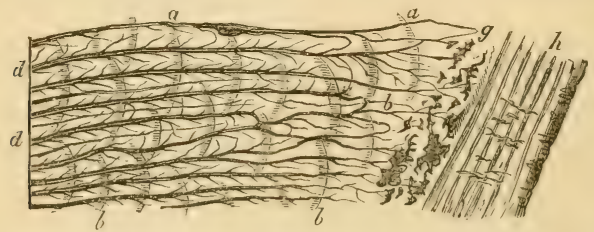

Frg. 9.-IItghly mannitied section of Dentine and cement, from the fang of a Human Molitr: $a, b$, marks of the oriciual dentiual $p l_{1}$; $d$, dentiual tubes, terminatiug in the very sensitive, modified layer, $g ; h$, cement.

lacuna nor (save in Shark's teeth) canaliculi. It shows, instead, under the miscroscope, innumerable parallel tubes, reaching from the ontside to the pulp-eavity within. The "ivory" of Elephants consists of dentine. Enamel is the hardest substance in the body, and is composed of minute six-sided filores, set closely together. It is wanting in the teeth of most Fishes, Snakes, Sloths, Armadillos, Spermwhales, etc.

True dental tissue is confined to Vertebrates.

(7) Muscular Tissue.--If we examine a piece of lean meat, 
we find it is male up of a number of fuscicuti, or bundles of fibres, placed side by side, and bound torgether by connective tissne. The microscope informs us that each fibre is itself a bundle of smaller fibres; and when one of these is more closely examined, it is found to be inclosed in a delicate, glossy tube, called the sarcolemma. This tube is filled with very minute, parallel fibrils, averaging $\frac{1}{10000}$ of an inch in diameter, and having a beaded as-

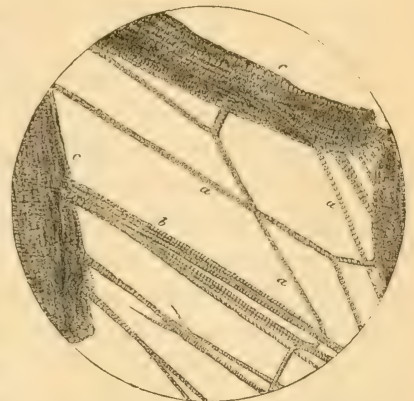

Fig. 10.-Striated Muscular Fibre (of the Pig), $\times 200$. The constituent cells are seen at $a$; $c$ is a fasciculus, or bundle. lect, each fibril being a row of cells. Tissne of this descrip-

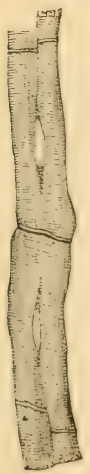

Fr:. 11. - Striated Inscular Fibres, from the heart of Man, divided by trancverse septa into separate nucleated portions. tion constitutes all ordinary muscle, or "lean meat," and is marked by regular cross-lines, or strice.

Besides this striated muscular tissue, there exist, in the coats of the stomach, blood-vessels, and some other parts of Vertebrates, smooth muscular fibres, or membranes, which show a nucleus under the microscope, and do not break up into fibrils. The gizzards of fowls exhibit this form.

All muscle has the property of shortening itself when excited; but the contraction of the striated kind is under the control of the will, while the morement of the smooth filmes is involuntary. ${ }^{20}$ Muscles are well supplied with arteries, reins, and nerves; but the color is due to a peculiar pigment, not to the blood. 
Muscular tissue is found in all animals, from the Coral to Man.

(8) Nervous Tissue.-Nerrous matter exists under three forms: First-the cellular, consisting of nucleated cells,

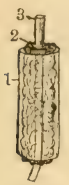

Fig. 12.-Structure of a Nerve: 1, sheath, or neurilemma: 2 , medullary substance of Schwanu: 3 , axis cyliuder, or primitive baud. varying from $\frac{1}{6000}$ to $\frac{1}{200}$ of an inch in diameter, and distributed through the body, particularly in the gray portion of the brain, spinal cord, and nerve-centres, or ganglia. Second-the fibrous, consisting of pale, flat, extremely fine filaments. They abound in the sympathetic nerves, the only nerres found in the Invertebrates. Third - the tubulur. These are nuch larger than the fibrous, the coarsest being $\frac{1}{200}$ of an inch in diameter. They consist of tubes inclosing a transparent filme and a riscid fluid called the nervemarrow. ${ }^{21}$ The delicate tube itself is called neurilemma,

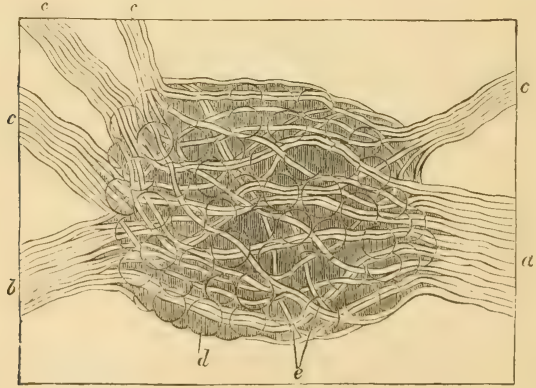

Fra. 13.-A Gauglion of the Sympathetic Nerve of a Monse.

analogous to the sarcolemma of muscular tissue. Nerretubes are found only in back-boned animals, and chiefly in the white substance of the brain and spinal cord.

A bundle of fibrons or tubular nerrous matter, surromded by connective tissue, constitutes a nerve. 
3. Organs, and their Functions.-Animals, like Plants, grow, reproduce, and die: these three are the capital facts of every organisu. Out of these may issue some peculiar phenomena, as Motion and Will.

Life is manifested in certain special acts, called functions, performed by certain special parts, called orgens. Thus, the stomach is an organ, whose function is digestiun. A single organ may manifest vitality, but it does not (sare in the very lowest forms) show forth the whole life of the animal. For, in being set apart for a special purpose, an organ takes upon itself, so to speak, to do something for the benefit of the whole animal, in return for which it is absolved from doing many things. The stomach is not called upon to circulate or purify the blood.

There may be functions without organs, as the organless Amoula digests, respires, mores, and reproduces by its gencral mass. But as we ascend the scale of animal life, we pass from the simple to the complex: groups of cells or tissues, instead of being repetitions of each other, take on a difference, and become distingnished as special parts with specific duties. The higher the rank of the animal, the more numerous the organs. The more complicated the structure, the more complicated the functions. But in all animals, the functions are performed under conditions essentially the same. Thus, respiration in the Sponge, the Fish, and in Man has one object and one means, though the methods differ. A function, therefore, is a group of similar phenomena produced by like causes.

The life of an animal consists in the accimnulation and expenditure of force. The tissues are store-houses of power, which, as they waste and decay, is given off in varions forms. Thus, the nerrous tissue generates nerve-force; the muscles, motion: and the fatty elements, heat. If we contemplate the phenomena presented by a Dog, the most obvious fact is his power of moving from place to place, 
a power produced by the interplay of muscles and bones. We observe, also, that his motions are neither mechanical nor irregular; there is method in his movement. He has the power of willing, seeing, hearing, fecling, etc.; and these functions are accomplished by a delicate apparatus of nerves.

But the Dog does not exhibit perpetual motion. Sooner or later he becomes exhausted, and rest is necessary. Sleep gives only temporary relief. In erery exercise of the muscles and nerves there is a consumption or waste of their substance. The blood restores the organs, but in time the blood itself needs renewal. If not renewed, the animal becomes emaciated, for the whole body is laid moder contribution to furnish a supply. Hence the feelings of humger and thirst, impelling the creature to seek food. This alone will maintain the balance between wasie and repair. We notice, therefore, an entirely different set of functions, involving, however, the use of motion and will. The Dog seizes a piece of meat, grinds it between its teeth, sends it into the stomach, where it is digested, and then into the intestine, where it is further changed; there the nowrishing part is absorbed, and carried to the heart, which propels it throngh little tubes, called blood-ressels, all over the body. In this process of digestion, certain fluids are required, as saliva, gastric juice, and bile: these are secreted by special organs, called glands. Moreover, since all the food eaten is not fitted to make blood, and as the blood itself, in going around the body, acts like a scarenger, picking up worn-out particles, we have another function, that of excretion, or removal of useless matter from the system. The kidneys and lungs do much of this; but the lungs do something else. They expose the blood to the air, and introduce oxygen, which, we shall find, is essential to the life of every animal.

These centripetal and centrifugal movements in the 
body-throwing in and throwing out-are so related and involved, especially in the lower forms, that they can not be sharply defined and classitied. It has been said that every Dog has two lives-a regetative and an cminal. The former includes the processes of digestion, circulation, respiration, secretion, etc., which are common to all life; the functions of the other, as motion, sensation, and will, are peculiar to animals. The heart is the centre of the reggetative life, and the brain is the centre of the animal life. The aim of the regetative organs is to nourish the individnal, and reproduce its kind; the organs of locomotion and sense establish relations between the individual and the world withont. The former maintain life; the others express it. The former derelop, and afterward sustain the latter. The regetative organs, however, are not independent of the animal; for without muscles and nerves we could not procure, masticate, and digest food. The cluser the connection and dependence between these two sets of organs, the higher the rank..$^{22}$

All the apparatus and phenomena of life may be in clinded under the heads of

\section{Netrition, \\ Motrion, \\ Sensation.}

These three are possessed by all animals, but in a variety of ways. No two species have exactly the same mechanism and method of life. We must learn to distinguish between what is vital and what is only accessory. That only is essential to life which is common to all forms of life. Our brains, stomachs, livers, hands, and feet are luxuries. They are necessary to make us human, but not living, beings. IIalf of our body is taken up with a complicated system of digestion; but the Amula has neither month nor stomach. We have an elaborate apparatus of motion; the Oyster can not stir an inch. 
Nutrition, Motion, and Sensation indicate three steps up the grade of life. Thus, the first is the prominent function in the Coral, which simply "vegetates," the powers of moving and feeling being very feeble. In the higher Insect, as the Bee, there is great activity with low organs of nutrition. In the still higher Mammal, as Man, there is less power of locomotion, though the most perfect nutritive system; but both functions are subordinate to Sensation, which is the crowning development.

In studying the comparative anatomy and physiology of the animal kingdom, our plan will be to trace the various organs and functions, from their simplest expression upward to the highest complexity. Thus, Nutrition will begin with absorption, which is the simplest method of taking food; going higher, we find digestion, but in no particular spot in the body; next, we see it confined to a tube; then to a tube with a sac, or stomach; and, fiually, we reach the complex arrangement in Man.

\section{CHAPTER VI.}

\section{NUTRITION.}

Nutrition is the earliest and most constant of vital operations. While the organs of motion and sensation seem to be wanting in some lower forms, the means of vegetative life are always present. So prominent is the nutritive apparatus, that an animal has been likened to a moving sac, organized to convert foreign matter into its own likeness, to which the complex organs of animal life are but auxiliaries. Thus, the bones and muscles are levers and cords to carry the body about, while the nervous system directs its motions in quest of food. 
The objects of nutrition are growth, repair, and propagation. The first olject of life is to grow, for no animal is born finished. Some animals, like plants, grow as long as they live ${ }^{23}$ but the majority soon attain a fixed size. In all animals, however, without exception, food is wanted for another purpose than growth, namely, to repair the waste which is constantly going on. For every exercise of the muscles and nerves involves the death and decay of those tissnes, as shown by the excretions. The amount of matter expelled from the body, and the amount of nourishment needed to make good the loss, increase with the activity of the animal. The supply must equal the demand, in order to maintain the life of the individnal; and as an organism can make nothing, it must seek it from withont. Not only are the muscles and nerres wasted by use, but every organ in the body; so that the whole structure needs constant renewal. An animal begins to die the moment it begrins to live. The function of nutrition, therefore, is constructire, while motion and sensation are destructive.

Another source of demand for food is the production of germs, to propagate the race, and the nourishment of such offepring in the egg and infantile state. This reproduction and development of parts which can maintain an independent existence is a regetative phenomenon (for plants have it), and is a part of the general process of Nutrition. But it will be more conrenient to consider it hereafter (chapters xix., xx.). Still, another necessity for aliment among the higher animals is the maintenance of bodily heat. This will be treated under the head of Respiration.

For the present, we will study Nutrition, as manifested in maintaining the life of an adult individual.

In all animals, this process essentially consists in the introduction of food, its conversion into tissue, and the removal of worn-out material. 
1. The food must be procured, and swallowed. (Ingestion.)

2. The food must be dissolved, and the nutritious parts separated into a fluid. (Digestion.)

3. The nutritive fluid must be carefully taken up, and then distributed all over the body. (Absorption and Circulation.)

4. The nutritive fluid, now called blood, must be exposed to the air, to absorb oxygen and liberate carbonic acid. (Respiration.)

5. The tissnes must repair their parts wasted by use, by transforming particles of blood into living matter like themselves. (Assimilation.)

6. Certain matters must be strained from the blood, some to serve a purpose, others to be eagst ont of the system. (Secretion and Excretion.)

The mechanism to accomplish all this in the lowest forms of life is exceedingly simple, a single cavity performing all the functions. But in the majority of animals the applaratns is very complicated: there is a set of organs for the prehension of food; another, for digestion; a third, for absorption; a fourth, for distribution; and a tifth, for purification.

\section{CHAPTER VII.}

THE FOOD OF ANIMALS.

Tre term food includes all substances which contribute to nutrition, whether they simply assist in the process, or are actually appropriated, and become tissue. With the food is usnally combined more or less indigestible matter, which is separated in digestion. 
Food is derived from the mineral, vegetable, and animal kingdoms. Water and salt, for example, are inorganice. The former is the most abundant, and a very essential article of food. Most of the lower forms of aquatic life seem to live by drinking: their real nourishment, however, is present in the water in the state of solution. The Earthworm, some Beetles, and certain sarage tribes of Men swallow earth; but this, likewise, is for the organic matter which the earth contains. As no animal, so far as we now know, is produced inmediately from inorganic matter, so no animal can be sustained by it.

Nutritions or tissue-forming food eomes from the organic world, and is either albuminous, as the lean meat of animals and the gluten of wheat; oleaginous, as animal fat and regetable $\mathbf{i l}$; or saccherine, as starch and sugar. The tirst is the essential food-stuff; no substance can serre permanently for food-that is, can prevent loss of weight and change in the body-mless it contains albuminous matter. The other two are not absolutely vital. Albumen contains nitrogen, which is necessary to the formation of tissue; fats and sugars are rich in carbon, and therefore serve to maintain the heat of the body. Warm-blooded animals feed largely on farinaceous or starchy substances, which in digestion are converted into sugar. But any animal, of the higher orders certainly, whether herbirorous or carnirorons, would starre, if fed on pure albumen, oil, or sugar. Nature insists upon a mixed diet, and so we find in all the staple articles of food, as milk, meat, and bread. at least two of these principles present. As a rule, the nutritive principles in regetables are less abundant than in animal food, and the indigestible residue is consernently greater. The nutriment in flesh increases as we ascend the animal seale; thus, Oysters are less nourishing than Fish; Fish, less than Fowl; and Fowl, less than the tle:h of Quadrupeds. 
Many animals, as most Insects and Mammals, live solely on regetalle food, and some species are restricted to particular plants, as the Silk-worm to the white mulberry. ${ }^{24}$ But the majority of animals feed on one another; such are hosts of the microscopic forms, and nearly all the radiated species, marine Shells, Crustaceans, Beetles, Flies, Spiders, Fishes, Reptiles, Birds, and clawed Quadrupeds.

A few, as Man himself, are ommivorons, $i$.e., are maintained on a mixture of animal and regetable food. The use of tire in the preparation of food is peculiar to Man, who has been called "the cooking animal." A few of the strictly herbivorons and carnivorous animals have shown a eapacity for changing their diet. Thus, the Horse and Cow may be bronght to eat fish and flesh; the Sea-birds can be habituated to grain; Cats are fond of alligatorpears; and Dogs take naturally to the plantain. Certain animals, in passing from the young to the mature state, make a remarkable change of food. Thus, the Tadpole feels upon regretable matter; but when it becomes a Frog it lives on Insects.

Many tribes, especially of Reptiles and Insects, are able to go without food for months, or even years. Insects in the larral, or caterpillar, state are very voracious; but upon reaching the perfect, or winged, state, they eat little-some species taking no food at all, the month being actually closed. The male of the minute Notommata takes in no nutriment from the time it quits its egg till its death.

In general, the greater the facility with which an animal obtains its food, the more dependent is it upon a constant supply. Thus, carnivores endure abstinence better than herbivores, and wild animals than domesticated ones. 


\section{CHAPTER VIII.}

HOW $\Lambda$ NIM $\Lambda \mathrm{LS}$ E $\Lambda$ T.

1. The Prehension of Food. - (1) Liquids. - The simplest method of taking nourishment is by absorption through the skin. The Tape-worm, for example, has neither mouth nor stomach, but imbibes the juices of the animal it infests. Many other animals, especially Insects, live upon liquid food, but obtain it by suction through a special orifice or tube. Thus, we find a month, or sucker, furnished with minnte teeth for lancing the skin of animals, as in the Leech; a bristle-like tube fitted for piercing, as in the MLosquito; a sharp sucker armed with barbs, to fix it securely during the act of sucking, as in the Lonse; and a long, flexible proboscis, as in the Buttertly. Bees have a hairy, chammeled tongue, and Flies have one terminating in a large fleshy knob, with or withont little "linives" at the base for cutting the skin: both lap, rather than suck, their food.

MIost animals drink by suction, as the Ox; and a few lyy lapping, as the Dog; the Elephant pumps the water up with its trunk, and then pours it into its throat; and Birds (excepting Dores) fill the beak, and then, raising the head, allow the water to run down.

Many aquatic animals, whose food consists of small particles diffused throngh the water, have an apparatus for creating currents, so as to bring such particles within their reach. This is particularly true of low, fixed forms, which are unable to go in search of their food. Thus, the Sponge draws nourishment from the water, which is made to circulate, through the system of canals traversing its body, 
by the vibration of minute liairs, or cilia, lining the camals. The microscopic Infusoria have cilia surromuling the mouth, with which they draw or drive into the body little currents containing nutritious particles. Bivalve shells, as the Oyster and Clam, are likewise dependent. upon this method of procuring food, the sills being fringed with cilia. So the singular fish, Amphioxus (the only example among Vertebrates), employs ciliary action to obtain the infusorial organisms on which it feeds. The Greenland Whale has a mode of ingestion somewhat nuipue, gulping great rolumes of water into its moutl, and then straining out, through its whalebone sieve, the small animals which the water may contain.

(2) Solids.- When the food is in solid masses, whether floating in water or not, the animal is usually provider

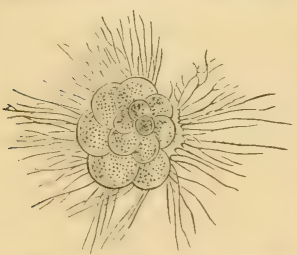

Fin. 14,-A Rhizopod (Rotalict Tencta), with psendopodia extended, $x: 30$. with prehensile appendages for taking hold of it. The jellylike Amœba has neither mouth nor stomach, but extemporizes them, seizing its food by merely applying its soft body to it, and then wrapping itself around it. Other minute creatures (Foraminifera) extemporize arus by throwing out thread-like prolongations of their bodies (psendopodia), which adhere to their prey, and then contract.

$\Lambda$ higher type is seen in Polyps and Jelly-fishes, which have hollow tentacles aromel the entrance to the stomach (Fig. 194). These tentacles are contractile, and, moreover, are eovered with an immense number of minute sacs, in which a highly elastic filament is coiled up spirally. When the tentacles are tonched by a passing animal, as a Crab, they seize it, and at the same moment throw ont their myriad filaments, like so many lassos, which increase 
the adhesive power of the tentacles, and probably also emit a fluid, which paralyes the victim; the month, meanwhile, expands to an extraordinary size, and the creature is soon ingulfed in the digestive bag.

In the next stage, we find no tentacles, but the food is bronght to the month by the flexible lobes of the body, commonly ealled "arms," which are covered with humdreds of minute suckers; and if the prey, as an Orster, is too large to be swallowed, the stomach protrudes, like a proboscis, and sucks it out of its shell. This is seen in the Star-fish (Fig. 207).

A great adrance is shown by the Sea-urchin, whose mouth is provided with five sharp teeth, set in as many jaws, and eapable of being projected so as to grasp, as well as to masticate, its food.

In Molluslis having a single shell, as the Snail, the chief organ of prehension is a straplike tongue, covered with minute recurved teeth, or spines, with which the animal rasps its food, while the upper lip is armed with a sharp, horny plate (Fig. 27). In many marine species, as the Whelk, the tongue is situated at the end of a retractile proboscis, or muscular tube. In the Cuttle-fish, we see the sudden derelopment of an elaborate system of prehensile organs. Besides a spinous tongue, it has a pair of hard mandibles, resembling the beak of a Parrot, and working vertically; and around the mouth are eight or ten powerful arms furnished with numer-

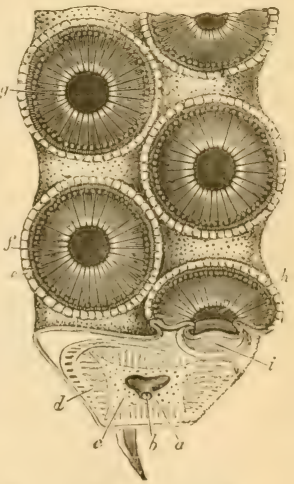

Fri, 15. - suckers on the Tentacles of a Cuttle-iish: $a$, hollow axis of the arm, containing nerve and artery: $c$, cellular tissue; $d$, radiating tibres: $h$, raised marsin of the disk around the aperture $f$, ", which contains a retractile membrane, of "piston," $i$. 
ons cup-like suckers. So perfect is the adhesion of these suckers, it is easier to tear away a limb than to detach it from its hold.

The Articulated animals exhibit a great variety of means for procuring nourishment, in addition to the suctorial contrivances already mentioned, the inmmerable modifications of the mouth corresponding to the diversity of food. The Earth-worm swallows earthy matter, which it secures with its lips, the upher one being prolonged. Other worms (as Laodicea) are so constructed that the gullet, which is frequently armed with teeth and forceps, can be tmrned inside ont, to form a proboscis for seizing prey. Millepedes, Caterpillars, and Grubs have a pair of horny jaws moving horizontally. The Centipede lias a second pair of jaws, which are really moditied feet, terminated by curved fangs containing a poison-duct. The IIorse-shoe Crab uses its feet for prehension, and the thighs, or basal joints, of its legs to masticate the food and force it into the stomach. The first six pairs of legs in the Lobster and Crab are likewise appropriated to convering food into the month, the sixth being enormonsly dereloped, and fumished with powerful pincers, one of which serves as an anchor, enabling the creature to hold

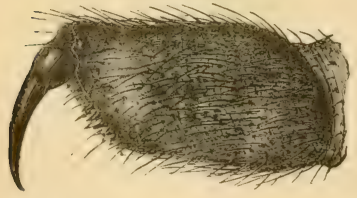

Fic. 16. - One of the Fangs, or Perforated Maudibles, of the Spider. fast to some fixed object, while the other is an instr'ument for seizing or cutting 'its prey. Scorpions have a similar pair of claws for prehension, and also a pair of small forceps for holding the food in contact with the mouth. In their relatives, the Spiders, the claws are wanting, and the forceps end in a fang, or hook, which is perforated to convey renom. ${ }^{26}$

The biting Insects, as Beetles and Locusts, have two 
pairs of horny jaws, which open sidewise, one above and the other below the oral orifice. The upper pair are called mandibles; the lower, maxillae. The former are armed with sharp teeth, or with cutting edges, and sometimes are fitted, like the molars of quadrupeds, to grind the food. The maxillae are similar, but smaller, and in some Insects have appendages called palpi, or feelers, which not only select, but hold, the food steady while they are divided by the mandibles and maxillax: such appendages represent a third pair of jaws. The Mantis seizes its prey with its long fore legs, crushes it between its thighs, which are armed with spines, and then delivers it up to the jaws for mastication. All Articulates more their jaws horizontally.

The back-boned animals generally apprehend food by means of their jaws, of which there are two, moring vertically. The toothless Sturgeon draws in its prey by powerful suction. The Ilag-fish has a single tooth, which it plunges into the sides of its rictim, and, thus securing a firm hold, bores its way into the flesh by means of its sawlike tongue. But Fishes are usually well provided with teeth, which, being sharp and curving inward, are strictly prehensile. The fins and tongue are not prehensile. A mouth with horny jaws, as in the Turtles, or bristling with teeth, as in the Crocodile, is the only means possessed by nearly all Reptiles for securing food. The Toad, Frog, and Chameleon capture insects by darting out the tongue, which is tipped with glutinous saliva. The constricting serpents (Boas) crush their prey in their coils before swallowing; and the renomons Snakes have a poison-fang. No Reptile has prehensile lips. All Jirds use their toothless beaks in procuring food, but birds of prey also seize with their talons, and Woodpeckers, Inmmers, and Parrots with their tongnes. The beak raries greatly in shape, being a hook in the Eagle, a probe in the Woodpecker, and a shovel in the Duck. 
Among the Quadrupeds we find a fer special contrivances, as the trunk of the Elephant, and the long tongnes of the Giraffe and Ant-eater; but, as a rule, the teeth are the chief organs of prehension, alwass aided more or less by the lips. Ruminants, like the Ox, having hoofs on their feet, and no upper front teeth, employ the lips and tongue. Such as ean stand erect on the hind legs, as the

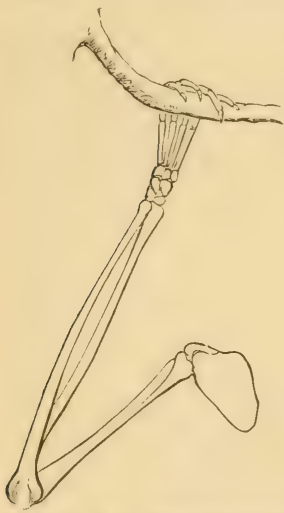

Fit: 17.-Arm of the Thumbless Monkey (Ateles). Squirrel, Bear, and Kangaroo, use the front limbs for holding the food and bringing it to the mointh, but never one limb alone. The clawed animals, like the Cat and Lion, make use of their feet in securing prey, all four limbs being furnished with curved retractile claws; but the food is conreyed into the mouth by the movement of the head and jaws. Man and the Monkeys employ the haud in bringing food to the mouth, and the lips and tongue in taking it into the cavity. The thumb on the human hand is longer and more perfect than that of the Apes and MLonkevs; but the foot of the latter is also prehensile.

2. The Mouths of Animals. - In the Parasites, as the Tape-worm, which absorb nomrishment through the skin, and Insects, as the May-fly and Bot-fly, which do all their eating in the larval state, the month is either wanting or rudimentary. ${ }^{26}$ The Ammea, also, has no mouth proper, but wraps itself around its food.

In the Animalenles it is simply a round or oral opening to the body-cavity, crenerally hordered with cilia, and situated on the side of the body, or at one extremity.

An elliptical or quadrangular orifice, surrounded with 
fentacles, and leading directly to the stomach, is the ordinary mouth of the Polyps and Jelly-fishes. In those which are fixed, as the Actinia, Coral, and Iydra, the month looks upward: in those which freely move about, as the Jelly-fish, it is generally muderneath, the pusition of the animal being reversed. In some, the margin, or lip, (an be protruded like a proboscis; and in all it is exceedingly dilatable.

The moutl of the Star-fish and Sca-urchin is a simple romel aperture, followed by a very short throat. In the Star-fish, it is inclosed ly a ring of hard tubercles. In the Sea-urchin, it is armed with five sharp tecth, resembling little conical wedges, set in as many jaws, and surromuded by a muscular membrane and minute tentacles.

Among the headless Mollusks which do nut move abont, the oral apparatus is very simple, being inferior to that of the radiated animals. Thus, the immorable Ascidian has a month without tentacles or lips, and in a strange place, for it is in the interior of the body, at the bottom of the respiratory sac; the aperture at the top of the creature being really for the entrance of water for the double purpose of respiration and nutrition, and any alimentary particles which enter with the water must find their way to the true mouth below. In the Orster and Bivalves generally, the mouth is an marned slit-a mere inlet to the stomach, situated in a kind of hood, formed ly the union of the gills at their origin, and between two pairs of delicate lips. These lips malie a fumw, along which pass the particles of food drawn in by the cilia.

()f the higher Mollusks, the little Clio (one of the I'ternpods) has a triangular mouth, with two jaws armed with sharp horny teeth, and a tongne covered with spiny hooklets all directed hackward. Some Univalves have a -imple fleshy tuhe. Other', as the Whelk, have an extensible proboscis, which unfolds itself, like the finger of a glove, 
and carries within it a rasp-like tongue, which can bore into the hardest shells. Such as feed on regetable matter,

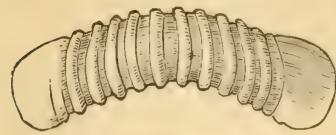

Fiti. is.-Jaw of the Common Snaii (Helix albolabris). as the Snail, have no proboscis, but on the roof of the mouth a curved horny plate fitted to cut leaves, ete., which are pressed against it by the lips, and on the floor of the month a small tongue covered with delicate stria. As fast as the tongue is worn off by use, it grows out from the root.

The mouth of the Cuttle-fish strikingly resembles that of the Vertebrates, and is the most elerated type below the Fishes. A broad circular lip nearly conceals a pair of strong horny mandilles, not unlike the beak of a parrot, but reversed, the upper mandible being the shorter of the two, and the jaws, which are cartilaginons, are imbedded in a mass of muscles, and move rertically. Between them is a fleshy tongne eorered with papillie and spines.

The parasitic Worms, living within or on the outside of other animals, generally have a sucker at one end or underneath, serving simply for attachment, and another which is perforated. The latter is a true suctorial moutll, being the sole inlet of food. It is often surrounded with hooklets or teeth, which serve both to scarify the victim and secnre a firm hold. In the Leech, the month is a triangular opening with thick lips, the upper one prolonged, and microscopic teeth. In many Worms it is a fleshy tube, which can be drawn in or extended, like the eyestalks of the Suail, and contains a minute dental apparatus inside.

Millepedes and Centipedes have two lateral jaws and a form-lobed lip.

In Lobsters and Crabs, the month is situated underneath the head, and consists of a soft upper lip, then a pair of 

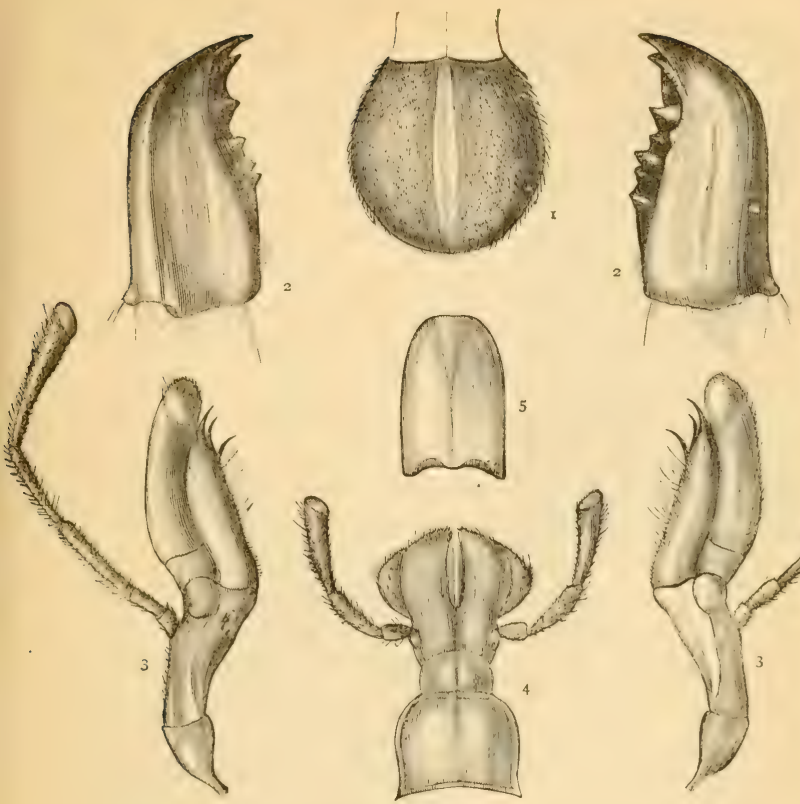

Frg. 19. - Month of a Locust dissected: 1, labrum, or upper lip; 2, mandibles: 3 , jaws; 4. labium, or lower lip; 5, tongue. The appendages to the maxillie and lower lip are palpi.

upper jaws provided with a short feeler, below which is a thin bifid tongue; then follow two pairs of membranons muder jaws, which are lobed and hairy; and next, three pairs of feet changed into jaws (Fig. 2tt). The Ilorse-shoe Crab has no jaws, the thighs answering the purpose. The Barnacle has a prominent mouth, with three pairs of rudimentary jaws.

With few exceptions, the months of Insects in the larral, or caterpillar, state are fitted only for biting, the two jaws being horny shears. But in the winged, or perfect, state, 


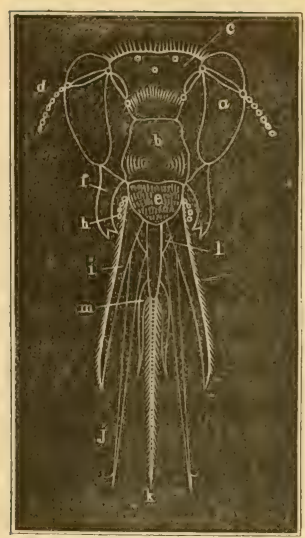

Fre. 20, - Ffend of a Wild Bee $(A n$ throphora retusa), front view: $a$, compound eyes: $b$, clypens: $c$, three simple eyes: $d$, anteunie: $e$, Labrum : $f$, mandibles; $i$, maxille; $h$, maxillary palpi ; $l$, palpiper; $j$, labial palpi; $m$, paraglossæ; $k$, ligula.

of taking food. In the Bee tribe, we have a transition between the biting and the sucking Insects - the npper jaws "supply the place of trowels, spades, pickaxes, saws, scissors, and knives," while the maxillæe are developed into a sheath to inclose the long, slender, hairy tongue which laps up the sweets of flowers. In the suctorial Butterfly, the lips, mandi-
Insects may be divided into the masticating (as the Beetle) and the suctorial (as the Butterfly). In the former group, the oral apparatus consists of two pairs of horny jaws (mandibles and maxilla), which work horizontally between an upper (labrum) and an under (labium) lip. The maxillæ and under lip carry sensitive jointed threads, or feelers (palpi). The front edge of the labium is commonly known as the tongue (ligula). ${ }^{27}$ In such a mouth, the mandibles are the most important parts; but in passing to the suctorial Insects, we find that the mandibles are secondary to the maxillie and labium, which are the only means

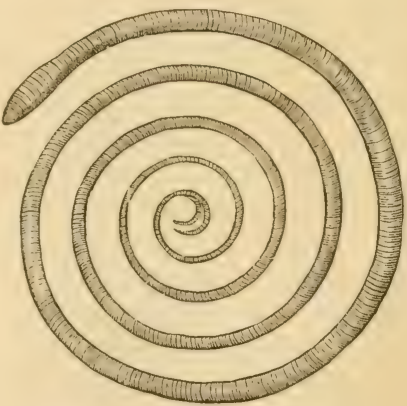

Fro. 21.-Proboscis of a Butterfy. 
bles, and palpi are reduced to rudiments, while the maxilla are the only useful oral organs. 'These are excessively lengthened into a proboscis, their edges locking by means of minute teeth, so as to form a central canal, throngh which the liquid food is pumped up into the month. Seen under the microscope, the proboscis is made up of innumerable rings interlaced with spiral muscular fibres. The probuscis of the Fly is a

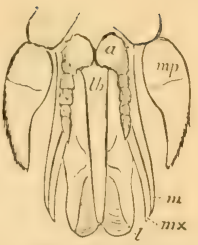

Fif. 22. - Mouth of the Horse - fly (T'ubanus lineola): $\alpha$, autennz: $m$, mandibles ; $m x$, maxille; mp, maxillary palpi ; $l b$, labrum: $l$, libium, or tongue.

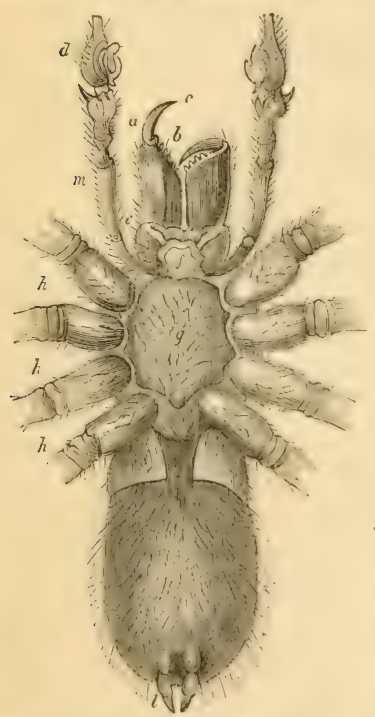

Fig. 23.-Inder Surfice of Mille Spider: $a$, $c$, poison-fang: $b$, teeth on interior margin of mandible, $e ; f$, labium: $q$, thorn $: h$, limbs: $i$, abdomen: $l$, spinnerets: $m$, maxillary palpus; $d$, dilated terminal joint. modified lower lip; that of the Bugs, fitted both for piercing and suction, is formed by the union of four bristles, which are the mandibles and maxillæe strangely altered.

As most of the Arachnids live by suction, the jaws are seldom used for mastication. In the Scorpion, the apparent representatives of the mandibles of an Insect are transformed into a pair of small forceps, and the palpi, so small in Insects, are dereloped into formidable claws: both of these organs are prehensile. In Spiders, the so-called mandibles, which move more or less vertically, end in a fang; and the club-like pal$\mathrm{pi}$, often resembling legs, 
have nothing to do with ingestion or locomotion. Buth Scorpions and Spiders have a soft upper lip, and a groove within the mouth, which serres as a canal while sucking their prey. The tongue is external, and situated between a pair of diminutive maxillæ.

The mouth of Vertebrates is a cavity with a fixed roof (the hard palate) and a movable floor (the tongue and lower jaw), having a transverse opening in front, ${ }^{28}$ and a narrow outlet behind, leading to the gullet. Sare in Birds and some others, the cavity is closed in front with lips, and the margins of the jaws are set with teeth.

In Fishes, as in nearly all aquatic animals, the mouth is the common entry to both the digestive and respiratory organs; it is, therefore, large, and complicated by a mechanism for regulating the transit of the food to the stomach and the airrated water to the gills. The slits leading to the gills are provided with rows of processes which, like a sieve, prevent the entrance of food, and with valves to lieep the water, after it has entered the gills, from returning to the mouth. So that the months of Fishes may be said to be armed at both ends with teeth-bearing jaws. A few Fishes, as the Sturgeon, are toothless; but, as a class, they have an extraordinary dental apparatus - not only the upper and lower jaws, but eren the palate, tongue, and throat, being sometimes studded with teeth. Erery part of the mouth is evidently designed for prehension. Lips are usually present; but the tongue is often absent, or very small, and as often aids respiration as ingestion.

Reptiles have a wide mouth, even the insect-feeding Toads and the Serpents can stretch theirs enormonsly. True fleshy lips are wanting; hence the sarage aspect of the grimning Crocodile. With some exceptions, as Toads and Turtles, the jaws are armed with teeth. Turtles are provided with horny beaks. The tongue is rarely absent, but is generally too thick and short to be of much use. 


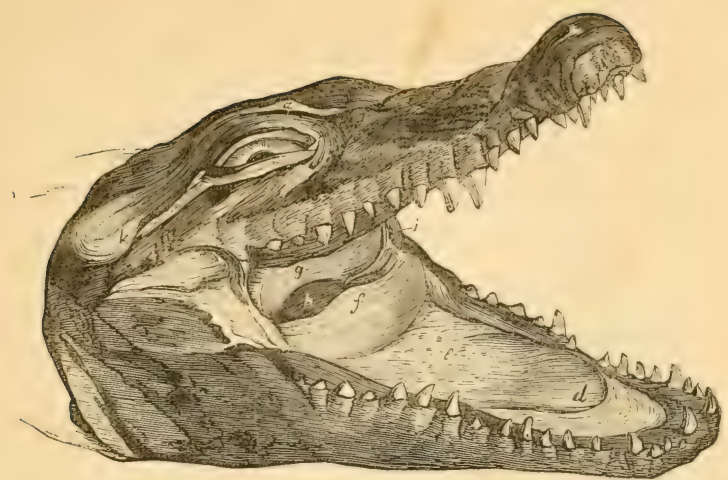

Fic. 24.-MIouth of the Crocodile : $d$, tongne; $e$, glands ; $f$, inferior, aud $g$, superior, valve, separatiug the cavity of the mouth from the throat, $h$.

In the Toad, Frog, and Chameleon it is singularly extensile: rooted in front and free behind, it is shot from the mouth with such rapidity that the Insect is seized and swallowed more quickly than the eye can follow. Snakes have a slender forked tongue, consisting of a pair of muscular eylinders, which is solely an instrument of tonch.

Birds are withont lips or teeth, the jaws being covered with horn forming a beak. This raries greatly in shape, being extremely wide in the Whip-poor-will, remarkably long in the Pelican, stont in the Eagle, and slender in the Hummer. It is hardest in those that tear or bruise their food, and softest in water-birds. The tongue is also corered with a horny sheath, and generally spinons, its chief function being to secure the food when in the month. It is proportionally the largest and most fleshy in the Parrots.

The main characteristics of the mammalian mouth are fleshy lips and mobile checks." In the duck-billed Monotremes lips are wanting, and in the Porpoises they are barely represented. But in the herbivorous quadrupeds 
they are the chief organs of prehension; in the carnirorons tribes they are thin and retractile; while in the Whale the upper lip falls clown like a curtain, orerlapping the lower jaw several feet. As a rule, the mouth is terminal; but in the Elephant, Taph, Ilog; and Shrew, the upper lip blends with the nose to form a proboscis, or snout. The mouth is comparatively small in the Elephant

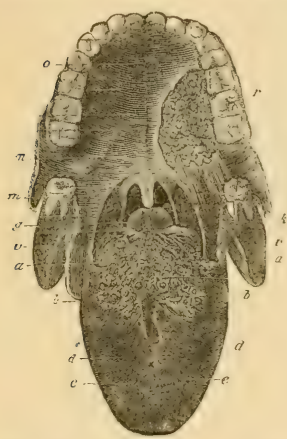

Fig. 25,-Human Tongue and adjacent parts: $\alpha$, lingual papillæ; $b$, papillæ forming $\mathrm{V}$-shaped lines: $d$, fungiform papillæ: $e$, filiform papillæ; $\alpha$, epiglottis; $m$, nvula, or conical process, hanging from the soft palate, $n ; 0$, hard palate; $r$, palatine grands, the mucous membrane being removed; $v$, section of the lower jaw. and in gnawing animals like the Squirrel, wide in the Carnirores, short in the Sloth, and long in the Ant-eater. Teeth are usually present, but rary in form and number with the habits of the animal. The Ant-eater is toothless, and the Greenland Whale has a sieve made of horny plates. The tongue conforms in size and shape with the lower jaw, and is a muscular, sensitive organ, which serves many purposes, assisting in the prehension, mastication, and swallowing of food, besides being an organ of taste, tonch, and speech. Its surface is covered with minute prominences, called papillo, which are arranged in lines with mathematical precision. In the Cats, these are developed into recurved spines, which the animal uses in cleaning bones and combing itŝs fur. Similar papillæ oceur on the roof and sides of the month of the $\mathrm{Ox}$ and other Ruminants. The tongue is remarkably long in the Ant-eater and Giraffe, and almost immorable in the Gnawers, Elephants, and Whales.

3. The Teeth of Animals. - Nearly all animals have certain hard parts within the month for the prehension or 
trituration of solid food. If wanting, the leos are often armed with spines, or pincers, to serve the same purpose, as in the Ilorse-shoe Crab; or the stomach is lined with "gastric teeth," as in some marine Snails; or the deficiency is supplied by a muscular gizzard, as in Birds, Ant-eaters, Insects, and Cuttle-fishes. Even the Lobster and (rab), in adclition to their emplicated oral organs, have the stomach furnished with a powerful set of teeth.

The Sea-urchin is the first of animals, and the only one below Articulates and Mollusks, which exhibits any thing like a dental apparatus. Five calcareous teeth having the shape of three-sided prisms, each set in a triangular pyramid, or " jaw," are moved upon each other by a

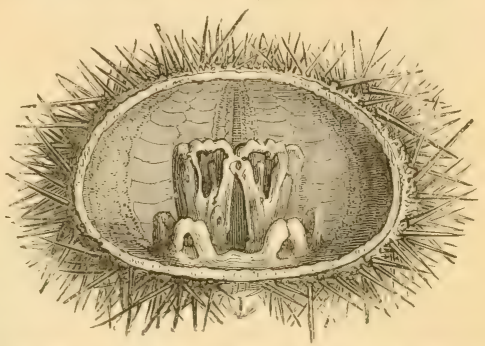
complex arrange- Frs. 26.-Echinus bisected, showing masticating apparatus. ment of levers and muscles. Instead of moving up and down, as in Vertebrates, or from right to left, as in Articulates, they converge toward the centre, and the food pasies between ten grinding surfaces.

The mimute Rotifers (a gromp of minute Articulates) lave a curions pair of homy jaws. That which answers to the lower jaw is fixed, and ealled the "anvil." 'The "nper jaw consists of two pieces called "hammers," which are sharply notehed, and beat upon the "anvil" between them.

The horny-toothed mandibles of Insects, alrealy mentioned, are mainly prehensile, but also serve to divide the food in a measure.

The three little white ridges in the mouth of the Leech 
are the convex edges of horny semicircles, each bordered by a row of nearly a hundred hard, sharp teeth. When

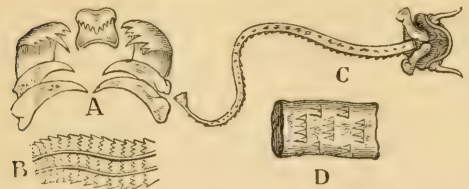

Fic. 27.-Teeth and Masticatory Apparntus of Gasteropods : $A$, pertion of odontophore, or " tongue," of Trelutina, enlarged ; $B$, portion of odontophore of Whelk (Buccinum undatum), magnified - the entire tongue has 160 rows of teeth: $C$, head and odoutophore of Limpet (Patella vulgata); $D$, portion of same, greatly magnified, to show the transverse rows of silicenus teeth. the mouth, or sucker, is applied to the skin, a sawing movement is given to the horny ridges, so that the "bite" of the Leech is really a saw-cut.

The dentition of the univalve Mol-

luskss, or the Snails, is generally lingual, i.e., it consists of microscopic teeth, usually siliceous and amber-colored, planted in rows on the tongue. The teeth are, in fact, the serrated edges of minute plates. The number of these plates varies greatly; the garden Slug has 160 rows, with 180 teeth in each row.

All Birds, and some other Vertebrates, as Ant-eaters, ${ }^{30}$ Turtles, Tortoises, Toads, and Sturgeons, have no teeth. Their absence is generally associated with a horny beak, a wide gullet, and a muscular stomach (gizzard).

In a few Vertebrates, horny plates take the place of teeth, as the Duck Mole (Ornithorhynchus) and Whalebone

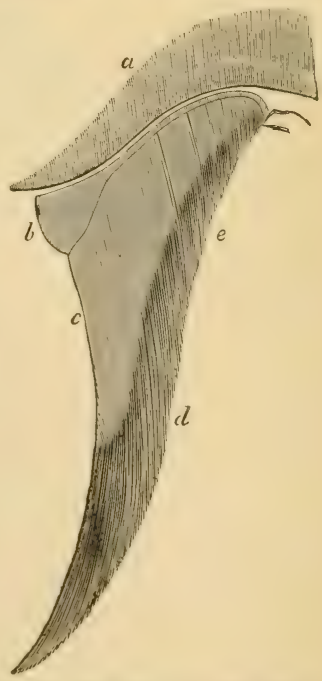

Fra. 2S.-Section of the Upper Jaw of 4 Whale (Balcenoptera), showing baleenplates: $a$, superior maxillary bone; $b$, ligamentous gum attaching the horny body of the baleen-plate, $c ; d$, fringe of bristles; $e$, smaller plates. 
Whale. In the former, the plates consist of closely set rertical hollow tubes; in the latter, the haleen, or whalebone, plates, triangular in shape, and fringed on the inner side, hang in rows from the gams of the upper jaw. In some Whales there are abunt 300 plates compusing the outer row in each jaw. ${ }^{31}$

True teeth, consisting mainly of a hard, calcareons substance called dentinc, are found only in back-boned animals. They are distinct from the skeleton, and differ from bone in containing more mineral matter, and in not showing, under the microscope, any minute carities, called lacunce. A typical tooth, as found in Man, consists of a central mass of dentine, capped with enamel and surrounded with cement. The first tissue is always present, while the others may be absent. It is a mixture of animal and mineral matter disposed in the form of extremely fine tulses and cells, so minute as to prevent the admission of the

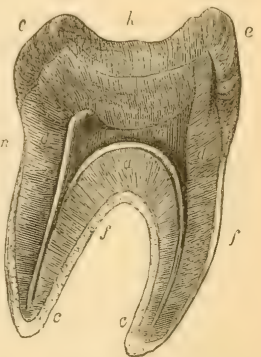

Fis. 29.-Section of Human Molar, enlareel: k, crown; $n$, neck; $f$, fang: $e$, enamel; $d$, deurine: $c$, cemeut; $p$, pulpcavity.

red particles of blood. One modification of it is irory, seen in the tusks of Elephants. Enamel is the hardest tissme of the body, and contains not more than two per (ent. of animal matter. It consists of six-sided fibres set side by side, at right angles to the surfaces of the dentine. Cement dosely resembles bone, and is present only in the teeth of the higher animals.

Teeth are usually confined to the jaws; but the mumber, size, form, structure, position, and mode of attachment vary with the food and habits of the animal. As a rule, animals developing large numbers of teeth in the hack part of the month are inferior to those having fewer teeth, and 
those nearer the lips. The teeth of Mammals only have fangs.

The teeth of Fishes present the greatest variety. In number, they range from zero to hundreds. The IIag-fish (Myxine) has a single tuoth on the roof of the month, and two serrated plates on the tongue; while the mouth of the Pike is crowded with teeth. In the very lowest of the class, we find teeth, short and blunt, in the shape of cubes, or prisms, arranged like mosaic work. Such parementteeth (seen in some Ritys) are fitted for grinding sea-weed

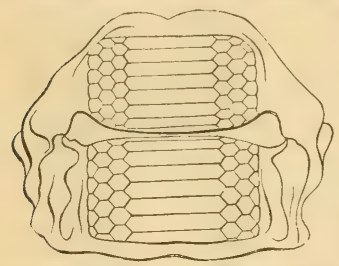

Fig. 30.-Jiws and Pavement-teeth of a Raty (Miliobates). and crushing shell-fish. But the cone is the most common form: sometimes so slender and close as to resemble plush, as in the Perch; or of large size, and flattened like a spear-head with serrated edges, as in the Shark; but more often like the canines of Mammals, curved inward to fit them for grappling. In the Shark, the teeth are confined to the fore part of the mouth; in the Carp, they are all situated on the bones of the throat; in the Parrot-fish, they oceupy both back and front; but in most Fishes, the teeth are developed also on the roof, or palate, and, in fact, on nearly every bone in the mouth. They seldom appear (as in the Salmon) on the upper maxillary. As to mode of attachment, the teeth are generally anchylosed (fastened by bony matter) to the bones which support them, or simply bound by ligaments, as in the Shark. In a few Fishes, the teeth consist of flexible cartilage; but almost invariably they are composed of some kind of dentine, enamel and cement being absent.

Of Reptiles, Toads, Turtles, and Tortoises are toothless; Frogs have teeth in the upper jaw only; Snakes have a 
more complete set, but Saurians possess the most perfect dentition. The number is not fixed even in the same species: in the Alligator it varies from 72 to 85 . The teeth are limited to the jawbones in the higher forms (Saurians); but in others, as the Serpents, they are planted also in the roof of the month. With few exceptions, they are conical and curved (Fig. 35). In the Serpents they are longest and sharpest; and the renomons species have two or more fangs in the upper jaw. These fangs contain a canal, through which the poison is forced by muscles which compress the gland. The bones to which they are attached are movable, and the fangs ordinarily lie flat upon the gums, but are brought into a rertical position in the act of striking. As a rule, the teeth of Rep-

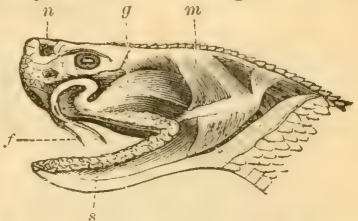

Fig. 31.-Poison Apparatus of the Rattlesnake: $g$, gland, with duct, leading to the fin: $f ; m$, elevator muscles of the jaw, which, in coutracting, compress the gland: $s$, salivary glands on the edge of the jaws; $n$, nostril. tiles are simply soldered to the bone which supports them, or lodged in a groove; but those of Crocodiles are set in sockets. Reptilian teeth are made of dentine and a thin laver of cement, to which is added in most Saurians a coat of enamel on the crown.

In the majority of Mammals, the teeth are limited in number and definite in their forms. The number ranges from 1 in the Narwhal (but the longest tooth in the kingdom) to 220 in the Dolphin. The arerage is 32 , necurring

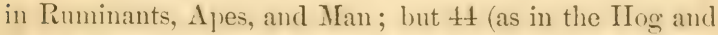
Mole) is called the typical or normal number, and this number is exceeded only in the lowest gromps. When more than 4t, the teeth are of the Reptilian type, small, pointed, and of nearly equal size, as in the Porpoise. In the higher Mammals, the tecth are comparatively few, and differ so much in size, shape, and use, that they can 
be classed into incisors, canines, premolars, and molars. For such a dental series exhibits a double purpose, prehension and mastication. The chisel-shaped front teeth are titted for cutting the food, and lience called incison's. These vary in number: the Lion has six in each jaw; the Squirrel has two in each jaw, but remarkably developed; the (Ox has none in the upper jaw, and the Elephant none in the lower; while the Sluth hats none at all. ${ }^{32}$ The ca-

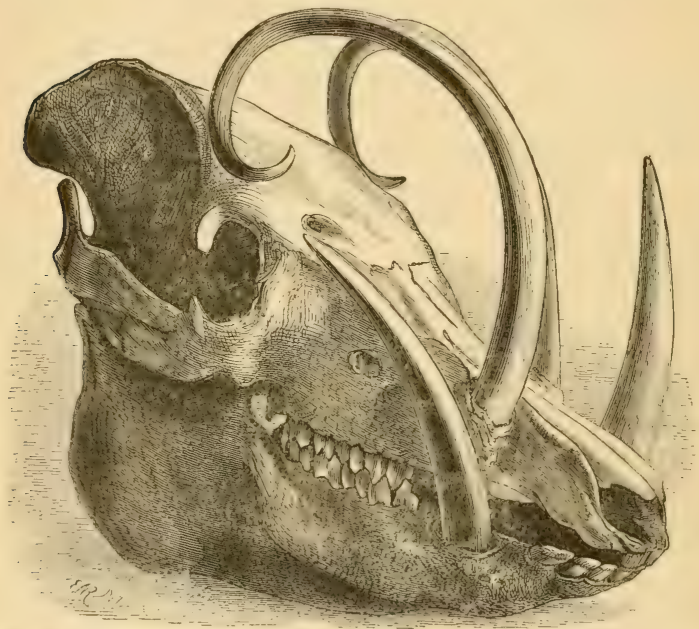

Frg. 32,-Skull of the Babirusa, or Malayan IIng, showing growth and curvature of the caniues.

nines, so called hecanse so prominent in the Dug, are conical, and, except in Man, longer than the other teeth. They are designed for scizing and tearing; and they are the most formidalile weapons of the wild arnirores. There are never more than four. They are wanting in all Podents, and in nearly all herbirorous quadrupeds. The molars, or grinders, vary greatly in shape, but close- 
Iy correspond with the structure and habits of the animal, so that a single tooth is sufficent to indicate the mode of life and to identify the species. ${ }^{33}$ In the Ruminants, Rodents, Ilorses, and Elephants, the summits of the molar's are flat, like mill-stones, with transverse or curving ridges of enamel. In the Cats and Dogs, they are narrow and sharp, passing by each other like the blades of scissor', and therefore cutting, rather than grinding, the food. The more purely earnirorous the species, and the more it feeds upon living prey, the fewer the molars. In animals living on mixed diet, as the Hog and Man, the crowns have blunt tubercles. Premolars, or bicuspicls, are those which were preceded by milk-teeth; the true, or back, molars had no predecessors.

The dentition of Mammals is expressed by a formula, which is a combination of initial letters and figmes in

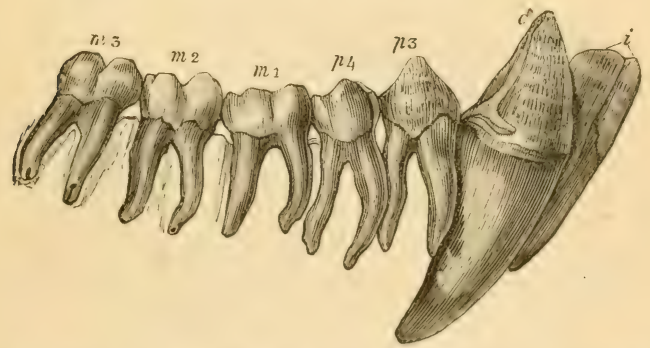

F14. 30. -Teeth of the right lower jaw of adult male Chimpanzec (Tromlodites niger), natural size. The molar series does not form a curve, as in Mav.

fractional form, to show the number and kind of teeth on each side of both jaws. Thus, the formula for Man is : $i, \frac{2-2}{2-2} ; c, \frac{1-1}{1-1} ; p, \frac{22}{2-2} ; m, \frac{3-3}{3-3}=32$.

The teeth of Mammals are alwars restricted to the margins of the jaws, and form a single row in each. But they never form an unbroken series in any liring species, ex- 
cept Man. ${ }^{34}$ The teeth implanted in the premaxillary bone, and in the corresponding part of the lower jaw, whaterer their number, are incisors. The first tooth behind the premaxillary, if sharp and projecting, is a canine.

Each tooth has its particular bony socket. ${ }^{35}$ The molars are still further strengthened by having two or more diverging fangs, or roots, a feature peculiar to this class. The incisors and canines have but one fang; and those that are perpetually growing, as the incisors of Rodents and Elephants, have none at all. The teeth of flesh-eating Mammals usually consist of hard dentine, surrounded with cement and capped with enamel. In the herbivorons tribes, they are very complex, the enamel and cement being inflected into the dentine, forming folds, as in the molar of the $\mathrm{Ox}$, or plates, as in the compound tooth of the Elephant. This arrangement of the three tissues, which

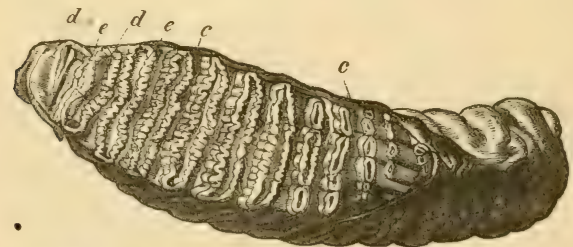

Frg. 34.-Upper Molar Tonth of Indian Elephant (Elephas Inticus), showing transverse arrangement of dentine, $d$, with festooned border of enamel plates, $e ; c$, cement; one-third natural size.

differ in hardness, secures a surface with prominent ridges, well adapted for grinding. The cutting teeth of the Rodents consist of dentine, with a plate of cnamel on the anterior surface, and the mequal wear preserves a chisellike edge. Enamel is sometimes wanting, as in the molars of the Sloth and the tnsks of the Elephant.

In Fishes and Reptiles, there is an almost mimited succession of teeth; but Mammalian teeth are cast and renewed but once in life. 
Vertebrates use their teeth for the prehension of food, as weapons of offense or defense, as aids in locomotion, and as instruments for uprooting or cutting down trees. But in the higher class, they are principally adapted for dividing or grinding the food. ${ }^{36}$ While in nearly all other Vertebrates the food is bolted entire, Mammals masticate it before swallowing. Animals that masticate most thoronghly, digest most rapidly. Mastication, however, is more essential in the digestion of regetable than of animal food; and hence we find the dental apparatus most efficient in the herbivorons quadrupeds. The food is most perfectly reduced by the Rodents.

'Teeth, as we slall see, are appendages of the skin, not of the skeleton, and, like other superficial organs, are liable to be modified in accordance with the habits of the creature. They are, therefore, of great zoological value; for, such is the harmony between them and their uses, the naturalist can predict the food and general structure of an animal from a sight of the teeth alone. For the same reason, they form important guides in the classification of animals; while their durability renders them arailable to the paleontologist in the determination of the nature and affinities of extinct species, of which they are often the sole remains. Even the structure is so peculiar that a fragment will sometimes suffice.

4. Deglutition, or How Animals Swallow.-In the lowest forms of life, the mouth is but an aperture opening immediately into the body-cavity, and the food is drawn in by ciliary currents. But in the majority of animals, a muscular tube, called the gullet, or a'sophagus, intervenes between the mouth and stomach, the circular fibres of which contract, in a wave-like manner, from above downward, propelling the morsel into the stomach. ${ }^{37}$ In the higher Mollusks, Articulates, and Vertebrates, deglutition is generally assisted by the tongue, which presses the food 
backward, and by a glairy juice, called saliva, which fircilitates its passage through the gullet. ${ }^{3 *}$ Tertebrates have a cavity behind the mouth, called the throut, or pharynx, which may be considered as a fumel to the exophagus. ${ }^{39}$ In air-breathers, it has openings leading to the windpipe, nose, and ears. In Man, as in Mammals generally, the process of deglutition is in this wise: the food, masticated by the teeth and lubricated by the saliva, is forced by the tongue and cheeks into the pharynx; the soft palate keeping it out of the nasal aperture, and the ralve-like epiglottis falling down to form a bridge orer the opening to the windpipe. The moment the pharynx receives the food, it grasps it tightly, and, the muscular fibres contracting above it and left lax below it, it is rapidly thrust into the œsophagus. Here, a similar morement (the peristaltic) strips the food into the stomach. ${ }^{40}$ The rapidity of these contractions transmitted along the osophagus may be observed in the neck of a Horse while drinking.

Deglutition in the Serpents is painfully slow, and somewhat peculiar. For how is an animal, without limbs or molars, to swallow its prey, which is often much larger than its own boly? The Boa-constrictor, e.g., seizes the

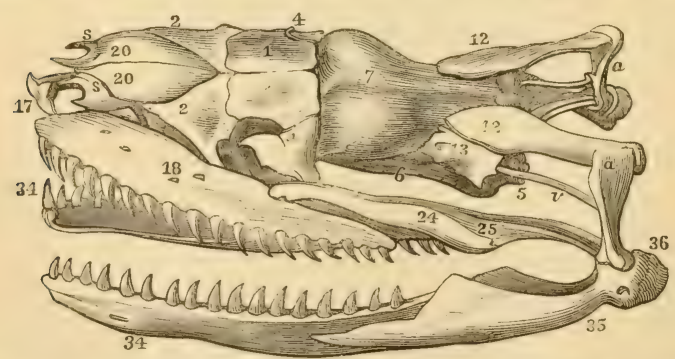

Fra. 25.-Skull of 13oa-comstrictor: 1 , frontal ; 2 , prefrontal ; 4 , postfrontal ; 5 , basioccipital; 6 , sphenoid: 7 , parietal: 12 , mastoid; 13 , alisphenoid; 17 , premaxillary; 18 , maxillary ; 20, nasal ; 24, transverse ; 25 , internal pterygoid; 34 , dental, lower jaw ; 35,36 , angular; a, tympanic; $s$, prenasal ; $v$, petrosal. 
head of its victim with its sharp recurving teeth, and crushes the body with its overlapping coils. Then, slowly uncoiling, and covering the carciss with a slimy mucus, it thrusts the head into its month by main force, the month stretching marrelonsly, the skull being loosely put together. One jaw is then unfixed, and the teeth withdrawn by being pushed forward, when they are again fastened farther back upon the animal. The other jaw is then protruded and refastened; and thus, by successire morements, the prey is slowly and spirally drawn into the wide gullet.

\section{CHAPTER IX.}

THE ALIMENTARY CANAL.

The Alimentary Canal is the great route by which n1ttritive matter reaches the interior of the body. It is the most universal organ in the animal kingtom, and the rest are secondary or subservient to it. In the higher animals, it consists of a mouth, pharynx, gullet, stomach, and intestine.

It is a general law, that food can be introduced into the living system only in a fluid state. While plants send forth their roots to seek nourishment from withont, auimals, which may be likened to plants turned outside in, have their roots (called absorbents) directed inward along the walls of a central tube or cavity. This earity is for the reception and preparation of the food, so that animals may be said to carry their soil about with them. The necessity for such a cavity arises not only from the fact that the food, which is usually solid, must be dissolved, so as to make its way through the delicate walls of the cavity into the system, but also from the occurrence of intervals be- 
tween the periods of eating, and the consequent need of a reservoir. For animals, unlike plants, are thrown upon their own wits to procure food.

The alimentary canal is a continuation of the skin, which is reflected inward, as we turn the finger of a glove. We find every grade of this reflection, from the mere depression in the side of the body of the Amœba, to the sac of the Sea-anemone and the long intestinal tube of the Ox. So that food in the stomach is still outside of the true body. In fact, there are certain Worms, living inside of other animals, which have neither mouth nor stomach, but imbibe nourishment through their skin. ${ }^{41}$ Such a method of taking foud is a link between the plant's outside mode of nutrition and the internal mode of the animal: fundamentally, there is no difference.

The feeblest sign of a digestive cavity is that extemporized by the jelly-like Amwba. Wherever a minute seaweed or animalcule happens to come in contact with its

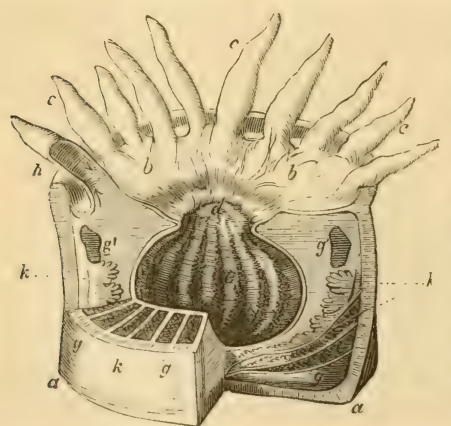

Frg. 36.-Dissected Actinia: $a$, the thick opaque skin consisting of ectoderm and endoderm, lined with muscular fibres; $c$, the tubular tentacles communicating with the interspaces, $k$, between the membraneous vertical folds, $g ; g^{\prime}$, orifices in the walls allowing passage of respiritory water from one compartment to another; $d$, mouth leading to gastric cavity, $e$. body, the spot retracts, forming a depression, which sinks deeper and deeper, till the edges meet, and the prey is ingulfed. After the soluble parts are dissolved, the indigestible residne is brought to the surface by a reverse process.

A step higher than this is seen in Infusoria and the IIydra, where a definite oral 
orifice, or month, leads to a permanent body-cavity, and serves both for the inlet of food and the ontlet of matter's not wanted. These animals may be likened to a tube or bag with one opening. There is no great difference between the membrane which lines this "stomach" and that which clothes the body; for the Iydra has been turned inside out, and digested as well. The Polyps have also but one extemal opening; but from this hangs down a short tube, open at both ends, reaching about half-way to the bottom of the body-carity. Such an arrangement would be represented by a bottle with its neck turned inward. In this suspended sac, which is somewhat constricted at the extremities, digestion takes place; but the product passes freely into all the surrounding chambers, along with the water for respiration. The Meduse, or Jelly-fishes, preserve the same type of a digestive apparatus; but the sac is cut off from the general eavity, and numerous canals radiate from it to a circular canal near the margin of the disk. In the Star-fishes, the sac sends off two branches, or canals, to each ray. But these radiating canals serve a donble purpose, for they not only carry nutritive matter, but bring back the excretions.

Thus far we have seen but one opening to the digestive carity, rejected portions returning by the same road by which they enter. But a true alimentary canal should have an anal aperture distinct from the oral. The simplest form of such a canal is exhibited by the Sponge, in its system of absorbent pores for the entrance of liquid, and of several main chamnels for its discharge. The apparatus, howerer, is not marked off from the general carity of the body, and, as in the preceding cases, digestion is not distinct from circulation. ${ }^{42}$

The Sea-urchin presents us with an important adrance -one carity with two orifices; and the complicated apparatus of higher animals is but the derelopment of this 


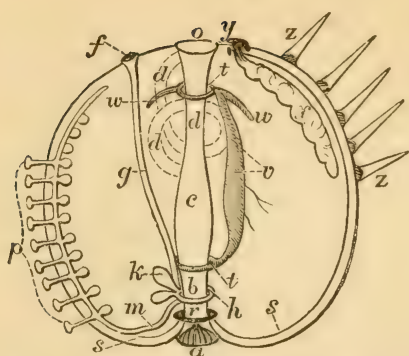

Frg. 37.-Diagrammatic Section of a Sea-urchin (Echinus) : $a$, mouth ; $b$, œsophagus; $c$, stomach : $d$, intestine; $f$, madreporiform tubercle: 7 , sand-canal; $h$, ambulacral ring; $k$, Poliau vesicles, which are probably reservoirs of fluid; $m$, ambulacral tube; 0 , anus; $p$, ambula$c r a$, with their contractile vesicles; $r$, nervous ring around the gullet; $s$, two nervous trunks, the right terminating, at anal pole, in a small ganglion; $t$, blood-vascular rings connected by $v$, the contractile heart; $w$, two arterial trunks radiating from the anal ring; $x$, an ovary opening at the anal pole in a genital plate, $y ; z$, spines, with their tubercles. type. This first rudiment of an alimentary canal begins in a mouth well provided with teeth and muscles, and extends spirally to its outlet, which generally opens on the upper, or opposite, surface. Moreover, while in many of the Worms the canal is a simple tube rumning through the axis of the cylindrical body from oral orifice to anal aperture, the canal of the Sea-urchin shows a distinction of parts, foreshadowing the pharynx, gullet, stomach, and intestines of Man himself. Both month and vent have muscles for constriction and expansion; and, as the rent is on the summit of the shell, and the latter is corered with spines, the ejected particles are seized by delicate forks (pedicellaria), and passed on from one to the other down the side of the body, till they are drolped off into the water. ${ }^{43}$

The next higher modification we find in the Articnlate subkingdom. In the Worms, the digestive tract is either a straight, unvarying tube, or divided up into ponches (sacculated), as in the Leech, with clusters of little glands, called follicles, along the side, which are the rudiments of a liver. In Myriapods and Larva, the same general plan is continned, the canal passing in a straight line from one extremity to the other, but showing a division into gullet, stomach, and intestine. ${ }^{44}$ Crustaceans, like the Lobster, have a short gullet leading to a large cavity, situated in 
the head of the animal, which is a gizzard, rather than stomach, as it has thick muscular walls armed with teeth. A well-marked constriction separates this organ from the intestine. The liver is highly developed; instead of numerous follicles, there is a large symmetrical organ, divided into two lobes, pouring its secretion into the upper part of the intestine, which is the true stomach.

\section{Among Insects,} there is great rariation in the form and length of the canal. The following parts can generally be dis-

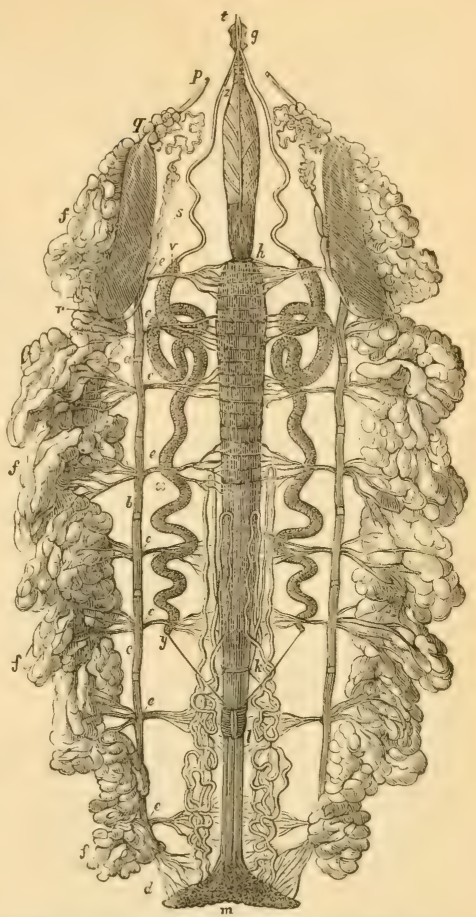

Fro. 3S.-Anatomy of a Caterpillar: $g, h$, œsophagus: $h$. $i$, stomach; $k$, hepatic vessels; $l, m$, intestine; $q, r$, salivary glands: $p$, salivary dnct ; $a, b, c$, longitudinal tracheal trunks; $d, e$, air-tubes distributed to the viscera : $f$. fat-muss; $v, x, y$, silk-secretors: $z$, their excretory ducts, terminating in $t$, the spiuneret, or $f u$ sulus.

tinguished: gullet, crop, crizzard, stomach, and large and small intestines, with many glandular appendages. The crop, crizzard, and large intestine are sometimes absent, especially in the carnivorons species. In IBees, the crop is called the "honey-bag." The gizzard is found in In- 
sects having mandibles, and is frequently lined with rows of horny teeth, which are specially developed in Grass-

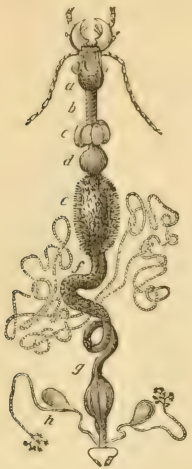

Fra. 39.-Alimentary Canal of a Beetle: $a$, pharynx: $b$, gullet, leading to crop, $c$, gizzard, $d$, and stomach, $e$; $f$, delicate biliary tubes: $g$, intestine; $h$, other secreting organs.

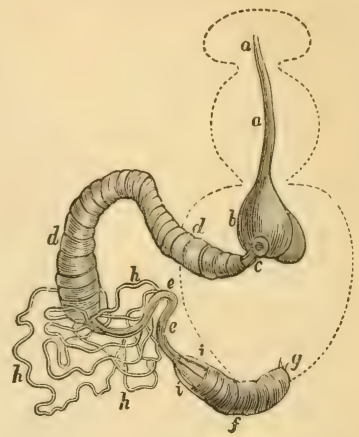

Fig. 40.-Alimentary Canal of the Bee (Apis mellifica) : $a$, gullet; $b$, crop; $c, d$, stomach; $e$, small intestive; $f$, large intestine; $g$, anal orifice; $h$, biliary vessels; $i$, auxiliary glands.

hoppers, Crickets, and Locusts. The intestines are remarkable for their convolutions. Insects have no true liver; but its functions are performed by little tubes $($ cece $a)$ around the stomach. ${ }^{46}$

The alimentary eanal of Spiders is short and straight, the pharynx and gullet being very minute. The stomach is characterized by sending out tubular prolongations, and the intestine ends in a large bladder-like expansion. Scor-

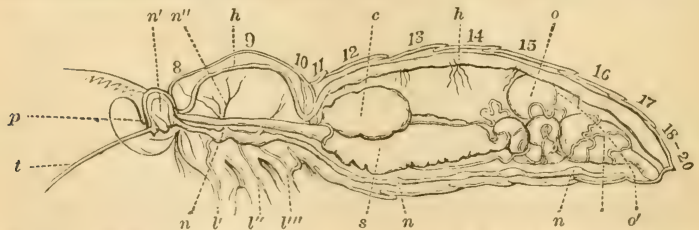

Fig. 41.-A natomy of a Sphinx Moth: $n$, nervons cord : $n^{\prime}$, brain sending off nerves to the legs, $l^{\prime}, l^{\prime \prime}, l^{\prime \prime \prime}$, and for the wings at $n^{\prime \prime} ; h$, dorsal vessel, or heart ; $c$, crop ; 8 , stomach; $i$, intestines; $o$, reproductive organs ; $o^{\prime}$, oviduct; $8-20$, segments. 
pions have no stomachal cavity--a straight intestine passes directly through the body.

In bivalve Mollusks, like the Clam, the month (which is a mere aperture) opens at once into the stomach, which lies imbedded in a large liver, and the intestine, describing a few turns, passes directly through the liearto ${ }^{\text {in }}$ In the mivalve Mollusks, like the Snail, the gullet is long, and frequently expands into a crop; the stomach is often domble, the anterior being a gizzard provided with teeth for mastication; the intestine passes throngh the liver, and ends in the fore part of the body, usually on the right side.

The highest Mollusks, as the Cuttle-fish and Nautilus, exhibit a marked advance. A mouth with powerful mandibles leads to a long gullet, which ends in a strong muscular gizzard resembling that of a fowl. ${ }^{47}$ Below this is a carity, which is either a stomach or duodenum; it receires the bile from a large liver. The intestine is a tube of uniform size, which, after one or two slight curves, bends up, and opens into the "funnel" near the month.

Fishes have a simple, short. and wide alimentary canal. The stomach is separated from the intestine by a narrow "pyloric" oritice, or ralve, but is not so clearly distingrished fiom the grullet, so that regrurgitation is

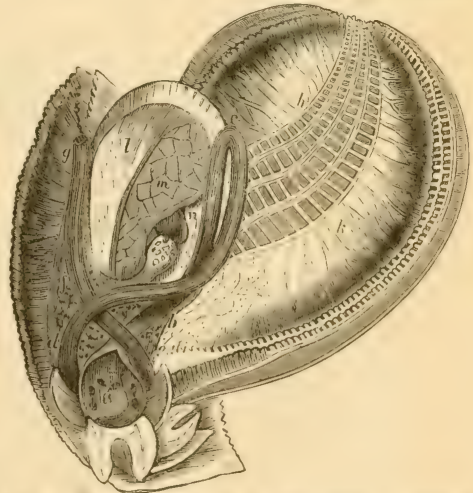

Fir. 42. - Alimentary (anal of the Ovster: $a$, stomach laid open; $d$, liver: $b, c, d, f$, convolutions of the intestine: $n$, anal aperture; $n, n$, anricle and ventricle: $l . m$, adductor muscle; $h, k$, lobes of mouth divided to show the renous canals at the base of the grills. 


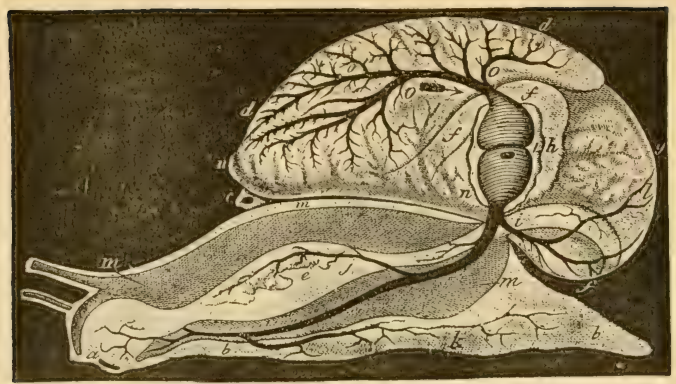

FrG. 43,-Anatomy of a Gasteropod (Snail) : $a$, mouth ; $b$, foot ; $c$, anus ; $d$, lung; $c$, stonach, covered above by the salivary glands; $f$, iutestine; $g$, liver; $h$, heart: $i$, aorta; $j$, gastric artery ; $l$, hepatic artery $; ~ k$, artery of the foot ; $m$, abdominal cavity, supplying the place of a venous sinus; $n$, irregular canal communicating with the abdominal cavity, and carrying the blood to the luug; $o$, vessel carrying blood from the lung to the heart.

easr. ${ }^{48}$ Indeed, it is common for Fishes to disgorge the indigestible parts of their food, and some, as the Carp,

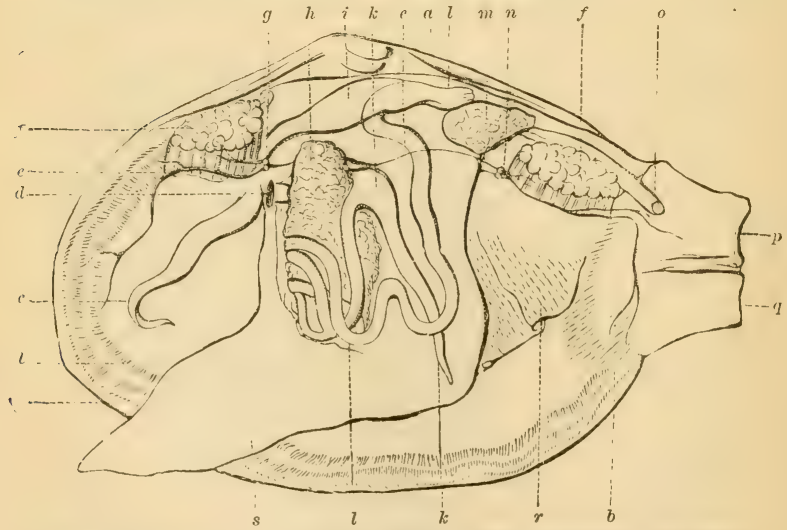

Fig. 44.-Anatomy of a Lamellibranch (Mactra): $a$, shell ; $b$, mautle : $c$, tentacles, $\overrightarrow{\sigma r}$ lips; $d$, mouth ; $e$, nerves: $f$, muscles: $q$, anterior and, $n$, posterior ganglion: $h$, liver ; $i$, heart $;$, stomach; $l$, intestine passing through the heart; $m$, kidney : $o$, anal end of the intestine; 2 , exhalent and, $q$, inhalent respiratory tubes, or siphons; $r$, gills; $s$, foot. 
send the food back to the pharynx to be masticated. The stomach is nsmally bent, like a siphon; but the intestine is nearly straight, and withont any marked distinction into small and large. Its appendages are a large liver and a rudimentary pancreas.

In the amphibious Reptiles, as the Frogs, the digestive apparatus is very similar to that of Fishes; but the two kinds of intestines can be more readily distinguished. 'The higher Reptiles generally have a long wide gullet, which passes insensibly into the stomach, and a short intestine (about twice the length of the body) very distinctly divided into small and large by a constriction. ${ }^{49}$ The vegetable-feeding Tortoises have a. comparatively long intestinal tube; and the Serpents have a slender stomach, but little wider than the rest of the alimentary canal.

The stomach of the Crocodile is more complex than any hitherto mentioned. It resembles that of the Cuttle-fish, but offers a still more striking analogy to

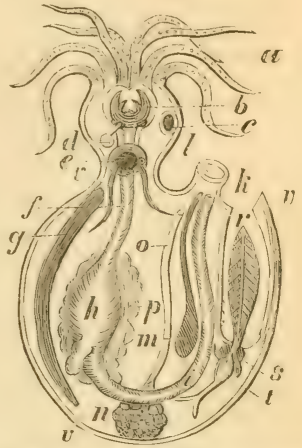

Fri. 45.-Anatumy of a cephalupod (diagram): $a$, tentacles : $b$, masticatory apparatus; $c$, eye; $d$, salivary gland; $e$, nervous qunglia : $f$, $a^{2}<$ oph:arus: ", iuternal shell, or "cuttle-bone:" $h$, stomach ; $i$, intestine : $k$, anus; $l$, funnel; $m$, ink-bag; $n$, ovary; 0 , oviduct: $p$, liver; $r$, gill contained in the branchial chamber : s, branchial heart : $t$, systemic heart; $v$, mantle. the gizzard of a Pird, having very thick walls, and the musenlar fibres radiating precisely in the same manner. So that, in this respect, the Crocudile may be considered as the connecting link between Reptiles and IBirds." It is in Crocodiles also that the duodenmm, a small pouch, with which the intestine hegins, is first distinctly defined. Into this ponch, the liver and pancreas, or sweet-breal, pour their secretions. Furthermore, in the lower animals, the 
intestines lie more or less loose in the abdomen; but in the Crocodile, and likewise Birds and Mammals, they are supported by a membrane called mesentery.

In Birds, the length of the alimentary canal varies with

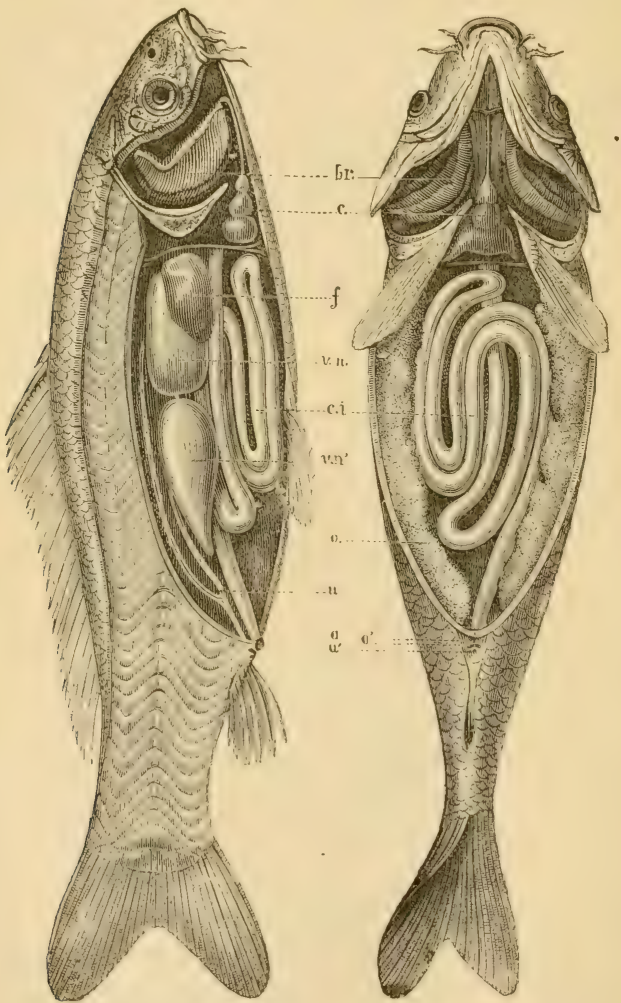

Frg. 46.-Anitomy of the Carp: $b r$, branchire, or gill-openings; $c$, heart : $f$, liver : $i n$ : swimming bladder; ci, intestinal canal ; 0 , ovarinm: $u$, urethra. The side-view shows the disposition of the muscles in vertical tlakes. 
their diet, heing greatest in those living on grain and fruit. The gullet corresponds in length with the neck, which is longest in the long-legred tribes, and in width with the fool. In those that swallow large fish entire, the gullet is dilatable, as in Snakes. In nearly all Birds, the food is delayed in some cavity before digestion: thus, the Pelican has a bag moder the lower jaw, and the Commorant lats a capacious gullet, where they store up tishes; while these that gorge themselves at intervals, as the Vulture, or feed on seeds and grains, as the Turkey, hare a pouch, called the crop, dereloped near the lower end of the gullet. ${ }^{51}$ The Ostrich, Goose, Sran, most of the Waders, and the fruit or insect eating Birds, which find their food in tolerable abundance, and

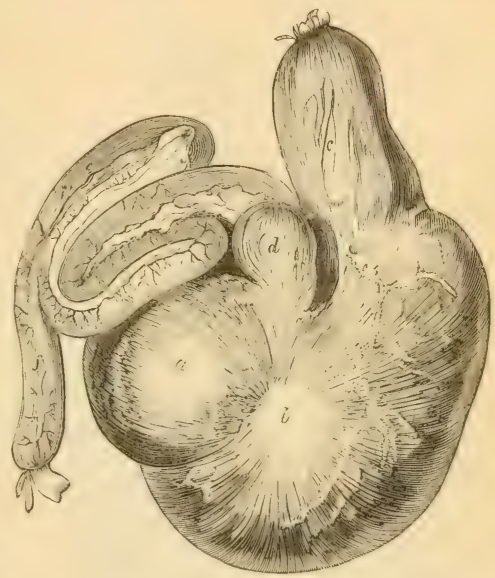

Frg. 47. - Stomach of the Crocorlile: $a$, muscular fibres radiuting from a central tendon, $b ; d$, commeucement of duodenum ; $c$, œsophagus ; $f$, intestine.

take it in small guantities, have no such reservoir. Pigeons have two crops.

In all Birls, the food passes from the cullet into the proventriculus, or stomach proper, where it is mixed with a "castric juice" secreted from glands on the surface. Thence it soes into the gizzard, an oval sac of highly muscular texture, and lined with a tough homy skin." The gizzard is most highly developed, and of a deepr-red 
color, in the Scratchers and flat-billed Swimmers (as Fowls and Swans); but comparatively thin and feeble in Birls of Prey (as the Eagle). The gizzard is followed by the

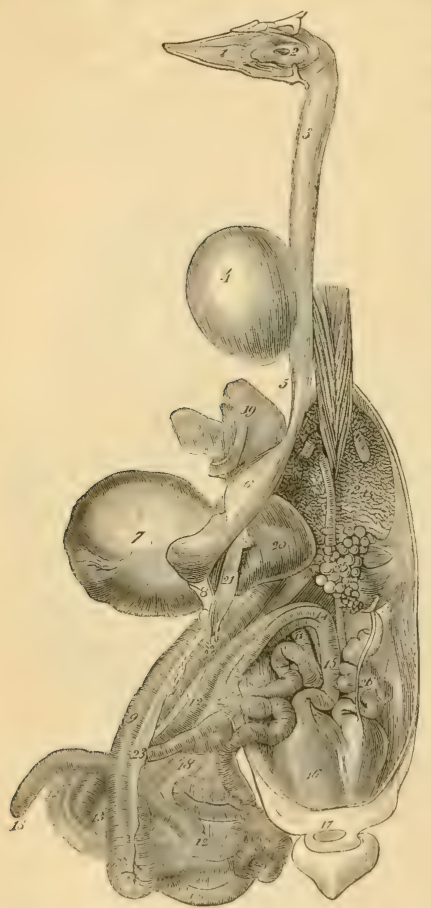

Fig. 45.-Digestive Apparatus of the Fowl: 1, tongue; 2 , pharynx; 3,5 , esophagus: 4 , crop ; 6 , proventriculıs; 7 , pizzard; $8,9,10$, dnodenum : 11,12 , small intestine: 13, two caen (analogue of the colon of mammals): 14 , their insertion into the intestinal tulie: 15 , rectum: 16 , clinaca: 17 , anus: 18 , mesentery : 19, 20, left and right lobes of liver: 21, gnll-bladder; 22, insertion of pancreatic and biliary ducts; 23 , paucreas; 24 , lung : 25 , ovary ; 26 , ovicluct. intestines, which are longer than those of Reptiles: the small intestine begins with a loop (the duodenum), and is folded several times upon itself; the large intestine is short and straight, terminating in the sole outlet of the body, the cloaca. A liver and pancreas are alwars attached to the upper part of the small intestine.

The alimentary canal in Mammals is clearly separated into four distinct cavities: the pharynx, or throat; the osophagns, or gullet; the stomach; and the intestines.

The pharynx is more complicated than in Birds. It is a funnel-shaped bag, having seren openings leading into it: two from the nostrils, and two from the ears; 
one from the windpipe, gnarded by the epiglottis; one from the mouth, with a fleshy curtain called the soft palate; and one from the œsophagus. It is the natural passage for food between the mouth and the oesophagus, and of air between the nostrils and windpipe. Like the mouth, it is lined with a soft mucous membrane.

The esophagus is a long and narrow tube, formed of two muscular layers: in the outside one, the fibres rum lengthwise; in the other, they are circular. It is also covered more or less with a sheath of striated fibres, and lined with mucous membrane. While in all Fishes, Reptiles, and Birds the ventral chamber is one, in Mammals it is divided, by a partition called the diaphragm, into two

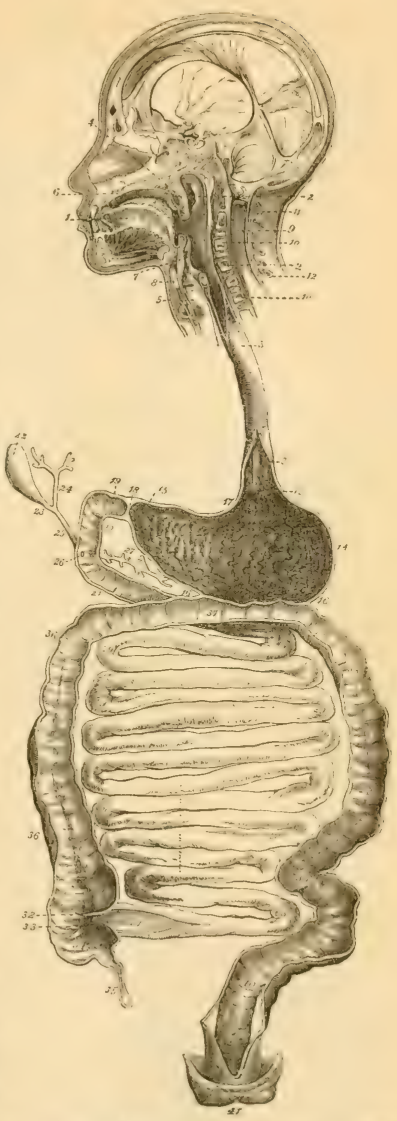

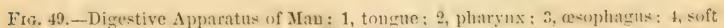
palate : 5 , larynx; 6 , palate: 7 , epiglottis; 8 , thyroid cartilage; 9 , beginuing of spinal marrow ; $10,11,12$, vertebre, with spinous processes; 13 , cardiac orilice of stomach; 14 , left end of stomach; 18 , pyloric valve; $19,20,21$, duodenum; 22 , gall-bladder: $2 \overline{\%}$, duct from pancrens: 28,29 , jejunum of intestiue; 30 , ileum; 34 , cecum; $36,37,35$, colon, or large intestine; 40 , rectum. 
cavities-the thorax, containing the heart, longs, etc.; and the abdomen, containing the stomach, intestines, etc. The

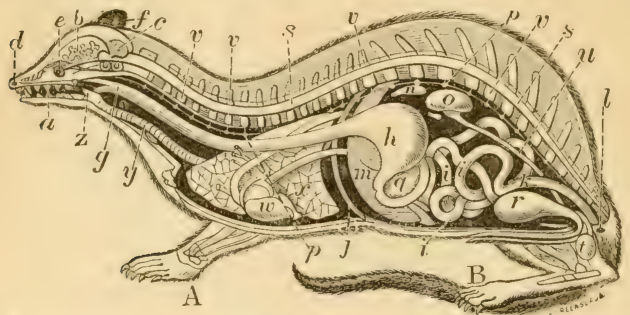

Frg. 50.-Ideal Section of a Mammalian Vertebrate: $A$, pectoral, or fore limb: $B$, pelvic, or hiud limb; $a$, mouth; $b$, cerebrum; $c$, cerebellum ; $d$, nose; $e$, eye $f$, ear ; $g$, esophagus ; $h$, stomach ; $i$, intestine ; $j$, diaphragm, or midrift ; $k$, rectum, or termination of intestiue ; $l$, auus; $m$, liver: $n$, spleen; 0 , kiduey : $p$, sympathetic system of nerves; $q$, pancreas; $r$, urinary bladder; $s$, spinal cord; $u$, ureter; $v$, vertebral column; $v$, heart; $x$, lung; $y$, trachea, or windpipe; $z$, epigluttis.

assophagus passes through a slit in the diaphragm, and almost immediately expands into the stomach.

In the majority of Mammals, the stomach is a muscular hag of an irregular oral shape, lying obliquely across the ahdomen. In the Flesh-eater's, whose food is easy of solntim, the stomach is nsually simple, and lies nearly in the

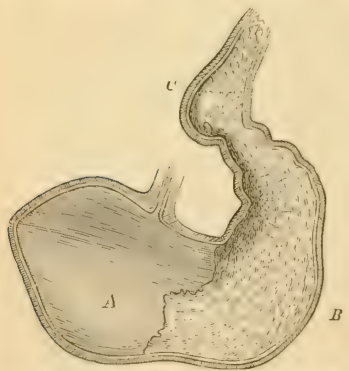

Fif. 51.-Cection of Iforse's Stomach: $A$ left sac; $B$, right sac; $C$, duodeuum. course of the alimentary canal; but in proportion as the food departs more ridely in its composition from the body itself, and is therefore more difficult to digest, we find the stomach increasing in size and complexity, and turned aside from the general comrse of the canal, so as to retain the food a longer time. ${ }^{\text {s3 }}$ The inlet, or opening, into the asophagus is called cardiac; the outlet, 
or opening, leading into the intestines is called pyloric. In the Carnivores, Apes, and most odd-toed quadrupeds, the stomach resembles that of Man. That of the toothless Ant-eater has the lower part turned into a kind of

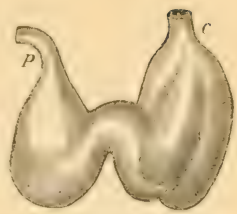
gizzard for crushing its food. The Frs.52.-stumach of the PorElephant's is subdivided by numerons folds. In the Horse, it is constricted in the middle; and in the Rodents, Porpoises, and Rangaroos, the constriction is carried so far as to make two or three sections. But animals that chew the end (Ruminants) have the most

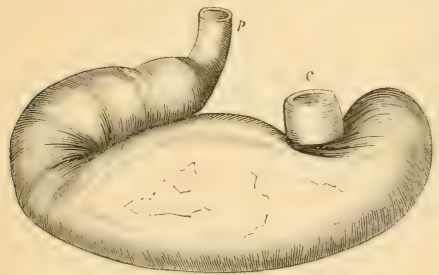

Fig. 5i,-_Stomach of the Limu: $c$, cardiac orifice, or entrance of cesophagus; $p$, pyloric. complex stomach. It is divided into four peculiar chambers: First, the paunch (rumen), the largest of all, receives the lalf-mosticated food when first swallowed. The inner surface is covered with papillæ, except in the Camel, which has large cells for storing "up water. From this, the food passes into the honey-coml, stomach (reticulum), so named from its structure. Lir uids swallowerl usually go directly to this cavity, withont passing through the paunch, and hence it is sometimes

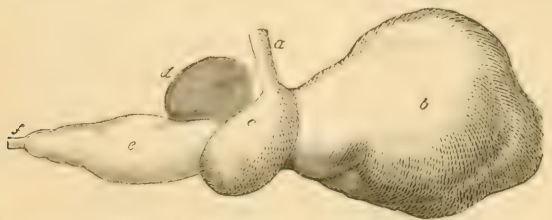

Fis. 54.-Complex Stomach of a Ruminant: $a$, gullet; $b$, rumen, or paunch ; $c$, reticulum; $d$, psalterium, or manyplies; e', abomasus ; $f$, pylorus leading to duodenum. 
called the water-bag. Ilere the food is made into little balls, and returned to the month to undergo a thorough mastication. When tinally swallowed, it is directed, by a groove from the asophagns, to the third, and smallest, cavity, the manyplies (psulterium), named from its numerotis fords, which form a strainer to keep back any mndivided food; and thence it passes into the true stomach (abomasus), from which, in the calf, the remet is procured for curdling milk in the manufacture of cheese.

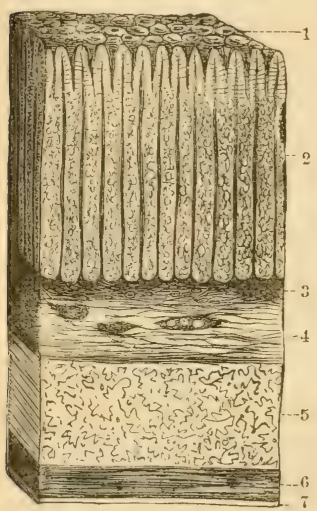

FIo. 55. - Vertical Section of the C'oats of the Stomach: 1 , surfice of mucous membrane, and months of stistric follicles; 2, gitstric tul)uli, or follicles: 3 , deuse connective tissue; 4 , submucous tissue; 5 , transverse muscular fibre: 6 , longitudinal mu=cular fibre; $\tau$, tibrous, or serous, coat.
This fourth cavity is like the human stomach in form and function, and is the only part which secretes gastric juice. The rumen and reticulum are rather dilatations of the œesophagus than parts of the stomach itself; while the latter is divided by constriction into tro chambers, the psalterium and abomasus, as in many other animals.

In structure, the stomach resembles the cesophagus. The smooth ontside coat (peritonoum) is a reflection of the membrane, which lines the whole aldomen. The middle, or muscular, coat consists of three layers of fibres, rumning lengthwise aromd and obliquely. The successive con traction and relaxing of these fibres produce the wormlike motion of the stomach, called peristaltic. The innermost, or mucons, memlrane, is soft, velvety, of a reddishgray color in Man, and filled with multitudes of glands, which secrete the gastric juice. The human stomach, 
when distended, will hold about five pints; that of the Kangaroo is as long as its body.

The intestinal canal in Mammals begins at the prloric end of the stomach, where there is a kind of valve or circular muscle. Like the stomach, it varies greatly, according to the nature of the food. It is generally longest in the Vegetahle-feeder's, and shortest in the Flesh-feeders. The greater length in the former is dne to the fact that regetable food requires a longer time for digestion, and that a greater bulk of such food is required to obtain a given quantity of nutriment. The intestines measure 150 feet in a full-grown $\mathrm{Ox}$, while they are but three times the length of the body in the Lion, and six times in M[an. Save in some lower forms, as the Whales, there are two main divisions, the "small" and "large" intestines, at the junction of which is a valve. The former is the longer of the two, and in it digestion is completed, and from it absorption takes place. The large intestine is a temporary lodging-place for the useless part of the food, until it is expelled from the body. The be-

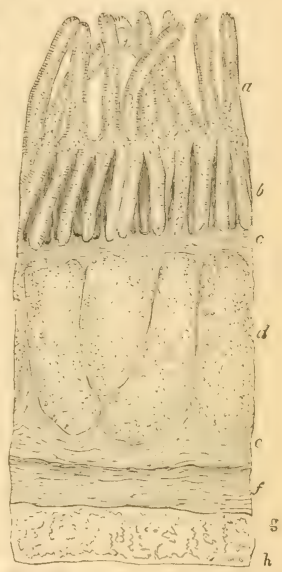

Fia. 56.-Section of the W:all of the Human Intestine (ileum), $\times 50: a$, villi : $b$ and $d$, whomds; $c$ and $e$, mucons membrane: $f$, circular museles; $" t, h$, longitudinal muscles. griming of the small intestine is ealled the duodenum, into which the ducts from the liver and pancereas open. The intestinal canal has the same structure as the stomach, and by a peristaltic motion its contents are propelled downward. The inside surface of the small intestine is covered with a host of thread-like processes (iilli), resembling the pile of relvet. 
In taking this general survey of the snceession of forms which the digestive apparatus presents among the principal gronps of animals, we can not fail to trace a gradual speciulizution. First, a simple excaration in the lody, one orifice serving as inlet for food and ontlet for indigestible matter; next, a sac, or short tube, with walls of its own suspended in the body-cavity; then, a canal passing throngh the bouly, and, therefore, having both mouth and rent; next, an apparatus for mastication, and a swelling of the central part of the canal into a stomach, having the special endowment of secreting gastric juice; then, a distinction between the small and large intestine, the former thickly set with rilli, and receiving the secretions of large glands. We also notice that food, the means of obtaining it, the instruments for mastication, and the size and complexity of the alimentary canal, are closely related.

\section{CHAPTER $\mathrm{X}$.}

HoW ANIMALS DIGEST.

The object of the digestive process is the reduction of food into such a state that it can be absorbed into the srstem. For this purpose, if solid, it is dissulved; for fluidity is a primary condition, but not the only one. Many soluble substances have to undergo a chemical change before they can form parts of the living body. If albumen or sugar be injected into the veins, it will not be assimilated, but be cast out unaltered.

To produce these two essential changes, solution and transmutation, two agencies are used-one mechanical, the other chemical. The former is not always needed, for many animals find their food already dissolred, as the 
Butterfly: lut solid substances, to facilitate their solution, are gromed or torn into pieces by teeth, as in Man ; by jaws, as in the Lobster; or ly a gizzard, as in the Turkey.

The chemical preparation of food is indispensable." It is accomplished by one or more solvent thids secreted in the alimentary canal. The most important, and one always present, is the gastric juice, the secretion of which is restricted to the stomach, when that cavity exists. In the higher animals, numerous gilands pour additional fluids into the digestive tube, as saliva into the upper part or month, and bile and pancreatic juice into the upper part of the intestine. In fact, the mucous membrane, which lines the alimentary canal thronghont, abounds with secreting pores.

The Digestive Process is sulstantially the same in all animals, but it is carried further in the more highly developed forms. In the Infusoria, the food is acted mon by some secretion from the walls of the body-cavity, the exact natme of which is mknown. In the Star-fish and Sea-mehin, we find two solvents - a gastric juice, and another resembling bile; but the two appear to mingle in the stomach. Mrollusks and Articulates show a clear distinction between the stomach and intestine, and the contents of the liver are poured into the latter. There are, therefore, two stages in the digestive act: first, the food is dissolved by the gastric juice in the stomach, forming chyme; secondly, the chyme, upon entering the intestine, is changed into chyle by the action of the bile, and is then ready to be absorbed into the system.

In Vertebrates, a third solvent is added, the pancreatic juice, which aids the bile in completing digestion. But Mammals have a still more perfect and elaborate proceess; for in them the saliva of the month acts chemically. upon the food; while the saliva in all other animals his 
no other office, so far as we know, than to moisten the food for swallowing.

Taking Man as an example, let us note the main facts in the process. During mastication, by which the relative surface is increased, the food is mixed with saliva, which converts the starch into sugar.. ${ }^{56}$ Passed into the stomach, the now sweetish, pulpy mass is subjected to the action of the gastric juice, a pectuliar acid, which has $n 0$ effect on starch or oil, but readily dissolves the allumen, fibrine, gelatine, and like constituents of the food..$^{56}$ While this solution is going on, the miscular walls of the stomach successively contract and relax, rolling the food about, and mixing it thoronghly with the gastric juice, and, at the same time, moring the whole mass toward the pyloric

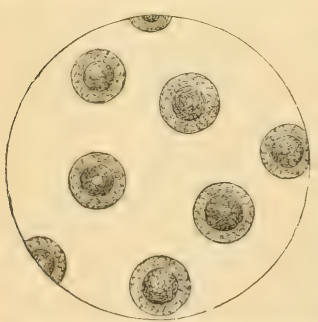

F16, 57.-Chyle Corpuscles, $\times 500$. orifice. ${ }^{57}$ Some of the chyme thus produced is at once absorbed into the blood-vessels of the stomach; but the greater part is pressed forward through the pylorus into the duodenum. As soon as the chyme enters this cavity, it separates into a white, creamy substance, called chyle, and a residuary mass, which is gradually conrerted into frees, and expelled from the srstem. ${ }^{68}$ Exactly how this change from chyme to chyle is produced is not known; but it is the most inportant part of the digestive process.

Chyme differs from food in having starchy particles changed into sugar, and much of the albuminous portion chemically altered by the gastric juice; but the conversion of the starch is not complete, and certain albuminons parts, and all of the oily particles, remain untouched. In the dnodenum, the whole mass is acted upon by secretions from the liver and pancreas. While the 
gastric secretion was acid, these are alkaline; and their office seems to be-the subdivision of the fatty matter into minnte particles (emulsiom), till they are diffused through the liquid, like atoms of butter in milk, thus fitting it to he absorbed into the blood; and the completion of the work begm by the saliva and gastric juice. In this they are assisted by the "intestinal juice" secreted by the mucons lining of the small intestine, the action of which is merely supplementary. The chyle is slowly driven throngh the small intestine by the creeping, peristaltic motion of its walls, the nutritions portion being taken up by the absorbents, as described in the next chapter, while the undigested part remaining is discharged from the large intestine.

\section{CHAPTER XI.}

\section{THE ABSORBENT SYSTEN.}

TuE nutritive matter (chỵle), prepared by the digestive process, is still outside of the organism. How shall it enter the living tissue?

In animals, like the Infusoria and Polyps, whose digestive department is not separated from the borly-eavity, the food, as soon as dissolved, mingles freely with the tissues and organs it has to nomish. In the higher Invertebrates having an alimentary canal, the chyle passes, ly simple transudation, throngh the walls of the canal directly into the soft tissues, as in Insects, or is alsorled from the camal by veins in contact with it, as in Sea-urchins, Mollusks, Worms, and Crustaceans, and then distributed through the body.

In Tertelnates only do we find a special absorbent system. Three sets of ressels are concerned in the general 
process by which fresh material is taken up and added to the blood: Veins, Lacteals, and Lymphatics. Only the two former draw material from the alimentary canal.

It is a general law that the food is absorbed as fast as it is dissolved, and, therefore, there is a constant loss in the passage down the canal. In the month and asophlatgus, the absorption is slight; but much of that which has yielded to the gastric juice, with most of the water, is greedily absorbed by the veins of the stomach, and made to join the enrent of blood which is rushing to the liver. Absorption by the veins also takes place from the slin and lungs. Medicinal or poisonous gases and liquids are readily introduced into the srstem by these channels.

We have seen that the oily part of the food passes unchanged from the stomach into the small intestine, where, acted upon by the pancreatic juice, it is cut up into extremely minute particles. These, and the remaining nu-

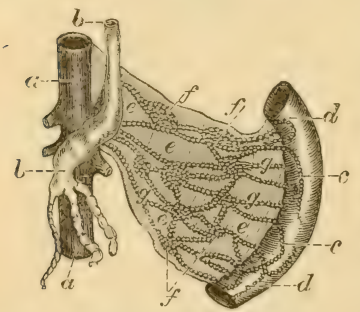

Fic. 5S.-Lacteal System of Mammal: $\alpha$, descending aorta, or privcipal artery: $b$, thoracic duct: $c$, origin of lacteal vessels, $g$, in the walls of the intestine, $c l$; $e$, mesentery, or membrane attaching the intestine to walls of the body: $f$, lacteal, or mesenteric, glands. tritive substances not taken up by the blood-ressels, enter the system in a roundabout way. A multitude of microscopic tubes form a network in the walls of the intestine, and even rum into the little relvety villi with which the intestine is lined. ${ }^{59}$ The rilli, projecting into the digested food, like rootlets into the soil, absorb the chyle, which is immediately passed into the net-work of tubes, called lacteals, from the milky character of the chyle which they convey, in Mammals. These lacteals unite into larger trunks, which lie in the mesentery (or membrane which suspends the intestine to the back wall of the abdomen), and these pour 
their contents into one large vessel, the thoracio duct, lying along the backbone, and joining the great jugular rein in the neck.

While the lacteals spring from the intestine only, the lymphatics come from all parts of the body, more especially the skin. The two are closely allied in structure and office, and both empty into the thoracic duct; so that they may be regarded as two sets of roots issuing from one common trunk. They differ in the nature of the fluid they contain, the lymphatics carrying transparent lymple, abounding with minute colorless disks, or cells; while chyle has, in addition, a crowd of oil-globnles, which render it white and opaque. ${ }^{61}$ Both coagnlate upon exposure to the air. The chief function of the lymphatics seems to be to gather up matters which have served a purpose in the system, but which may agrain lie niserl in the blower, and to return to the circu-

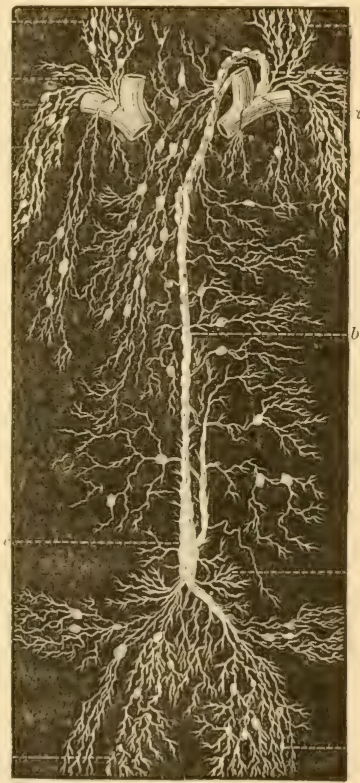

Fin.. 59.-Principal Lymplattes of the Human Body: $a$, union of left jugular and subclavian veins: b, thor:acic duct: $c$, receptaculum chyli. The oval botlies are glands. lation that superfluons part of the blowel poured out npon the tissues, over and above what was needed.

Like the rorts of Plants, the alsorbent ressels do not commence with open mouths; but the fluid which enters them must traverse the membrane which corers their 
minute extremities. The pores of this membrane (which, thongh invisible, are demonstrable) are so many short cap-

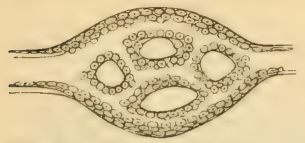

Fig. 60. - Diacram of a I,ymph Glund, showing change from er)ithelial to uncleated cells. illary tubes; so that the passage of the ehyle is a physical necessity, and is not dependent on a vital or some other mysterions principle. But as capillary attraction can not produce motion beyond the capillary tubes, another force is called into play, namely, diffiusion. The chyle, liaving passed through the membrane, meets a fluid (lymph), with which it is miscible, and diffuses itself into that fluid, leaving room for a fresh supply to enter the membrane. ${ }^{62}$ In this way a slow but strong current is kept up, which is probably aided by a rhythmical contraction of successive portions of the lacteals themselves. In Fishes and Reptiles, the absorbents are provided with pulsating sacs, called lymphatic hearts. In Pirds and Mammals, they are furnished with valves, which prevent the backward flow of the contents.

\section{CHAPTER XII.}

\section{THE BLOOD OF ANIMALS.}

The Blood is that peculiar fluid derived from digested food which carries to the living tissnes the materials necessary to their growth and repair. The great bulk of the Lody is ocenpied with apparatus for the preparation and circulation of this vital fluid.

The blood of the lower animals (Invertebrates) differs so willely from that of Man and other Tertebrates, that the former were long supposed to be without blood. In them the blood is commonly colorless; but it has a bluish 
cast in Crustaceans ; recldish, yellowish, or greenish, in Worms; and reddish, greenish, or brownish, in Jellyfishes. The red liquid which appears when the head of a Fly is crushed is not blood, but comes from the eves. In Fishes, Reptiles, Birds, and Mammals, the blood is red, excepting the white-blooded tish, dmplicoxus. ${ }^{63}$

As a rule, the more simple the fabric of the body, the more simple the nutritive fluid. In Sponges and Infusoria, it is sea-water carrying organic particles; in the low Polyps and Jelly-fishes, it is merely chyme; in all other Invertebrates, having a complete alimentary canal, it is chyle; in the backboned animals, it is a highly complex and distinct fluid.

In all animals, however, from Sponge to Man, the blood, apparently a clear, homogeneous fluid, really consists of minute grains, or globules, of organic matter Hoating in water. If the blood of a Frog be ponred on a tilter of blotting-paper, a transparent fluid (called plasma) will pass through, leaving red particles, resembling sand, on the upper surface. Under the microscope, these particles prove to be cells, or flattened disks (called corpuscles) containing a nucleus; some are colorless, and others red. The red disks
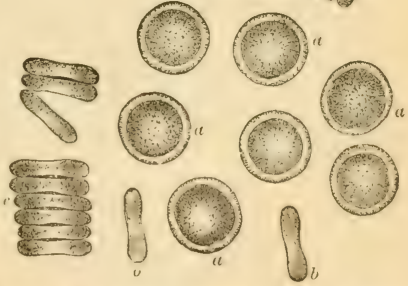

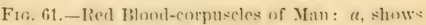
circular contour: $b$, a biconcave sectim; $c$, a group in chains.

have a tendency to rum together; the colonless ones remain single. Meanwhile, the plasma separates into two parts by coacrulating: that is, minnte fibres form, comsisting of fibrine, leaving a pale yellowish fluid, culled se. 
mum. Had the bluod not been filtered, the corpuscles and fibrine wonld have mingled, forming a jelly-like mass, known as clot. Further, the serum will coagulate if heated, dividing into lardened albumen and a watery fluid, called serosity, which contains the soluble salts of the blood.

These several parts may be expressed thus:

$$
\operatorname{Blood}\left\{\begin{array}{l}
\text { Corpuscles } \begin{array}{l}
\text { colored } \\
\text { colorless }
\end{array} \\
\text { Plasma }
\end{array} \begin{array}{l}
\left\{\begin{array}{l}
\text { fibrine } \\
\text { serum }
\end{array}\right. \text { \{albumen. } \\
\text { serosity }=\text { water and salts. }
\end{array}\right.
$$

If now we examine the nntritive fluid of the simplest

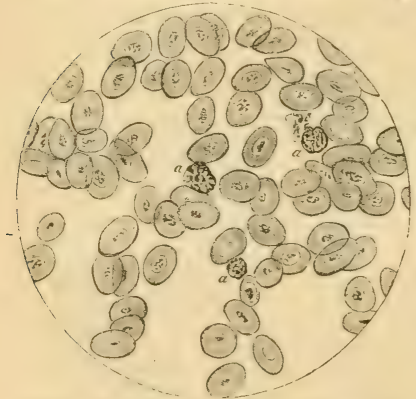
animals, we will find only a watery fluid containing granules. In Radiates and the lowest Articulates and Mollusks, there is a similar fluid, with the addition of a few white corpuscles. But there is no fibrine, and, therefore, it does not coagulate. In Fur. ti2.-Xinclented Blood-cells of a Frog, $\times 250$. the higher Articulates and Mollusks, the circulating fluid resembles the chrle as we find it in the thoracic duct of Vertebrates, containing colorless nucleated cells, and coagulating. ${ }^{65}$ In Vertebrates, there are, in addition to the plasma and white corpuscles of Inrertebrates, red corpuscles, to which their blood owes its peculiar hne. In Fishes, Reptiles, and Birds, i.e., all the backloned animals born from eggs, these rerl corpuscles are nucleated; lut in those of Mammals, no nuclens has been discovered.6

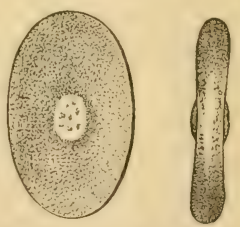

Fr. 68.-Elliptienl Corpunscle of the Frog, slowing a white prominence at the centre. 
All blood-eorpuscles are microseopic. The white are nure uniform in size than the red; and generally smaller (except in Mammals), being about $\frac{1}{2} \mathbf{s}_{0}$ of an inch in diameter. The red corjuscles are largest in Reptiles (thoso

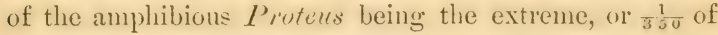
an inch), next in Fishes, then Birds and Mammals. The smallest known are those of the Musk-deer. In Mammals, the size agrees with the size of the animal only within a natural order; but in Birds the correspondence holds good throughout the class, the largest being found in the Ostrich, and the smallest in the Inmming-lird. In Man, they measure $\frac{1}{200}$ of an inch, so that it would take 40,000 to cover the head of a pin.

As to shape, the colorless corpuscles are orlinarily globular, or sac-like, in all animals; but they are constantly (-hanging. The form of the red disks is more permanent, although they are soft and elastic, so that they squeeze through very narrow passages. They are oval, circular,

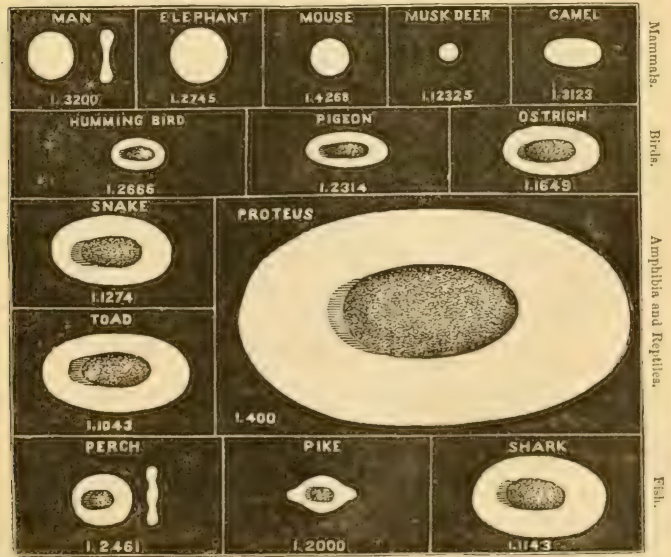

Frg. 64.-Comparative size and shane of the red corpuseles of various Animals. 
or angular, in Fishes; oval in Reptiles, Birds, and the Camel tribe; and circular in the rest of Mammals. They are double-convex when oval, and double-concare when circular.

Blood is always hearier than water; but is thimner in cold-blooded than in warm-blooded animals, in herbirores than in carnivores. The blood of lirds, which is the lottest known, being $10^{\circ}$ higher than Man's, is richest in red corpuscles. In Man, they constitute about one-half the mass of blood. The white globules are far less munerous than the red; they are more abundant in venous than arterial blood, in the sickly and ill-fed than in the healthy and vigorous, in the lower Vertebrates than in Birds and Manmals.

There is less blood in cold-blooded than in warm-blooded animals; and the larger the animal, the greater is the

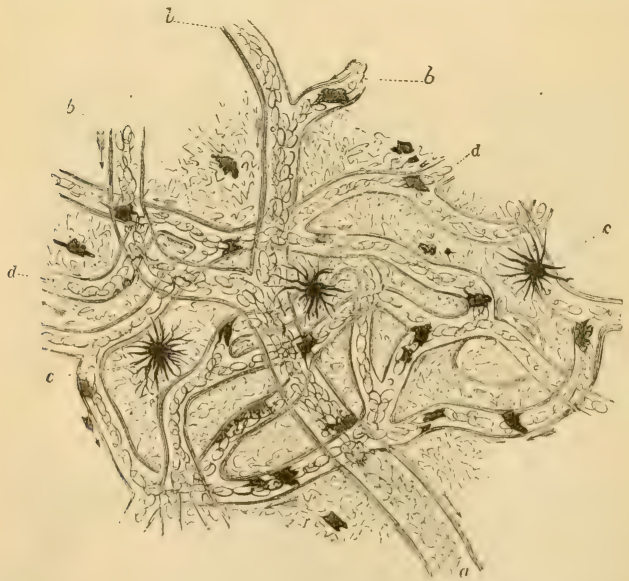

Frg. 65.-Capillary ('irculation in the Weh of a Fros's Font, $x$ ton: $a, b$, small reins; d, capillaries in which the oval corpuscles are seen to fullow one another in single series; $c$, pigment-cells in the skin. 
propertion of blood to the body. Man has abont a gallon and a half, equal to one-tenth of his weight. The heart of the Greenland Whale is a yard in diameter.

The main Office of the Blood is to supply nourishment to, and take anway waste matters from, all parts of the body. It is at once purveyor and scavenger. In its circulation, it passes, while in the arterial half of the cap. illaries, within an infinitesimal distance of the various tissnes. The plasma, carrying the nutritive matter needed, exudes through the walls of the capillary tubes; the tissue assinilates or makes like to itself whaterer is suitable for its growth and repair; and the lymphatics (the escapepipes) take up any surplus, and return it to the blood. At the same time, the renous part of the capillary network absorks the waste products of the tissues, expelling the gases by the lungs, and the solid matter's by the skin and kidneys. The special function of the sereral constitnents of the blood is not clearly known. The colorless corpuscles in Vertebrates are supposed to be the source of the red disks. The latter are probably the carrier's of gases, absurbing oxygen in the lungs, which they gire to the tissues, and receive carbonic acid in exchange.

Like the solid tissnes, the blood, which is in reality a liquid tissne, is sulject to waste and renewal, to growth and decay. Its source is the product of digestion, not only the lacteal chyle, which is the only fluid in the body that has never formed part of the blood, but also the chyme alsorbed by the blood-ressels of the stomach. Chyle differs from blood chiefly in containing less albumen and filsrine, and no red disks. The transmutation is accomplished by the small glands (mesenteric) attached to the lacteals, the lymph, and the lungs. In the low organisms, the mutritive fluid is prepared by contact with the tissnes, without passing through special organs. 


\section{CHAPTER XIII.}

THE CIRCLLATION OF THE BLOOD.

The Blood is kept in continual motion in order to nourish and purify the body and itself. For as life means work, and work brings waste, there is constant need of fresh material to make good the loss in erery part of the srstem, and of the remoral of matter which is no longer fit for use.

In the very lowest animals, where every part of the

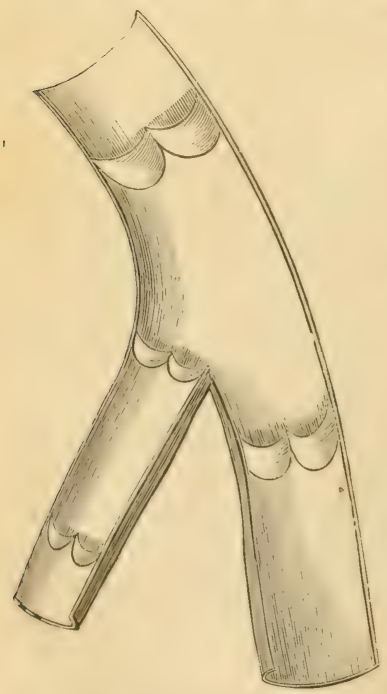

Frg. 66.-Venous Valves. They usually occur in pairs, as represented. structure is equally capable of absorbing the digested food and is in contact with it, there is no oceasion for any circulation, althongh in them even it is not allowed to stagnate. But in proportion as the power of absorption is confined to certain parts, the more need and the greater complexity of an apparatus for conreying the nutritions fluid to the varions tissnes.

In nearly all animals, the nutritive fluid is conveyed to the varions parts of the body by a system of tubes, called blood-vessels. The higher forms 
have two sets-arteries and reins, in which the blood moves in opposite directions, the former carrying blood fir()m a central reservoir or heert, the latter taking it to the heart. The walls of these tubes are male of three coats, or layers, of tissue, the arteries being elastic, like rubber, and many of the reins being furnished with valves. ${ }^{67}$ In Vertebrates, the great artery coming out of the heart is called aorta, and the grand renous trunk, entering the heart on the opposite side, is called vena cava. Both sets divide and subdivide until their branches are finer than hairs; and joining these finest arteries and finest veins are intermediate nicroscopic tubes, called capillaries (in Man about $\frac{1}{3000}$ of an inch in diameter). ${ }^{68}$ In these only, so thin and delicate are their walls, does the blood come in contact with the tissues or the air.

In all animals having a special

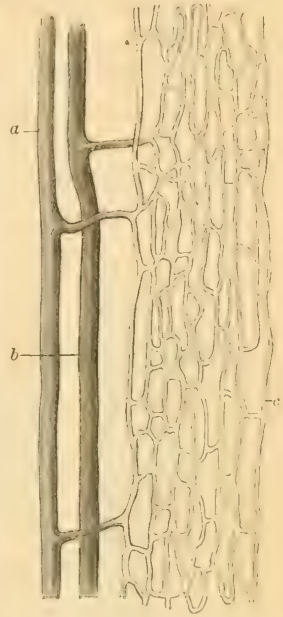

Fic. 67. - Relation of artery, $a$, vein, $b$, and raprillaties, en as seen in the muscles of at Dow. orean for respiration (gills or lumgs), there are two sets of capillaries, since there are two circulations-the systemir. from the heart around the sristem to the heart again, and the pulmonary, from the heart thromgh the respiratory orwan back to the heart. This doulle course may be illustrated by the figure 8 .

There is no true system of hlood-ressels below the sitarfish. The canals of the Sponge are really on the outside of the animal. In the Infusoria and Polyps, the nutritive matter mixed with water rises and falls in the hudy-cavity. The simplest provision for the distribution of the products 
of digestion is shown by the Jelly-fish, whose stomach sends off radiating tubes.

The first Approach to a Circulatory System is made by the Star-fish and Sea-urchin. A vein runs along the whole length of the alimentary tube, to absorb the chyle, and forms a circle aromel each end of the tube. Thene circular vessels send off branches to rarious parts of the body; but as they are not comnected by a net-work of capillaries, there can be no eircuit (Fig. 37).

The next higher type is exhibited by the Articulates. If we examine the back of any thin-skimed Caterpillar,

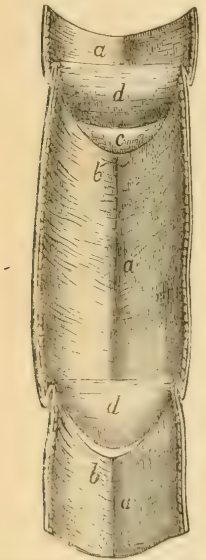

Fri: 6s. -Part of the Dorsal Vessel, or Heart, of a Cirkchafer hisected: $a, b$, muscular walls; $d$, valves between the compartments; $c$, valve defending one of the orifices communicating with the general cavity of the abdomen.

a long pulsating tube is seen rumning beneath the skin from one end of the body to the other. 'This dor'sal vessel, or heart, as it is called, is open at both ends, and divided by valres into compartments, permitting the blood to go forward, but not backward. Each compartment communicates by a pair of slits, guarded by ralres, with the bodyeavity, so that fluids may enter, but can not escape. "Circulation" is very simple. We have seen that the chyle exudes through the walls of the alimentary canal directly into the eavity of the abdomen, where it mingles with the bloud already there. This mixed fluid is drawn into the dorsal tube through the valrular openings as it expands; and upon its contraction, all the sidevalves are closed, and the fluid is forced toward the head. Passing out at the front opening, it is again diffused among and between the tissues of the body. The bluod, therefore, does nut describe a circle in definite 
channels so as to return constantly to its point of departure.

Certain Worms (as the Earth-worm) have a rentrai tube, convering the blood from head to tail, with numerous cross canals joining the rentral and dorsal tulbes. In the Lobster and Crab, Sinider and Scorpion, the dorsal

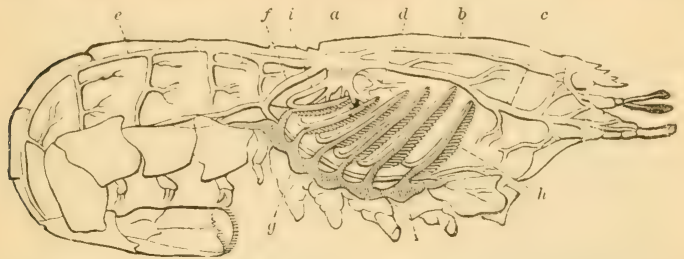

Frg. 69,-Circulation in a Lobster: $a$, heart; $b$, artery for the eyes : $c$, artery for antemise $d$, hepatic artery; $e$, superior abdominal artery $f$, sternal artery $g$, venous sinuses transmitting blood from the body to the brauchire, $h$, whence it returus to the heart by the branchio-cardiac vessels, $i$.

tule semds off a system of arteries (not found in Insects); but the bloud, as it leares these tubes, escapes into the general cavity, as in other Articulates. The Lobster and Crah, howerer, show a great adrance in the concentration of the propelling power into a short muscular sac-the first rudiment of a true heart.

A third derelopment of the cirenlatory system is furnished by the Mollusks. Comparatively sluggish, they need a powerful force-pump in the form of a compact heart. In the Orster and Snail, we find such an organ having two cavities - an auricle and a rentricle, one for receiving, and the other for distributing, the blood. The auricle injects the blood into the ventricle, which propels it hy comtless arteries to the various organs. Thence it passes, not immediately to the veins, as in higher animals, but into the spaces around the alimentary canal. A part of this is carried by ressels to the gills or lung, and then returned with the mpurified portion to the auricle. The 
whole of the blood, therefore, does not make a complete circuit.

A still higher form is seen in the Cuttle-fish, the high-

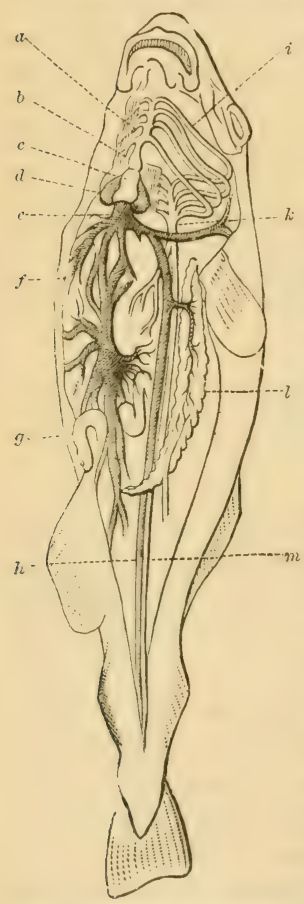

Fig. 70.-Circulating Apparatus in the Fish : $a$, branchial artery; $b$, arterial bulb; $c$, ventricle; $d$, auricle ; $e$, venous sinus; $f$, portal vein ; $g$, intestine; $h$, vena cava; $i$, branchial vessels; $k$, dorsal artery, or aorta; $l$, kidneys; $m$, dorsal artery. est of Invertelrates. Instead of a double heart, we find a triple one, a rentricle to throw the blood over the system, and two auricles to force it into the gills. Hitherto, there has been a propelling cavity on the "arterial" side only; but now the veins which collect the blond from the system to send it back to the heart by the way of the gills, are furnished with two branchial hearts, which accelerate the circulation through those organs. Many of the arteries and veins are joined by capillaries, but not all; so that in no invertebrate animal is the blood returned to the heart by a continuons closed system of blood-ressels.

As a rule, in all animals having any circulation at all, the current always takes one direction. This is generally necessitated by valres. But a curions exception is presented by the Ascidians (a group of low Mollusks), whose tubular heart is valveless, and the contractions occur alternately at one end and then the other; so that the bloorl oscillates to and fro, and a giren ressel is at one time a 
vein and at another an artery. In this respect it resembles the foetal heart of higher animals.

In Vertebrates only is the circulating current strictly contined to the bleod-ressels; in no case does it escalpe inte the general cavity of the body. In other respects, there is no great advance in the apparatus of the lowest Tertelmates over that of the highest. Mollusks. The heart of Fishes, as in the Orster, is duuble, but its position is reversed. Instead of driving arterial blood over the body, it receires the returning, or renons, blood, and sends it to the gills. Re-collected from the gills by minute tubes, called capillaries, the blood is passed into a large artery, or aorta, along the back, which distributes it by a complex system of capillaries among the tissnes. These capillaries unite with the ends of the reins which pass the blood into the auricle of the heart. ${ }^{63}$

In Reptiles generally (as Frogs, Snakes, Lizards, and

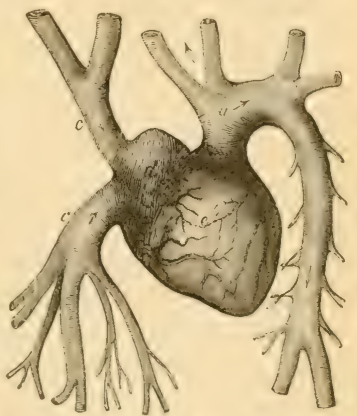

Frs. 71.-Diagram of a sincle IIeart: $d$, auricle; $e$, ventricle; $c$, veins leading to atuicle ; $a$, aorta, or maiu artery. Turtles), the heart has three carities-two auricles and one rentricle. The renous bleod from the body is received into the right auricle, and the puritied blood from the lungs into the left. Both throw their contents into the rentricle, which pumps the mixed blood in two directions-partly to the lungs, and partly around the system. Circulation is, therefore, incomplete, sinee the whole current does not pass through the lungs, and three kinds of blood are found in the body-arterial, venous, and mixed.

The ventricle of these Reptiles is partially divided by a partition. In the Crocodile, the division is complete, so 
that there are really fom cavities--two auricles, and two

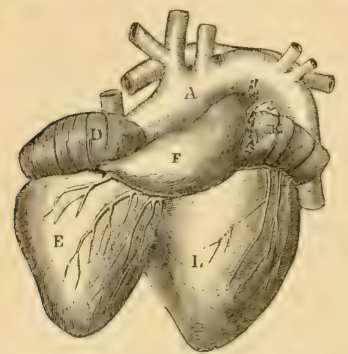

Fig. 72.-Heart of the Dugrum, a typical four-chambered heart, the parts being more separated than in higher animals: $E$, right ventricle; $L$, left ventricle; $\mathrm{D}$, right aturicle; $\mathrm{F}$, pulmonary artery : $\mathrm{K}$, left auricle; $\boldsymbol{\Lambda}$, aorta. ventricles. But both ventricles send off aortas which cross one another, and at that point a small aperture brings the two in communication. The venous and arterial currents are, therefore, mixed, but not within the heart, as in the other Reptiles, nor so extensively. In the structure of the heart, as well as gizzard, Crocodiles approach the Birds.

\section{The Highest Form of the}

Circulating System is possessed by the warm-blooded Vertebrates, Birds, and Mammals. Not a drop of blood (ean make the circuit of the body without passing throngh the lungs, the circulation to and from those organs being as perfect as the distribution of arterial blood. The heart consists of four cavities - a right auricle and rentricle, and a left auricle and rentricle. In other words, it is a hollow musele divided internally by a rertical partition into two distinct chambers, each of which is again dirided by a valce into an anricle and a rentricle. The work of the right auricle and ventricle is to receive the blood from the reins, and

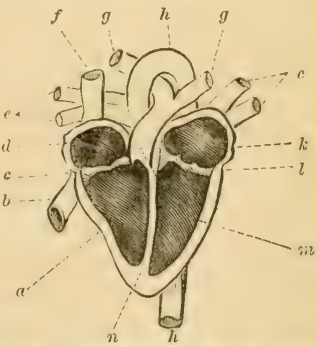

Fis. 73.- Theoretical Section of the Human Heart: $a$, risht ventricle: $b$, inferior vena cava; $c$, tricuspid valve; $d$, right auricle; $e$, pulmonary veins: $f$, superior vena cava : $q$, pulmonary arteries: $h$, aorta $; ~ k$, left auriele; $l$, mitral valve; $m$, left ventricle; $n$, septum. send it to the lungs; while the other two receive the 
blood from the lungs, and propel it over the body. The left rentricle has more to do than any other eavity. The two auricles contract at the same instant; so, also, do the ventricles. The sounds which they respectively make may be imitated by the words lubb, tup. The conrse of the current in Birds and Mammals is as follows: the renous blood brought from the system is discharged by two or three large trunks ${ }^{70}$ into the right auricle, which immediately forces it past a valre ${ }^{n 1}$ into the right ventricle. The ventricle then contracts, and the blood rushes through the pulmonary artery past its semilunar valves into

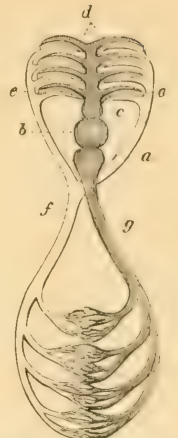

Fre. it.-Plan of Circulation in Fishes: $\alpha$, anricle ; $b$, ventricle; $c$, pulmonary artery; $e$, pulmonary veins, bringing blood from the gills, $d$, and uniting in the aorta, $f ; g$, vena cava. the lungs, where it is changed from blue to crimson, returning by the pulmonary vein to the left auricle. This
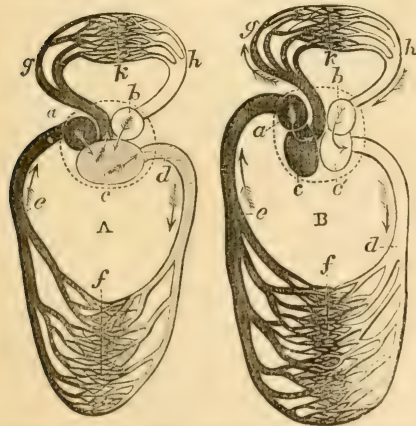

Frgs, 75, 76. - A, Plan of Circulation in Amphihia and Reptiles; B, Plan of Circulation in Birds and Mammals: $\pi$, risht auricle receiving vemous blond from the system; $b$, left auricle receiving arterial blood from the lungs; $c, c^{\prime}$, ventricles; $d, e, f$, systemic artery, vein, and capillaries; $g$, $h, k$, pulmonary artery, vein, and capillaries. sends it past the mitral valves into the left ventricle, which drives it by the semilunar valves into the aorta, and thence, by its ramifying arteries and capillaries, into all parts of the body except the lungs. From the capillaries, the blood, now changed from crimson to blue, is gathered by the reins, and conreyed back to the heart.

The Rate of the 
Blood-current generally increases with the activity of the animal, being most rapid in Birds. ${ }^{72}$ In Insects, however, it is comparatively slow; but this is becanse the air is taken to the blood - the whole body being bathed in air, so that the blood has no need to hasten to a special organ. Nerertheless, the pulsations in a Bee at rest are nearly doubled when it is lively. The motion in the arteries is two or three times faster than in the reins, but diminishes as the distance from the heart increases. In the aorta of the Horse, the blood moves $12 \frac{1}{2}$ inches per second; in that of $\mathrm{Man}, 10 \frac{1}{2}$; in the capillaries of Man, 2 inches per minute; in those of a Frog, 1.

The Cause of the Blood-current may be cilia, or the contractions of the body, or pulsating tubes or hearts. In the higher animals, the impulse of the heart is not the sole means: it is aided by the contractions of the arteries themselves, the morements of the chest in respiration, and the attraction of the tissues for the arterial blood in the capillaries. In the Chick, the blood moves before the heart hegins to beat; and if the heart of an animal be sudilenly taken out, the motion in the capillaries will eontinue as before. It has been estimated that the force which the human heart expends in twenty-four hours is equivalent to lifting 124 tons one foot.

\section{CHAPTER XIV.}

HOW $\triangle$ NIMALS BREATHE.

Arterial Blood, in passing through the srstem, both loses and gains certain substances. Its loss is niade good by fresh prodncts of digestion; and the solid or fluid waste matters which it has taken up are remored by excretion. 
But it becomes tainted, also, by carbonic acid gas, and loses the free oxygen which it possessed. It is this difference in the gateous contents which makes the great difference between the crimson blocd of the arteries and the dark-purple blood of the reins in the higher animals.

The First Object of Respiration is to convert venous into arterial blood. It is done by bringing it to the surfare, so that the carbonic acid may be exhaled and oxygen absorherl. The apparatus for this purpose is analogous to the one used for circulation. In the lowest animals, the two are combined. But in the highest, each is essentially a pump, distributing a fluid (in one case air, in the other blord) throngh a series of tubes to a system of cells or capillaries. They are also closely related to each other: the more perfect the circulation, the more careful the provision made for respiration.

Respiration is performed either in air or in water. So that all animals may be classed as air-bretcthers or weter-breuthers. The latter are, of conrse, aquatic, and seck the air which is dissolved in the water. Land-snails, Myriapods, Spiders, Insects, Reptiles, Birds, and Mammals breathe air directly; the rest, with few exceptions, receive it through the inedium of water. In the former case, the organ is internal; in the latter, it is more or less on the ontside. But however raried the organs - tubes, wills, or lungs-they are all constructed on the same principle.

(1) Sponges, Infusoria, and Polyps lave no separate respiratory apparatus, but absorb air, as well as food, from the currents of water passing through them.

In the Star-fish, Sea-urchin, and the like, we find the first distinct respiratory organs, although none are exclusively devoted to respiration. There are two sets of eanals-one carrying the nutrient fluid, and the other, radiating from a ring arome the month, distributing aerrated 


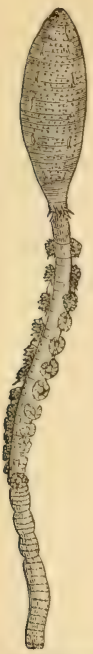

TII. IT.-Lob-worm (Amicula piscetorum), a dorsibrauchiate, showing the tufts of capillaries, or external gills. The large head is without eyes or jaws.

water. This may be called the "waterpipe system." Besides this, there are numerous gill-like fringes, which probably aid in respiration.

Fresh-water Worms; like the Leech and Earth-worm, breathe by the skin. The body is always covered by a viscid fluid, which has the property of absorbing air. The air is, therefore, bronght into immediate contact with the soft skin, underneath which lies a dense net-work of blood-vessels.

All the rest of water-breathing animals have gills. The simplest form is seen in Marine Worms: delicate veins projecting through the skin make a series of arborescent tufts along the side of the body; as these float in the water, the blood is purified. Bivalve Mollusks have four flat gills, consisting of delicate membranes filled with blood - vessels and covered with cilia. In the Oyster, these ribbon-like folds are exposed to the water when the shell opens; but in the Clam, the mantle incloses them, forming a tube, called siphon, through which the water is driven by the cilia. ${ }^{73}$ The aquatic Gas teropods (Univalves) have either tufts, like the Worms, or comb-like ciliated gills in a carity behind the head, to

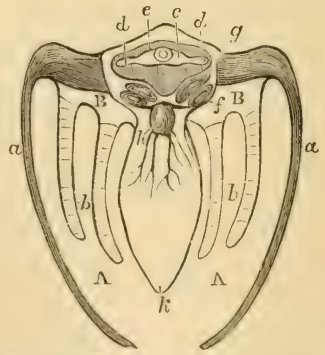

FIG. $7 \mathrm{~S}$ - - Diagrammatic Section of a Lamellibranch (Anorlon): $a$, lobes of mantle; $b$, gills, show ing transveree partitions: $c$, ventricle of heart; $d$, auricles; $e$, pericardium ; $f, g$, glandular sacs: $h$, venus simus; $k$, foot; $A$, branchial, or pallial, chamber; $\mathbf{B}$, epibranchial chamber. 
which the water is admitted by a siphon. The Cuttle-fish has similar that gills covered by the mantle; but the water is drawn in by muscular contractions instead of by cilia. The end of the siphon through which it is ejected is ealled the finnet. The leaf-shaped gills of Lobsters and Crabs are also placed in tubular cavities, and a current is kept up by a little valre worked by the jaws.

The perfection of apparatus for apuatic respiration is seen in Fishes. The gills are comb-like fringes supported on four or five bony or cartilaginous arches, and consist of myriads of microscepic capillaries, the object being to expose the renous blood in a state of minute subdivision to streams of water. The gills are always covered; and the water taken in by the mouth passes betreen the gills, and escapes by a single opening on each side, in most Fishes, but by tive slits in the Sharks. The act of "breathing water" resembles swallowing, only the water enters the gills instead of the gullet.

(2) Air-breathers have trachece, or lungs. The former consist of two principal tubes, which plass from one end of the body to the other, opening on the surface by apertures, called spiracles, resembling a row of button-holes along the sides of the abdomen, and ramifying through the smallest and most delicate organs, so that the air may follow the blood wherever it circulates. To keep the pipes erer open, and at the same time leave them flexible, they are

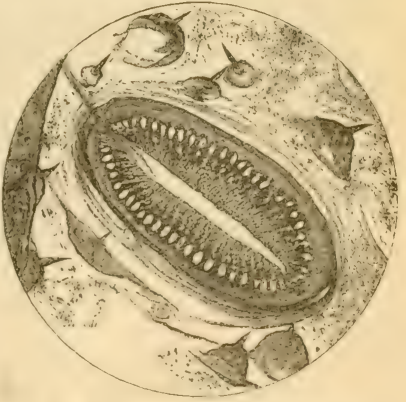

Fro. 79.-Spiracle of an Insect, $\times 75$. provided with an elastic spiral thread, like the rubber 
tube of a drop-light. Respiration is performed by the

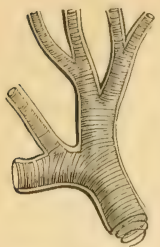

Fig. S0, - Tracheal Tube of au Insect, highly maguitied, showing elastic spiral thrend. movements of the abdomen, as may be seen in the Bee when at rest. This "airpipe system," as it may be termed, is best developed in Insects.

The "nerres" of an Insect's wing consist of a tube within a tube: the imner one is a trachea carrying air, and the onter one, sheathing it, is a blood-vessel. So perfect is the aëration of the whole body, from brain to feet, the blood is oxygenized at the moment when, and on the spot where, it is carbonized; only one kind of fluid is, therefore, circulating - arterial. It is difficult to drown an Insect, as the water can not enter the pores; but if a drop of oil be applied to the aldomen, it falls dead at once, being suf-

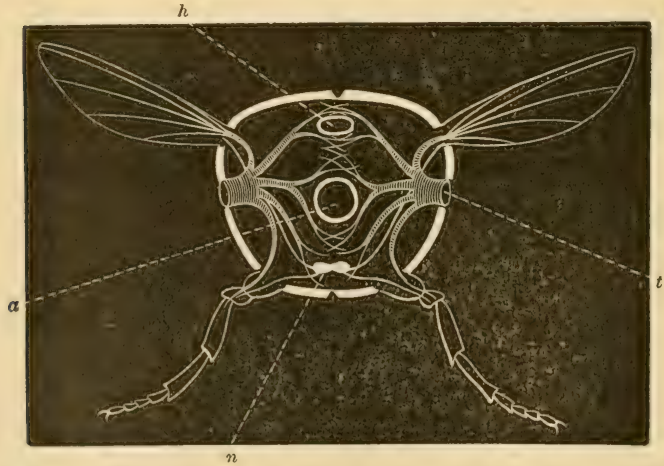

Frg. S1.-Iteal Section of a Bee: $a$, alimentary canal; $h$, dorsul ves-el; $t$, trachea ; $n$, nervous cord.

focated. The largest spiracle is ustally fond on the thorax, as under the wing of a Moth: such may be strangled by pinching the thorax.

In Millipedes and Centipedes, the spiracles open into 
little sacs comnected together by tubes; in Spiders and Scorpions, the spiracles, usually four in number, are the mouths of sacs without the tubes, and the interior of the sac is gathered into folds; land Snails have one spiracle, or aperture, on the left side of the neck, leading to a large cavity, or sac, lined with fine blood-vessels. These sacs represent the primitive idea of a lung, which is but an infolding of the

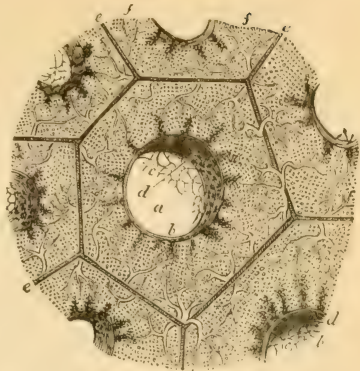

Fra. S2.-Section through a bronchial tube, Lung of a Bird, maguitied: $\alpha$, the cavity; $b$, its lining membran s supporting bloodvessels : $c$, perforations at the orifices of the lobular passages, $d$; $e$, interlobular spaces, containing the termimal branches of the pulmonary vessels supplying the capillary plexus, $f$, to the meshes of which the air gets access by the lobular passages. skin, divided up into cells, and corered with capillary veins. ${ }^{74}$

Like the alimentary canal, the lungs of an animal are really an inflected portion of the outer surface; so that

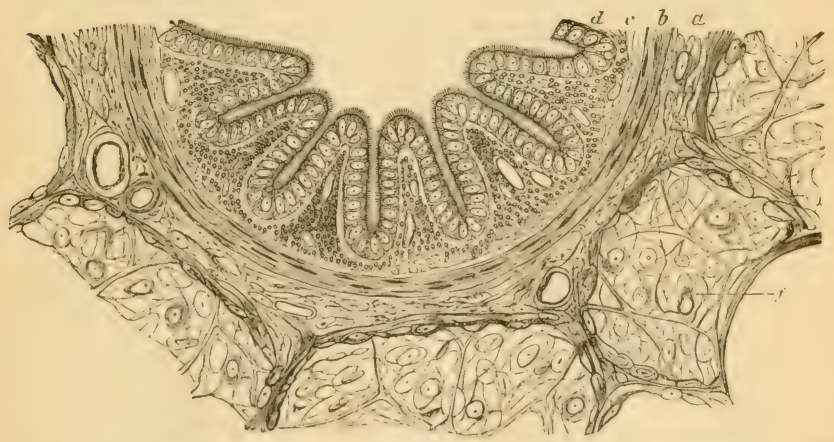

Fia. 83. - Part of a transwerse section of a Pig's Bronchial Twig, $\times 240: a$, onter tibrons layer ; $b$, mnscular layer; $c$, inner fibrous layer; $c$, epithelial layer; $f$, one of the neighboring alveoli. 
breathing by the skin and breathing by lungs are one in principle. Indeed, in many animals, especially Frogs, respiration is carried on by both lungs and skin.

All Vertebrates have two kinds of respiratory organs in the comre of their life. From Fish to Man, all have gills

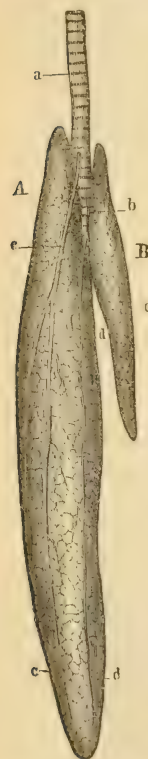

Frt: St. - Lungs of a reptile: $a$, tracheil: $b$, its bifurcution: $e$, pulmonary artery: d, pulmouary vein : the sac, 13 , is rudimentary. in the embryo state. $^{25}$ Fishes, and a few Amphibians, keep them through life; but in the rest they disappear. All, too, have lungs; but fully developed only in Reptiles, Birds, and Mammals. The lung of the Fish (the air-bladder) remains rudimentary. A few adult Amphibians, as Proteus and Siren, retain both gills and lungs, thus forming a link between Fishes and Reptiles. But Frogs and Salamanders begin life as waterbreathers, and when mature have lungs only:

The lungs of Vertebrates are elastic membranons sacs, divided more or less into cells to increase the surface. Upon the walls of the cells are spread the capillary blood-ressels. The smaller the cells, the greater the extent of surface upon which the blood is exposed to the influence of the air, and, therefore, the more active the respiration and the purer the blood. The lungs are relatively largest in Reptiles, and smallest in Mammals. But in the cold-blooded Amphibians and Reptiles, the air-cells are few and large; in the warm-blooded Birds and Nammals, they are excedingly numerous and minute. ${ }^{\text {re }}$ In Birds and Mammals, the blood in the capillaries is exposed to the air on all sides; in the Reptiles, on one only. Respiration is most perfect in Birds; they require, relatively to their weights, more air than Nammals or Reptiles, and most 
quickly die for lack of it. In Birds, respiration is not confined to the lmigs; but, as in Insects, extends through a great part of the body. Air-sacs connected with the lungs exist in the abdomen and moler the skin of the neck, wings, and legs. Even the bones are hollow for this purpose; so that if the windpipe be tied, and an opening be made in the wing-bone, the Bird will continne to respire. The right lung is usmally the larger; in some Snakes, the left is wanting entirely. In Mammals, the lungs are freely suspended in the thorax; in other Vertebrates, they are fastened to the back.

The lungs communicate with the atinosphere by means of the trachea, or windpipe, formed of a series of cartilaginous rings, which keep it constantly open. It begins in

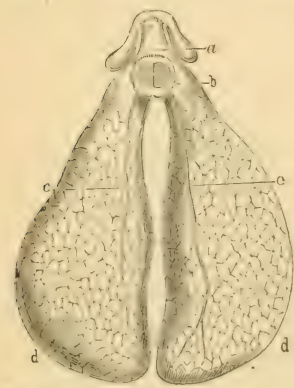

Fra. 85.-Lings of a Frog: $a$, hyoid apparatus; $b$, cartilaginous ring at root of the lungs; $c$, pulmonary vessels; $d$, pulmonary saes having this peculiarity common to all coldblouled air-breathers, that the trachen does not divide into bronchial branches, but terminates abruptly by orifices which open at once into the geueral cavity. A cartilatiunus net-work divides the space into little sacs, on the walls of which the capillaries are spread.

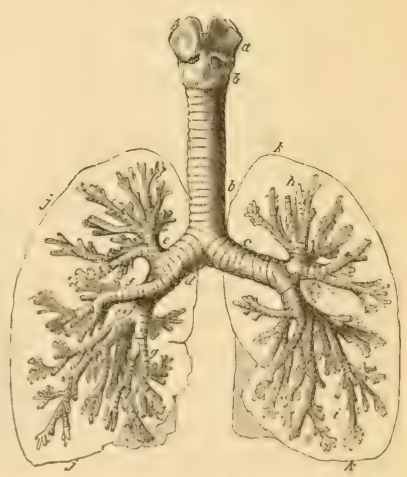

Frs: - fi, - Toistribution of Air-tubes in Mammalian Lungs: $a$, laryux; $b$, trachea; $c, d$, left and right bronchial tubes; $e, f, g$, the ramifications. In Man the subdivision contimues until the ultimate tubes are one-twenty-fitth of an inch in diameter. Each lobule represents in miniature the structure of the entire lung of a Frog.

the back part of the month, opening into the pharynx by a slit, called the glottis, which, in Mammals, is protected 
by the ralve-like enightottis. The trachea passes along

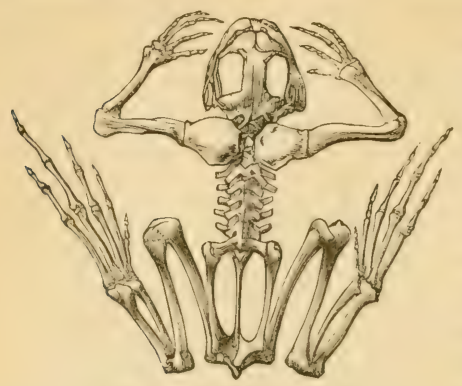

Frg. S7.-Skeleton of a Frog. the neck in front of the esophagus, and divides into two branches, or bronchi, one for each lung. In Birds and Mammals, the bronchial tubes, after entering the lungs, subdivide again into minute ramifications.

Vertebrates are the only animals that breathe through the mouth or nostrils. Fishes inspire only. Frogs, having no ribs, and Turtles, whose ribs are soldered together into a shield, are compelled to swallow the air. Snakes, Lizards, and Crocodiles draw it into the lungs by the play of the ribs. ${ }^{77}$ Birds, unlike other animals, do not inhale the air by an active effort; for that is done by the springing-back of the brewst-bone and ribs to their natural position. To expel the air, the breastbone is drawn down toward the backbone by muscles, which compresses the lungs.

Mammals alone have a perfect thorax, i.e., a closed

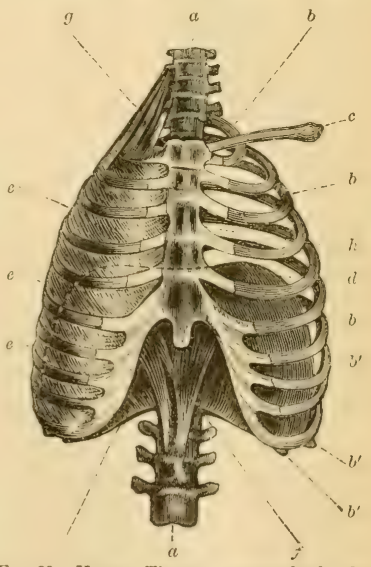

Frc. 88.-Human Thorax: $a$, vertebral column: $b, b^{\prime}$, ribs, the lower ones false: $c$, clavicle; $e$, intercostal muscles, removed on the left side to show the diaphragm, $d$; $f$, pillars of the diaphragm attached to the lumbar vertebre; $g$, muscles for elevating the ribs; $h$, steruum. 
earity.for the heart and lungs, with moval,le walls (breastbone and ribs) and a dirferaym, or muscular partition, separating it from the abdomen. ${ }^{\text {i }}$ Inspiration (or filling the lungs) and expiration (or emptying the lungs) are both accomplished by muscular exertion; the former, by raising the ribs and lowering the diaphragm, which enlarge the calpacity of the chest, and the air rushes in to prevent a vacum, the latter, by the ascent of the diaphragm and the descent of the ribs.

As a rule, the more active and more muscular an animal, the greater the demand for oxygen. Thus, warmblooded animals live fast, and their rapidly decaying tissues call for rapid respiration; while in the cold-blooded creatures the waste is comparatively slow. Respiration is most actire in Birds, and least in water-breathing animals. The sluggish Toad respires more slowly than the busy Bee, the Mollusk more slowly than the Fish. But respirations, like beats of the heart, are fewer in large Mammals than in small ones. In average Mail inluales abont 700 cubit feet of air per day.

Another result of respiration, besides the purification of the blood, is the production of heat. The chemical combination of the oxygen in the air with the carbon in the tissues is a true combustion; and, therefore, the more active the animal and its breathing, the higher its temperature. Birls and Mammals liave a temperature of about $105^{\circ}$ and $100^{\circ}$ respectively, and are called rrem-lntoodiel. Fishes and Reptiles have a lower and more variable temperature, ranging from $35^{\circ}$ to $80^{\circ}$, and are called coldbluodid. The liee is from $3^{\circ}$ to $10^{\circ}$, and the Earth-worm and Snail from 1. $1^{\circ}$ to $2^{\circ}$, higher than the air. The mean

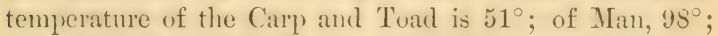
Dug, 99\%; Cat, $101^{\circ}$; Siquirrel, $105^{\circ}$; Swallow, $111^{\circ}$. 


\section{CHAPTER XV.}

\section{SECRETION AND EXCRETION.}

In the circulation of the blood, not only are the nutrient materials deposited within the body in the form of tissue, but certain special fluids are separated and conveyed to the external or internal surfaces of the body. These fluids are of two kinds: some, like saliva, gastric juice, bile, milk, etc., are for useful jurposes; others, like sweat and urine, are expelled from the system as useless or injurious.

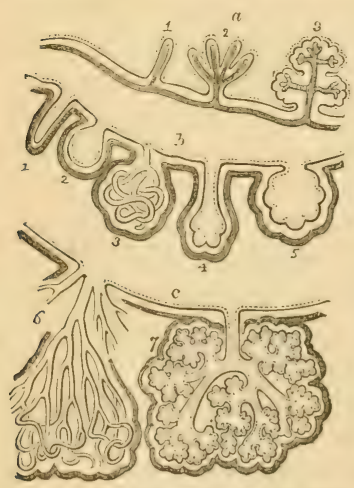

Fic. \$9. - Three plaus of secreting $\mathbf{M e m}$ branes. The heavy line represents the areolar-vascular layer: the next line is the basement, or limiting membrane; and the dotted line the epithelial layer: $a$ shows increase of surfice by simple plaited or fringed projections; $b$, tive modes of increase by recesses, forming simple glands, or follicles; $c$, two forms of compound glands.
The separation of the former is called secretion; the removal of the latter is $e x$ cretion. The two functions differ also in this, that secretion is intermittent, as, $e$. $g$, the gastric juice is formed when wanted, while excretion is constant day and night. Both processes, however, are substantially alike.

In the lowest forms, there are no special organs, but secretion and excretion take place from the general surface. Even in the higher animals, there are secreting membranes. The membranes lining the nose and alimentary canal and inclosing the lungs, heart, and joints, secrete lubricating fluids. 
The infolding of such a membrane into little saces or short tubes (follicles), each having its own outlet, is the type of all secreting and excreting organs. The lower tribes have nothing higher, and the apparatus for preparing the gastric fluid attains no further derelopment even in Man. When a cluster of these follicles, or sares, discharre their contents by one common duct, we have a glunel. But whether membrane, follicle, or grland, the organ is covered with a net-rork of blood-ressels, and lined with epithelial cells, which are the real agents in the process.

The chief Secreting Organs are the sulivury glumls, gustric fullicles, puncreas, and lierer, all situated alung the digestive tract.

1. The salivary glands, which open into the month, secrete saliva. They exist in nearly all animals, except Fishes, Crocodiles, and Whales, and are most largely dereloped in such as live on vegetable food. The saliva serves to lubricate or dissolve the food for swallowing, and, in Mammals that masticate, aids also in digestion. ${ }^{79}$

2. The gastric follicles are minute tubes in the walls of the stomach secreting gastric juice. They are found in all Vertebrates, and in the higher Mollusks and Articulates. In the lower forms, a simple membrane lined with cells serves the same purpose. Under the microscope, the soft mucous membrane of the human stomach presents a honey-comb aplearance, caused by numerous depressions or cells. It the bottom of these de-

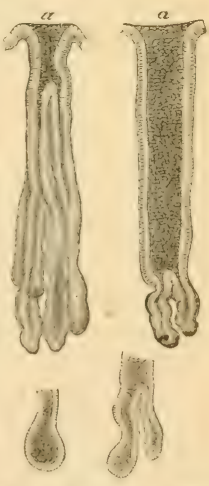

Fir. no.-Follicles from the Stomach of a De: $x$ 15n): near the mouth, $a$, there is a lining of columu:r epithelium. pressions are clusters of spots, which are the orifices of 
the tubular follicles. The follicles are less than $\frac{1}{3000}$ of an inch in diameter, and number millions.

3. The pancreas, or "sweetbread," so important in the process of digestion, when present, exists only in the Ver-

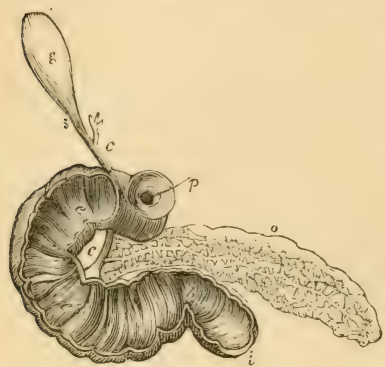

FIG. 91.-Paucreas of Man, $o$; $g$, gall-bladder ; $s, c y s t i c$ duct; $c$, duct from the liver; $p, p y$ loric valve; $e, i$, duodenum. tebrates and the higher Mollusks. In its structure and its secretion it closely resembles the salivary glands. In the Cuttle-fish, it is represented by a sac; in Fishes, by a group of follicles. It is proportionally largest in Birds whose salivary glands are deficient. The pancreatic juice enters the duodenum.

4. A liver in some form is fomd in all animals having a distinct digestive cavity. In Mullusks and Vertebrates, it is the largest gland in the body. The higher the animal, the more compact the organ. Thus, in Polyps it is represented by yellowish cells lining the stomach; in Insects, by delicate tubes along the intestine; in Molluslis, by a cluster of sacs, or follicles, forming a loose compound gland. In Vertebrates, the liver is well defined, and composed of a multitude of lobules (which give it a gramular appearance) arranged on the capillary veins, like grapes on a stem, and containing nucleated secreting cells. It is of variable shape, but usually two, three, or five lobed, and is centrally situated--in Mammals, just below the diaphragm. In most Vertebrates, there is an appendage to the liver, called the gall-blatder, which is simply a reservoir for the bile when not wanted.

The liver is both a secretory and excretory organ. For while the bile performs an essential, though mysterious, 
part in the digestive process, it is decomposing matter filtered from the blood, and, if not cast ont of the system,

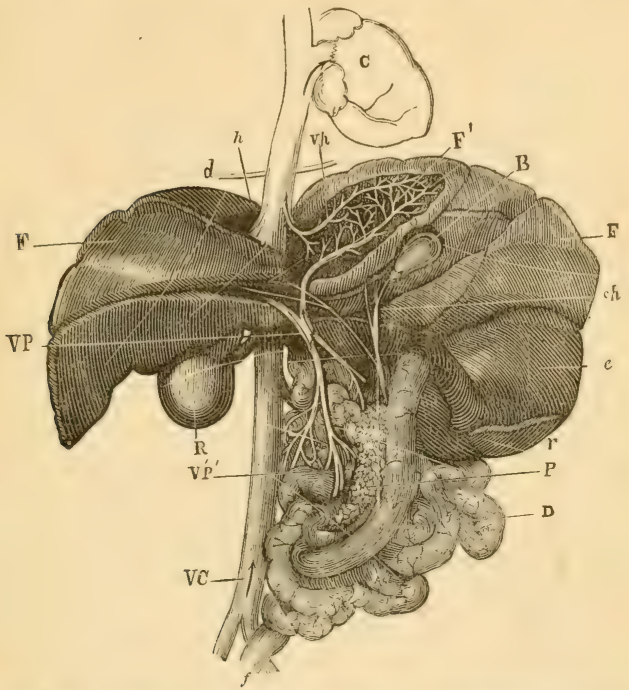

F10. 92.-Liver of the Dog, F, F : 1), duodenum and intestines: P, pancrens: $r$, spleen: $e$, stomach ; $f$, rectum; $\mathrm{R}$, right kidney; $\mathrm{B}$, gall-bladder; $c h$, cystic duct; F, lobe of liver dissected to show distribution of portal vein, VP, and hepatic vein, $v h ; d$, diaphragm; VC, vena cava; $\mathrm{C}$, heart.

produces jaundice. It is reabsorbed by the lacteals, but is tinally discharged by oxidation through the lungs. In animals of slow respiration, as Crustaceans, Mollnsks, Fishes, and Reptiles, fat accumulates in the liver. "Codliver oil" is an example.

The great Excreting Organs are the lungs, the lidd. neys, and the stin; and the substances which they remove from the system-carbonic acid, water, and ureaare the products of decomposition, or organic matter on its way back to the minoral kingdom. ${ }^{60}$ Different as these 
organs appear, they are constructed upon the same principle: each consisting of a rery thin sheet of tissue separating the blood to be purified from the atmosphere, and straining ont, as it were, the noxions matters. All, moreover, excrete the same substances, but in very different proportions: the lungs exhale carbonic acid and water, with a trace of urea; the lidneys expel water, mea, and a little carbonic acid; while the skin partakes of the nature of both, for it is not only respiratory, especially among the lower animals, bnt it performs the work of the kidneys when they are diseased.

1. The lung (and likewise gills) are mainly excretory organs. The oxygen they impart sweeps with the blood throngh every part of the body, and unites with, i. e., burns up, the effete matters, which, set free by muscular and nervous exertion, would poison the system, if not removed. The carbonic-acid gas thus gencrated is carried hy the reins to the lungs, and there exhaled in lueath-

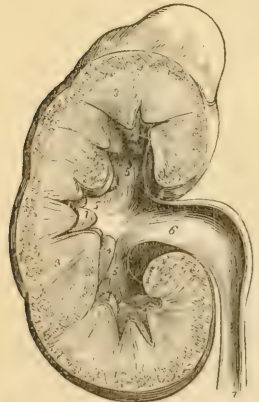

Frf. 93. - section of IIuman Kidney, showing the tubular portion, 3 , eromperl into cones; $\pi$, the nreter, or outlet of the secretion. ing. This process is more immediately necessary to life than any other: the arrest of respiration is fatal.

2. While the lungs (and skin also, to a slight degree) are sources of gain as well as loss to the blood, the kidneys are purely excretory organs. Their sole function is to eliminate the solid products of decay which can not pass out by the lungs. In Mammals, they are discharged in solution; but from other animals who drink little the excretion is more or less solid. In Insects, the kiciners are grouls of tubes; in the higher Mollusks, they are represented hy spongy masses of fullicles; in Vertebrates, they are 
well-dereloped grlands, two in number, and consisting of closely packed tubes.

3. The skin of the soft-slimned animals, particularly of Amphibians and Mammals, are covered with minute pores, which are the ends of as many delicate tulbes that lie coiled "1) into a knot within the true skin. These are the sweat-chlands, which excrete watery rapor, and with it certain salts and gases. The importance of this excretion, known as perspiration, is shown by the fact that if the shin be varnished over, the animal will die. (On the accession of Leo $\mathbf{X}$. to the papal chair, a child was grilded all over, at Florence, to represent the Golden $\Lambda \mathrm{ge}$, and it died in a few hours.

Besides these secretions and excretions, there are others, confined to particular animals, and designed for spe(.ial purposes: such are the oily matters secreted from the skin of quadrupeds for lubricating the hair and keeping the skin Hexible; the tears of Reptiles, Birds, and Mammals; the milk of Mammals; the ink of the Cuttle-fish; the poison in the stings of Jelly-fishes and Insects; and the silk of Spiders and Caterpillars.

\section{CHAPTER XVI.}

THE SKIN $\Lambda$ ND SKELETON.

The Skin, or Integument, is that laver of tissue which cover's the outer surface of the body. The term Skeleton is applied to the hard parts of the body, whether external or internal, which serve as a frame-rork or protection to the softer organs, and afford points of attachment to muscles. If external, as the crust of the Lobster, it is called Exosticleton; if internal, as the bones of Man, it is called 
Endosketeton. The former is but a modification of the skin.

1. The Skin.-The skin is a very complex tissue, since it serves not only for a corering, but also for an organ of excretion, absorption, and touch. In the lowest forms, as Amoebe and Infusoria, it is an extremely delicate film, or membrane, but little more consistent than the body which it enrelopes. But thronghont the animal kingdom, from the slimy coat of the Polyp to the thick hide of the Rhinoceros, the skin shows a similar structure-an inner and an outer layer; the former called dermis ; the latter, epidermis. ${ }^{81}$

Except in the low and immature forms, as Worms and Caterpillars, the skin of Articulates is hardened into a crust. The loose skin, called the mantle, which envelopes the body of the Mollusk corresponds to the true skin of ligher animals. The border of the mantle is surrounded with a delicate fringe, and, moreorer, contains minute glands, which secrete the shell and the coloring matter by which it is adorned. The Tunicates have a leathery epidermis, remarkable for containing, instead of lime, a substance resembling regetal,le cellulose.

In Mammals, whose skin is most fully dereloped, the dermis is a sheet of tongh elastic tissue, consisting of interlacing fibres, and containing blood-ressels, lymphatics, sweat-glands, and nerves. It is the part converted into leather when hides are tanned, and attains the extreme thickness of three inches in the Rhinoceros. The upler surface is corered with a rast number of minute projec:tions, called papille, each the termination of a nerve; these are the essential agents in the sense of tonch. ${ }^{82}$ They are best seen on the tongue of an $\mathrm{Ox}$ or Cat, and on the human fingers, where they are arranged in rows.

Corering this sensitive layer, and accurately molded to all its furrows and ridges, lies the bloodless and nerreless 
epidermis. It is that part of the skin which is raised in a blister. It is thickest where there is most pressure or hard nsage: on the back of the Camel it attains musual thickness. The lower portion of the epidermis (called rete mu-

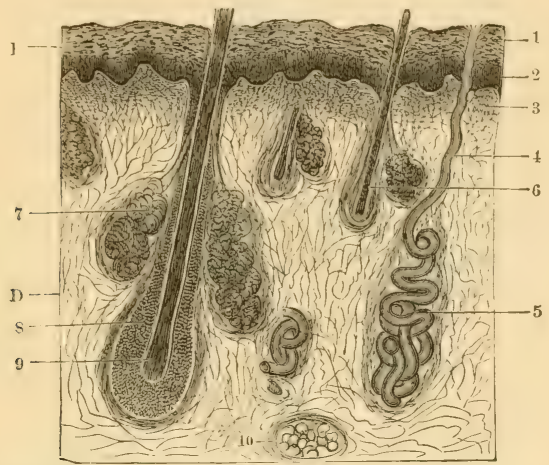

Fig. 94.-Section of Skin, from Horse's Nostril : E, epidermis; D, derma; 1, hurny layer of epidermis ; 2, rete mucusum; B, papillary layer of derma ; 4, excretury duct of a sudoriparous, or sweat, gland: 5 , glomernle, or convoluted tule of the same; 6 , hair follicle; 7 , sebaceous gland; 8 , interual sheath of the hair follicle: 9 , bulb of the hair; 10 , mass of adipose tissue.

cosum) is (omparatively soft, and consists of nucleated cells containing pigment-gramules, on which the color of the animal depends. Toward the surface, the cells hecome flattened, and finally, on the outside, are changed to horny scales (Fig. 2, c).

These scales, in the higher animals, are constantly wearing off in the form of semf, and as constantly being renewed from below. In Lizards and Serpents, the old epidermis is cast entire, being stripped off from the head to the tail; in the Toad, it comes off in two pieces; in the Fros, in shreds; in Fishes and some Mollusks, in the form of slime. IIowerer modified the epidermis, or whaterer its appendages, the like process of removal goes on. Mammals shed their hair; Birds, their feathers; and Crabs, 
their shells. When the loss is periodical, it is termed moulting.

2. The Skeletons. - (1) The Exoskeleton is dereloped by the hardening of the skin, and, with rery few exceptions, is the only kind of skeleton possessed by invertebrate animals. The usual forms are coral, shells, crusts, scales, plates, hairs, and feathers. It is horny or calcareous; while the endosticleton is generally a deposit of earthy material within the body, and is nearly confined to the Vertebrates.

The microscopic particles of living jelly; called Polycistines and Foraminifira, eover themselves with siliceons and calcareous shells of the most beautiful patterns. The Sponge has an internal skeleton of horny tibres, which is the sponge of commerce. Coral is the
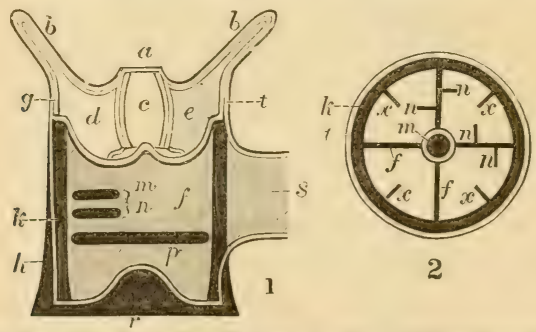

FIG. 95,-1, Vertical Section, and, 2, Transverse Section, of a Sclerndermic Corallite: $a$, mouth ; $b$, tentacles; $c$, stomach ; $d$, intermesenteric chamber; $e$, mesentery ; $f$, septum; $a$, endoderm; $h$, epitheca $; k$, theca, or outer wall ; $m$, columella; $n$, short partitions; $p$, tabula, or transverse partitions, a characteristic of extinet corals ; $r$, sclerobase; $s$, canenchyma, or common substance connecting a neighboring corallite ; $t$, ectoderm ; $x$, pali, or imperfect partitions.

solid frame-work of certain Poly $\mathrm{f}^{\mathrm{s}}$. There are two kinds: one represented by the common white coral, which is a calcareous secretion within the body of the Polyp, in the form of a cylinder, with partitions radiating toward a centre (scleroulemic); the other, represented by the solid red coral of jewelry, is a central axis deposited by a group of Polyps on the outside (sclerobasic). 
The skeleton of the Star-fish is a leathery skin studded with calcareous particles. The Sea-urchin is corered with an inflexible shell of elaborate and beantiful construction. The shell is really a calcified skin, being a net-work of fibrous tissue and earthy matter. It raries in shape from a sphere to a disk; and consists of hundreds

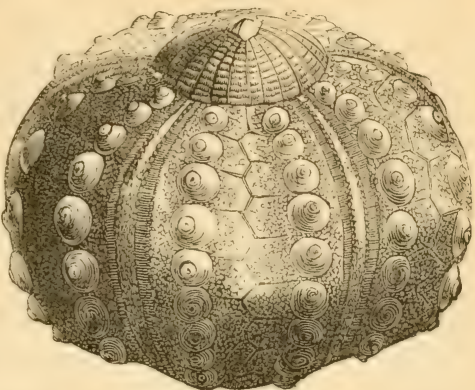

Fio. 96.-Shell of Sen-turchin (Cidaris) without its Epines. of angular pieces accurately fitted together, like mosaicwork. These form ten zones, like the rils of a melon, five broad mes alternating with fire narrower ones. The former (called intercmbulacra) are corered with tuber-

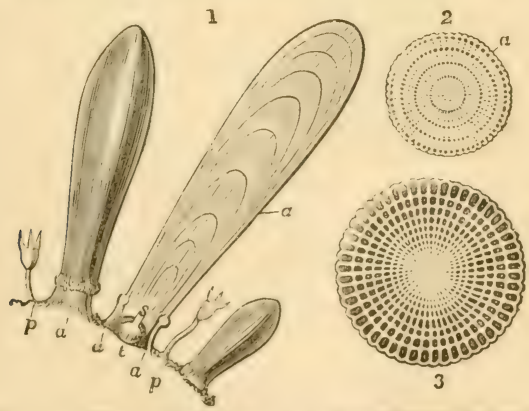

Ftc. 97.-Structure of Sea-turchins' Spines: 1, a, spine of Cituris cut longitudinally: $t, s$, ball and socket joint ; $p$, pedicellarie; 2,3 , transverse sections of spines of Cidaris and Echinus.

cles bearing movable spines. The narrow zones (called ambulucre, as they are likened to walks throngh a furest) 
are pierced with small holes, throngh which the animal sends out fleshy tentacles.

The skin of the Crab and Lobster is hardened by calcareous deposit into a "crust," or shell $\xi^{* 3}$ but, instead of forming one piece, it is divided into a series of segments, which move on each other. The number of these segments, or rings, is usually twenty-one-to the head, thosax, and abdomen, seven each. In the adult, howerer, the rings of the head and thorax are often soldered together into one shield, called cephuto-thorax; and in the IIorseshoe Crab all the divisions of the skeleton are quite obliterated. The shell of Crustaceans is periodically cast off, for they continue to grow eren after they hare reached their mature form. This molting is a rery remarka-

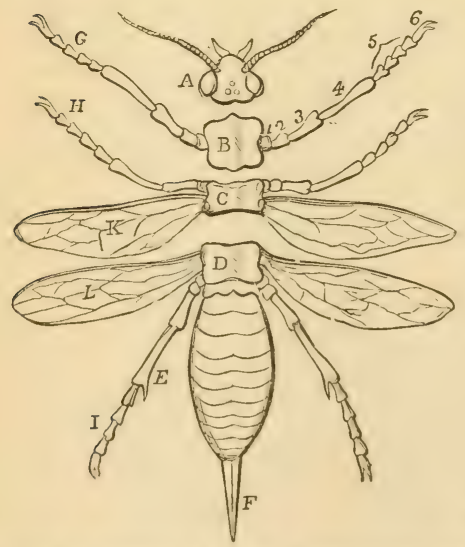

Fig. 95,-Diagram of an Insect: A, head bearing the eyes and antennæ: B, prothorax, or pronotum, carrying the first pair of legrs: C, mesothorax, carrying the second pair of legs and first pair of wings: $D$, carrying the third pair of legs and second pair of wings: E, abdomen, with ovipositor, F; 1, coxa, or hip : 2, trochanter; 3 , femur, or thigh; 4 , tibia, or shank: 5 , tarsus, or foot ; 6 , claw. ble operation. How the Lobster can draw its legs from their cases without unjointing or splitting them has long been a puzzle. ${ }^{84}$ But the cast-off skeleton is a perfect copy of the animal, retaining in their places the delicate coverings of the eyes and antennæ, and eren the lining membrane of the stomach with its teeth !

The horny erust of Insects differs from that of Crus- 
taceans in consisting mainly of chitine and in containing no lime. The head, thorax, and abdomen are distinct, and usually consist of thirteen visible segments-one for the head, three for the thorax (called prothorax, mesothorax, and metuthorax), and nine for, the abdomen. The antenne, or feelers, legs, and wings, as well as hairs, spines, and scales, are appendages of the skeleton. As Insects grow only during the larral, or caterpillar, state, molting is confined to that period.

The shells of Mollusks are well-known examples of exoskeletons. The mantle, or loose skin, of these animals secretes calcareous earth in successive layers, converting the epidermis into a "shell." ${ }^{\text {s }}$ So various and characteristic is the microscopic structure of shells, that a fragment is sometimes sufficient to determine the group to which it belongs. A large class of shells is represented by that of the Orster, which is composed of three parts: the external brown epidermis, of horny texture; then the prismatic portion, consisting of minute columns set perpendicularly to the surface; and the internal nacrenus layer, or "mother-of-pearl," made up of exceedingly thin plates. The pearly lustre of the last is due to light falling upon the outeropping edges of wary lamine. ${ }^{.6}$ In many cases, the prismatic and nacreous layers are traversed by minute tules. Another trpical shell-structure is seen in the common Cone, a section of which shows three layers, besides the epidermis, consisting of minute plates set at different angles. The Nautilus is composed of two distinct layers: the outer one having the fracture of broken china; the inner one, nacreous.

Most living shells are made of one piece, as the Snail; these are called "mivalies." Others, as the Clam, consist of two parts, and are called "biralves." In either case, a ralve may be regarded as a hollow cone, growing in a spiral form. The ribs, ridges, or spines on the ont- 
side of a shell mark the successive periods of growth, and, therefore, correspond with the age of the animal. The following figmres show the principal parts of the ordinary bivalses and mivalies. The valves of a bivalve are generally equal, and the umbones, or beaks, a little in front of the centre. The valves are bound together by a ligament near the umbones, and often, also, by means of a "hinge" formed by the "teeth" of one valve interlocking into cavities in the other. The aperture of a univalve is

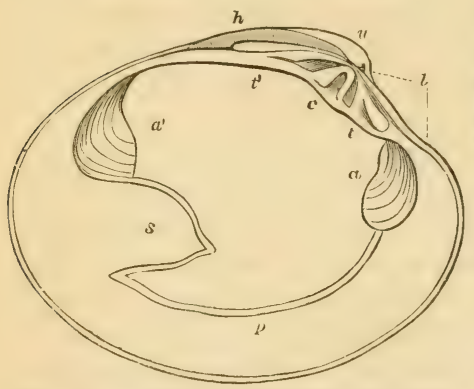

Fig. 99.-Left Valve of a Bivalve Mullusk (Cytherea chione): $h$, hinge ligament: $u$, nmbo; $l$, lumule; $c$, cardinal, and $t, t^{\prime}$, lateral, teeth ; $\alpha, a^{\prime}$, impressions of the anterior and posterior adductor muscles; $p$, pallial impression; $s$, sinus occupied by the retractor of the siphons.

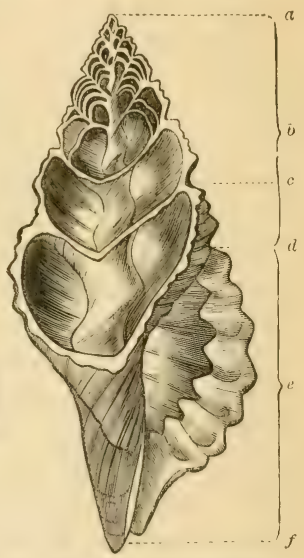

Fit. 100.-_Section of a Spiral Univalve (Triton corrugatus): $a$, apex; $b$, spire; $c$, suture: $d$, posterior canal; $e$, outer lip of the aperture; $f$, anterior caual.

frequently closed by a horny or ealcareous plate, called "operculum," which the animal carries on its back, and which is a part of the exoskeleton.

Imbedded in the back of the Cuttle-fish is a very light spongy "bone," which, as already observed, is a secretion from the skin, and, therefore, belongs to the exoskeleton. It has no resemblance to true bone, but is formed, like shells, of a number of calcareous plates. Nerertheless, the Cuttle-fish does exhibit the first traces of an endo- 
slieleton: these are plates of cartilage, one of which surromels the brain, and hence may be called a skull. To this cartilage, not to the "cuttle-bone," the muscles are attached.

In Vertebrates, the exoskeleton is subordinate to the endoskeleton, and is feebly dereloped in comparison. It is represented by a great variety of appendages to the skin, which are mainly organs for protection, not for support. Some are horny developments of the epidermis, such as hair's, feather's, nails, claws,

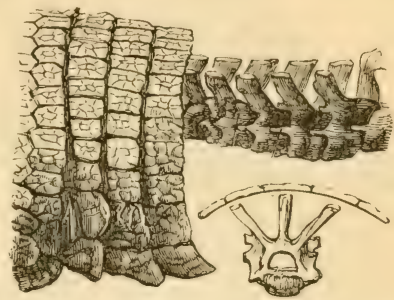
hoofs, hor'us, and the Fro. 101.-Skeletal Architecture in the Armadilscales of Reptiles; oth- lo, showing the re

ers arise from the hardening of the dermis by calcareous matter, as the scales of Fishes, the plates of Crocorliles and Turtles, and the shield of the Armadillo.

The scales of Fishes (and likewise the spines of their vertical fins) lie imbedded in the overlapping folds of the skin, and are corered with a thin epidermis. The scales of the bony Fishes (Perch, Salmon, etc.) consist of two

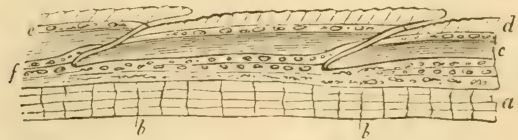

FIG. 102.-Diacrammatic Section of the Skin of a Fish ( Farp) : $a$, derm, showing laminated structure with vertical tibres, $b$; $c$, gristly layer; $e$, laminated layer, with calcareous granules: $d$, superticial portion developing into scales; $f$, scale-pit.

lavers, slightly calcareons, and marked by concentric and radiating lines. Those of the Shark have the structure of teeth, while the scutes, or plates, of the Crocudiles, Turtles, and Armadillos are of true bone. 


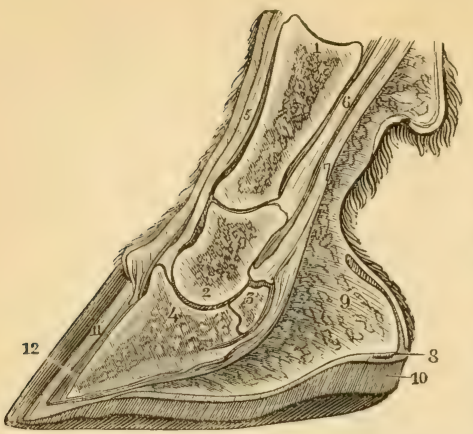

FIG. 103.-Vertical Section of the Forefoot of the Horse (middle digit) : 1, 2, 4, proximal, middle, and distal, or ungual, phalanges; 3 , sesamoid, or nnt-bone; 5 , 6,7 , tendons; 9 , elastic tissue; 8,10 , internal and external floor of the hoof; 11, 12, internal and external walls.

Beaver and Rat, have the same structure. Nails are flattened horny plates dereloped from the upper surface of the fingers and toes. Claws are sharp conical nails, being developed from the sides as well as upper surface; and hoofs are blunt cylindrical claws. Hollow horns, as of the Ox, may be likened to claws sheathing a bony case. The horn of the Rhinoceros is a solid mass of epidermal fibres. "Whalebone," the rattles of the Rattlesnake, and the beaks of Turtles and Birds, are likewise epidermal.

Hairs, the characteristic clothing of Mammals, are elongated horny cones, composed of "pith" and
The scales of Snakes and Lizards are horny epidermic plates covering the overlapping folds of the true skin. In some Turtles these plates are of great size, and are called "tortoise - shell ;" they cover the bony dermal plates. The scales on the legs of Birds, and on the tail of the

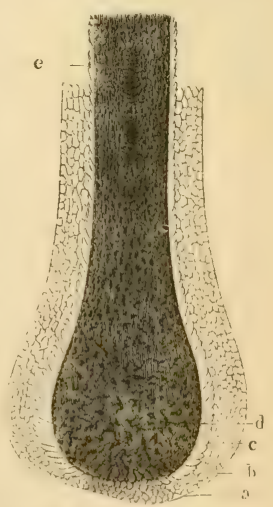

Fin. 104.-Section of the Root and part of the Shaft of a Human Hait: it is covered with epidermic scales, the inner layer, $c$, forming the outer covering of the shaft, being imbricated; the root consists of angular cells loaded with pigment. 
"crust." The latter is an outer layer of minute overlapping scales, which are directed toward the point, so that rubbing a human hair or fibre of wool between the thumb and finger pushes the root-end away. The root is bulbous, and is contained in a minute depression, or sac, formed by an infolding of the skin. Hairs are usually set obliquely into the skin. Porcupine's quills and IIedgehog's spines make an easy transition to feather's, which differ from hairs only in splitting up into numerous laminæ. They are the most complicated of all the modifications of the epidermis. They consist of a "quill" (answering to the bulb of a hair), and a "shaft," supporting the "vane," which is made up of "barbs," "barbules," and interlocking "processes." The quill alone is hollow, and has an orifice at each end. The teeth of Mollusks and Articulates are also epidermal structures; but the teeth of Vertebrates are dereloped from the dermis. In all cases, teeth belong to

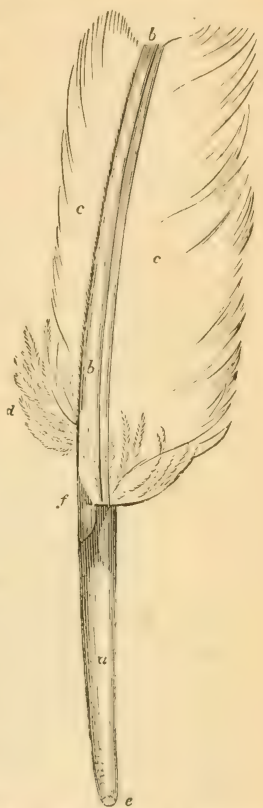

Fig. 105. - Parts of a Feather: $a$, quill, or barrel : $b$, shalt : $c$, vane, or beart; $d$, accessury plume, or down; $e, f$, lower aud upper umbilicus, or orifice, leading to the interior of the quill.

the exoskeleton. A human tooth and an oyster-shell represent each other, structure for structure.

(2) The Endoskeleton, as we have seen, has its first representative in the Cuttle-fish. With this exception, it is peculiar to Verteluates. In the Cuttle-fish, and some Fishes, as the Sturgeon and Shark, it consists of cartilage; but in all others (when adult) it is bone or osseous 
tissue. Tet there is a diversity in the composition of bony skeletons: that of fresh-water Fishes contains the least earthy matter, and that of Birds the most. Hence the density and ivory-whiteness of the bones of the latter. Unlike the shells of Mollusks and the crust of the Lobster, which grow by the addition of layers to their borders, bones are moist, living parts, penetrated by bloodvessels and nerres, and corered with a tongh membrane, called periosteum, for the attachment of muscles.

The surface of bones is compact; but the interior may be solid or spongy (as the bones of Fishes, Turtles, Sloths, and Whales), or hollow (as the long bones of Birds and the active quadrupeds). There are also carities (called "sinuses") between the inner and outer walls of the skull, as remarkably shown by the Elephant. The cavities in the long bones of quadrupeds are filled with marrow; those in the long bones of Birds and in skulls contain air.

The number of bones not only differs in different animals, but varies with the age of an individnal. In very early life there are no bones at all; and ossification, or the conversion of eartilage into bone, is not completed until maturity. This process begins at a multitude of points, and theoretically there are as many bones in a skeleton as centres of ossification. But the actual number is usually much less - a result of the tendency of these centres to coalesce. Thus, the thigh-bone in youth is composed of five distinct portions, which gradually unite. So in the lower Vertebrates many parts remain distinct which in the higher are joined into one. The oeciput or backbone of Man's skull is the union of three or four bones, which are seen separate in the skull of the Fish.

A complete skeleton, made up of all the pieces which might enter into its composition, does not exist. Every animal has some deficiency. All have a skull and back- 
bone; but in the development of the varions parts, and especially of the appendages, there is endless variety. Fishes come nearest to the archetype skeleton; but while they possess a complete set of skull-bones, they have no

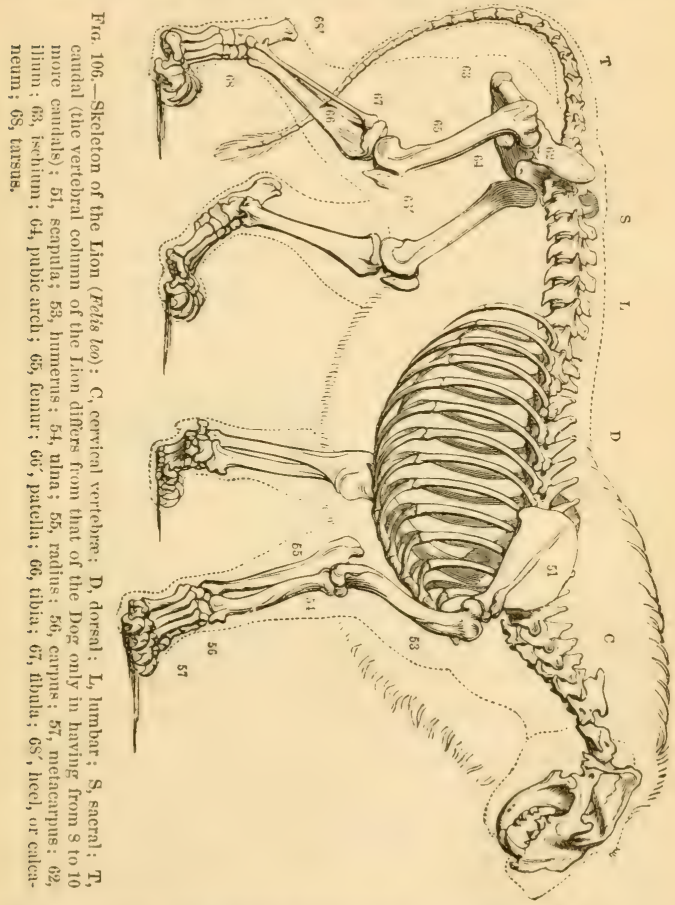

representatives of fingers and toes. The Snake has plenty of rils and tail, but no breast-bone; the Frog has a breastbone, but neither tail nor ribs. As the skeleton of a Fish is too eomplicated for the primary student, we will select for illustration the skeleton of a Lion-the type of quad- 
rupeds. It should be remembered, however, that all Vertebrates are formed on one plan.

The vertebrate skeleton consists of a series of rings, called rertebre, arranged along the back of the body, with certain appendages, as limbs, ribs, etc. The vertebre are always present, but the appendages are inconstant. In the lowest Fishes, the spinal column is a contimnous cylinder, with scarcely a trace of division, and in Birds, also, it is much consolidated; but usually the rertebra are separable. They range in number from 10 in the Frog (not counting the head) to 305 in the Boa-constrictor.

A typical vertebra consists of a number of bony pieces so arranged as to form two arches, or hoops, connected by

B.
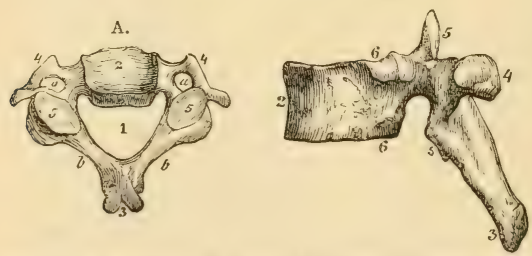

FIG. 107.-Vertebræ-A, cervical : B, dorsal: 2, centrum ; 4, transverse process, containing foramen, $a$, for artery ; 5 , articular process; 3 , spinous process, or neural spine: 1 , nenral canal; 6 , facets for head of rib, the tubercle of the rib titting in a facet on the process, $4 ; b$, laminæ or neurapophyses.

a central bone, or centrum. ${ }^{87}$ The upper hoop is called the neural arch, because it encircles the spinal marrow; the lower hoop is called the hamal arch, because it incloses the heart and the great central blood-ressels. An actual vertebra, however, is subject to so many modifications, that it deriates more or less from this ideal type. Selecting one from the middle of the back for an example, we see that the centrum sends off from its dorsal side two branches, or processes, called neurapophyses. These meet to form the neural arch, under which is the neural cunal, and above which is a process called the neural 
spine. On the anterior and posterior edges of the arch are smooth surfaces, or zygapophyses, which in the natural state are covered with cartilage, and come in contact with the corresponding surfaces of the preceding and succeeding rertebra. The bases of the arch are notched in front and behind, so that when two vertebre are put together a romul opening (intervertebral formen appears between the pair, giving passage to the nerves issuing from the spinal cord. From the sides of the arch, blunt transverse processes project outward and backward, called diupopliyses. Such are the main elements in a representative vertebra. The hamal arch is not formed by any part of the rertebra, but by the ribs and breast-bone. Theoretically, however, the ribs are considered as elongated processes from the centrum (plevorapoyllysses), and in a few cases a homul spine is dereloped from the breast-bone corresponding to the neural spine.

The vertebre are united together by ligaments, but chiefly by a very tough, dense, and elastic substance between the centra. The neural arches form a continnous canal which contains and protects the spinal cord; hence the vertebral columm is called the neuroskeleton. The column is always more or less curved; but the beantiful sigmoid curvature is peculiar to Man. The vertebre gradually increase in size from the head toward the end of the trumk, and then diminish to the end of the tail. The neural arch and centrum are seldom wanting; the first vertebra in the neck has no centrum, and the last in the tail is all centrum. The vertebre of the extremities (head and tail) depart most widely from the typieal form.

The vertebral column in Fishes and Snalies is divisible into three regions -- head, trunk, and tail. But in the higher animals there are six kinds of rertebra: crunicl, cemical, dorsal, lumbar, sacral, and conudul.

The cranial vertebre form the skull. They are greatly 


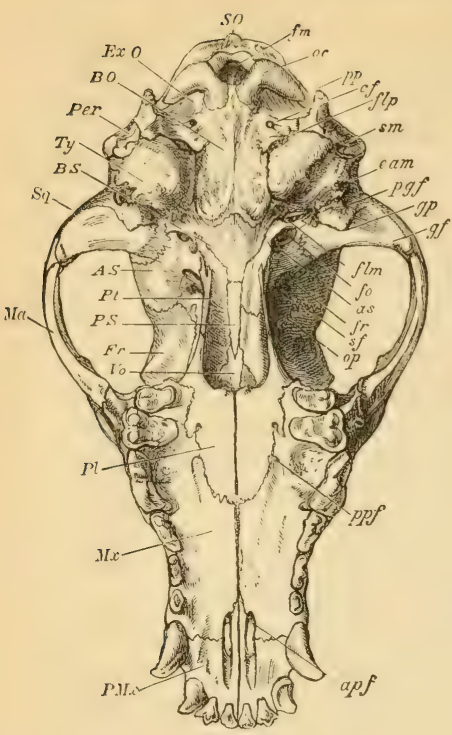

Fig. 10S.

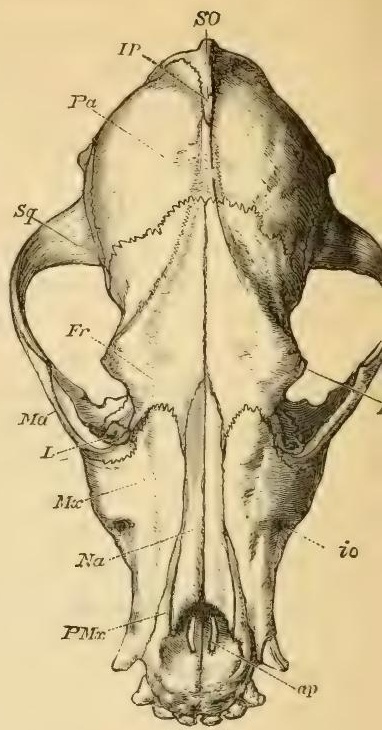

Fic. 109.

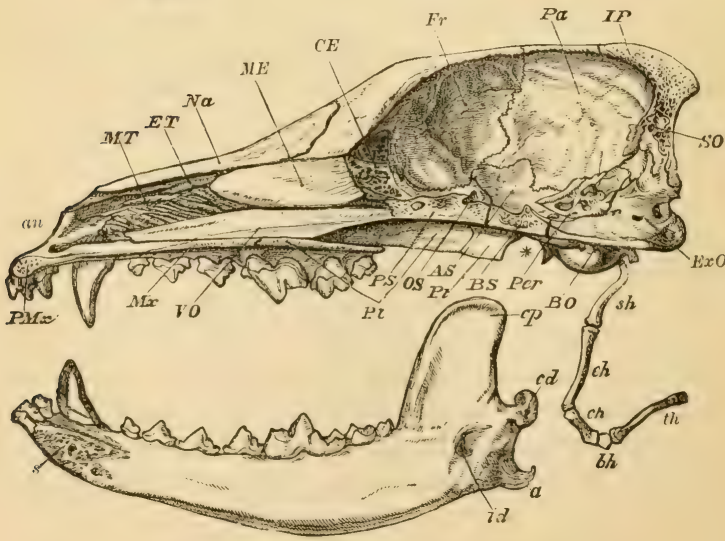




\section{BONES OF TIIE MAMMALIAN SKULL.*}

BRAIN-CASE.

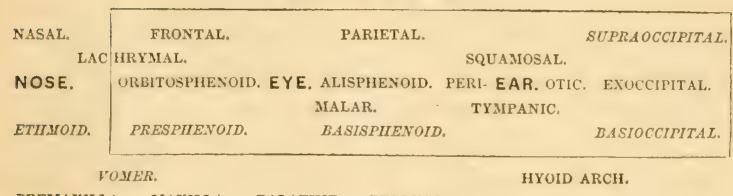

PREMAXILla, Maxilla, PALATINE. PTERygoid,

LOWER JAW, OR MANDIBLE.

THE SKULL OF THE DOG.

Fig. 10S.- Tnder surface. Fis. 109.-Upper surface. Fic. 110.-Longitudinal vertical section; one-balf natural size: $S O$, supraoccipital : ExO, exoccipital ; $B O$, basioccipital; $I P$, interparietal ; $P a$, parietal ; $F^{\prime} r$, frontal ; $S q$, squamosal; $\boldsymbol{J f} a$, malar; $L$, lachrymal; $J I x$, maxilla; $P M I x$, premaxilla; $N a$, nasal; $M T$, maxilloturbinal: $E T$, ethmoturbinal ; $M E$, ossitied portion of the mesethmoid; $C E$, cribriform, or sieve-like, plate of the ethmoturbinal; IrO, vomer; PS, presphenoid; $O S$, orbitosphenoid; $A S$, alisphenoid; $B S$, basisphenoid; $P l$, palatine; $P t$, pterygoid; Per, periotic; $T y$, tympanic bulla ; $a$, anterior narial aperture; $a p$, or apf, anterior palatiue foramen; $p l f$, posterior palatine foramen; io, infraorbital foramen; $p n f$, postorbital process of frontal bone; op, optic foramen : $s f$, sphenoidal fissure; $f r$, foramen rotundum, and auterior opening of alisphenoid caual; $a s$, posterior opening of alisphenoid canal ; $f 0$, foramen ovale ; fim, firn-

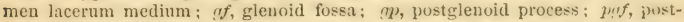
glenoid foramen; eam, external auditory meatus; sm, stylomastuid foramen; $f l p$, forameu lacerum posterius ; $c f$, condylar forameu ; $p p$, paroccipital process : $o c$, occipital condyle; $f m$, foramen magnum ; $a$, angrular process; $s$, symphysis of the mandible where it unites with the left ramus; $i d$, inferior dental caunl; $c d$, condyle; $c p$, coronoid process; the * indicates the part of the cranium to which the condyle is articulated when the mandible is in place; the upper border in which the teeth are implanted is called alveolar; $s h, c h, c h, b h, t h$, hyoidean apparatus, or os linguce, supporting the tongue. In the skulls of old animals, there are three ridges: octipital, behind; santtal median, on the upper surface; and superorbital, across the frontal, in the region of the eyebrows. The last is highly developed in the Gorilla.

* In this diagram, modified from Huxley's, the italicized bones are single: the rest are double. Those in the line of the Ethmoid form the Cranio-fuciul 1 xis: these, with the other ephenoids and occipitals, are developed in cartilage; the rest are membraue bones. In the Human skull, the three vecipitals coalesce into one. 
modified, as the neural arches are expanded to inclose the brain. The number of distinct bones composing the skull is greatest in Fishes, and least in Birds: this arises from the fact that the boues remain separate in the former case, while those of the chick become united togrether (anchylosed) in the full-grown Bird. A skull consists of the brain-case and the face. The principal parts of the skull, as shown in the Dog's, are: 1. The occipitul bone behind, containing a large hole, or foramen magnum, on each side of which are rounded prominences, called condyles, by which the skull articulates with the first cerrical vertebra. 2. The parietal. 3. The frontul. These three form the main walls of the brain. 4. The sphenoid, on the floor of the skull in front of the occipital, and consisting of three pieces. 5. The temporal, in which is sitnated the ear. In Man this is one bone; but in most animals there are three-the periotic, tympanic, and squamosal. 6. The malar, or "cheek-bone," which sends

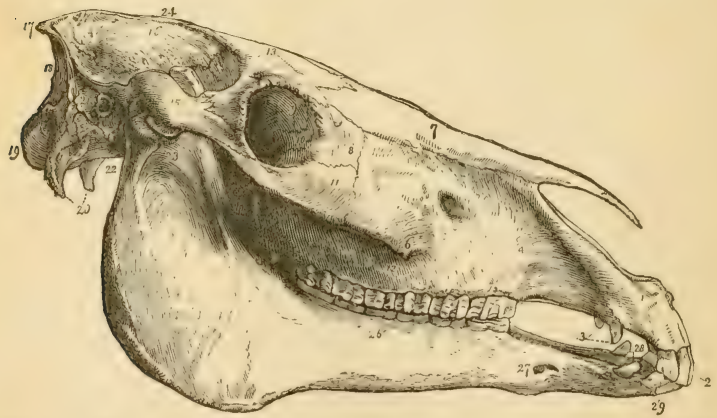

Fig. 111. - Skull of the Horse: 1, premaxillary bone; 2, npper incisors; 3, upper canines: 4, superior maxillary; 5 , infraorbital foramen: 6 , superior maxillary spine; 7 , nasal bones; 8 , lachrymal; 9 , orbital cavity ; 10 , lachrymal fossa ; 11 ; malar; 12, npper molars; 13 , frontal ; 15 , zygomatic arch ; 16, parietal; 17 , occipital protuberance; 15 , occipital erest ; 19, occipital condyles; 20, styloid processes; 21 , petrons bone; 22 , basilar process; 23 , condyle of inferior maxillary : 24 , parietal crest ; 25 , inferior maxillary; 26 , lower molars; 27 , anterior maxillary foramen; 28, lower canines; 29, lower incisors. 
back a process to meet one from the squamosal, forming the zygomatic arch. 7 . The nusal, or roof of the nose. 8. The maxilla; that part of the upper jaw in which the canines, premolars, and molars are lodged. 9. The premaxillu, in which the upper incisors are sitnated. 10. The pulutine, which, with the maxillary bones, forms the rouf of the mouth. There are two appendages to the skull: the mandible, or lower jaw, whose condyles, or rounded extremities, fit into a cavity (the glenoid) in the temporal bone; and the hyoid, situated at the root of the tongue.

The cervical vertelere, or bones of the neck, are peculiar in having an orifice on each side of the centrum for the passage of an artery. The first, called atlcts, because it supports the head, has no centrum, and turns on the second, called axis, around a blunt process, called the odontoid. The centra are usually wider than deep, and the neural spines very short, except in the last one. The number of cervical vertebrie ranges from 1 in the Frog to 25 in the Swan.

The dorsal vertebre are such as bear ribs, which, uniting with the breast-bone, or sternum, form a bony arch over the heart and lungs, called the thor ax. The stermum may be wanting, as in Fishes and Snakes, or greatly developed, as in Birds. When present, the first rertebria whose ribs are connected with it is the first dorsal. The neural spines of the dorsal series are generally long, pointing backward.

The lumbar vertebre are the massive vertebre lying in the loins between the dorsals and the hip-bones.

The socrul vertelme lie between the hip-bones, and are generally consolidated into one complex bone, called sucrum.

The caudal vertebre are placed behind the sacrum, and form the tail. They diminish in size, lusing proe- 
esses and neural arch, till finally nothing is left but the centrum. They number from 3 or $t$ in Man to 270 in the Shark.

Besides the lower jaw, hyoid, and ribs, Vertebrates have other appendages to the spinal column - two pairs of limbs. ${ }^{k 3}$ The fore limb is divided into the pectoral arch (or shoulder girdle), the arm, and the hand. The arch is fastened to the ribs and vertebræ by powerful muscles, and consists of three bones, the scapula, or shoulder-blade, the coracoid, and the clavicle, or collar-bone. The scapula and coracoid are generally united, the latter forming a process of the former; and the clavicles are frequently wanting, as in the hoofed animals. The humerus, radius, and utna are the bones of the arm, the first articulating by ball-and-socket joint with the scapula, and by a hinge-joint with the radius and vlna. The humerus and radius are always present; but the ulna may be absent. The bones of the hand are divided into those of the carpus, or wrist; the metacarpus, or palm; and the phalanges, or fingers. The fingers, or "digits," range in number from 1 to 5 .

The hind limb is composed of the pelvic arch (or hipbones), the leg, and the foot. These parts correspond closely with the skeleton of the fore limb. Like the shoulder, the pelvic arch, or os innominatum, consists of three bones-itium, ischium, and pubis. The three are distinct in Reptiles and in the young of higher animals; but in adult Birds and Mammals they become mited together, and are also (except in Whales) solidly attached to the sacrum. The two pelvic arches and the sacrum thus soldered into one make the pelvis. The leg-bones consist of the femur, or thigh; the tibia, or shin-bone; and the fibula, or splint-bone. The rounded head of the femur fits into a carity (acetabulum) in the pelvic arch, while the lower end articulates with the tibia, and sometimes 
(as in Birds) with the fibula also. An extra bone, the patella, or knee-pan, is hung by a muscle in front of the joint between the femur and tibia of the higher animals. The foot is made up of the tarsus, or ankle; the metatırsus, or lower instep; and the phalanges, or toes. The toes number from 1 in the Horse to 5 in Man.

Certain parts of the skeleton, as of the skull, are firmly joined together by zigzag edges or by overlapping; in either case the joint is called a suture. But the great majority of the bones are intended to move one upon another. The rertebræ are locked together by their processes, and also by a tough fibrous substance between the centra, so that a slight motion only is allowed. The limbs furnish the best examples of movable articulations, as the ball-and-socket joint at the shoulder, and the hingejoint at the elbow. The bones are held together by ligaments, and, to prevent friction, the extremities are covered with cartilage, which is constantly lubricated with an unctuous fluid called synovia.

CHEMICAL COMPOSITION OF BONES.

\begin{tabular}{|c|c|c|c|c|}
\hline \multirow[b]{2}{*}{$\begin{array}{l}\text { Phosphate of Lime, with trace of } \\
\text { Fluate of Lime........................ }\end{array}$} & Cop. & Tоптогев. & HAWK. & MaN. \\
\hline & 57.29 & 52.66 & 64.39 & 59.63 \\
\hline Carbonate of Lime..................... & 4.90 & 12.53 & 7.03 & 7.33 \\
\hline Phosphate of Magnesia............. & 2.40 & 0.82 & 0.94 & 1.32 \\
\hline 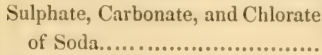 & 1.10 & 0.90 & 0.92 & 0.69 \\
\hline Glutine and Chondrine............. & 32.31 & 31.75 & 25.73 & 29.70 \\
\hline Oil $\ldots \ldots \ldots \ldots \ldots \ldots \ldots \ldots \ldots \ldots \ldots \ldots \ldots \ldots \ldots \ldots \ldots \ldots \ldots \ldots$ & 2.00 & 1.34 & 0.99 & 1.33 \\
\hline & 100.00 & 100.00 & 100.00 & 100.00 \\
\hline
\end{tabular}




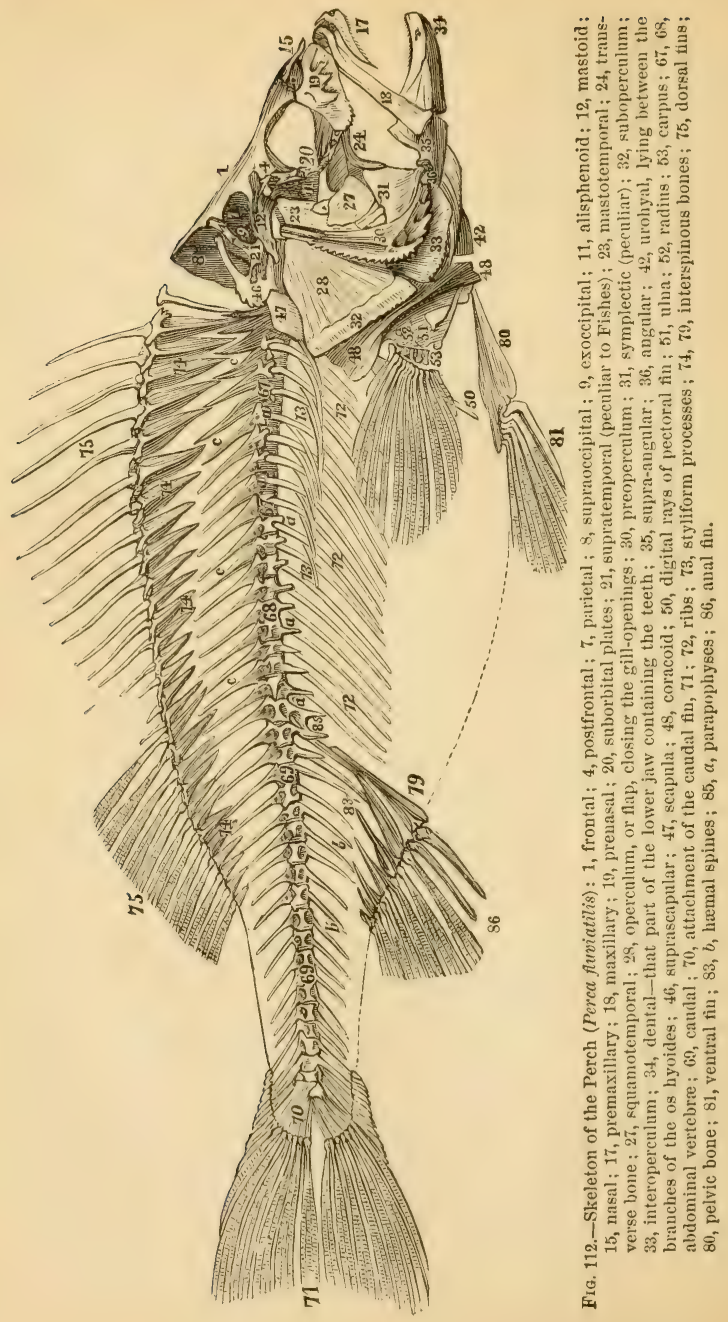



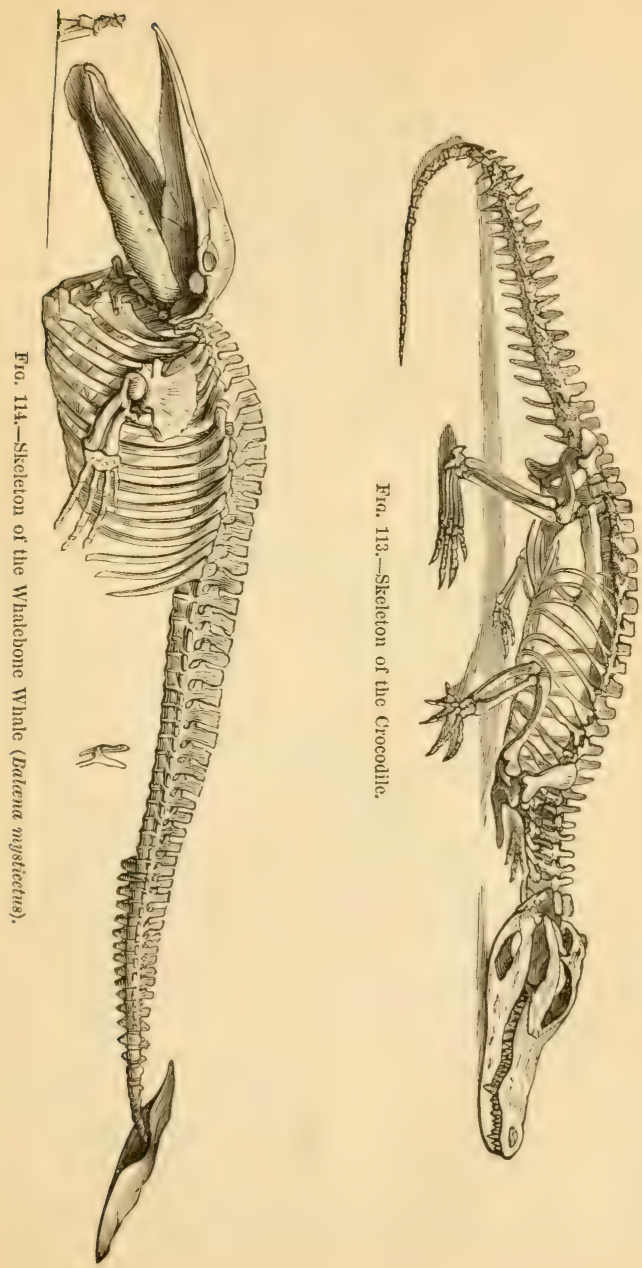


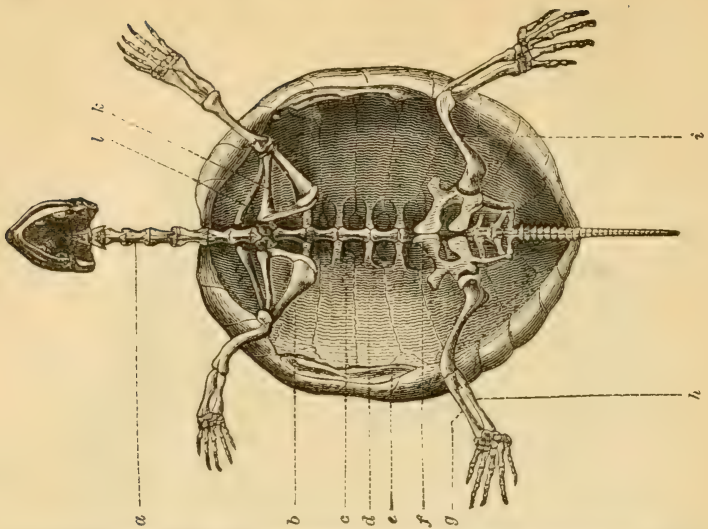

FtG. 115,-Skeleton of the Tortoise (plastron removed) : $a$, cervical vertebræ; $c$, dorsal vertebre; $d$, ribs; $c$, sternal ribs (the marginal bones of the carapax); $l$, scapula ; $k$, clavicle; $b$, coracoid bone; $f$, pelvis; $i$, femur; $g$, tibia $h$, fibula.

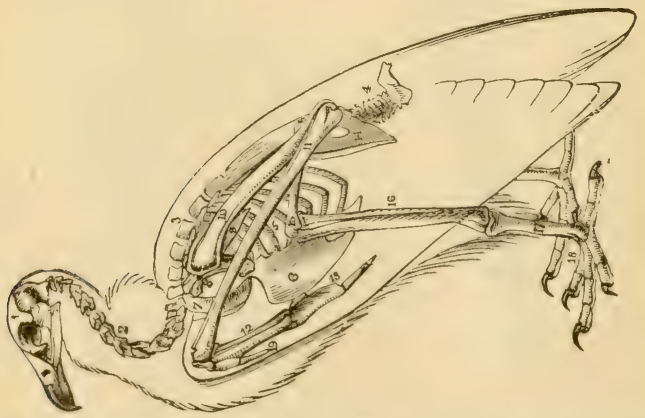

Fic. 116.-Skeleton of a Vulture: 1, cranium-the parts of which are separable only in the chick: 2 , cervical vertebre; 3 , dorsal; 4 , coccygeal, or caudal; the lumbar and sacral are consolidated together, and to the ribs, $5 ; 6$, steruum, or breastbone, extraordinarily developed; 7 , furculum, clavicle, or "wish-bone ;" 8 , coracoid: 9, scapula: 10 , humerus: 11 , ulna, with rudimentary radius; 12 , metacarpals; 13 , phalanges of the great digit of the wing ; 19 , thumb; 14 , pelvis: 15 , femur: 16, tibia and fibula, or crus: 17, metatarsus (tarsus is wanting in Birds) ; 18, fnternal digit, or toe, formed of three phalanges; the middle toe has four phalanges; the outer, five; and the back toe, or thumb, two. 


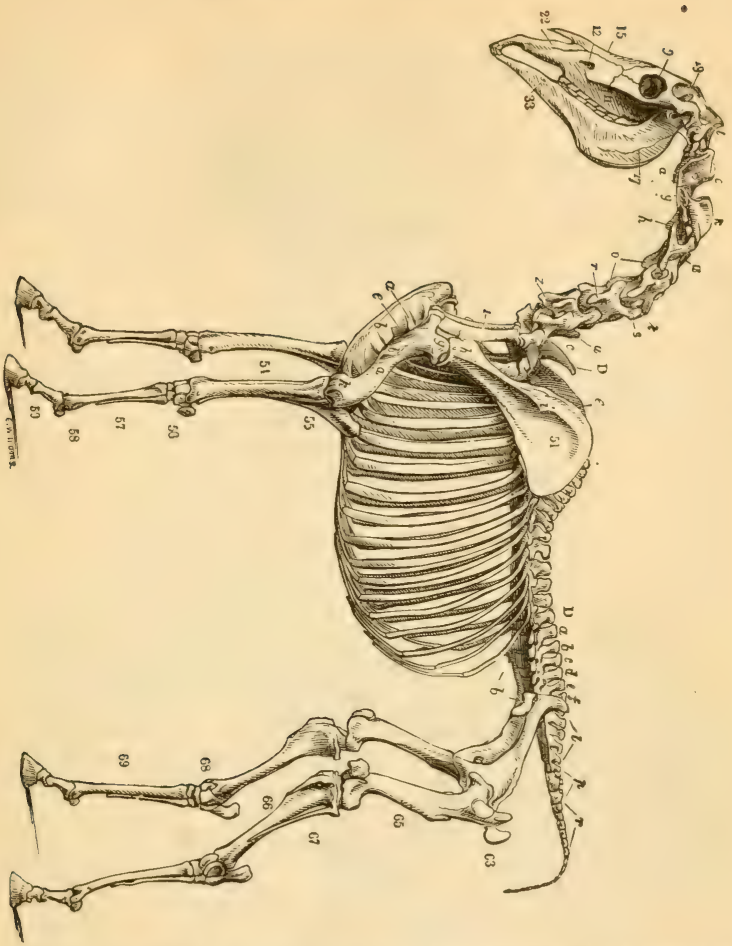

Fig. 117.-Skeleton of the Horse (Equus caballus): 22, premaxillary: 12, foramen in the maxillary: 15 , nasal ; 9, orbit ; 19 , coronoid process of lower jaw ; 17 , surface of implantation for the masseter muscle; there are seven cervical vertebra, nineteen dorsal, D-D; five lumbar, $a-c$; five sacral, $f-l$; and seventeen caudal, $p-r$; 51 , scapula, or shoulder-blade; $i$, spine, or crest ; $h$, coraenid process (acromion wanting) : 1, first pair of ribs (clavicle wanting, as in all U'ugnlates): e, sternum: $a$, shaft of humerns; $b$, deltoid ridge: $y$, head fitting in the glenoid cavity of the scapula-near it is a great tuherosity for the attachment of a powerful muscle; $k$, condyles: 54 , radius, to which is firmly anchylosed a rudimentary ulna, 55 , called olecranon: 56 , the seven bones of the carpus, or wrist: 57 , large metacarpal, or "cannon-bone," with two "splint-bones:" 5s, fetlock-joint; 58, phalanges of the developed digrit, corresponding to the third finger in Man; 62, pelvis: 63, the great trochanter, or prominence on the femur, $65 ; 66$, tibia; 67 , rudimentary fibula; $6 S$, hock, or heel, falsely called knee; 69 , metatarsals. 


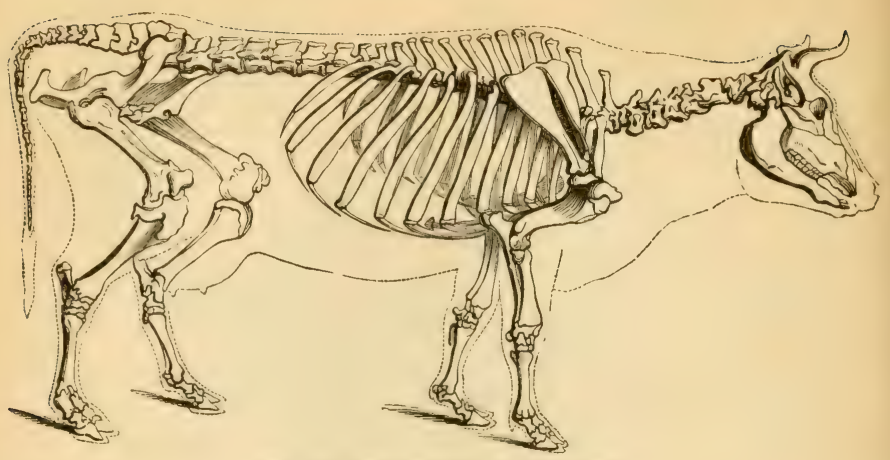

Fig. 118,-Skeleton of the Ox (Bos taurus).

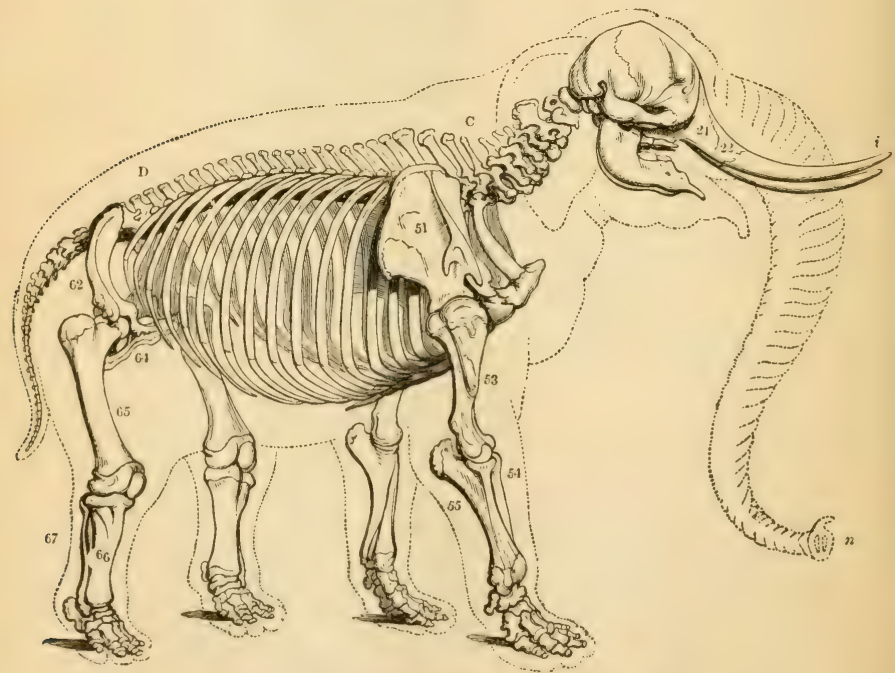

Frg. 119.-Skeleton of an Elephant (Elephas Indicus). 


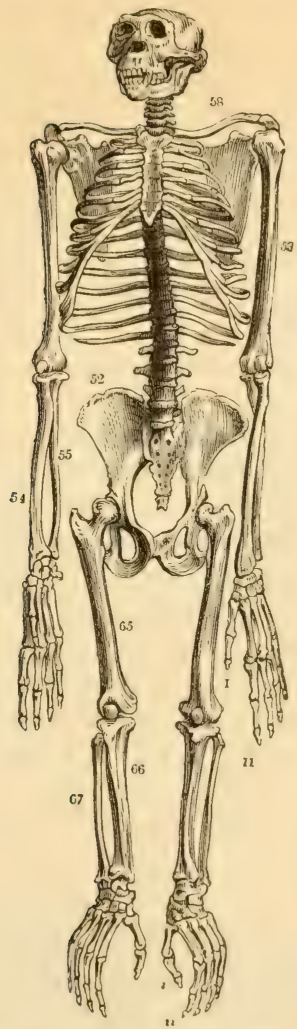

Yrc. 120.-Skeleton of the Chimpanzee (Troglodytes niger). 


\section{CHAPTER XVII.}

HOW ANIMALS MOVE.

1. Muscle.-The power of animal motion is rested in protoplasm, cilia, and muscles. The simplest forms of life, as the structureless Sponge and Amœba, more by the contraction and extension of the protoplasm of which they consist. In nearly all animals we find with the microscope myriads of little hair-like cilia, which are incessantly vibrating. They are seen on the outside of Infusoria, serving as paddles for locomotion; they fringe the gills of the Oyster, creating currents for respiration; and they line the passage to our lungs to expel the mucus. The cause of ciliary motion is unknown; no muscle or nerve has been traced to them. Water seems to be a necessary condition.

But muscular tissue is the great motor agent, and exists in all animals from the Coral to Nan. The power of contractility, which in the Amoba is diffused throughout the body, is here confined to bundles of highly elastic fibres, called muscles. When a muscle contracts, it tends to bring

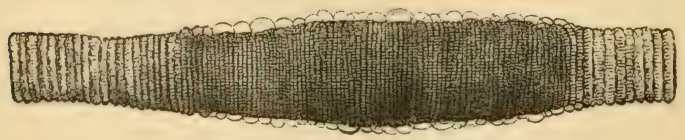

Frg. 121.-A Contracting Mnscle.

its two ends together, thus shortening itself, at the same time increasing in thickness. This shrinking property is excited by external stimulants, such as electricity, acids, alkalies, sudden heat or cold, and eren a sharp blow; but 
the ordinary cause of contraction is an influence from the brain convered by a nerve. The property, however, is independent of the nerrous system, for it does not cease immediately after death. The amount of force with which a muscle contracts depends on the number of its fibres; and the amount of shortening, on their length.

As a rule, muscles are white in cold-blooded animals, and red in the warm-blooded. They are white in all the Invertebrates, Fishes, Batrachians, and Reptiles, except Salmon, Sturgeon, and Shark; and red in Birds and Mammals, except in the breast of the common fowl, and the like. ${ }^{89}$

It is also a rule, with some exceptions, that the voluntary muscles of Vertebrates, and all the muscles of the Lobster, Spider, and Insect tribes, are striated; while the involuntary muscles of Vertebrates, and all the muscles of Radiates, Worms, and Mollusks, are smooth. All muscles attached to internal bones, or to a jointed external skeleton, are striated. The voluntary muscles are generally solid; and the involuntary, hollow. ${ }^{90}$

This leads to another classification of muscles: into those which are attached to solid parts within the body; those which are attached to the skin or its modifications; and those having no attachments, being complete in themselves. The last are hollow or circular muscles, inclosing a cavity or space, which they reduce by contraction. Examples of such are seen in the heart, blood-ressels, stomach, iris of the eye, and around the mouth. In the lower Invertebrates, the muscular system is a net-work of longitudinal, transverse, and oblique fibres intimately blended with the skin, and not divisible into separate muscles. As in the walls of the human stomach, the fibres are usually in three distinct layers. This arrangement is exhibited by soft-bodied animals, like the Sea-anemone, the Snail, and the Earth-worm. Four thousand fibres have been counted 
in a Caterpillar. There are also "skin-muscles" in the higher animals, as those by which the Horse produces a twitching of the skin to shake off Insects, and those by which the hairs of the head and the feathers of Birds are made to stand on end. Invertebrates, whose skin is hardened into a shell or crust, have muscles attached to the inside of such a skeleton. Thus, the Oyster has a mass of parallel fibres connecting its two valves; while in the Lobster and Bee, fibres go from ring to ring, both longitudinally and spirally. The muscles of all Invertebrates are straight parallel fibres, not in bundles, but distinct, and usually flat, thin, and soft.

The great majority of the muscles of Vertebrates are attached to the bones, and such are voluntary. The fibres, which are coarsest in Fishes (most of all in the Rays), and finest in Birds, are bound into bundles by a web-like tissue; and the muscles thus made up are arranged in layers around the skeleton. Sometimes their extremities are attached to the bones (or rather to the periosterem) directly; but generally by means of white inelastic cords, called tendons. In Fishes, the chief masses of muscle are disposed along the sides of the body, apparently in longitudinal bands, reaching from head to tail, but really in a series of vertical flakes, one for each vertebra. In proportion as limbs are dereloped, we find the muscles concentrated about the shoulders and hips, as in quadrupeds. The bones of the limbs are used as levers in locomotion, the fulcrum being the end of a bone with which the moving one is articulated. Thus, in raising the arm, the humerus is a lever working upon the scapula as a fulcrum. The most important muscles are called extensors and flexor's. The former are such as pass over the back of a joint to extend the bone beyoud it; while the flexors lie in front of the joint to bring the same bone into an angle with its fulcrum-as in bending the arm. 
2. Locomotion.-All animals have the power of voluntary motion, and all, at one time or another, have the means of moving themselves from place to place. A few are free in the embryo-life, and tixed when adult, as the Sponge, Coral, Crinoid, and Oyster. There may be no regular well-defined means of progression, as in the Amoba, which extemporizes arms to creep over the surface; or movement may be accomplished by the contraction of the whole body, as in the Jelly-fish, which, pulsating about fifteen times in a minute, propels itself backward throngh the water. So the Worms and Snakes swim by the undulations of the body.

But, as a rule, animals are provided with special organs for locomotion. These become reduced in number, and progressively perfected, as we advance in the scale of rank. Thus, the Animalcule is covered with thousands of hair-like cilia; the Star-fish has hundreds of soft, unjointed, tubular suckers; the Centipede has from 30 to 40 jointed hollow legs; the Lobster, 10 ; the Spicler, 8 ; and the Insect, 6; the Quadruped has 4 solid limbs for locomotion; and Man, only 2.

(1) Locomotion in Water.-As only the lower forms of life are aquatic, and as the weight of the body is partly sustained by the element, we must expect to find the organs of progression simple and feeble. The Infusoria swim with great rapidity by the incessant vibrations of the delicate filaments, or cilia, on their bodies. The common Squid on our coast admits water into the interior of the body, and then suddenly forces it out through a funnel, and thus moves backward, or forward, or around, according as the funnel is turned-toward the head, or tail, or to one side. The Lobster has a fin at the end of its tail, and propels itself backward by a quick down-stroke of the abdomen.

But Fishes, whose bodies offer the least resistance to 
progression through water, are the most perfect swimmers. Thus, the Salmon can go twenty miles an hour, and eren

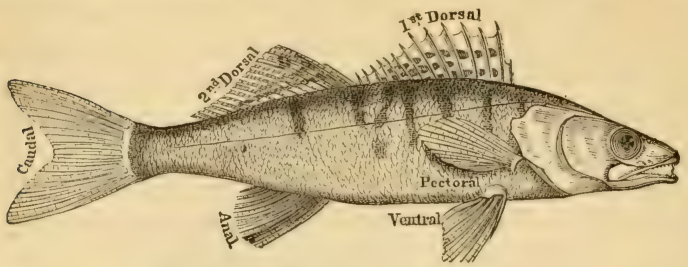

Fra. 122.-The Fins of a Fish (Pike-perch).

ascend cataracts. They have fins of two kinds: those set obliquely to the body, and in pairs; and those which are vertical, and single. The former, called pectoral and ventral tins, represent the fore and hind limbs of quadrupeds. The vertical fins, which are only expansions of the skin, vary in number; but in most Fishes there are at least three: the caudal, or tail-fin; the dorsal, or back-fin;

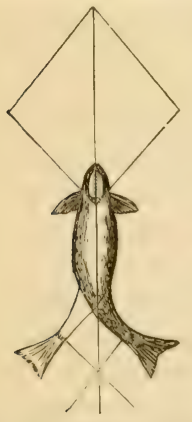

F'ro. 123.-Diagram illustrating the locomotion of a Fish. The tail describes the arc of an ellipse; the resultant of the two impulses is the straight line in front. and the anal, situated on the abdomen, near the tail. The chief locomotive agent is the tail, which sculls like a stern-oar; the other fins are mainly used to balance and raise the body. When the two lobes of the tail are equal, and the vertebral column stops short at its base, as in the Trout, it is said to be homocercal. If the vertebræ extend into the upper lobe, making it longer than the lower one, as in the Shark, the tail is called heterocercal. The latter is the more effective for varying the course; the Shark, e.g., will accompany and gambol around a ship in full sail across the Atlantic. The Whale swims by striking the 
water up and down, instead of laterally, with a fin-like horizontal tail. Many air-breathing animals swim with facility on the surface, as the Water-birds, having webbed toes, and most of the Reptiles and Quadrupeds.

(2) Locomotion in Air. - The power of flight requires a special modification of structure and an extraordinary muscular effort, for air is 800 times lighter than water. Nevertheless, the velocity attainable by certain Birds is greater than that of any Fish or Quadruped; the Hawk being able to go 150 miles an hour. The bodies of Insects and Birds are made as light as possible by the distribution of air-cavities. ${ }^{91}$

The wings of Insects are generally four in number; sometimes only two, as in the Fly. They are moved by muscles lying inside the thorax. They are simple expansions of the skin, or crust, being composed of two delicate films of the epidermis stretched upon a net-work of tubes. There are three main varieties: thin and transparent, as in the Dragon-fly; opaque, and corered with minute colored scales, which are in reality flattened hairs, as in the Butterfly; and hard and opaque, as the first pair (called elytra) of the Beetle.

The wings of Birds, on the other hand, are modified fore-limbs, consisting of three sets of feathers (called primary, secondary, and tertiary), inserted on the hand, forearm, and humerus. The muscles which give the downward stroke of the wing are fastened to the breast-bone; and their power, in proportion to the weight of the Bird, is as 10,000 to 1 . Tet the Insect is eren superior in rigor and velocity of flight. ${ }^{22}$ In ascending, the Bird slightly rotates the wing, striking downward and a little backward; while the tail acts as a rudder. A short, rounded, concave wing, as in the common Fowl, is not so well fitted for high and prolonged flight as the long, broad, pointed, and flat wing of the Eagle. The wing is folded by 
means of an elastic skin connecting the shoulder and wrist, which is stretched when the wing is expanded.

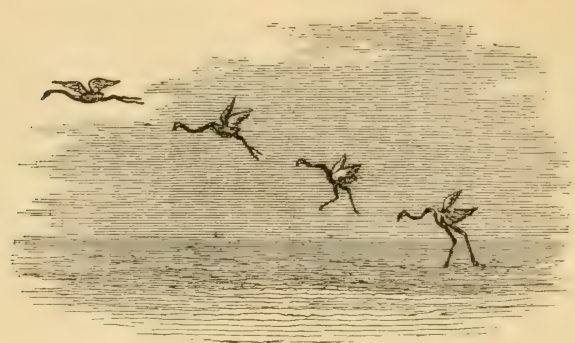

Fic. 124.-Flamingoes taking Wing.

Besides Insects and Birds, a few other animals have the power of flight, as Bats, by means of long webbed fingers; Flying Fishes, by large pectoral fins; and Flying Reptiles, Flying Squirrels, and the like, by membranes between the fore and hind legs.

(3) Locomotion on Solids. - This requires less muscular effort than swimming or flying. The more unyielding the basis of support, the greater the amount of force left to more the animal along. The simplest method is the suctorial, the animal attaching itself to some fixed object, and then, by contraction, dragging the body onward. But the higher and more common method is by the use of bones, or other hard parts, as levers.

The Star-fish ereeps by the working of hundreds of tubular suckers, which are extended by being filled with fluid forced into them by little sacs. The Clam moves by fixing and contracting a muscular apjendage, called a "foot." The Snail has innumerable short muscles on the under side of its body, which, by snccessive contractions resembling minute undulations, enable the animal to glide forward apparently without effort. The Leech 
has a sucker at each end: fixing itself by the one on its tail, and then stretching the body, by contracting the muscular fibres which run around it, the creature fastens its month by suction, and draws forward the hinder parts by the contraction of longitudinal muscles. The Earthworm lengthens and shortens itself in the same way as the Leech, but instead of suckers for holding its position, it has numerous minute spines pointing backward; while the Caterpillar has short legs for the same purpose. The legless Serpent moves by means of the scutes, or large scales, on the under side of the body, acted upon by the ribs. In a straight line, locomotion is slow; but by curving the body laterally or vertically, it can glide or leap with great rapidity.

MIost animals have morable jointed limbs, acted upon as levers by numerons muscles. The Centipede has fortytwo legs, each with five joints and a claw. The Crab has five pairs of six-jointed legs; but the front pair is modified into pincers for prehension. With the rest, which end in a sharp claw, the Crab moves backward, forward, or sideways. The Spider has eight legs, usually serenjointed, and terminating in two claws toothed like a

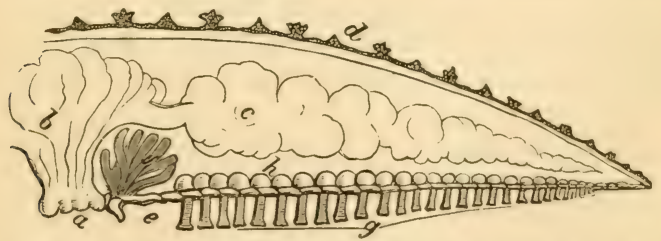

FIG. 125.-Diagrammatic section of Star-fish : $a$, mouth; $b$, stomach : $c$, crenm, or intestine: $d$, dorsal surface; $e$, ambulacral plates: $f$, ovarium $; g$, tubular feet; $h$, internal sacs for extending the feet.

comb, and a third which acts like a thumb. In rumning. it mores the first right leg, then the fourth left; next, the first left, and then the fourth right; then the third right 
and second left together; and, lastly, the third left and second right together. The front and hind pairs are, therefore, mored like those of a quadruped. The Insect

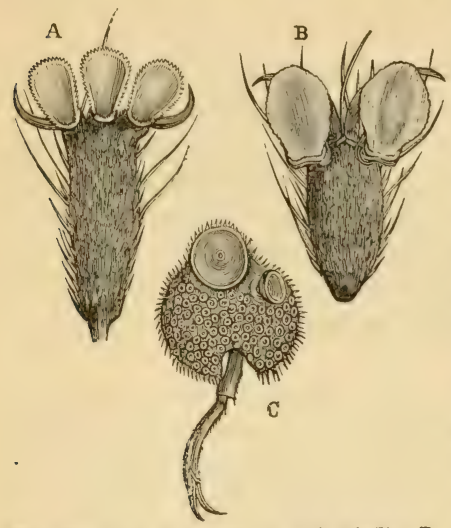

Fro. 126. - Feet of Insects: A, Bibio febrilis; B, House-fly (Arusca domestica); C, Water-beetle (Lytiscus).

has six legs, each of five joints: the coxa, or hip; trochanter; femur; tibia, or shank; and tarsus. The last is subdivided usually into five joints and a pair of claws. Such as can walk upside down, as the Fly, have, in addition, two or three suckers between the claws. ${ }^{93}$ While the leg-bones of Vertebrates are covered by the muscles which moved them, the limbs of Insects are hollow, and the muscles inside. The fore legs are directed forward, and the two hinder pairs backward. In motion, the fore and hind feet on one side, and the middle one on the other, are mored simultaneously, and then the remaining three.

The four-legged animals have essentially the same apparatus and method of motion. The Crocodile has an awkward gait, owing to the fact that the limbs are short, and placed far apart, so that the muscles act at a mechanical disadvantage. The Tortoise is prorerbially slow for a similar reason. Both swim better than they walk. Lizards are light and agile, but progression is aided by a wriggling of the body.

The locomotive organs of the mammalian quadrupeds 
are much more highly organized. The hones are more eompact; the vertebral columm is arched, and yet elastic, between the shoulder and hip, and the limbs are placed vertically molerneath the bucly. 'The bunes of the fore limb are nearly in a line; but those of the hind limb, which is mainly used to project the body forward, are more or less inclined to one another, the angle being greatest in animals of great speed, as the Ilorse. Sume walk on hoofs, as the Ox (Ungulate); some on the toes, as the Cat (Digitigrade); other's on the sole, tonching the gromed with the heel, as the Bear (Plantigrade). In the
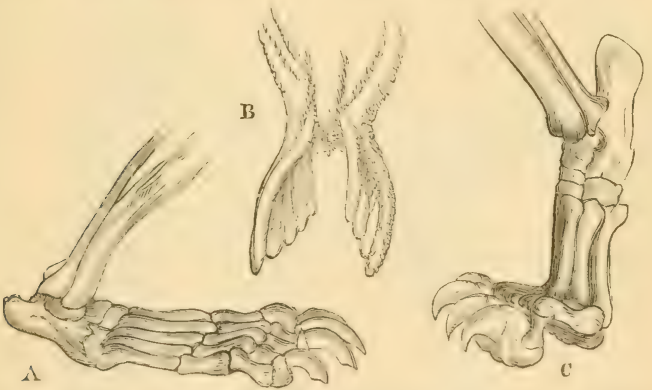

Fig. 127.-Feet of Carnivores: A, Plantigrade (Bear); B, Pinnigrade (Seal); C, Digitigrade (Lion).

Pimigrade Seal, half of the fore limb is huried under the skin, and the hind limbs are turned backward to form a fin with the tail. The normal number of toes is fire; but some may be wanting, so that we have one-toed animals (ais IInre), two-tued (as Ox), three-toed (as Rhinoceros), four-toed (as Ilippopotamus), and five-toed (as the Elephant). The IIorse steps on what corresponds to the nail of the midlle finger; and its swiftness is mainly owing to the solidity of the extremities of the limbs. IIorses of the wreatest speed have the shumlder-joints directed at a considerable angle with the arm. 
The order in which the legs of quadrupeds suceced each other determines the various modes of progression, called the walk, trot, gallop, and leap. Many, as the Hurse, have all these morements; while some only leap, as the Frog and Kangaroo. In leaping animals, the hind limbs are extraurdinarily dereloped. In many Mammals, like the Squirrel, Cat, and Dog, the fore legs are used for prehension as well as locomotion, and such have a collar-bone. Monkeys use all four, and also the tail, for
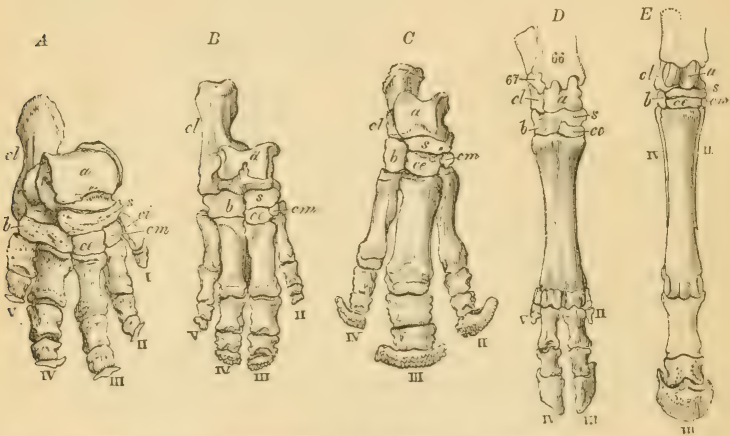

Fig. 12s,-Feet of Hoofed Mammals: A, Elephant: $B$, Hippopotamus ; $C$, Rhinoceros; $D, \mathrm{Ox} ; E$, Horse. $a$, astragalus; $c l$, calcaneum, or heel; $s$, naviculare; $b$, cuboides; $c c, c i, c m$, cuneiform bones; the numbers iudieate the digits in use.

locomotion and prehension, keeping a horizontal attitude; while the $A$ pes, lialf erect, as if they were half-cuadruped, half-biperl, go shambling along, tonching the gromed with the knnckles of one hand and then of the other. In descending the scale, from the most anthropoid $\Lambda$ pe to the true quadruped, we find the centre of gravity placed increasingly higher up - that is, farther forward. Birds and Men are the only true bipeds; the former standing on their toes, the latter on the soles of the feet. Terrestrial Birds walk and run; while Birds of Flight usually 
hop. The Ostrich ean for a time ontrun the Arabian Ilorse; and the speed of the Cassowary exceeds that of the swiftest Greyhound.

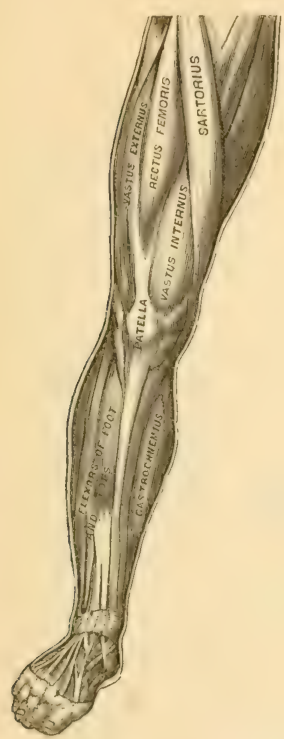

Fig. 129.-Muscles of the Human Leg: sartorius, or "tailor's muscle," the longest muscle in the body, flexes the leg upon the thigh; rectus femoris and vastus externus and internus extend the leg, maintaining an erect posture; gastrocnemine, or "calf," used chiefly in walking, for raising the heel. Another layer underlies these superficial muscles.

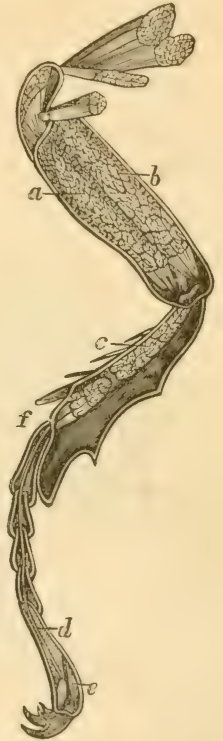

Frc. 130.-Muscles of an Insect's Leg (Melolontha vnlqaris): $a$, llexor, and $b$, extensor, of tibia; $c$, llexor of foot: $d$, accessory muscle; $e$, extensor of claw : $f$, extensor of tarsus. The joints are restricted to movements in one plane: and therefore the muscles are simply flexors and extensors. All the muscles are within the skele. ton. 


\section{CHAPTER XVIII.}

THE NERVOUS STSTEM.

Nervous Matter exists in the form of cells, fibres, or tubes. In the cellular state it is grayish, and accumulated

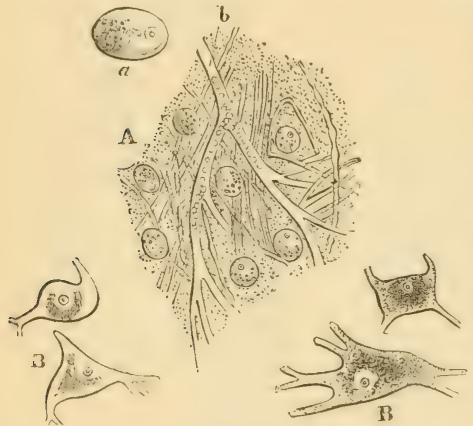

F1G. 131. - Nerve-cells from Fuman Brain: A, associated with nerve-tubes and blood-vessels; B, multipolar nucleated cells. in masses, called ganglia, or centres, which alone originate nerrous force; the fibrous and tubular kinds are generally white, and arranged in bumdles, called nerves, which serve only as conductors. Most nerres consist of white fibres, and go in pairs, each member having a distinct office: one carries impressions received from the external world to the gray centres, and hence is called an afferent, or sensory, nerve; the other conducts an influence generated in the centre to the muscles, in obedience to which they contract, and hence it is ealled an efferent, or motor, nerve. Thus, when the finger is pricked with a pin, an afferent nerve convers the impression to the great centre-the brain, which immediately trans-

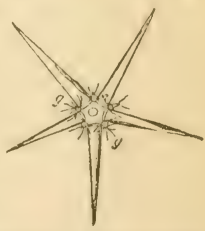

Fig. 132.-Nervous Sys. tem of a Star-fish: consisting of five ganglia, $g$, around the mouth, which send to each ray a pair of nerres. 
mits an order by an efferent nerve to the muscles of the hand to contract. If the former are ent, sensation is lost, but voluntary motion remains; if the latter are cut, the animal loses all control over the muscles, although sensibility is perfect; if both are cut, the animal is said to be paralyzed. The nature of nerve-force, and exactly how the nerves terminate in the skin and muscles, are unsolved problems.

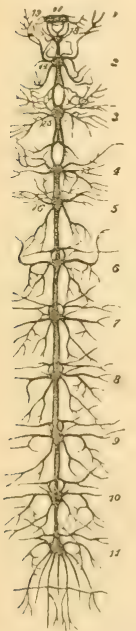

Fro. 134. - Nervous System of a Caterpillar (Sphinx ligustri); the nirst is the cephalic, or head, ganglion.
As to the velocity of a nervous impulse, we know it is far less than

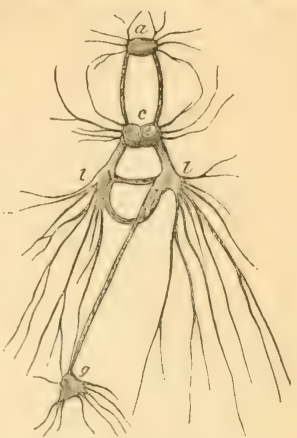

Fifr. 133. - Nervous Syrstem of a Mrollusk, the Gitsteropud Aplys$i a$ : $\alpha$, anterior ganglion ; $c$, cephalic; $l$, lateral; $g$, abdominal. that of electricity or light, and that it is more rapid in warm-blooded than in coldblooded animals, heing nearly twice as fast in Man as in the Frog.

Nervous matter in the form of cells doubtless exists in the very lowest animals, although it is invisible under the most powerful microscopes. ${ }^{\circ 4}$ But a neivous system of centres and nerres for keeping up a communication between different parts of the body is not required in such as have no distinct organs; we would look for it only in those possessing a well-defined muscular system. In the Star-fish we detect the first clear specimen of cells and fibres connected together to receive and convey impressions. It consists of a ring around the month, made of five ganglia of equal size, with radiating nerves. The Mollusks 
are distinguished by an irregularly scattered nerrous system. They have two or more ganglia around the gullet, and one or two more in the posterior region; all are mited by threads, and send off nerres to the varions organs. The articulated animals generally have a donble nervons cord lying along the ventral side, and studded with ganglia of nearly uniform size, except the first, which is the largest of all, and represents the brain. In the simple Earth-worm there is no trace of ganglia; in the Centipede and Caterpillar there is a ganglion for each segment; but in the higher forms, as the Bee, several ganglia are fused together in the head and thorax, indicating a concentration of organs for sensation and locomotion.

In Tertebrates, the nervous system is more highly dereloped, more complex, and more concentrated than in the lower forms. In fact, there are some parts, as the brain, to which we find nothing analogons in the Invertebrates; and while the actions of the latter are mainly, if not wholly, antomatic, those of backboned animals are roluntary. Its position, moreover, is peculiar, the great mass of the nerrous matter being accumulated on the dorsal side, and inclosed by the neural arches of the skeleton.

The brain and spinal eord lie in the earity of the skull and spinal columm, wrapped in three membranes. Buth consist of gray and white nerrons matter; but in the brain the gray is on the outside, and the white within; while the white of the spinal cord is external, and the gray internal. Both are double, a deep fissure rumning from the forehead backwark, dividing the brain into two hemispheres, and the spinal cord resembling two columns welded together; eren the nerres come forth in pairs to the right and left. So that a person may be said to consist of two inclividuals acting simultaneonsly. If the two halves of the brain do not act in concert, the man is said to be insane; if one 
lalf of the spinal cord is diseased, one side of the body is paralyzed. The brain is the organ of sensation; the spinal cord is the organ of mere life and motion. The brain may be removed, and yet the animal, though it can not feel, will live for a time, showing that it is not absolutely essential to life; in fact, the brain does nothing in apoplexy and deep sleep. But if the spinal cord be destroyed, the animal dies, for it can neither move nor breathe, as all the afferent and efferent nerres terminate in the cord.

The Brain is that part of the nervous system contained in the skull. ${ }^{95}$ It increases in size and complexity as we pass from the Fishes, by the Reptiles and Birds, to Mammals. Thus, the body of the Cod is 5000 times heavier than its brain -in fact, the brain weighs less than the spinal cord; while in Man, the brain, compared with the body, is as 1 to 36 , and is 40 times heavier than the spinal cord. The brains of the Cat weigh only $1 \mathrm{oz}$; ; of the Dog, 6 oz. $5 \frac{1}{2} \mathrm{dr}$; and of the Horse, 22 oz. 15 dr. The only animals whose brains outreigh Man's are the Elephant and Whale; the maximum weight

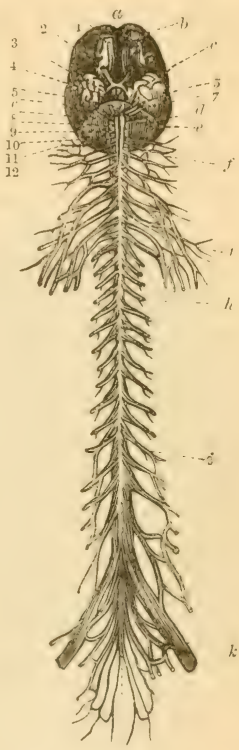

$l$

Frg. 135.-Human Brain and Spinal Cord, one-tifth natural size: $a$, great longitudinal tissure; $b$, anterior lobe: $c$, middle lobe; $d$, medulla olblongata; $e$, cerebellum: $f$, first spinal nerve; $g$, brachial plexus of nerves supplying the arms: $h$, riorsal nerves; $i$, lumbar nerves; $k$, sacral plexus of nerves for the limbs, $l$, caud: equina: the fignres indicate the twelve pairs of cranial nerves, of which 1 is olfactory, 2 are optic, and $S$ auditory.

of the Elephant's being 10 lhs.: and of the Whale's, 5 lls.s; while the human does not exceed 4 lbs. Yet the human 
brain is hearier in proportion to the body. But quality must be considered as well as quantity, else the Dunliey will ontrank the Ilorse, and the Canary-bird, Man; for their brains are relatively heavier.

The main parts of the brain are the ceretrum, cerebcllum, and medulla oblongata.

The cerebrum is a mass of white fibrons matter covered by a layer of gray cellular matter. In the lower Terte-

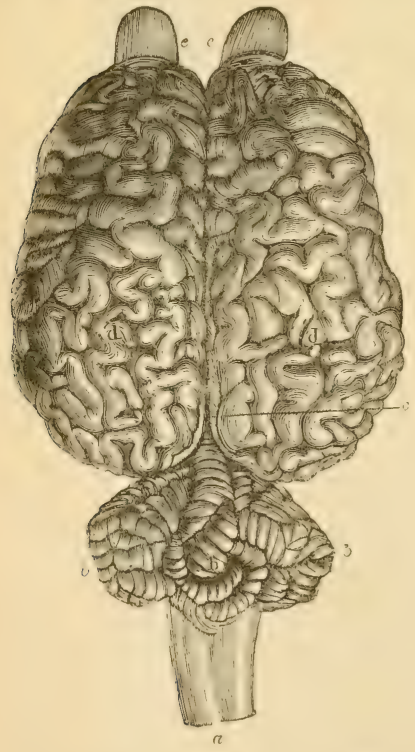

Fre. 136. - Brain of the Horse-npper view, onehalf natnral size: $a$, medulla oblongata; $b$, lateral and middle lobes of cerehellum ; $c$, interlobular fissure; $d$, cerebral hemispheres; $c$, olfactory lobules. brates, the exterior is smooth; but in most of the Mammals it is convoluted, or folded, to increase the amount of the gray surface. The convolutions multiply and deepen as we ascend the scale of size and intelligence, being very complex in the Elephant and Whale, Monkey and Man. As a rule, they are proportioned to the intelligence of the animal; yet the brains of the Dog and Horse are smoother than those of the Sheep and Donliey. Evidently the quality of the gray matter must be taken into account. Save in the bony Fishes, the cerelurm is the larest portion of the brain; in Man, it is orer eight times hearier than the cerebellum. 
The cerebellum, or "little brain," lies behind the cere- brum, and, like it, presents an external gray layer, with a white interior. In Mammals, it is likewise finely conroluted, consisting of gray and white lamina, and is divided into tro lohes, or hemispheres. In the rest of the Vertebrates, the cerebellum is nearly or quite smooth; and in the lowest Fishes it is merely a thin plate of nervous matter. In many Vertebrates, however, it is larger, compared with the cerebrum, than in Man, since in Min the cerebrum is extraordinarily dereloped.

The medulla oblongata is the comnecting link between the cerebrum and cerebellum and the spinal cord. In structure, it resembles the spinal cord-the white matter being external, and the gray internal. The former lies beneath or behind the brain, passing through the foramen magnum of the skull, and merging imperceptibly into the cord. The latter is a continuous tract of gray matter in. closed within strands of white fibres, and corresponds to the rentral cord in Insects. It usually ends in the lumbar region of the vertebral column; but in Fishes it reaches to the end of the tail. In Fishes and Reptiles, the cord ontweighs the brain; in Birds and Mammals, the brain is heavier than the cord. In Man, it weighs aloout an ounce and a half.

The parts of the brain are always in pairs; but in relative derelopment and position they differ widely in the several classes of Vertebrates. In Fishes and Fieptiles, they are arranged in a horizontal line; in Birls and Mammals, they lie on top of each other, till, in Man, the axis of the brain is at right angles with the spinal cord. In looking down upon the brain of a Corl, we see in front a pair of olfactory lobes (which send forth the nerves of smell), behind them the small cerebral hemispheres, then the large optic lobes (in which origninate the nerves of sight), and, last of all, the thin cerehellum. Not till we reach 
Man and the Apes do we find the cerebrum so highily developed as to overlap both the olfactory lobes in front and the cerebellum

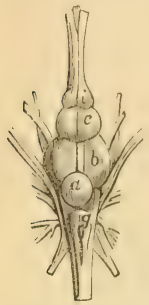

Frg. 137.-13rain of the Perch, upper view : $a$, cerebellum; $b$, cerebrum; $c$, olfactory gauglia ; $i$, olfactory nerves; $g$, supplementary lobes.

behind.

Functions of the Brain. - The cerebrum is the source of intelligence and will. It has no direct communication with the ontside world, receiving its consciousness of external objects and events through the spinal cord and the nerves of special sense. The nerves of smell and sight alone come from the cerebrum. ${ }^{96}$

The cerebellum seems to preside over the muscular movements. When re-

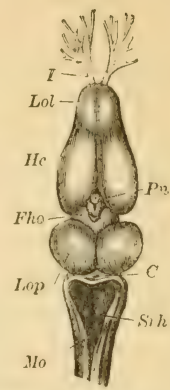

Fir. 138. - Brain of the Frog, upper view, $\times 4$ : $I$, olfactory nerves; $L \circ$, olfactory lobes; $H c$, cerebral hemispheres: $P n$, pineal gland; Fho and Srh, third and fourth ventricles: Lop, optic lobes: $C$, cerebellum; JIo, medulla oblongata.

moved, the animal desires to execute the mandates of the

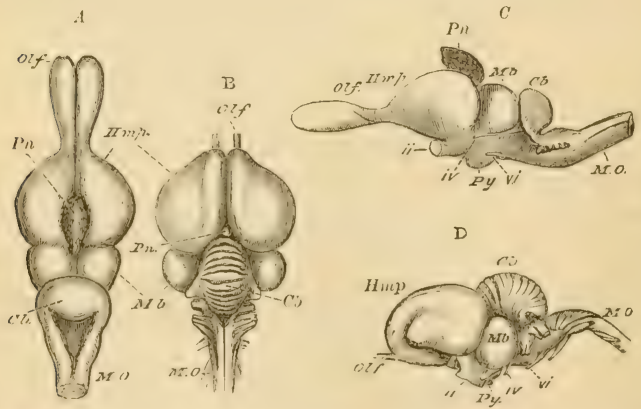

Fra. 139.-A, C, upper and sicle views of the Brain of a Lizard. B, D, upper and side views of the Brain of a Turkey: Olf, olfactury lobes; $H \mathrm{~m}$, cerebral hemispheres; $I^{2} n$, pineal gland: $M b$, optic lobes of the middle urain; $C b$, cerehellnm: $M O$, medulla oblongata: $i i$, optic nerves; $i v$ and $v i$, nerves for the muscles of the eve; $P y$, pituitary body. 
will, but can not; its motions are irregular, and it acts as if intoxicated. It is largest in animals capable of the

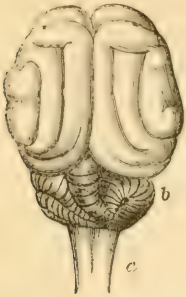

Fro, 140.-Brain of the Cat (Felis domestica) : $a$, medulla oblongata; $b$, cerebellum; $c$, cerebrum.

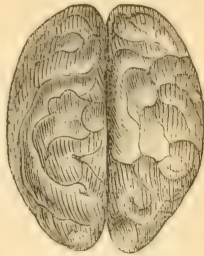

Frg. 141. - Brain of the Orang-utan, upper surface; one-third natural size.

most complicated movements: being larger in the Ape than in the Lion, in the Lion than in the Ox, in Birds than in Reptiles.

The medulla oblongata is not only the medium of communication between the brain and the spinal cord, but it is itself a nervous centre: the

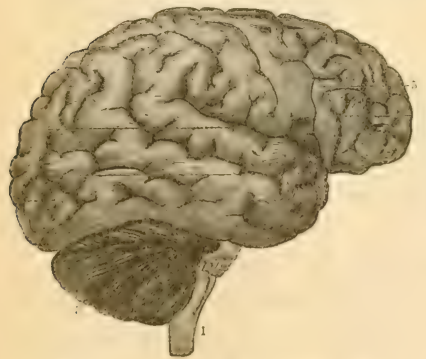

Frg. 142.-Humau Brain, side vicw: 1, medulla oblongata: 3 , cerebellum: 5 , frontal convolutions of cerebrnm.

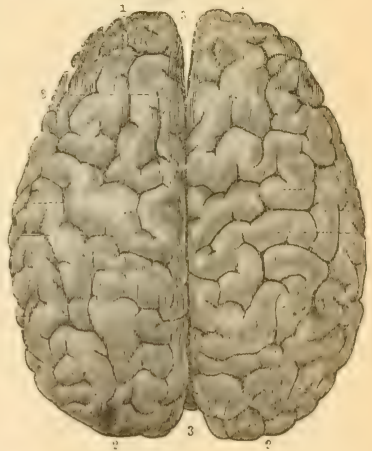

Fro. 143.-Human Brain, upper view, one-third natural size: 1 , auterior lobes; 2 , posterior: 3 , great mediau tissure.

brain alove and the cord below may be removed without deatls to the animal, but the destruction of the medulla 
is fatal. Of the twelre pairs of nerves issuing from the contents of the skinll (enceplaton), ten come from the medulla oblongata. Among these are the nerres of hearing and taste, and those that control the lungs and heart.

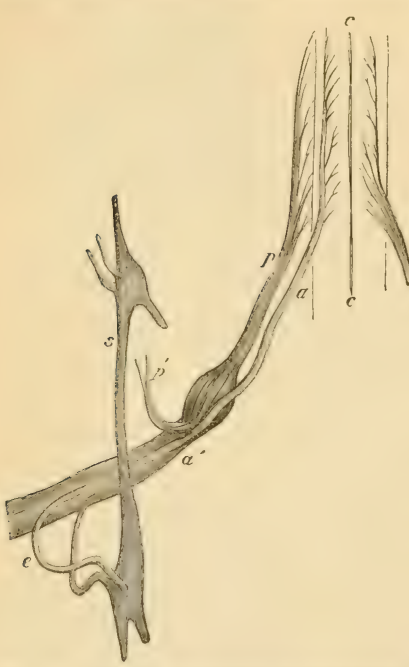

Frg. 144. - Relation of the Sympathetic and Spinal Nerves: $c$, fissure of spinal cord ; $a$, anterior of a dursal spinal nerve: $p$, posterior rost, with its ganglion; $a^{\prime}$, anterior branch; $p^{\prime}$, posterior branch: $s$, sympathetic; $e$, its double juuction by white and gray filaments.

Respiration ceases immediately when the medulla is injured.

The spinal cord can of itself generate nerveforce; but it is mainly a conductor-propagating through its central gray matter the impressions received by the nerves to the brain, and taking back through its fibrous part the impulses of the brain. In Man, thirty-one pairs of nerves arise from the cord to supply the whole body, except the head. Each nerve has an anterior and posterior root: its power of cansing muscular contraction is lodged in the former (hence called motor'), and the power of giring rise to sensation resides in the latter (sensory). The fibres leading from the lirain to the cord cross one another in the medulla oblongata, so that if the right cerebral hemisphere he diseased, the left side of the body loses the porrer of voluntary motion.

The sympathetic nemous system is a donble chain of knots, or ganglia, lying along the sides of the rertebral 
colmmm. From these ganglia nerves are given off, which, instead of going to the skin and muscles, like the spinal nerves, form net-works about those internal organs over which the will has no control, as the heart, stomach, and intestines. Their apparent oftice is to stimulate these organs to constant activity. By some anatomists, the gangylia are considered as reservoirs of nervous fur'ce.

\section{The Senses.}

Sensation is the conscionsuess of impressions on the sensory nerves. These impressions produce some change in the brain; but what that change is, is a clarkness on which no hypothesis throws light. Obvionsly, we feel only the condition of our nervous system, not the objects which excite that condition.

All animals pussess a general sensibility diffused over the greater part of the body. ${ }^{97}$ But, besides this (save in the rery lowest forms), they are endowed with special nerves for receiving the impressions of light, somnd, ete. These nerves of sense, as they are called, although structmally alike, transmit different sensations: thus, the Ear can not recognize light, and the Eye can not distinguish souncls. In the higher animals, the organs of sight, hearing, and smell are sitnated in pair's on each sicle of the liead; that of taste, in the mucous membrane covering the tongue; while the sense of touch is diffused over the skin. Sight and hearing are stimnlated, each by one agent only; while tonch, taste, and smell may be excited by various substances. The agents awakening sight, hearing, and tonch are plyysical; thuse cansing taste and smell are chemical. Animals differ widely in the numbers and keemess of their senses. But there is 110 sense in any one which does not exist in some other.

Touch is the simplest and the only universil sense; mu animal is without it. It is likewise the most positive ann? 
certain of the senses. Wherever it exists, there is a tissue containing a net-work of capillaries and the terminations of sensory nerves. In the Sea-anemone, Snail, and Insect,

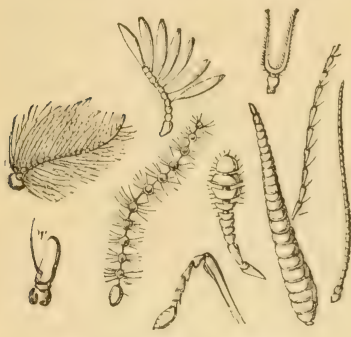

Frg. 145.-Various Antennæ.

it is most acnte in the "feelers" (tentacles, horns, and antennæ) $;^{98}$ in the Oyster, the edge of the mantle is most sensitive; in Fishes, the lips; in Snakes, the tongue; in Birds, the beak and under side of the toes; in Quadrupeds, the lips and tongue; and in Monkeys and Man, the lips and the tips of the tongue and fingers. In the most sensitive parts of Birds and Mammals, the true skin is raised up into multitules of minute elevations, called propille, containing loops of capillaries and nerre-filaments. There is a correspondence between the delicacy of tomch and the derelopment of intelligence. The Cat and Dog are more sagacious than hoofed animals. The Elephant and Parrot are remarkably intelligent, and are as celebrated for their tactual power.

Taste is more refined than touch, since it gives a knowledge of properties which can not he felt. It is always placed at the entrance to the digestive canal, as its chief purpose is to guide animals in their choice of food. No special organ of taste can be detected in the Invertebrates, although all seem to exercise a facnlty in selecting their food. Even

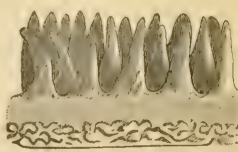

Fra. 146.-Papillie of Human Palm, $\times 35$, the cuticle being removed. in Fishes, Reptiles, and Birds this sense is very obtuse, for they bolt their food. But the higher animals have it well developed. It is confined to the tongue, and is most 
(ielicate at the root. ${ }^{93} \quad \mathrm{~A}$ state of solution and an actual contact of the fluid are necessary conditions.

Smell is the perception of odors, i.e., certain substances in the gaseons state. Many Invertebrates have this sense: Snails, e. g., seem to be guided to their food by its scent, and Flies soon find a piece of meat. But it is impossible to say what or where the organ is. Most probably it is united with the instrument of touch. In Vertebrates, it is placed at the entrance to the respiratory tube, in the upper region of the nose. There the olfactory nerres, which issue from the

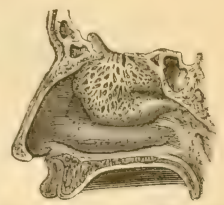

Fiti. 14i.-O)lfactory Nerves on the wall of the nasal cavity. front lobe of the cerebrum, and pass through the ethmoid hone, or roof of the nasal cavity, are distriluted orer a moist mucous membrane. The odorous substance, in a gaseous or finely divided state, is dissolved in the mucus covering this membrane. In Fishes and Reptiles generally, this organ is feebly developed: Sharks, howerer. gather from a great distance aromnd a carcass. In the Porpoises and Whales it is nearly or entirely wanting. Ammong Birds, Waders have the largest olfactory nerres; but Tultures seem to have the lieenest scent. It is most acute in the carnivorous quadrupeds, and in some wild herbirores, as the Deer. In Man it is less delicate, but has a wider range than in any brute.

Hearing is the perception of sound. The simplest form of the organ is a sac filled with fluid, in which float the soft and delicate ends of the auditory nerve. The viluations of the fluid are usually strengthened by the presence of minute hard granules, called otoliths. The Invertelorates have no higher apparatus than this; and it is probable that they can distinguish one noise from another, but neither pitch nor intensity. In all animals the organ is double, but not always located in the head. In 
the Clam, it is found at the base of the foot; some Grasshoppers have it in the forelegrs and in many Insects it is

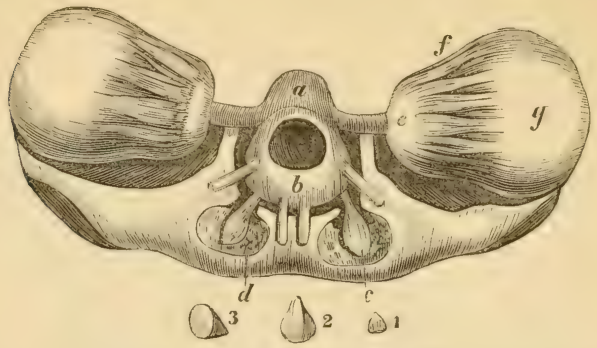

Fig. 145,-Drain and Autlitory Apparatus of the Cuttle-fish: $a, b$, brain; $c$, auditory apparatus; $d$, the cavity in which it is lodged; $e, f, g$, eyes; $1,2,3$, otoliths.

on the wing. Lobsters, Crabs, and most Insects have the auditory sacs at the base of the antennæ. ${ }^{100}$

A complex organ of hearing, located in the head, exists in all Vertebrates, save the rery lowest Fishes. As complete in Man, it consists of the following parts: 1st. The

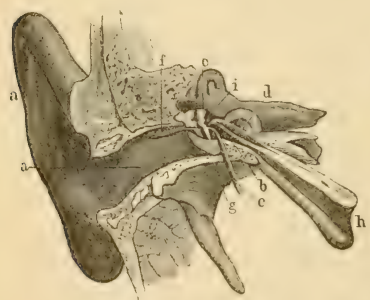

TT 149. Section of Human Ear: $a$ external ear, with auditory canal; $b$, tympanic cavity containing the three bones; $c$, hammer, and its three nuscles, $d, e, f ; g$, tympanic membrane, or head of the drum; $h$, Eustachian tube lending to the pharyux; $i$, labyriuth, with semicircular canals and cochlea visible.

cates with the external air by means of the Eustachian tube, which opens at the back part of the month. 3d. exterual ear (which is peculiar to Mammals); the auditory canal, abont an inch long, lined with hairs and a waxy secretion, and closed at the bottom by a membrane, called tympanum, or "drum of the ear." 2d. The middle ear, containing three little bones (the smallest in the body), malleus, incus, and stapes, articulated together. The carity communi- 
The internal ear, or labyrinth, an irregular cavity in the solid part of the temporal bone, and separated from the middle ear by a bony partition, which is perforated by two small holes. The labyrinth consists of the restibule, or entrance; the semicirculur cancals, or tubes; and the cochtea, or spiral caual. While the other parts are full of air, the labyrinth is filled with a liquid, and in this float the ends of the anditory nerve. The vibrations of the air, collected by the external ear, are concentrated upon the tympanum, and thence transmitted through the chain of little bones to the fluid in the labyrinth.

Now, the essential organ of hearing is the labyrinth, which is, substantially, a bag filled with fluid and nervefilaments. Fishes generally have but little more. In Reptiles there are added a tympanum, chain of bones, cochlea, and Eustachian tube; the tympanum being external. Birds have, extra to Reptiles, an auditory passage, opening on a level with the surface of the head, and surrounded by a circle of feathers. Mammals only liave an external ear. ${ }^{101}$

Sight is the perception of light. ${ }^{103}$ In all animals it depends upon the peenliar sensitiveness of the optic nerre to the ribrations of ether. But while in Vertebrates this nerre comes from the middle mass of the brain, in Invertebrates it is derired from a ganglion. Many animals are utterly destitute of risual organs, as all the Protozoans, and the lower Radiates and Mollusks, besides intestinal Worms and the blind Fish of Mammoth Care. Around the margin of the Jelly-fish, and at the end of the rays of certain Star-fishes and Sea-urchins, are colored spots, supposed to be rudimentary eyes; but as a lens is wanting, there is no image; so that the creature ean merely distingruish light from darkness and color without form. Such an eye is nothing but a collection of pigment granules on the expansion of a nerrous thread, and the percep- 
tion of light is the sensation of warmth, the pigment absorbing the rays and converting them into heat.

Going higher, we find a lens introduced forming a dis-

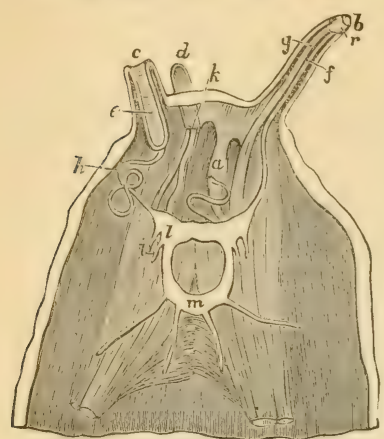

FIG. 150,-Head of a Snail bisected, showing structure of tentacles: $a$, right inferior tentacle retracted within the body; $b$, right superior tentacie fully protruded; $c$, left superior tentacle partially inverted; $d$, left inferior tentacle; $f$, optic nerve;,$q$, retractor muscle $; h$, optic nerve in loose folds; $i$, retractor muscle of head ; $k$, nerve and muscle of left inferior tentacle; $l, m$, nervous collar. tinct image. The Snail, for example, has two simple eyes, called ocelli, mounted on the tip of its long tentacles, consisting of a globular lens, ${ }^{103}$ with a transparent skin (cornea) in front, and a colored membrane (choroid) and a nerrons net-work (retina) behind. Such organs are the only eyes possessed by Myriapods, Spiders, Scorpions, and Caterpillars. Adult Insects usually have three ocelli on the top of the head. But the proper visual organs of Lobsters, Crabs, and Insects are two compound eyes, perched on pedestals, or fixed on the sides of the head. They consist of an immense number of ocelli pressed together so that they take an angular form-four-sided in Crustacea, sixsided in Insects. They form two rounded protuberances variously colored-white, yellow, red, green, purple, brown, or black. Under the microscope, the surface is seen to be divided into a host of facets, ${ }^{104}$ each be-

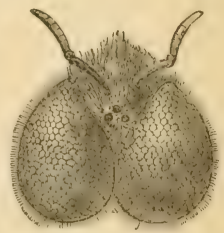

Fre. 151.-Hend of the Bee, showing compound eyes, the three ocelli, or stemmata, and the antennæ. ing an ocellus complete in itself. Each cornea is convex on one side, and either conrex or flat on the other, so that 
it produces a focus like a lens. Behind the cornea, or lens, is the pigment, having a minute aperture, or "pupil." Next (in place of the "vitreous humor" of Vertebrates) is a conical tube - one for each facet-with sides and bottom lined with pigment. These tubes converge to the optic ganglion, the fibres of which pass through the tubes to the cornea. ${ }^{105}$ Vision by such a compound eye is not a mosaic; but each

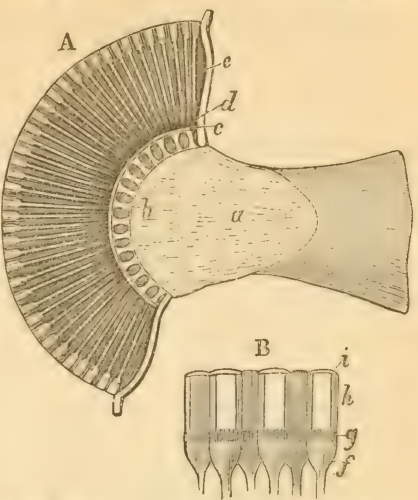

Fig. 152.-Eye of a Beetle (Ilelwluntha): $A$, section; $a$, optic ganglion; $b$, secondary nerves ; $c$, retina; $d$, pigment liyer; $e$, proper optic nerves: $B$, sroup of ocelli ; $f$, bulb of optic nerve; $g$, layer of pigment; $h$, vitreous humor; $i$, cornea. ocellus gives a complete image, although a different per-

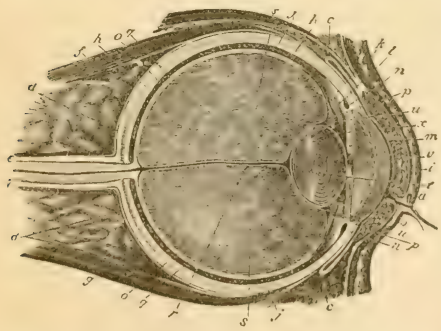

Frr. 153,-Section of IIuman Eye: $a$ and $b$, upper and lower lid: c, conjunctiva, of nucons membrane, lining the inner surface: $d$, external membrane: $c$, sheath of optic nerve: $f, a$, muscles for rolline the eye up or down: $h$, sclerotic: $i$, transparent cornea : $j$, choroid : $k, l$, ciliary muscle for adjusting the eye for distance; $m$, iris and pupil; $n$, canal; $o$, retima: s, vitreous humor; $t$, crystalline; $v$, anterior chamber; $x$, posterior chamber. spective from its neighbor. The multiplied images are reduced to one mental stereoscopic picture, on the principle of single vision in ourselves.

The eyes of the Cuttle-fish are the largest and the most perfect among Invertebrates. They resemble the eres of higher animals in haring a crystalline lens with a chamber in front (open, 
howerer, to the sea-mater), and a chamber behind it filled with "vitreous humor."

The eye of Vertebrates is formed by the infolding of the skin to create a lens, and an outgrowth of the brain

10

9

8

6

7

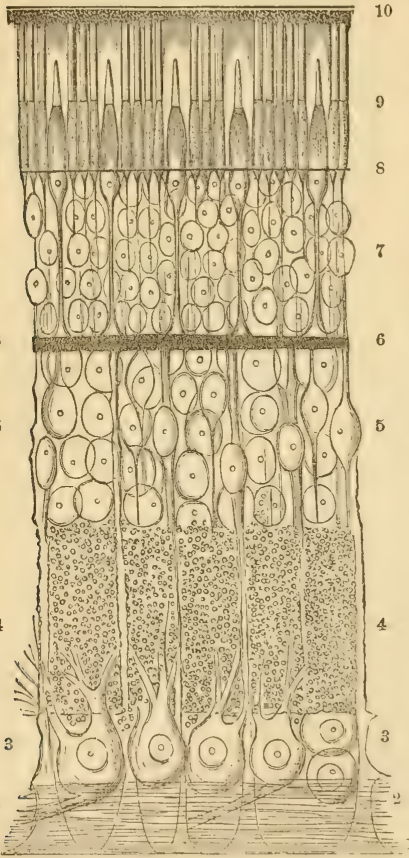

F'IG. 154.-Section of the Human Retina, $\times 400: 1$, internal limiting membrane: 2 , optic-nerve fibres; 3 , ganglion cells; 4 , internal molecular layer: 5 , internal grauules; 6 , external molecular layer; 7 , external granules; 8 , external limiting membrane; 9 layer of rods and cones; 10 , pigment layer. to make a sensitive layer. It consists of a white spherical case (sclerotic) made of tough tissue, with a trausparentfront,called the cornea. This case is kept in shape by two fluids - the thin aqueous humor filling the cavity just behind the cornea, and the jelly-like vitreous humor occupying the larger posterior chamber. Between the two humors lies the donbleconvex crystalline lens. On the front face of the lens is a contractile circular curtain (iris), with a hole in the centre (pupil); and lining the sclerotic coat is the choroid membrane, covered with dark pigment. The optic nerre, entering at the back of the eye through the sclerotic and choroid coats, expands into the transparent 
retina, which consists of several layers-fibrous, cellular, and granular. The most sensitive part is the surface lying next to the black pigment. And here is a peculiarity of the vertebrate eye: the nerve-fibres entering from belind, turn back and look toward the bottom of the eye, so that vision is directed backward; while invertebrate vision is directly forward. In Vertebrates only, the optic nerves cross each other (decussate) in passing from the brain to the eyes; so that the right side of the brain, e.g., receives the impressions of objects on the left side of the body. ${ }^{100}$

Generally, the eyes of Vertelrates are on opposite sides of the head; but in the Flat-fishes both are on the same side. Usually, both eyes see the same object at once; but in most Fishes the eyes are set so far back, the fields of vision are distinct. The cornea may be flat, and the lens globular, as in Fishes; or the cornea very conrex, and the lens flattened, as in Owls. Purely aquatic animals have neither eyelids nor tear's; but nearly all others (especially Birds) have three lids. ${ }^{107}$ The pupil is usually round; but it may be rhomb-shaped, as in Frogs; rertically oral, as in Crocodiles and Cats; or transversely oval, as in Geese, Doves, Horses, and Ruminants. Many quadrupeds, as the Cat, have a membrane (tupetum) lining the bottom of the ereball with a brilliant metallic lustre, usually green or pearly: it is this which makes the eyes of such animals luminous in the dark.

\section{Instinct and Intelligence.}

The simplest form of nervous excitement is mere sensation. Above this we have sensation awakening consciousness, out of which come those roluntary activities grouped together under the name of Instinct; and, finally, Intelligence.

The lowest forms of life are completely under law, for their movements seem to be due solely to their organiza- 
tion. They are automatons, or creatures of necessity. Such, also, are some actions in the higher animals, as breathing, the beating of the heart, the contractions of the iris, and all the first movements of an infant. ${ }^{108}$ But, generally, the actions of animals are not the result of mere bodily organization.

The inferior orders are under the control of Instinct, i. e., an apparently untanght ability to perform actions which are useful to the mimal. ${ }^{109}$ They seem to be born with a measure of knowledge and skill (as Man is said to have innate ideas), accuired neither by reason nor experiment. For what could have led Bees to imagine that by feeding a worker-larva with royal jelly, instead of beebread, it would tum out a queen, instead of a neuter? In this case, neither the habit nor the experience conld be inherited, for the worker-bees are sterile. We can only guess that the discovery has been communicuted by the survivors of an older swarm. Uniformity is another characteristic feature of instinct. Different individuals of the same species execute precisely the sume movements under like circumstances. The career of one Bee is the career of any other. We do not find one clever and another stupid. Iloney-combs are built now as they were before the Christian era. The creatures of pure instinct appear to be tied down, by the constitution of their nerrous system, to one line of action, from which they can not spontaneonsly depart. The actions vary only as the structure changes. ${ }^{110}$ There is a wonderful fitness in what they do; but there is no intentional adaptation of means to ends.

All animals, from the Star-fish to Man, are gguided more or less by instinct; but the best examples are furnished by the insect-world, especially by the social IIymenopters (Ants, Becs, and Wasps). The Butterfly carefully provides for its youmg, which it is destined never to see; many Insects feed on particular species of plauts, which 
they select with wonderful sagacity; and Monkeys avoid poisonous berries; Bees and Squirrels store up food for the future; Bees, Wasps, and Spiders construct with marvelous precision; and the subterranean chambers of Ants and the dikes of the Beaver show engineering skill; while Salmon go from the ocean up the rivers to spawn; and Birds of the temperate zones migrate with great regularity.

But in the midst of this antomatism there are the glimmerings of intelligence and free-will. We see some evidence of choice and of designed adaptation. Pure instinct should be infallible. Yet we notice mistakes that remind us of mental aberrations. Bees are not so economical as has been generally supposed. A mathematician can make five cells with less wax than the Bee uses for four; while the IIumble-bee uses three times as much material as the Inive-bee. An exact hexagonal cell does not exist in nature. Flies lay egros on the carrion-plant becanse it happens to have the odor of putrid meat. The domesticated Bearer will build a dam across its apartment. Birds frequently make mistakes in the construction and location of their nests. In fact, the process of cheating animals relies on the imperfection of instinct. Nor are the actions of the brute creation always perfectly uniform; and so far as animals conform to cireumstances, they act from intelligence, not instinct. There is proof that some animals profit by experience. Birds do learn to make their nests: and the older ones build the best. Trappers know well that young animals are more easily caught than old ones. Bircls brought up from the eger, in eages, do not make the characteristic nests of their species; nor do they have the same song peculiar to their species, if they have not heard it. Chimney-swallows certainly built their nests differently in America three hundred years ago. A Bee $c(t)$ make cells of another shape, for it sometimes does; its actions, 
therefore, being elective and conditional, are in a measure the result of calculation.

The mistakes and rariations of instinct are indications that animals have something more - a limited range of that principle of Intelligence so luminous in Man. No precise line can be drawn between instinctive and intelligent acts; all we can say is, there is more freedom of choice in the latter than the former; and that some animals are most instinctive, others most intelligent. Thus, we speak of the instinct of the Ant, Bee, and Bearer, and the intelligence of the Elephant, Dog, and Monkey. Instinct loses its peculiar character as intelligence becomes developed. Ascending from the Worm and Oyster to the Bee, we see the movements become more complex in character and more special in their objects; but instinct is supreme. Still ascending, we observe a gradual fading-away of the instincts, till they become subordinate to higher faculties - will and reason. We can predict with considerable certainty the actions of animals guided by pure instinct; but in proportion as they possess the power of adapting means to ends, the more variable their actions. Thus, the architecture of Birds is not so uniform as that of Insects.

We must credit brutes with a certain amount of observation and imitation, curiosity and cumning, memory and reason. Animals have been seen to pause, deliberate, or experiment, and resolve. The Elephant and Horse, Dog. and Monkey, particularly, participate in the rational nature of Man, up to a certain point. Thinking begins wherever there is an intentional adaptation of means to ends; for that involves the comparison and combination of ideas. Animals have self-conscionsness: a Cat never mistakes another Cat for itself. They interchange ideas: the whine of a Dog at the door on a cold night certainly implies that he wants to be let in. Even Bees and Ants, it is well 
known, confer by passing their antenna. All the higher animals, too, have similar emotions, as joy, fear, love, and anger.

While instinct culminates in Insects, the highest development of intelligence is presented in Man. ${ }^{11}$ In Man only does instinct cease to be the eontrolling power. IIe stands alone in having the whole of his organization conformed to the demands of his brain; and his intelligent acts are characterized by the capacity for mlimited progress. The brutes can be improred by domestication; but, left to themselves, they soon relapse into their original wildness. Civilized Man also goes back to savagery; yet Man (though not all Men) has the ambition to exalt his mental and moral nature. Ile has a soul, or conscious relation to the Infinite, which leads him to aspire after a lofty ideal. Only he ean form abstract ideas. And, final$\mathrm{ly}$, he is a completely self-determining agent, with a prominent will and conscience-the highest attribute of the animal creation. In all this, Man differs profoundly from the lower forms of life.

\section{The Voices of Animals.}

Aquatic animals are mute. ${ }^{112}$ A world of Radiates, Mollusks, and Fishes, therefore, would be silent. Insects are about the only Invertebrates capable of producing sounds. Their organs are usually extermal, while those of higher animals are internal. Insects of rapid flight generally make the most noise. In some the noise is produced by friction (stridulation); in others, by the passage of air through the spiracles (humming). The shrill notes of Crickets and Grasshoppers are prodnced by rubbing the wings against each other, or against the thighs; but the Cicacla, or IIarrest-fly, has a special apparatus-a tense membrane on the abdomen, acted upon by muscles. The buzzing of Flies and humming of Bees are caused, in 
part, by the vibrations of the wings; but the true roice of these Insects comes from the spiracles of the thorax.

Snakes and Lizards have no rocal cords, and can only hiss. Frogs croak, ${ }^{113}$ and Crocodiles roar, by the vibration of the glottis. The huge Tortoise of the Galapagos Islands utter's a hoarse, bellowing noise.

The vocal apparatus in Birds is situated at the lower end of the trachea, where it divides into the two bronchi. ${ }^{14}$ It consists mainly of a bony drum, with a crossbone, having a rertical membrane attached to its upper edge. The membrane is put in motion by currents of air passing on either side of it. Five pairs of muscles (in the Sungsters) adjust the length of the windpipe to the pitch of the glottis. The various notes are produced by differences in the blast of air, as well as by changes in the tension of the membranc. The range of notes is commonly within an octare. Birds of the same family have a similar roice. All the Parrots have a harsh ntterance; Geese and Ducks quack; Crows, Nagpies, and Jays caw; while the Wrablers differ in the quality, rather than the kind, of note. ${ }^{115}$ The Parrot and Mocking-bird use the tongne in imitating human somnds. Some species possess great compass of voice. The Bell-bird can be heard nearly three miles; and Livingstone said he could distinguish the voices of the Ostrich and the Lion only by knowing that the former roars by day, and the latter by night.

The rocal organ of Mammals, mnlike that of Birds, is in the upuer part of the larynx. It consists of four cartilages, of which the largest (the thyroid) produces the prominence in the human throat known as "Adam's apple," and two elastic bands, called "vocal cords," just below the glottis, or upper opening of the windpipe. The various tones are determined by the tension of these cords, which is effected by the raising or lowering of the thyroid prominence. The will can not inthence the con- 
traction of the vocalizing muscles, except in the very act of rocalization. The rocal somels produced by Mammals may be distinguished into the ordinary roice, the ery, and the song. The second is the sound made by brutes. The Whale, Porpoise, Armadillo, Ant-eater, Porcupine, and Giraffe are generally silent. The Bat's voice is probably the shrillest sound andible to human ears. There is little modulation in brute utterance. The Opossum purrs, the Sloth and Kangaroo moan, the IIog grunts or squeals, the Tapir whistles, the Stag bellows, and the Eleplant gives a hoarse trumpet somed from its trumk and a deep groan from its throat. All sheep have a guttural voice; all the Cows low, from the Bison to

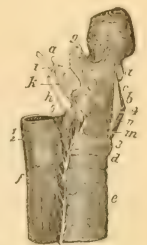

Fit: 15:,-IItuman Larynx, seen in protile: ", half of the hroid bone: $e$, tratcheis: $f$, esophacte; ; $g$, epiglot. tis. the Musk-ox; all the IIorses and Donkeys neigh; all the Cats miau, from the domestic animal to the Lion; all the Bears growl; and all the Canine family-Fox, Wolf, and Dog-bark or howl. The Howling-monkeys and Gorillas have a large carity, or sac, in the throat for resonance, cnabling them to utter a powerful roice; and one of the Gibbon-apes has the remarkable power of emitting a complete octare of musical notes. The human voice, taking the male and female together, has a range of nearly four octares. Mran's power of speech, or the utterance of articulate sounds, is due to his intellectual development rather than to any structural difference between him and the Apes. Song is produced by the glottis, speech by the mouth. 


\section{CHAPTER XIX.}

\section{REPRODUCTION.}

IT is a fundamental truth that every living organism las had its origin in some pre-existing organism. The doctrine of "spontaneous generation," or the supposed origination of organized structures out of inorganic parti. cles, has not yet been sustained by facts.

All animals, without exception, arise from eggrs. But while reproduction by eggs is common to all, it is only one

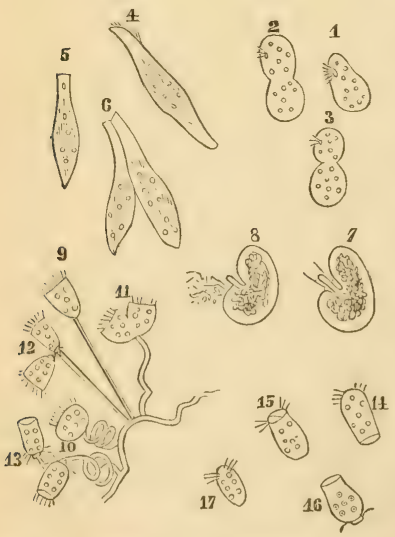

Frg. 156,-Reproduction of Infusoria (Vorticel$l a)$ by fission or self-division. among several modes of multiplication. For the lowest forms of life not only generate by eggs, but also by self-division and budding. ${ }^{316}$

Self - division, the simplest mode possible, is a natural breaking-up of the body into distinct surviving parts. This process is sometimes extraordinarily rapid, the increase of one animalcule (Paramecium) being computed at 268 millions in a month. It is most common in the Infusoria; but is occasionally exhibited even by the aquatic and intestinal worms.

Budding consists, in animals as in plants, in the growth 
of buds, generally from the exterior of the body, possessing all the essential parts of the parent stock. The buds may develop into individuals complete, but not distinct, forming, with others like itself, a compound animal, as the Coral; or the buds may become detached, giving rise to perfect independent individuals, as the IIydra (Fig. 186). The latter mode elosely resembles self-division. Rarely, as in the $\Lambda_{1}$ his, those little green insects cansing "blight," the budding is internal, and so rapid that the tenth generation would number one quintillion. Budding in the higher animals prodnces monstrosities, as doubleheads, double-thumbs, etc.

Generation by Eggs is accomplished by the mion of two dissimilar cells-a germ-cell, or orum; and a spermcell; the embryo being evolved from the former. ${ }^{117}$ An egg, which is the product of this union, is the lowest possible condition of animal life. It is a globular mixture of albumen and oil. A freshly laid Hen's egg, boiled hard, well exhibits the general structure. The outside shell consists of earthy matter (lime) deposited in a net-work of animal matter. It is minutely porous, to allow the passage of rapor and air to and fro. Lining the shell

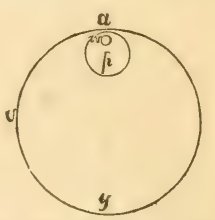

Fic. 15i.-Theoretical Egg, or ('ell: $i$, vitelline memorame; , oleaginus pole; $a$, albuminous pole; $p$, Purkinjean, or germinal, vesicle: "r, Warueriau, or germiual, dot. is a donble membrane (membrance putaminis) resembling delicate tissue-paper. At the larger end, it separates to inclose a bubble of air for the use of the chick. Next comes the albumen, or "white," in spirally arranged layers, within which floats the yolk. The yolk is prevented from moring toward either end of the egg by two twisted cords of albumen, called chuluzce; $;^{118}$ yet is allowed to rise toward one side, the yolk being lighter than the albumen. The yolk is composed of oily granules (about $\frac{1}{2} \sigma \sigma$ of an 
incl in diameter), inclosed in a sac, called the vitelline membrane, and disposed in concentric layers, like a set of vases placed one within the other. 'That part of the yolk which extends from the centre to a white spot (cicutricula) on the ontside can not be hardened, even with the most prolonged boiling. The cicatricula, or embryo-spot -the part for which all the rest was made-is a thin disk of cellular structure, in which the new life first appears. It is always on that side which naturally turns uppermost,

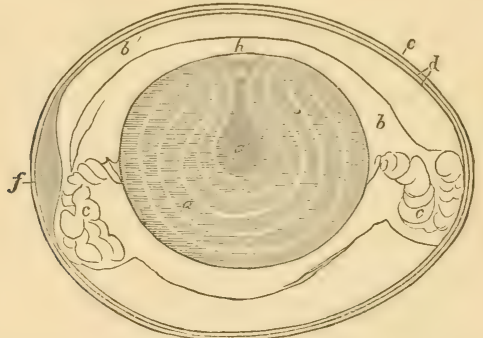

Fra. 15s.-Longitudinal section of Inen's Eirg before incubation: a, yolk, showing concentric layers: $a^{\prime}$, its semi-fluid centre, consisting of a white granular substance-the whole yolk is inclosed in the vitelline membrane; $b$, inuer dense part of the albumen; $b^{\prime}$, outer, thinner part ; $c$, the chalazæ, or albumen, twisted by the revolutions of the yolk; $d$, double shell-membrane, split at the large end to form the chamber $f ; e$, the shell; $h$, the white spot, or cicatricula, and under it the serminal vesicle of Purkinje, or nucleus, which is afterward ruptured, and becomes invisible.

for the yolk ean turn upon its axis; it is, therefore, always nearest to the external air and to the IIen's bodytwo necessary conditions for its development. There is another reason for this polarity of the egg: the lighter and most delicate part of the yolk, the cicatricula, is collected where the upper eavity of the animal, inclosing the nervous system, is to be; while the heavy oily portion remains beneath, where the lower eavity, inclosing the organs of nutrition, is afterward dereloped.

The essential parts of any egg are the germ-cell, or cic- 
atrienla, rolk, and vitelline membrane. The shell and albumen are often wanting. When the allumen is present, it is commonly covered by a membrane only, as in

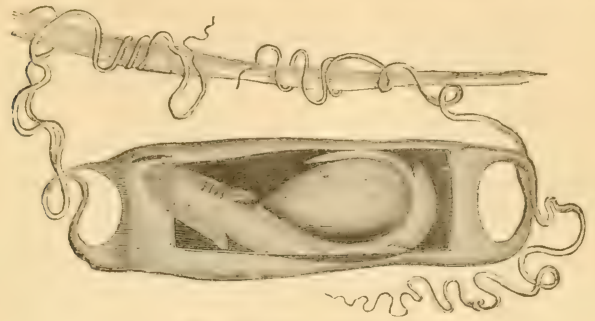

FiG. 159.-Egg of a Shark.

Frogs; in Sharks, the envelope is horny; and in Crocodiles it is calcareous, as in Birds.

The egres of all animals, in their essentials, are alike in kind, but not in degree. The eng of the Amoloa is a mere cell, with a liylet spont in one part of the contents. The egge of the IIydra differs in having this light spot sharply defined, and inclosed in a sac; or germimul resicle. In the Rablit's eng, there is another sac, called yerminal dot, inside the germinal vesicle; while the egros of most of the higher animals show a nucleolus within the germinal dot. An egres, therefore, closely resmbles a cell, consisting of an onter and an imner sac and a dot, or a series of hollow concentric spheres.

The size of an egg depends mainly upon the quantity of rolk it contains; and this is proportioned to the rrade of development which the embryo attains when it leaves the exrer. ${ }^{100}$ In the exors of the Star-fishes. Worms, Insects, Mollusks (except the Cuttle-fishes), and Mammals, the yolk is very minute and formative, $i$.e, it is converted into the parts of the future embryo. In the egges of Lobsters, Crabs, Spiders, Cephalopods, Fishes, Reptiles, and IBirls, 
the yolk is large and colored, and consists of two partsthe formative, or germ-yolk, immediately surrounding the germinal resicle; and the nutritive, or food-yolk, constituting the greater part of the mass, by which the young animal in the egg-life is nourished. In the latter case, the young come forth more mature than where the food-yolk is wanting.

$\Lambda$ s to form, eggs are oral or elliptical, as in Birds and Crocodiles; spherical, as in Turtles and Wasps; cylindrical, as in Bees and Flies; or shaped like a hand-barrow, with tendrils on the corners, as in the Shark. The eggs of some very low forms are sculptured or corered with hairs or prickles.

The number of eggs varies greatly in different animals, as it is in proportion to the risks during development. Thus, the eggs of aquatic tribes, being unprotected by the parent, and being largely consumed by many animals, are multiplied to prerent extinction. The spawn of a single Cod contains millions of eggs; that of the Oyster, 300,000 . A Queen-bee, during the five years of her existence, lays about a million eggs.

Egggs are laid one by one, as by Birds; or in clusters, as by Frogs, Fishes, and most Invertebrates. The spawn of the Sea-snails consists of rast numbers of eggs adhering together in masses, or in sacs, forming long strings.

As a rule, the higher the rank, the more care animals take of their eggs and their young, and the higher the temperature needed for egg-development. In the majority of cases, eggs are left to themselves. The fresh-water Mussel-shell (Unio) carries them between its gills, and the Lobster under its tail. The eggs of many Spiders are enreloped in a silken cocoon, which the mother guards with jealous care. Insects, as Flies and Moths, deposit their eggs where the larva, as soon as born, can procure its own food. Most Fishes allow their spawn, or roe, to 
float in the water; but a few build a kind of flat nest in the sand or mud, hovering over the exgs until they are hatched; while the Acari of the Amazons carries them in its mouth. The Amphibians, generally, envelop theix eggs in a gelatinous mass, which they leave to the elements; but the female of the Suriuam Toad carries hers on her back, where they are placed by the male. The great Amazon-Turtles lay their eggs in holes two feet deep in the sand; while the Alligators simply cover theirs with a few leaves and sticks. Nearly all Birds build nests, those of the Perchers being most elaborate, as their chicks are dependent for a time on the parent. ${ }^{120}$ The young of Marsupials, as the Kangaroo, which are born in an extremely immature state, are nourished in a pouch ontside of the body. ${ }^{121}$ But the embryo of all other Mammals is developed within the parent to a more perfect condition by means of a special organ, the plucenta. It is a general law, that animals receiving in the embryo state the longest and most constant parental care ultimately attain the highest grade of development.

\section{CHAPTER XX.}

\section{DEYELOPMENT.}

Development is the evolution of a germ into a complete organism. The study of the changes within the exw (onstitutes the science of Embryology; the transformations after the egro-life are called metamorphoses, and include growth and repair.

The process of development is a passage from the general to the special, from the simple to tho complex, from the homogeneuns to the heterogreneous, by a series of dif- 
ferentiations. It brings ont first the profounder distinetions, and afterward those more external. That is, the most essential parts appear first; $c . g$. the nerrous system and skeleton precede the digestive apparatus. And not only does derelopment tend to make the sereral organs of an individual more distinct from one another, but also the individual itself more distinguished from other individuals and from the medium in which it lives. With adrancing development, the animal, as a rule, accuires a more specific, definite form, gains the ability of maintaining a temperature of its own, and increases in weight and locomotive power. Life is a tendency to individuality.

Development of a Hen's Egg. - The first change is the segmentation of the formative part of the yolk (germyolk) by a process of self-division. It separates into two spheres, which subdiride into four more, and so on till the whole is broken up into a myriad of cells. These cells finally arrange themselves into a layer (called blesto-

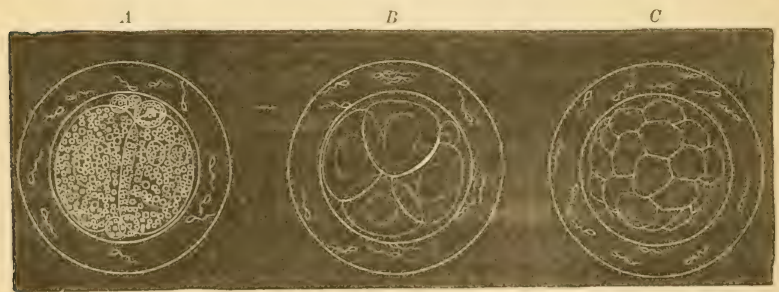

Fro. 160.-First Stages in Segmentation of a Mnmmalian Erry: $A$, first division into halves, with spermatozoa around it; $B$ and $C$, progressive subdivision, ultimately transforming the vitellus, or yolk, into it "mulberry mass" of globules, or enbryo-cells.

derm), lining the vitelline memlrane; and a round lightcolored disk in this layer is the germinal spot, or cientricula, already mentioned. This is the first trace of organization. Soon the germinal disk thickens, and splits into three layers: out of the upper one are ultimately formed 
the instruments of thought, sensation, and motion, or the brain, spinal colnmm, muscles, and skin; in the lower originates the digestive system; while the middle gives rise to the blood and the organs of eirenlation. The next
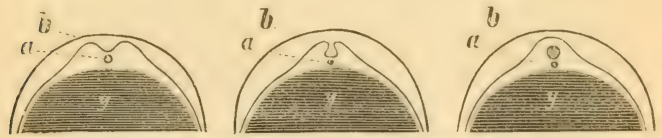

Fra. 161.-Vertical sections of an Eire, showing progres-ive stapes of derelopment: $a$, primitive streak: $b$, the furrow, becoming a closed caual in the last.

phase is the appearance of a faint straight furrow passing through the midlle of the external laver, called the primitive stripe, which corresponds to the axis of the future body. ${ }^{122}$ The walls of the furrow gradually rise, and at last meet, forming a canal, larger at one end than the other, which is filled with a fluid-the beginning of the brain and spinal marrow. Beneath the furrow, a delicate cartilaginous thread appears (called notochord)-the representative of the backbone. At the same time, the margin of the germ extends farther and farther orer the yolk, till it completely incloses it. So that now we see two cavities - a small one, containing the nerrous system; and a larger one below, for the digestive organs. Presently, numerous rows of dark-yellow corpuscles are seen on the middle layer, which are subsequently inclosed, forming a network of capillaries,

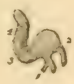

Fig. 162.-Rudimentary IIearts, human: 1, venots trunks; 2, auricle; 3 , ventricle; 4, bulbus arteriosus.

called the rascular area. A dark spot indicates the situation of the heart, which is the first distinctly bounded carity of the cireulatory system. It is a short tube lying iengthwise just behind the head, with a feeble pulsation, 
causing the blood to flow backward and forward. The tube is gradually bent together, mutil it forms a double carity, resembling the heart of a Fish. On the fourth day of incubation, partitions begin to grow, dividing the cavities into the right and left auricles and rentricles.
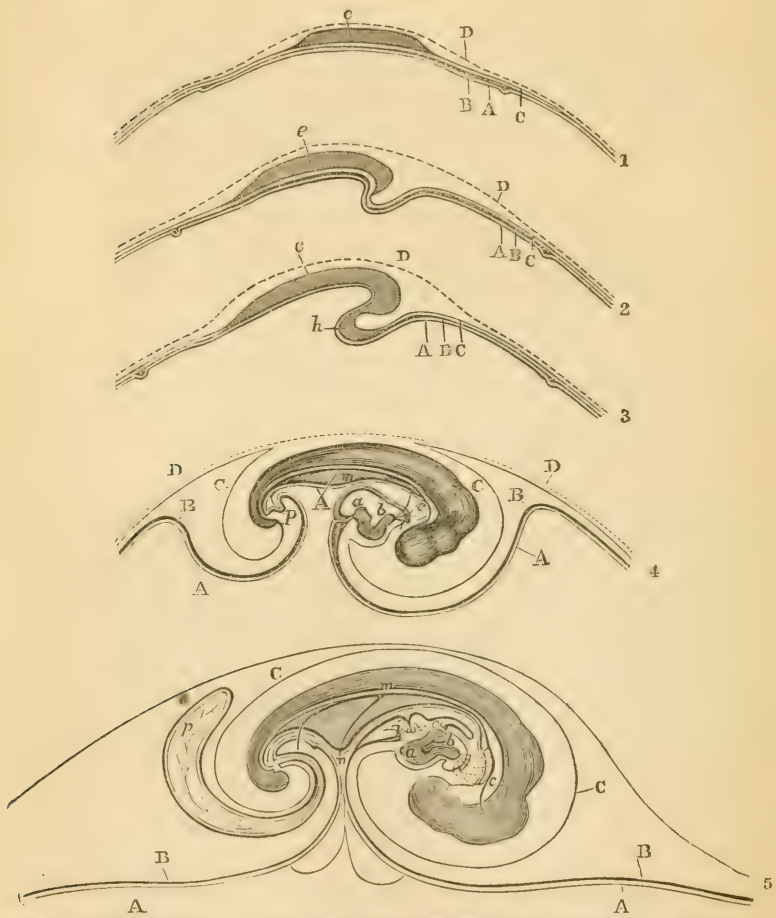

Figs. 1fin-167.-Embryo in a Iren's Egg durius the first five days: $\Lambda$, mucous layer; $\mathrm{B}$, vascular layer; C, blastoderm, or serous membrane, in the last figure forming the amniotic sac: $\mathrm{D}$, vitelline membrane; $c$; thickened blastoderm, the first rudiment of the dorsal part (in the last figmre it marks the place of the lungs); $h$, heart: $a, b$, its two chambers: o brauchial arteries; $m$, aorta; $i$, liver; $p$, allantois. 
The septum between the auricles is the last to be finish. ed; being elosed the moment respiration begins. The

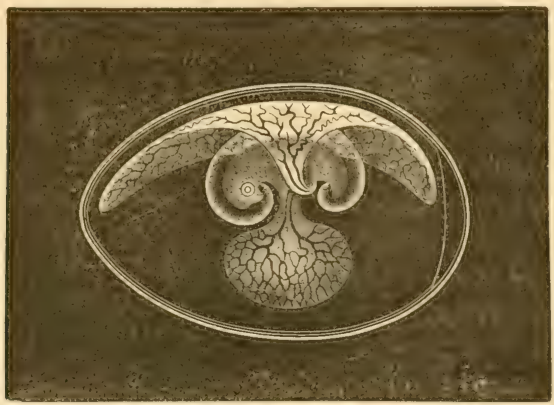

Frg. 16s,-Hen's Era, more hichly developed. The embryo is enveloped by the amnion, and has the umbilical vesicle, or remunt of the yolk, hanging from its under surface; while the allantois turus upward, and spreats out over the internal surface of the shell-membrane. (From Dalton's "Physiology.")

blood-ressels ramify in all directions through the yolk, making it a spongy mass, and all perform the same oftice: it is not till the fourth or fifth day that arteries can be distinguished from veins, by being thicker and by carrying blood only from the lieart. ${ }^{123}$

The embryo lies with its face, or ventral surface, toward the yolk, the head and tail curving toward each other. 1 delicate transirarent membrane (a prart of the upper layer of the blastoderm) rises like a hood orer

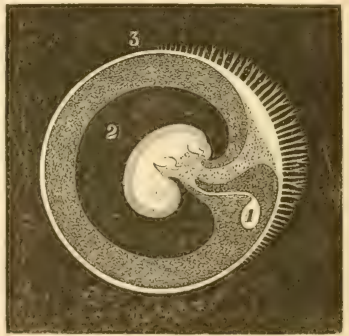

Fiti. 16:- Mammalian Entryn, with atlantois fully formed: 1, umbilical resicle, continining the list of the yolk: :, amnion; 3 , allantois, on which the fringes of the pliacentat are developing. (From Dalton's "Pliysiology.") the back of the embryo till it forms a closed sace called the amnion. It is tilled with a thin lipuid, which serves 
to protect the embryo. Meanwhile, another important organ is forming on the other side. A portion of the lower, or internal, blastodermic layer elongates downward, and then upward, spreading ont orer the whole inner surface of the shell, so that it surrounds both embryo and amnion. This is the cllcuntois. It is full of blood-ressels, and it serres as the respiratory organ until the chick picks the shell and breathes by its lungs. ${ }^{124}$ The churion is the outermost part of the allantois-in other words, the envelope of the orum; and the plucenta of Mammals is the shaggy, vascular edge of the chorion.

The alimentary canal is at first a straight tube closed at both ends, the middle being connected with the yolk-bag. As it grows faster than the body, it is thrown into a spiral coil; and at several points it dilates, to form the crop, stomach, gizzard, etc. The mouth is dereloped from an infolding of the skin. The liver is an outgrowth from the digestive tube, at first a cluster of cells, then of follicles, and finally a true gland. The lungs are dereloped on the third day as minute buds from the upper part of the alimentary canal, or pharynx. As they grow in size, they pass from a smooth to a cellular condition.

The skeleton at the beginning consists, like the notochord, of a gelatinons material, which gradually becomes condensed and cellular, turning to cartilage. Then minute canals containing blood-ressels arise, and earthy matter (chiefly phosphate of lime) is deposited between the cells. The primary bone thus formed is compact: true osseons tissue, with canaliculi, lamina, and Haversian canals, is the result of subsequent absorption. ${ }^{125}$ Certain bones, as those of the face and craninm, are not preceded by cartilage, but by comnectire tissue: these are called membrane bones. Ossification, or bone-making, begins at numerons distinct points, called centres; and, theoretical$1 y$, every centre stands for a bone, so that there are as 
many bones in a skeleton as centres of ossification. But the actual number in the adult animal is much smaller, as many of the centres coalesce. ${ }^{126}$ The derelopment of the backibone (ats, in fact, the growth of the whole ehick) is not from the head or from the tail, but from a central point midway between: there the first rertebra appear, and from thence they multiply forward and backward.

The limbs appear as buds on the sides of the body; these lengthen and expand so as to resemble paddlesthe wings and legs looking precisely alike; and, finally, they are divided each into three segments, the last one subdividing into digits. The feathers are dereloped from the outside cells of the epidermis: first, a horny cone is formed, which elongates and spreads out into a vane, and this splits up into barbs and barbules.

The muscles are formed either by the grorth in length of a single cell, or by the coalescence of a row of cells: the cell-wall thus produces a long tube-the sarcolemma of a fibre, and the gramular contents arrange themselves into linear series, to make fibrillæ. ${ }^{127}$

Nerrons tissue is derived from the multiplication and union of embryo-cells. The white fibres at first resemble the gray. The brain and spinal marrow are developed from the primitive stripe - that pale-white line on the cicatricula, which almost from the beginning is conical, foreshadowing head and tail. Soon the brain, by two constrictions, divides into fore-brain, mid-brain, and hindbrain. The fore-brain throws out two lateral hemispheres (cerebrum), and from these protrude forward the two olfactory lobes. From the middle-brain grow the optic lobes; and the hind-brain, afterward separated into cerebellum and medulla oblongata, is the origin of the earsacs,

Modes of Development.-The structure and embryology of a IIen's egge exhibit many facts which are conn. 
mon to all animals. But every grand division of the Ani. mal Kingdom has its characteristic method of dereloping.

Protozoans differ from all higher forms in not undergoing segmentation.

The egrg of the Sea-anemone, after segmentation, becomes a solid pear-shaped body, covered with cilia. Suon one end is indented; then the indentation deepens until it becomes a cavity, and the elge rolls inward till it extends half-way to the bottom. Little ridges are then seen in the interior, which finally become so many partition-walls; while minute protuberances around the opening, or month, are the begimnings of the tentacles. There is 110 distinc-
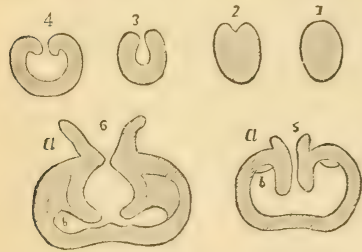

Fir. 1711.- Development of Sea-anemone, slichtly malnified: 1 , first stage after seermentation; 2 , shows the beginumg of the dimestive cavity: 6 , its completiou; $a$, teutacles; $b$, partitions.

tion into nerrons and digestive regions. The egg of the Oyster divides in two, as if to form two individuals, but soon two triangular disks appear, the rudiments of shells, and the two pulsating sac's are fused together into one heart. Then the embryo revolves in the $\mathrm{egg}$, and beconing fringed with cilia, it quits the egrg, and closes the valves, which were wide open. The embryo of an Insect shows from the first a right and left side; but the first indication that it is an Articnlate is the derelopment of a series of indentations dividing the body into successive rings, or joints. Next, we obserre that the back lies near the centre of the egrg, the rentral side looking ontward; i.e., the embryo is doubled upon itself backward. And, finally, the appearance of three pairs of legs proves that it will be an Insect, rather than a Worm, Crustacean, or Spider.

The Vertebrate embryo lies with its stomach toward 
the rolk, reversing the position of the Articnlate; but the grand characteristic is the primitive stripe, which is nearly confined to the eggs of Vertebrates. This is comnected with another, the setting apart of two distinct regionsthe nervous and nutritive. There are three modifications of Tertebrate development: that of Fishes and Amphibians, that of True Rieptiles and Birds, and that of MIammals. The annion and allantois are wanting in the aquatic Vertebrates; while the placenta (which is the allantois vitally connected with the parent) is peculiar to Mammals. In Mammals, the whole yolk is segmented; in Lirds, segmentation is confined to the small white speck seen in opening the shell.

At the ontset, all animals, from the Sponge to Man, are indistinguishable from one another. They are mainly drops of fluid, a little more transparent on one side than the other; and, in all cases, this almost homogeneons globule must derelop three well-defined parts - a germinal dot, germinal vesicle, and yolk. But while Vertebrates and Invertelurates ean trarel together on the same road up to this point, here they diverge-nerer to meet again. For every grand group early shows that it has a peculiar type of construction. Every egrg is from the first impressed with the power of dereloping in one direction only, and never does it lose its fundamental characters. The germ of the Bee is divided into secments, showing that it belongs to the Articulates; the germ of the Lion has the primitive stripe--the mark of the coming Vertebrate. The blastodermic layer of the Vertebrate egur rolls up into two tubes-one to hold the viscera, the other to contain the nerrous cord; while that of the Invertebrate egg forms only one such tubular division. The features which determine the subkingdom to which an animal belongs are first developed, then the characters revealing its class.

There are differences also in grade of derelopment as 
well as type. For a time there is no essential difference between a Fish and a Mammal: they have the same nervous, circulatory, and digestive systems. The first departure is the alteration of the heart of the Mammal, giving it four cavities; while the heart of the Fish remains in its rudimentary condition. We may call this arrested derelopment. There are many such eases, in which the embryo of an animal represents the permanent adult condition of some lower form. In other words, the higher species, in the course of their development, offer likenesses, or analogies, to finished lower species. The human germ, at first, can not be distinguished from that of any other animal: for aught we cau see, it may turn out a Frog or a Philosopher. The appearance of a primitive stripe excludes it at once from all Invertebrates. For a time, it assumes a structure seen only in the Fish, and then another, found only in Mammals. Later still, it is not unlike the embryos of the Ox, Dng, and Monkey suecessively; then it looks like any other infant, and finally it acquires the peculiarities of the race to which it belongs. ${ }^{128}$ All the meinbers of a gromp, therefore, do not reach the same degree of perfection, some remaining in what corresponds to the immature stages of the higher animals. Such may be called permanently embryonic forms.

Sometimes an embryo derelops an organ in a rudimentary condition, which is lost or useless in the adult. Thus, the Greenland Whale, when grown up, has not a tooth in its head, while in the embryo life it has teeth in both jars; unborn Calves have canines and upper incisors; and the female Dugong has tusks which nerer eut the gum. The "splint-bones" in the IIor'se's foot are unfinished metatarsals.

Animals differ widely in the degree of derelopment reached at ovulation and at birth. The eggs of Frogs 
are laid before they can hardly be said to have become fully formed as egrgs. The eggs of Birds are laid when there is scarcely a trace within them of the germinal spot; while the eggs of Mammals are retained by the parent till after the egg-stage is passed. ${ }^{129}$ Rimminants and terrestrial Birds are born with the power of sight and locomotion. Most Carnirores, Rodents, and perching Birds come into the world blind and helpless; while the human infant is dependent for a much longer time.

\section{Metamorphosis.}

Few animals come forth from the egg in perfect condition. The rast majority pass through a great variety of forms before reaching maturity. These metamorphoses (which are merely periods of growth) are not peculiar to Insects, though more apparent in them. Man himself is developed on the same general principles as the Butterfly, but the transformations are concealed from view. The Coral, when hatched, has six pairs of partitions; afterward, the spaces are dirided by six more pairs; then twelve intermediate pairs are introduced; next, twentyfour, and so on. The embryonic Star-fish has a long body, with six arms on a side, from one end of which the young Star-fish is apparently budded off. Soon the twelve-armed body dies, and the young animal is of age. Worms are continually growing by the addition of new segments. Nearly all Insects undergo complete metamorphosis, i.e., exhibit four distinct stages of existence-egg, larra, pupa, and imago. The worm-like larra ${ }^{130}$ may be called a locomotive-egg. It has little resemblance to the parent in structure or habits, eating and growing rapidly. Then it enters the pupa state, wrapping itself in a cocoon, or ease, and remaining apparently dead till new organs are developed; when it escapes a perfect winged Insect, or imago. ${ }^{131}$ Wings never exist in the larra; and Insects 
which undergo no apparent metamorphosis, as Lice, are wingless. The Grasshopper develops from the young lar-

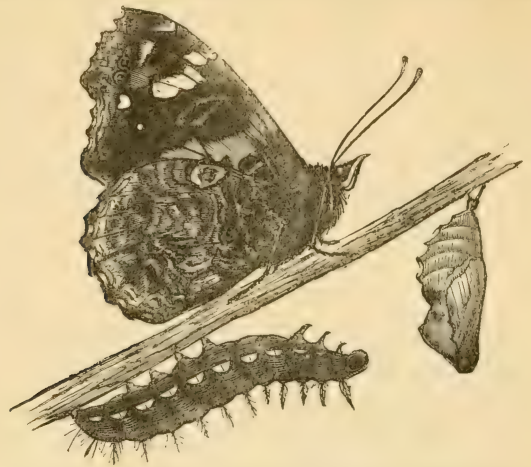

FIG. 171.-Butterfly in the Imago, Pupa, and Larva States.

va to the winged adult without changing its mode of life: the worm-like stage is passed within the egrg. In the de-

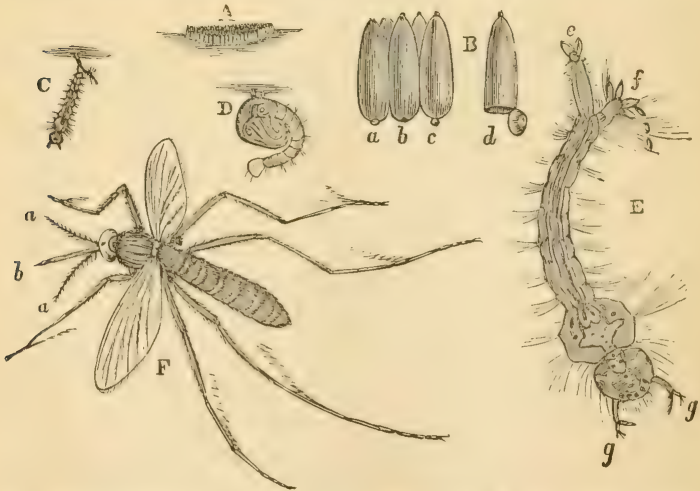

Fig. 172.-Metamorphosis of the Mosquito (Culex pijuens): $\Lambda$, boat of egcs: $B$, some of the eggs highly magnitied, $d$, with lid open for the escape of the larva, C; $\mathbf{D}$, pupa; E, larva maænitied, showing respiratory tube, $e$, anal fins, $f$, anteunx, $g$; $\mathrm{F}$, imago; $a$, anteunx; $b$, bcak. 
velopment of the common Crab, so different is the ontward form of the newly hatched embryo from that of the adult, that the former has been described as a distinct species.

The most remarkable example of metamorphosis among Vertebrates is furnished by the Amphibians. A Tadpole -the larva of the Frog-lias a tail, but no legs; sills, instead of lungs; a heart precisely like that of the Fish; a horny beak for eating regetable food, and a spiral intes-

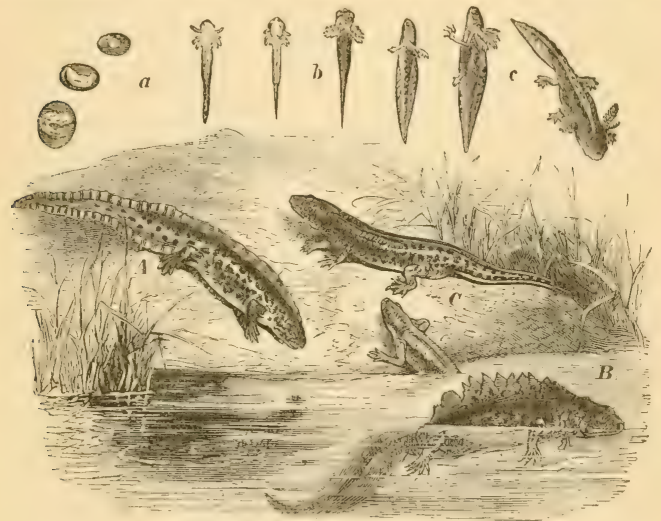

Ftg. 173.-Metamorphosis of the Newt.

tine to digest it. As it matures, the hinder legs show themselves, then the front pair; the beak falls off; the tail and gills waste away; lumgs are created; the digestive apparatus is changed to suit an animal diet; the heart is altered to the Reptilian type by the addition of another anricle; in fact, skin, muscles, nerres, bones, and blood. ressels ranish, being absorbed atom by atom, and a new set is substituted. Moulting, or the periodical renewal of epiclermal parts, as the shell of the Lobster, the skin of the Toad, the scales of Snalies, the feathers of Lirds, and 
the hair of Mammals, niay be termed a metamorphosis. 'The change from milk-teeth to a permanent set is another' example.

An animal rises in organization as development advances. Thus, a Caterpillar's life has nothing nobler about it than the ability to eat, while the Butterfly expends the power garnered up by the larva in a gay anci busy life. But there are seeming reversals of this law. Some mature animals appear lower in the scale than therr young. The larval Cirripede has a pair of magnificent compound eyes and complex antenne; when adult, the antennæe are gone, and the eyes are rednced to a single, simple minute eye-spot. So the germs of the sedentary Sponge and Oyster are free and actire. The adult ani. mal, however, is always superior in alone possessing the power of reproduction.

\section{Alternate Generation.}

Sometimes a metamorphosis extending orer several generations is required to evolve the perfect animal ; "in other words, the parent finds no resemblance to himself in any of his progeny, until he comes dorm to the greatgrandson." Thus, the Jelly-fish, or Medusa, lays egges which are hatched into larre rescmbling Infusoria-little transparent oral bodies eorered with cilia, by which they swim about for a time till they find a resting-place. One of them, for example, becoming fixed, derelops rapidly; it elongates and spreads at the upper end; a month is formed opening into a digestive eavity; and tentacles multiply till the mouth is surrounded by them. At this stage it resembles a IIydra. Then slight wrinkles appear along the body, which grow deeper and deeper, till the animal looks like "a pine-cone surmounted by a tuft of tentacles;" and then like a pile of sancers (about a dozen in number) with scalloped edges. Next, the pile breaks 
up into separate segments, which are, in fact, so many dis. sinct animals; and each turning over as it is set free, so as to bring the mouth below, develops into an adult Merusa, becoming more and more convex, and furnished with tentacles, circular canals, and other organs exactly like those of the progenitor that laid the original egg.

Here we see a Medusa producing eggs which develop) into Infusoria-like larva, and these grow into stationary

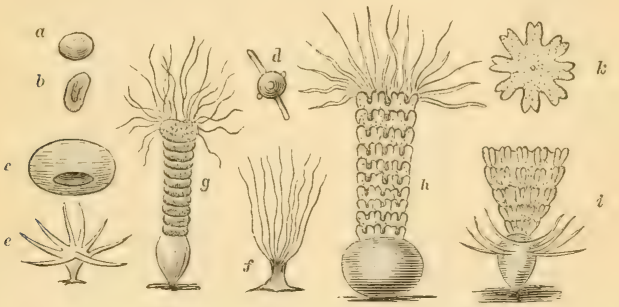

Frg. 174,-Alternate Generatiou: $a, b, c$, ova of an Acaleph (Chryscora); $d, e, f, \mathrm{H} y$ dras: $a, h$, Hydras with constrictions; $i$, Hydra undergoing tission; $k$, one of the separated segments, a free Medusa.

forms resembling Hydras. The IIydras then produce not only Medusa by budding in the manner described, but also other Hydras like themselves by budding and by egras. All these intermediate forms are transient states of the Jelly-fish; but the metamorphoses can not be said to occur in the same individual. While a Caterpillar becomes a Butterfly, this Mydra-like individual produces a number of Medusa. Alternate generation is almost confined to the low Radiates (Fig. 190).

\section{Growth and Repair.}

Growth is increase of bulk, as Development is increase of structure. It occur's whenever the process of repair exceeds that of waste, or when new material is added faster than the tissues are destroyed. There is a specific 
limit of growth for all animals, although many of the low cold-blooded forms, as the Trout and Anaconda, seem to grow as long as they live. After the body has attained its maturity, i.e., has fully dereloped, the tissues cease to grow; and nutrition is concerned solely in supplying the constant waste, in order to preserve the size and shape of the organs. A child eats to grow and repair; the adult eats only to repair. ${ }^{132}$ Birds develop rapidly, and so speud most of their life full-fledged; while Insects generilly, Fishes, Reptiles, and Manmals mature at a comparatively greater age. The perfect Insect rarely changes its size, and takes but little food; eating and growing are almost confined to larval life. The crust of the Sea-urchin, which is never shed, grows by the addition of matter to the margins of the plates. The shell of the Oyster is enlarged by the deposition of new lamina, each extending beyond the other. At every enlargement, the interior is lined with a new nacreous layer; so that the number of such layers in the oldest part of the shell indicates the number of enlargements. When the shell has reached its full size, new layers are added to the inner surface only, which increases the thickuess. It is the margin of the mantle which provides for the increase in length and breadth; while the thickness is derived from the whole surface. The edges of the concentric lamine are the "lines of growth." The Oyster is full-grown in about five years. The bones of Fishes and Reptiles are continually growing; the long bones of higher animals increase in length so long as the ends (epiphyses) are separate from the shaft. The limbs of Man, after birth, grow more rapidly than the trunk.

The power of regenerating lost parts is greatest where the organization is lowest, and while the animal is in the young or larval state. It is really a process of budding. The head of the IIydra, if separated, will reproduce a 
body and tail; if the tail is cut off, it will add a body and head. Certain Worms may be cut into several pieces, and each part will regain what is needed to complete the mangled organism. The Star-fish can reproduce its arms: the IIolothuria, its stomach; the Snail, its tentacles; the Lobster, its claws; the Spider, its legs; the Fish, its fins; and the Lizard, its tail. Nature makes no mistake by putting on a leg where a tail belongs, or joining an immatmre limb to an adult animal. ${ }^{13}$ In Birds and Mammals, the power is limited to the reproduction of certain tissues, as shown in the healing of wounds. Very rarely an entire human bone, removed by disease or surgery, has been restored. The nails and hair continue to grow in extreme old age.

\section{Likeness and Variation.}

It is a great law of reproduction that all animals tend to resemble their parents. A member of one class never produces a member of another class. The likeness is very accurate as to general structure and form. But it does not descend to every individnal feature and trait. In other wrords, the tendency to repetition is qualified by a tendency to rariation. Like produces like, but not exactly. The similarity never amounts to identity. So that we have two opposing forces-the hereditary tendency to copy the original stock, and a distinct tendency to deviate from it.

This is one of the most miversal facts in nature. Every derelopment ends in diversity. Every body knows that no two indiriduals of a family, human or brute, are absolntely alike. There are alwars individual differences by which they ean be distinguished. Evidently a parent does not project precisely the same line of influences upon each of its offspring.

This variability makes possible an indetinite modifica- 
tion of the forms of life. For the rariation extends to the whole being, even to every organ and mental characteristic as well as to form and color. It is very slight from generation to generation; but it can be accumulated by choosing from a large number of individuals those which possess any given variation in a marked degree, and breeding from these. Nature does this by the very gradual process of "natural selection ;" Man hastens it, so to speak, by selecting extreme varieties. Hence we have in our day remarkable specimens of Poultry, Cattle, and Dogs, differing widely from the wild races.

Sometimes we notice that children resemble, not their parents, but their grandparents or remoter ancestors. This tendency to revert to an ancestral type is called atuvism. Occasionally stripes appear on the legs and shonlders of the Horse, in imitation of the aboriginal Horse, which was striped like the Zebra. Sheep have a tendency to revert to dark color's.

The laws governing inheritance are unknown. No one can say why one peculiarity is transmitted from father to son, and not another; or why it appears in one member of the family, and not in all. Among the many canses which tend to modify animals after birth, are the quality and quantity of food, amount of temperature and light, pressure of the atmosphere, nature of the soil or water, habits of fellow-animals, etc.

Occasionally animals ocenr, widely different in structure, having a very close external resemblance. Barnacles were long mistaken for Shells, Polyzoans for Polyps, and Lamprey-cels for Worms. Such forms are homomonlic. Members of one group often put on the ontward appearance of allied species in the same locality: this is called mimic" $y$. "They appear like actors or masqueraders dressed up and painted for ammsement, or like swindlers endeavoring to pass themselves off for weil- 
known and respectable members of society." Thus, certain Buttertlies on the Amazons have such a strong odor that the Birds let them alone; and Buttertlies of another family in the same region have been found disguising themselves for protection by assuming the same form and color of wing. So we have bee-like Moths, beetle-like Crickets, wasp-like Flies, and ant-like Spiders; harmless and venomons Suakes copying each other, and Orioles departing from their usual gay coloring to imitate the plumage, flight, and voice of quite another style of Birds. The species which are imitated are much more abundant than those which minic them. There is also a general harmony between the colors of an animal and those of its habitation. We have the white Polar Bear, the sand-colored Camel, and the dusky Twilight-moths. There are Birds and Reptiles so tinted and mottled as exactly to match the rock, or ground, or bark of a tree they frequent; and there are Insects rightly named "Walkingsticks" and "Walking-leaves." These coincidences are not always accidental, but often intentional on the part of nature, for the benefit of the imitating species. Generally, they wear the livery of those they live on, or ape the forms more favored than themselves.

\section{Homology, Analogy, and Corretation.}

The tendency to repetition in the derelopment of animals leads to some remarkable affinities. Parts or organs, having the like origin and development, and therefore the same essential structure, whatever their form or function, are said to be homologous; while parts or organs anatomically different, but corresponding in use, are called analogous.

The following are examples of homolngy: the arms and legs of Man $;^{134}$ the upper and lower set of teeth; the parts of the vertebral column, however moditied; the 
scapular and pelvic arches; the hmmerns and femur; carpus and tarsus; the right and left sides of most animals; the dorsal and anal fins of Fishes; the arms of Man, the fore-legs of a IIorse, the paddles of a Whale, the wings of a Bird, the front flippers of a Turtle, and the pectoral fins of a Fish ; the proboscis of a Moth, and the jaws of a Beetle; the shell of a Snail, and both valves of a Clam; the follicles of Invertebrates, and the compact liver of Vertebrates. ${ }^{135}$ The wings of the Bird, Flying Squirrel, and Bat are hardly homologons, since the wing of the first is developed from the fore-limb only; that of the Squirrel is an extension of the skin between the fore and hind limbs; while in the Bat the skin stretches between the fingers, and then down the side to the tail. The legs of a Lobster and Lizard; the wings of a Butterfly and Bird; the gills of a Fish, and the lungs of other Vertebrates, are analogous. The air-bladder of a Fish is homologous with a lung, and analogons to the air-chambers of the Nautilus. The wings of Birds and Bats are both homologons and analogons; as likewise the contractile protoplasin of the Amœba, and the muscular tissue of the Vertebrate.

In the midst of the great variety of form and structure in the animal world, a certain harmony reigns. Not only are different species so related as to suggest a descent from the same ancestor, but the parts of any one organism are so closely connected and mutually dependent, that the character of one must receive its stamp from the characters of all the rest. Thus, from a single tooth it may be inferred that the animal had a skeleton and spinal cord, and that it was a carnivorous hot-blooded Mammal. Certain structures always co-exist. $\Lambda$ nimals with two occipital condyles, and non-nucleated blood-corpuscles, suckle their young, i.e., they are Mammals. All Ruminant hoofed beasts have horns and cloren-feet. If the hoofs are eren, the horns are eren, as in the Ox; if odd, as in 
the Rhinoceros, the horns are odd, $i$. e., single, or two placed one behind the other. Creatures with feathers always have beaks. Pigeons with short beaks have small
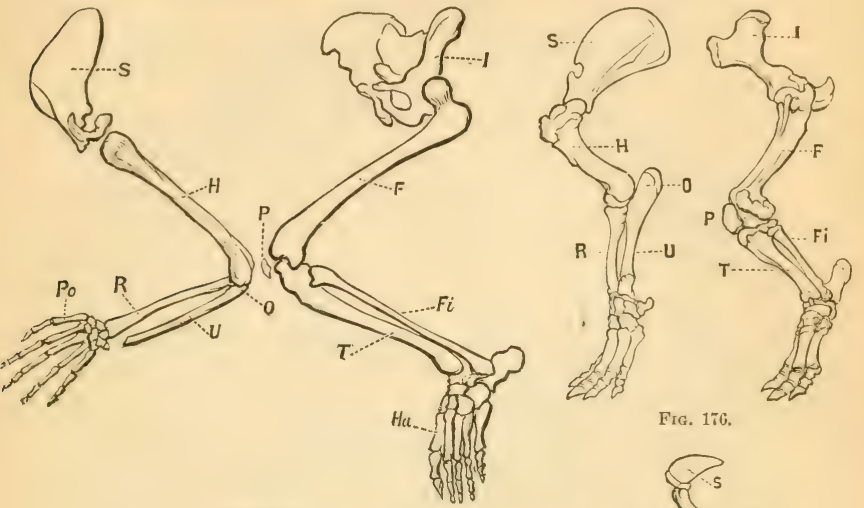

Fic. 175 .
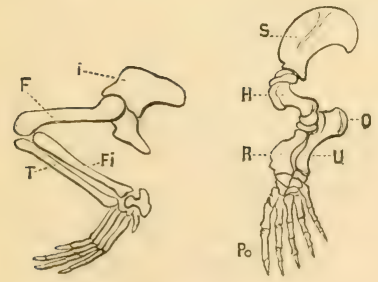

FIG. 177.

FIG. 170.

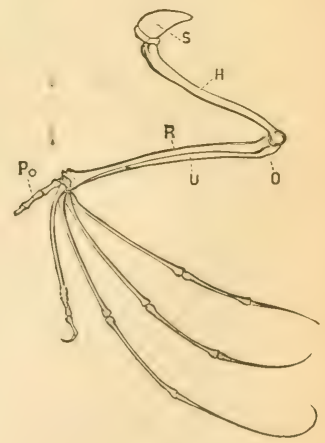

Fit. 178 .

IOMOLOGIES OF IIMBS.

Frt. 175. - Arm and Leg of MIan, as they are when he gets dorn on all fours. Fif. 176. -Fore and Hind Legs of Tapir. Fra. 177.-Fore Leg of Seal and Hind Leg of Alligator. Frg. 178. - Wing of the Bat. S, scapula; I, ilium, or shin-bone of pelvis; II, humerus: F, femur; O, olecranon, or tip of the elbow : $P$, patella ; $\mathrm{U}$, ulna; $\mathrm{T}$, tibia: $\mathbf{R}$, radius: Fi, tibula; $\mathrm{Po}$, pollex, or thumb; Ha, hallex, or great toe. Compare the fore and hind limbs of the same animal, and the fore or hind limbs of different animals. Note the directions of the homologens segments. 
feet; and those with long beaks, large feet. The long limbs of the IIomnd are associated with a long head. A white spot in the forehead of a IIorse generally goes with white feet. Hairless Dogs are deficient in teeth. Long wings usually accompany long tail-feathers. White Cats with blue eyes are deaf. A Sheep with numerous horns is likely to have long, coarse wool. Homologous parts tend to vary in the same manner; if one is diseased, another is more likely to sympathize with it than one not homologous. This association of parts is called correlation of growth.

\section{Relutions of Number, Size, Form, and Rank:}

The Animal Kingdom has been likened to a pyramid, the species diminishing in number as they ascend in the scale of complexity. This is not strictly true. The number of living species known is about 400,000, of which nearly nineteen-twentieths are Invertebrates. The Animalcules (not reckoned in this comnt) are innumerable. But next, the Articulates are the most numerous, then Vertebrates, Mollusks, and Radiates. Of Vertebrates, Fishes are most abundant; then follow Birds, Mammals, and Reptiles.

The largest species usually belong to the highest classes. The aquatic members of a groul are generally larger than the terrestrial, and the marine than the fresh-water. The extremes of size are an Infusorium, $\frac{1}{\mp 000}$ of an inch in diameter, the smallest animal ever measured, and the Whale, one hundred feet long, the largest animal ever created. The female is frequently larger than the male, as of the Nantilus, Spider, and Eagle. The higher the class, the more uniform the size. Of all animals, Insects and Birds are the most constant in their dimensions.

Every organism has its own special law of growth: a Fish and an Oyster, though born in the same locality, de- 
velop into very different forms. Yet a symmetry of plan underlies the structure of all animals. In the embryo, this symmetry of the two ends, as well as the two sides, is nearly perfect; but it is sulsequently interfered with to adapt the animal to its special conditions of life. It is a law that an animal grows equally in those directions in which the incident forces are equal. The Crinoid, rooted to the rockis, is subjected to like conditions on all sides, and, therefore, it has no right and left, or fore and hind parts. The lower forms, generally, are more or less geometrical figures: spheroidal, as the Sea-urchin; radiate, as the Star-fish; and spiral, as many Foraninifers. The higher animals are subjected to a greater variety of conditions. Thus, a Fish, always going through the water head foremost, must show considerable difference between the head and the hinder end; cr a Curtle, moring wer the ground with the same surface always down, must liave distinct dorsal and rentral sides.

Vievertheless, there is a striking nikeness between the two halves or any two organs situated on opposite sides of an axis. And, first, a bilateral symmetry is most constant. It is best exhibited by the Articulates and Tertebrates; but nearly all animals can be clearly divided into right and left sicles - in other words, they appear to be donble. A rertical plane would divide into two equal parts our brain, spinal cord, vertebral column, organs of sight, hearing, and smell; omr teeth, jaws, limbs, lungs, etc. In fact, the two haves of every egro are ilentical. There are many exceptions: the heart and liver of the higher Terteluates are eccentric; the nerrous system of Mollusks is scattered; the hemispheres of the human hrain are sometimes mequal; the corresponding bones in the right and left arms are not precisely the same length and weight; the Narwhal has an immense tusk wn the left side, with none to speak of on the other: Rablhits liave 
been born with one ear, and Stags with one horn; the Rattlesnake has but one limg; both eyes of the Flounder and IIalibut are on the same side; the claws of the Lobster differ; and the valves of the Oyster are mequal. But all these animals and their organs are perfectly symmetrical in the embryo state.

Again, animals exhibit a certain correspondence between the fore and hind parts. ${ }^{130}$ Thus, the two ends of the Centipede repeat each other. Indeed, in some Worns, the eyes are dereloped in the last segment as well as the first. So a Vertebrate may be considered, not only as two individuals placed side by side, but also as two individnals put end to end-the head and arms representing one, and the legs the other. In the embryo of Quadrupeds, the four limbs are closely alike. But in the adult, the fore and hind limbs differ more than the right and left limbs, becanse the functions are more dissimilar. An extreme want of symmetry is seen in Birds which combine aërial and land locomotion.

There is also a tendency to a vertical symmetry, or up-and-down arrangement - the part above a horizontal plane beirg a reversed copy of the part below. A good example is the posterior half of a Cod, while the tail of a Shark shows the want of it. This symmetry decreases as we ascend the scale. In most animals there is considerable difference between the dorsal and ventral surfaces; and in all the nervous system is more symmetrically disposed than the digestive.

Every animal is perfect in its kind and in its place. Yet we recognize a gradation of life. Some animals are manifestly superior to some others. But it is not so easy to say precisely what shall guide us in assorting living forms into high and low. Shall we make structure the criterion of rank? Plainly the simple Jelly - fish is beneath complicated Man. An ounce of muscle is worth a 
pound of protoplasm, and a grain of nerrous matter is of more account than a ton of flesh. The intricate and finished build of the IIorse elevates him immeasurably above the stupid Snail. The repetition of similar parts, as in the Worm, is a sign of low life. So also a prolonged posterior is a mark of inferiority, as the Lobsters are lower than the ('rabs, Snakes than Lizards, Monkeys than Apes. The possession of a head distinct from the region behind it is a sign of power. Ind in proportion as the fore-limbs are nsed for head purposes, the animal ascends the scale: compare the Whale, Iorse, Cat, Monkey, and Man.

But shall the Fish, never rising above the "monotony of its daily swim," be allowed to outrauk the skillful Bee? Shall the brainless, sightless, almost heartless Amphioxus, a Vertelorate, be allowed to stand nearer to Man than the Ant? What is the possession of a backbone to intelligence? No good reason can be given why we might not be just as intelligent beings if we carried, like the Insect, our hearts in our backs and our spinal cords in our breasts. So far as its activity is concerned, the brain may be as effective if spread ont like a map as packed into its present shape. Even animals of the same type, as Tertebrates, can not be ranked according to complexity. For while Mammals, on the whole, are superior to Birds, Birds to Reptiles, and Reptiles to Fishes, they are not so in every respect. Man himself is not altogether at the "head of creation. We carry about in our bodies embryonic structures. Thus, the embryo Bird has its bones full of marInw as we have all our life long; but afterward they become hollow air-sacs. So feather's are more complex than lıairs. That structural aftinity and vital dignity are not always parallel, may be seen by comparing an Australian and an Englishman. ${ }^{137}$

Function is the test of worth. Not mere work, however; for we must consider its quality and senpe. An 
animal may be said to be more perfect in proportion as its relations to the external world are more varied, precise, and fitting. Complexity of organization, variety, and amount of power are secondary to the degree in which the whole organism is adapted to the circumstances which surround it, and to the work which it has to do. Ascent in the animal scale is not a passage from animals with simple organs to animals with complex organs, but from simple individuals with organs of complex function to complex individuals with organs of simple function: the addition as we ascend being not function, but of parts to discharge those functions; and the adrantage gained, not another thing done, but the same thing done better. Advance in rank is exhibited, not by the possession of more life (for some animaleules are ten times more lively than the busiest Man), but by the setting apart of more organs for special purposes. The higher the animal, the greater the number of parts combining to perform each function. The porrer is increased by this division of labor. The most important feature in this specialization is the tendency to concentrate the nerrous energy toward the head (cephatization). It increases as we pass from the Oyster up to Man.

As a rule, fixed species are inferior to the free, water species to land species, fresh-water animals to marine, arctic forms to tropical, and the herbirorous to the carnivorous. Precocity is a sign of inferiority: compare the chicks of the IIen and the Robin, a Colt with a Kitten, the comparatively well-dereloped Caterpillar with the footless grub of the Bee. Among Invertebrates, the male is frequently inferior, not only in size, but also in grade of organization. Animals having a wide range as to climate, altitude, or depth are commonly inferior to those more restricted: Man is a notable exception.

There is some relation between the duration of life and 
the size, structure, and rank of animals. Tertebrates not only grow to a greater size, but also live longer than Inrertebrates. Whales and Elephants are the longest lived; and Falcons, Ravens, Parrots, and Geese, Alligators and Turtles, and Sharks and Pikes, are said to live a century. The life of Quadrupeds generally reaches its limit wheri the molar tecth are worn down: those of the Sheep last albont 15 years; of the Ox, 20 ; of the Ilorse, 40 ; of the Elephant, 100. Many inferior species die as soon as they have laid their egg', just as herbs perish as soon as they have flowered.

\section{The Struggle for Life.}

Every animal is striving to inerease in a geometrical ratio. But each lives, if at all, by a struggrle at some periud of its life. The meekest ereatures must fight, or die.

"There is no exception to the rule that every organic heing naturally increases at so high a rate that, if not destroyed, the earth would soon be covered by the progeny of a single pair." If the increase of the hmman race were not checked, there would not he standing-room for the descendants of Adam and Ere. A pair of Elephants, the slowest breeder of all known animals, would become the progenitors, in five centuries, of $15,000,000$ of Elephants, if death did not interfere. In fifteen years, a pair of Birds would increase to $2,000,000,000$. Evidently a rast number must perish, and a far greater host of ergess fail to mature. Whatever the average number of individuals in any comntry, twice that number mot die anmally. A single Cod, laving millions of exgro, if allowed to have its own way, would soon pack the ocean.

Yet, so nicely balanced are the forces of nature, the average number of each lind remains about the same. The total extinction of any one species is excedingly 
rare. The number of any given species is not determined by the number of eggs produced, but by its conditions. ${ }^{198}$ Aquatic birds ontmumber the land birds, becanse their food never fails, not because they are more prolific. The Fulmar-petrel lays but one egg, yet it is believed to be the most numerous bird in the world.

The main checks to the high rate of increase are: climate (temperature and moisture), acting directly or indirectly by reducing food; and other animals, either rivals requiring the same food and locality, or enemies, for the rast majority of animals are carnivorous. Offspring are continually varying from their parents, for better or worse. If feebly adapted to the conditions of existence, they will finally go to the wall. But those forms having the slightest advantage over others inhabiting the same region, being hardier or stronger, more agile or sagacious, will survive. Should this adrantageous variation become hereditary and intensified, the new variety will gradually extirpate or replace other kinds. This is what Mr. Darwin means by Natural Selection, and IIerbert Spencer by the Survival of the Fittest. 
PART II.

SYSTEMATIC ZOOLOGY 
Facts are stupid things until bronght into connection with some general law.-Agassiz.

No man becomes a proficient in any science who does not transcend system, and gather up new truth for himself in the boundless field of research. -Dr. A. P. Peabody.

Never ask a question if you can help it; and nerer let a thing go unknown for the lack of asking a question if you can't help it.-BEEcher.

He is a thoronghly good naturalist who knows his own parish thoroughly. -Ch.trles Kingslex. 


\section{CHAPTER XXI.}

\section{THE CLASSIFICATION OF ANIMALS.}

Tre Kingdom of Nature is a literal Kingdom. Order and beauty, law and dependence, are seen everywhere. Amidst the great diversity of the forms of life, there is mity; and this suggests that there is one general plan, but carried out in a variety of ways.

Naturalists have ceased to believe that each animal or group is a distinct, circumseribed idea. "Every animal has a something in common with all its fellows: much with many of them; more with a few; and, nsually, so much with several, that it differs but little from them." The oliject of classification is to bring together the like, and to separate the unlike. But how shall this be done? To arrange a library in alphabetical order, or according to size, binding, date, or language, would be musatisfactory. We must be guided by some internal character. We must decide whether a book is poetry or prose: if poetry, whether dramatic, epic, lyric, or satiric; if prose, whether history, philosophy, theology, philology, seience, fiction, or essay. The more we subdivide these groups, the more difficult the analysis.

A classification of animals founded on external resemblances, as size, color, or adaptation to similar habits of life, wonld be worthless. It would bring together Fishes and Whales, Birds and Bats, Worms and Eels. Nor should it be based on any one character, as the quality of the blood, structure of the heart, development of the brain, embryo-life, etc.; for no character is of equal value in every tribe. A natural classification must rest on those 
prevailing characters which are the most constant. ${ }^{139}$ And snch a classification can not be linear. It is impossible to arrange all animal forms from the Sponge to Man in a single line, like the steps of a ladder, according to rank. Nature passes in so many ways from one type to another, and so multiplied are the relations between animals, that one series is out of the question. There is a number of series, and series within series, sometimes proceeding in parallel lines, but more often divergent. The animals arrange themselves in radiating groups, each group being connected, not with two gronys merely, one above and the other below, but with sereral. Life has been likened to a great tree with comtless branches spreading widely from a common trunk, and deriving their origin from a common root; branches bearing all namner of flowers, every fashion of leares, and all kinds of fruit, and these for every use.

The groups into which we are able to cast the various forms of animal derelopment are rery unequal and dissinilar. Wre must remember that a genus, order, or class is not of equal value thronghont the kingdom. Moreover, each division is allied to others in different degrees-the distance between any two being the measure of that affinity. The lines between some are sharp and clear, between others indefinite. Like the islands of an archipelago, some groups merge into one another throngh comnecting reefs, other's are sharply separated by mfathomable seas, yet all have one common basis. Links have heen found revealing a relationship, near or distant, even between animals whose forms are very milike. How different a Fish and a Lizard! yet there is a strange creature (the $A$ xolotl of Mexico) whose organization is intermediate between the two, so that it is difficult to determine to which group it belongs. The Slow-worm is a transition between Lizards and Snakes; while the extinct Ichthyosaurus bridges the 
chasm between Crocodiles and Fishes. Birds seem isolated; but in ancient times there were flying Reptiles; while the Ornithorhynchus, Kangaroo, and Bat stand on the border-line between Aammals and the feathered tribe. Eren between the grand Vertebrate and Invertebrate divisions there thits a ghost-like form-the Amphioxus, half Worm, half Fish:

We have, then, groups subordinate to groups, and interlocking, but not representing so many successire degrees of organization. For, as already intimated, complication of structure does not rise in continuous gradation from one group to another. Every type starts at a lower point than that at which the preceding class closes; so that the lines overlap. While one class, as a whole, is higher than another, some members of the higher class may be inferior to some members of the lower one. Thus, certain Starfishes are nobler than certain Mollusks; the Nantilus is above the Wrorm, and the Bee is more worthy than the lowest Fish. The groups coalesce by their inferior species; c. ., the Fishes do not graduate into Reptiles through their higher forms, but the two come closest together low down in the scale. Man appears to be the goal of creation; but eren within the Vertebrate series, every step of development, say of the Fish, is away from the goal. The highest Fish is the one farthest from Man.

A number of animals may, therefore, have the same grale of derelopment, but conform to entirely different types. While a fundamental unity underlies the whole Animal Kingdom, suggesting a common starting-point, we recognize four or five distinct plans of structure. ${ }^{180}$ Thus, animals like the Coral, unlike all others, have the alimentary canal opening into the body-carity, have no separate nerrous and rascular regions, and the parts of the body radiate from a centre. Such form a sublingdom called C'elenteruta. Animals, like the Star-fish, hav- 
ing also a radiating body, but a closed alimentary caunl, and a distinct, symmetrical nerrous system, constitute the subkingdom Echinodermata. ${ }^{141}$ Animals, like the Snail, with a soft, unsymmetrical body, well-dereloped digestive apparatus, and scattered nervous system, form the subkingdom Mollusca. Animals, like the Bee, with a symmetrical body composed of numerous segments, a nerrous system consisting of a double chain of ganglia along the lower side of the body, and limbs on the same side as this nervons cord, form the sublingrom Articulatı. Animals, like the Ox, having a double nervons system, one (the ganglionic) lying on the upper side of the alimentary canal, the other and main part (spinal) lying along the back, and completely shut off from the other organs by a partition of bone or gristle, known as the "vertebral column," and haring limbs, nerer more than four, always on the side opposite the great nerrous cord, constitute the subkingdom Vertebrata.

Comparing these great divisions, we see that the Vertebrates differ from all the others chiefly in having a donble body-carity and a double nerrons system, the latter lying above the alimentary canal; while Invertebrates have one cavity and one nervons system, the latter being placed either below or arome the alimentary canal. The Articulate trye differs from the Mollusean mainly in being jointed. The Echinoderms and Coelenterates are built on the common trpe of a star; but they differ from each other in the presence or absence of distinct alimentary, circulatory, and nerrous systems.

But there are types within types. Thus, there are five modifications of the Vertebrate type-Fish, Amphibian, Reptile, Bird, and Mammal; and these are again divided and subdivided, for Mammals, e. g., differ among themselves. So that in the end we have a constellation of groups within groups, founded on peculiar characters of 
less and less importance, as we descend from the general to the special.

Individuals are the mits of the Animal Creation. An animal existence, complete in all its parts, is an individual, whether separate, as Man, or living in a community, as the Coral..$^{142}$

Variety: when two or more individuals differ by a single peculiarity only, such as size, color, or outline, one is called a variety of the other' as the various races of Men and breeds of Cattle. Tarieties are usually local. 1 cross between distinct races is called mongrel.

Species is the smallest group of individuals which can be defined by sereral constant characteristics. They are so alike, that it is possible for them to have descended from one pair; and they always transmit to their offspring some peculiarity of their organization. A cross hetween two distinct species, as the Horse and $\mathrm{Ass}$, is called a hybrid; as the Mule.

Genus is a group of species haring the same essential structure. Thus, the closely allied species, Cat, Tiger, and Lion, belong to one genus.

Family, or Tribe, is a group of genera having a similar form. Thus, the Dogs and Foxes belong to different genera, but betray a family likeness.

Order is a group of families, or genera, related to one another by a common structure. Cats, Dugs, IIrenas, and Tears are linked together hy important anatomical features; their teeth, stomachs, and claws show carnivorous habits.

Class is a still larger group, comprising all animals which agree simply in a special moditication of the type to which they belong. Thus, Fishes, Ampluibians, Reptiles, Iirds, and Manmals are so many aspects of the Vertebrate type.

Subkingdom is a primary clivision of the Animal King- 
dom, which includes all animals formed upon one of the four or five types of structure; as Vertebrate.

These terms were invented by Limneus, except Family and Subkingdom, which were added by Lamarck. To Linnæus we are also indebted for a scientific method of naming animals. Thus, a Dog in Zoology is called Canis fumiliaris, which is the union of a generic and specific name, corresponding to the surname and Christian name in George Washington, only the specific name comes last. It will be understood that these are abstract terms, expressing simply the relations of resemblance: there is no such thing as genus or species.

Classification is a process of comparison. He is the best naturalist who most readily and correctly recognizes likeness founded on structural characters. As it is easier to detect differences than resemblances, it is much easier to distinguish the class to which an animal belongs than the genus, and the genus than the species. In passing from species to classes, the characters of agreement become ferer and fewer, while the distinctions are more and more manifest; so that animals of the same class are more like than unlike, while members of distinct classes are more unlike than like.

To illustrate the method of zoological analysis by searching for affinities and differences, we will take an example suggested by Professor Agassiz. Suppose we see together a Dog, a Cat, a Bear, a Horse, a Cow, and a Deer. The first feature which strikes us as common to any two of them is the horn in the Cow and Deer. But how shall we associate either of the others with these? We examine the teeth, and find those of the Dog, the Cat, and the Bear sharp and cutting; while those of the Cow, the Deer, and the IIorse have flat surfaces, adapted to grinding and chewing, rather than eutting and tearing. We compare these features of their structure with the habits of these 
animals, and find that the first are carnirorous-that they seize and tear their prey; while the others are herbivorous, or grazing, animals, living only on regetable substances, which they chew and grint. We compare, further, the IIorse and Cow, and find that the IIorse has front teeth both in the upper and the lower jaw, while the Cow has them only in the lower; and going still further, and comparing the internal with the external features, we find this arrangement of the teeth in direct relation to the different structure of the stomach in the two animals-the Cow having a stomach with four pouches, while the IIorse lias a simple stomach. Comparing the Cow and Deer, we find the digestive apparatus the same in both; but though both have horns, those of the Cow are hollow, and last through life; while those of the Deer are solid, and are shed every year. Looking at the feet, we see that the herbivorous animals are hoofed; the carnivorous, clawed. The Cow and Deer hare cloven feet, and are ruminants; the IIorse has a single hoof, and does not chew the end. The Dog' and Cat walk on the tips of their fingers and toes (digitigrade); the Bear treads on the palms and soles (plantigrade). The claws of the Cat are retractile; those of the Dog and Bear are fixed.

In this way we determine the exact place of each animal. The Dog belongs to the kingdom Animaliu, subkingdom Vertebrata, class MLammalia, order C'urnivora, family Cunider, genus C'anis, species Fumiliaris, rariety IIound (it may be), and its individual name, perhaps, is "Rover." The Cat differs in belonging to the family Felidie, genus Felis, species C'utus. The Bear belongs to the family Ursidce, genus $U_{r}$ sus, and species $F$ rerox, if the Grizzly is meant. The IIorse, Cow, and Deer belong to the order Ungulata; but the IIorse is of the family Equide, genus Equus, species C'uballus; the Cow is of the family Bovida, genus Bos, species Taurus; the Deer 
is of the family Cervidce, genus Cervus, species Virginianus, if the common Deer is meant.

The fullowing diagram ronghly represents (for the relations of animals can not be expressed on a plane surface) the relative positions of the sublingdoms and classes according to aftinity and rank. It will be seen that the Vertebrate, Articulate, and Molluscan types stand at the angles of an isosceles triangle. The lowest Worms are simpler than the lowest Mollusks; yet Articulates, on the whole, are, perhaps, higher than the Mollusks: the former have more outward expression ; the latter, more concentration."

Mammalia.

$$
\begin{gathered}
\text { Vertebrata, Aves. } \\
\text { Reptilia. } \\
\text { Amphibia. } \\
\text { Pisces. }
\end{gathered}
$$

Cephalopoda.

Gasteropoda.

Lamellibranchiata, MolLusca.

Tunicata.

Polyzoa. Brachiopoda. Annelida.
Insecta.

Myriapoda,

Articulata. Arachnida. Crustacea.

Echinoidea. Holothuroidea.

Ecinnodernata.

Asteroidea.

Crinoidea.

Anthozoa.

Coelenterata.

Hydrozoa.

Spongida.

Infusoria.

Protozon.

Rhizopoda.

Gregarinida.

* 'The student should master the distinctions between the great groups, or classes, before proceeding to a miuuter classification. "The essential matter, in the first place," says Huxley, "is to be quite clear about the different classes, and to have a distinct knowledge of all the sharply definable modifications of animal structure which are discernible in the Animal Kingdom." 


\section{Subkingdom.--Рвотоzом.}

This division was proposed by Von Siebold in 1845 to contain that rast cloud of microscopic beings on the verge of the Animal Kingdom which could not be received into the other subkingdoms. It is artificial and provisional. The classes composing it are not founded on a common type, but are distinguished by the absence rather than the presence of positive characters. The time may come when the microscope will resolre these nebula, so that we can give them a natural classification. Probably some of them are transitory stages in the history of higher organisms. Many stand parallel to the Protophytes of the Vegetable World, and no definite line can be drawn between them.

Protozoans agree in being minute, aquatic, and exceedingly simple in structure, their bodies consisting mainly or wholly of the contractile, gelatinons matter called protoplasm, or sareode - the first homogeneous substance which has the power of controlling chemical and physical forces. No traces of nervons or muscular fibres, circulatory or digestive organs have been discovered. Yet they take and assimilate food, grow and multiply, which are the essential signs of life. The usual methods of reproduction are self-division and hudding.

The sulbkingdom may be divided into four classes: Gregarinida, Rhizopodu, Infusoria, and Spongidu. The perfectly homogeneous Moner'e of IIaeckel would rank lower than the Cregarina; but as they are doubtfully referred to the Animal Kingdom, we do not include them.

\section{Class I.-Gregarinida.}

The Gregarine, discorered by Dufour in 182S, are the simplest animal forms of which we hare any knowledge. They closely resemble a cell, or microscopic egrg; the only organ is a muclens, suspended in extremely mobile granu- 
lar matter; and the most conspicuous signs of life are the contraction and lengthening of the worm-like body. They feed by absorption, and are all parasites, living in the ali-

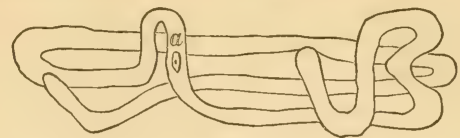

Fig. 179.-Gregarina gigantea, highly magnified: $\alpha$, nucleus.

mentary canal of higher animals; particularly in the Cockroach and Earth-worm. The name is derived from the fact that they occur in large numbers crowded together. By some authors they are associated with the parasitic Worms.

\section{Class II.-Rhizopoda.}

The Rhizopods are characterized by the power of throwing out at will delicate processes of their bodies, called pseudopoctia, or false feet, for prehension or locomotion. They possess no cilia. The representative forms are Amobo, Foraminifera, and Polycystina.

An Amoba is a naked, fresh-water Rhizopod; an indefinite bit of protoplasm, as structureless as a speck of

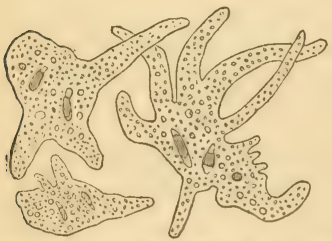

Frg. 150.-Amatar prinecps, $\times 150$; the same animal in various shapes. jelly, save that it is made of two distinct layers, and has a contractile carity inside. It has no particular form, as it changes continually. It moves by putting forth short, blunt processes, and eats by wrapping its body around the particle of food. The size ranges from $\frac{1}{70}$ to $\frac{1}{2300}$ of an inch in diameter. Specimens can be obtained by scraping the mucous matter from the stems and leaves in stagnant ponds. 
A Foraminifer differs from an Amœba in having an apparently simpler body, the protoplasm being without layers or cavity; but it has the property of secreting an envelope, usually of carbonate of lime. The shell thus formed is sometimes of extraordinary complexity and singular beanty. It is generally perforated by innumerable minute orifices (foramina) through which the animal protrudes its myriad of glairy, thread-like arms. The majority are compound, resembling chambered shells, formed by a process of budding, each new individual being added so as to make a straight series, a spiral, or a flat coil.
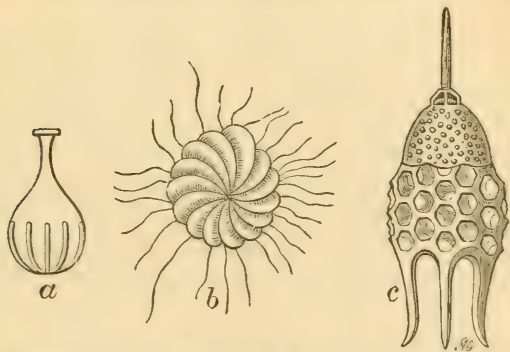

Frg. 151,-Rhizopods: $a$, a monothalamous, or single-chambered, Foraminifer ( $L$ * gena stricutu); $b$, a polytbalamous, or mauy-chambered, Foramisifer (Irolystomella crispa, with pseudopodia exteuded); $c$, a Radiolarian, one of the Polycystines (Podocystis Schomburgkii).

As a rule, the many-chambered species have calcareous, perforated shells; and the one-chambered have an imperforated membranous, porcelanons, or arenaceons envelope. The former are marine. There are few parts of the ocean where these microseopic shells do not ocem, and in astounding numbers. A single ounce of sand from the Antilles was calculated to contain over three millions. Their remains constitute a great proportion of the socalled sand-banks which block up many harbors. Tet they are the descendants of an ancestry still more prolific; for the chalk-cliffs of England, the building-stone of Paris, 
and the blocks in the Pyramids of Egypt are largely composed of extinct Foraminifers.

A Polycystine differs from a Foraminifer in secreting a siliceous, instead of a calcareons, shell, studded with spines; and the central part of the body is made up of many cells, and surrounded by a strong membrane. While Foraminifers live mostly at the bottom of the sea, Polycystines generally float on the surface. They are also more minute, but as widely diffused. They enter largely intr the formation of some strata of the earth's crust, and abound especially in the rocks of Barbados and at Richmond, Va.

\section{Class III.-Infusoria.}

This unassorted group of living particles derived its

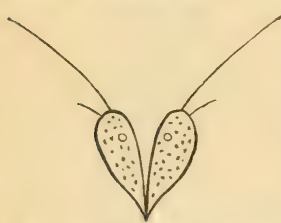

Fra. 182.-A Compound Mionad $($ Uvella $), \times 1000$. name from the fact that they were first discovered in vegetable infusions. Every drop of a stagnant pool is crowded with them. They are all single and microscopic, yet of varions sizes, the difference between the smallest and largest being greater than the difference between a Mouse and an Elephant. Some are fixed (as Vorticella); but the majority are free, and constantly in motion, propelled by countless cilia, as a galley by its oars. The delicate body consists of unorganized sarcode (i. c., there are no cellular tissues, but the whole body represents a single cell), corered by a membrane, or skin, and containing a

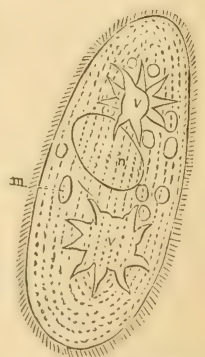

Fif. 183. - Infusorium (Paramecium aurelia), $\times 300: m$, mouth; $v$, contractile vesicles; $n$, nucleus. semi-fluid substance, a contractile carity, and several 
granules. On one side is a slight depression, or "mouth," leading to a short, funnel-shaped throat. A mouth and a rudimentary digestive eavity are the distinctive features of these Protozoans. They multiply so rapidly (chicfly by self-division), that a $I^{\prime}$ aramecium, the most common form, may become the parent of $1,364,000$ in 12 days.

There are two main groups: Flagellata, or Monads, provided with one or two flagella, or long bristle-like cilia; and Ciliata, which are furnished with mumerous vibratile cilia.

\section{Class IV.--Spongida.}

An ordinary Sponge is a compound animal, or, more properly, an aggregated colony of individual cells, supported on a skeleton of horny fibres, which are so united as to form a net-work of tubes. The essential part is the glairy, gelatinous substance investing this elastic framework. It consists of myriads of monthless, sarcode bodies, which in some respects resemble Amabr, but approach

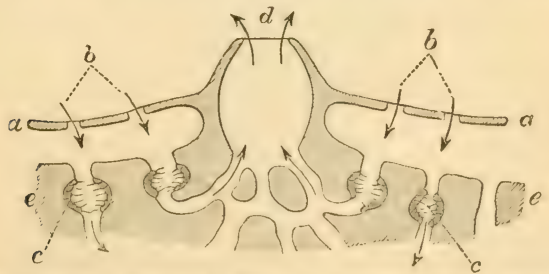

Fra. 1S4.-IIrpothetical Section of a Sponge : $a$, superticial layer : $b$, inhalent pores : $c$, ciliaterl chimbers; $d$, exhalent aperture, or osculum; $e$, deeper substauce of the Sponge.

the flagellate Infusoria in being uniciliated, and the IIydrozoa in having two layers of cells in the body-wall, and in producing true eggrs. While in other Protozoa aggregation is a result of growth, and the parts are not mutually dependent, in Sponges the parts work for the life of the whole, giving the mass a kind of individuality. Differen- 
tiation is carried to a higher degree, as we find ectoderm and endoderm, fibrous tissue, ciliated tracts, and a canalsystem for circulation.

When freshly taken from its element, a Sponge is hard and glistening on the outside, and strongly resembles a piece of liver. While living, constant currents of water issue from the large orifices, fed by smaller streams entering by the minute pores, the currents being caused by cilia

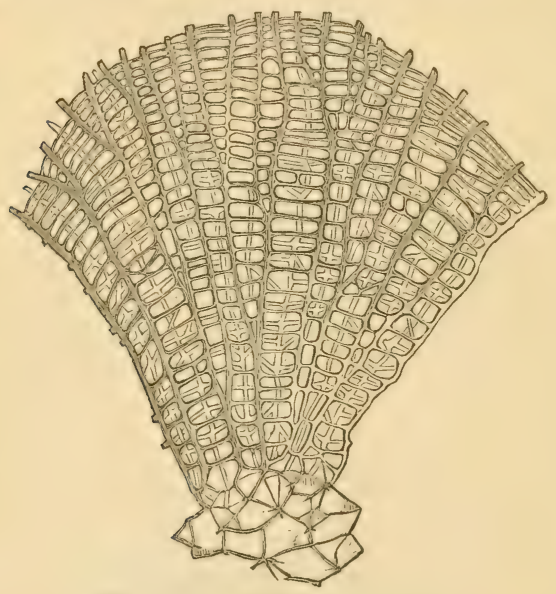

Fig. 155.-Horny Skeleton of a Sponge.

lining the passages. So that "the Sponge represents a kind of subaqueous city, where the people are arranged about the streets and roads, in such a manner that each can easily appropriate his food from the water as it passes along." The apertures, or "gates," can be closed at the will of the animal.

A few species are wholly gelatinous, having no skeleton; some are calcareous, aping the Corals; many are entirely siliceous, resembling spun glass, as the beautiful 
Venus flower-basket (Euplectella); but the majority have a tibrous, horny skeleton, which in some forms is strength. ened by siliceons needles (spicula). Excepting a few small fresh-water species (as spongilla), Sponges are marine. In the former, the gelatinous part is greenish; in the latter, it is brown, red, or purple. In preparing the sponge of commerce, this is rotted by exposure, and washed ont. The best fishing-grounds are the eastern end of the Mediterranean and around the Bahama Islands.

\section{Subkingdom.-Celenterata.}

These radiate animals are distinguished by having a distinct body-cavity, the walls of it consisting of two layers of cellular tissue, an outer (ectoderm) and immer (endoderm); and thread cells, which are minute sacs containing a fluid, and connected with barbed filaments capable of being thrown out for stinging purposes. Most are provided with hollow tentacles around the mouth. All are aquatic, and nearly all are marine. There are two classes, represented by the Hydra and Sea-anemone. Both reproduce by budding and by eggs; but in the former the eggs are developed from the exterior of the body, while in the latter they are internal.

\section{Class I.-Hydrozoa.}

These Calenterates have no separate digestive sac, so that the body is a simple tube, or cavity, into which the mouth opens. A nervous system is not apparent. Such are the fresh-water IIyclicl and the oceanic Jelly-fish (Acaleph or Medusa).

The body of the IIydra is tubular, soft, and sensitive, of a greenish or reddish color, and seldom over half an inch long. It is found spontaneously attached by one end to submerged plants, while the free end contains the orifice, or month, erowned with tentacles, by which 


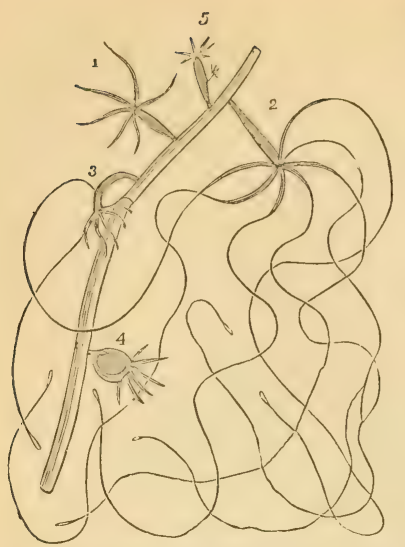

Frg. 186.-Hydra : 2, with tentacles fully extended; 3 , creeping; 5 , budding.

the creature feeds and creeps. Closely related to the Hydra are the compound Sertularians, often mistaken for delicate sea-weeds. The commonest species on our Atlantic coast (Dynamena) is of a paleyellow color, and hangs in fringes from seaweeds, shells, and rocks. The ordinary Acaleph has a soft, gelatinous, semi - transparent, bellshaped body, with tubes radiating from the central eavity to the circumference, where they are comnected by a circular canal, and with the margin fringed with stinging tentacles. The radiating parts are in multiples of four. Around the rim are minute colored spots, called "eye - specks," supposed to be the earliest indications of the organs of sight. In fine weather, these "sea-blubbers" are seen floating on the sea, mouth downward, moring about by flap-

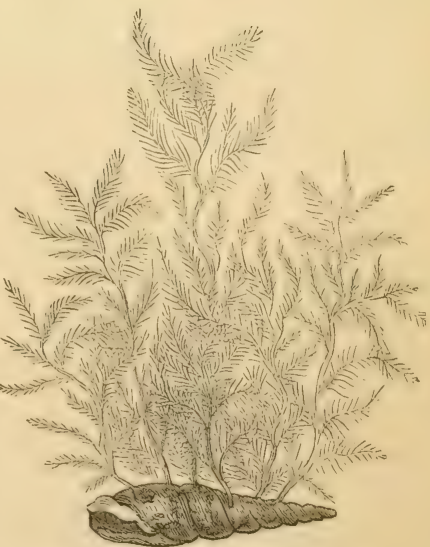

FIG. 1S7.-_Sertularia growing on a Shell. 


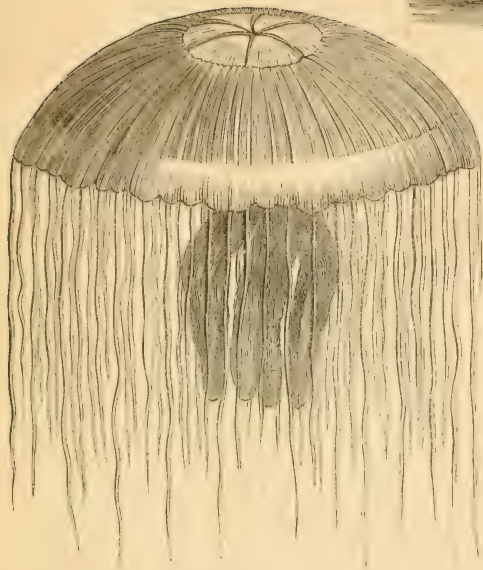

Fig. 1SS.-Medusa (Pelagia noctiluca), a free Lucernarian. Mediterranean.

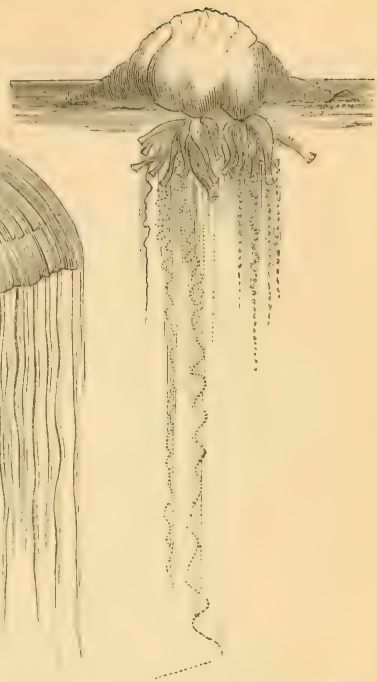

Fig. 189.-Portugnese Manof-war (Physalia), of natural size. Tropical Atlantic.

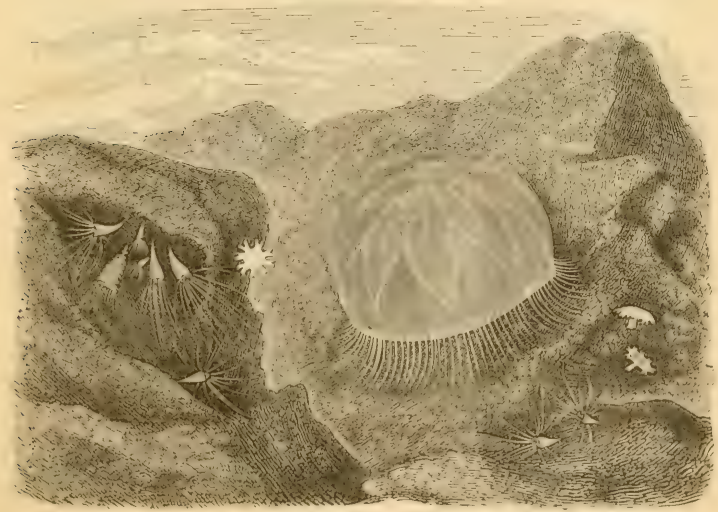

Fig. 190, -Jelly-tish (Aurclia aurita), with young in various staces. 
ping their sides, like the opening and shutting of an umbrella, with great regularity. They are frequently phos-

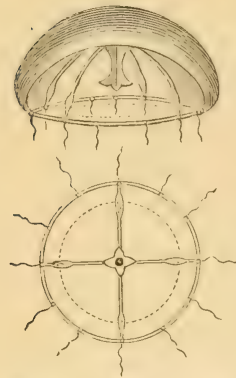

Frg. 191.-A Meatusa, seen in profile and from below, showing central polypite, radiating and maryiual canals.

phorescent when disturbed. Some are quite small, resembling little glass bells; the common Auretia is over a foot in diameter when full grown; while the Cyanea, the giant among Jelly-fishes, sometimes measures five feet, with tentacles forty feet long. When dried, nothing is left but a film of membrane weighing only a few grains.

There are two representative types: the Lucernaria, the Umbrella-acaleph, having a short pedicel on the back for attachment; tentacles disposed in eight groups around the margin, the eight points alternating with the fom partitions of the body-carity and the four corners of the month; not less than eight radiating canals, and no membranous veil. The common species on the Atlantic shore, generally found attached to eel-grass, is an inch in diameter, of a green color. Discophora, the ordinary Jel-

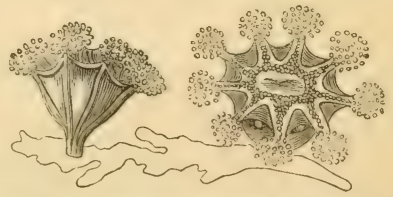

Fra. 192. - Lucernaria auricula attached to a piece of sea-tweed: natural size. The one on the right is abnormal, having a ninth tuft of tentacles.

ly-fish, is free and oceanic. It differs from the Lucernaria in its usually larger size and solid disk, four radiating canals, which ramify and open into a circular ressel, and a "veil," or shelf, always rumning around the mouth of the disk. $^{143}$ 


\section{Class II.-Anthozoa.}

These marine animals, which by their gay tentacles convert the bed of the ocean intr a flower-garden, or by their secretions build up coral-islands, have a body like a round gelatinous bag. One end, the base, is usually attached; the other las the month in the centre, surrounded by numerous hollow tentacles, which are corered with nettling lasso-cells. This upper edge is turned in so as to form a sac within a sac, like the neck of a bottle turned ontside in. The inner

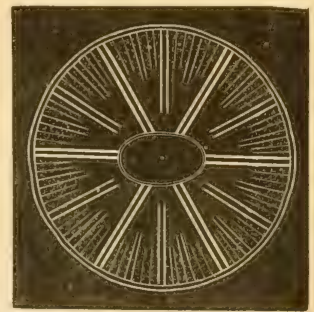

FIG. 193.-Horizontal Section of Actinia through the stomach, showing septa and compartments. one, which is the digestive earity, does not rearh the bottom, but opens into the general body-cavity. The space hetween these two concentric tubes is divided by a series of rertical partitions, some of which extend from the body-wall to the digestive sac, but others fall short of it

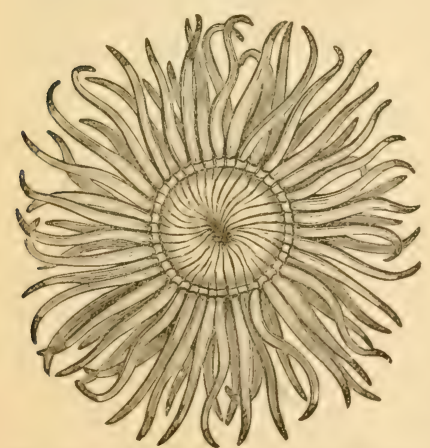

Fr6. 194.--Actinia expauded, seen from above, showing mouth.
Instead, therefore, of -the radiating tubes of the Acaleph, there are radiating spaces. No members of this class are microscopic. All are long-lived compared with the Hydrozoa, living for sereral years.

\section{Soft-bodied Pol-} yps.-The best-known representative of this group is the Actinia, or Sea-anemone. It leads a 
single life, and is capable of a slow locomotion. Muscular fibres run around the body, and others cross these at right

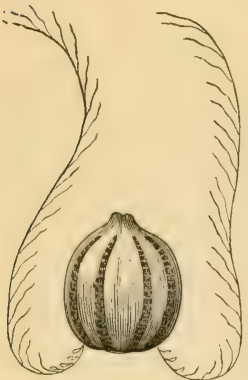

Fig. 195.-A Ctenophore (Pleurobrachia pileus); natural size. angles. The tentacles, which often number over 200, and the partitions, which are in reality double, are in multiples of six. At night or when alarmed, the tentacles are drawn in, and the aperture firmly closed, so that the animal looks like a rounded lump of fleshy substance plastered on the rock. It feeds on Crabs and Mollusks. It abounds on every shore, especially of tropical seas. The size varies from one-eighth of an inch to a foot in diameter.

The Ctenophor $\alpha$ (as the Pleuro. brachia, Cestum, and Beroë) likewise secrete no hard deposit. They are transparent and gelatinous, swimming on the ocean by means of eight bands of comb-like fringes, which work like paddles. The body is not contractile as in the Jellyfishes. They are considered the highest of Colenterates, having a complex nutritive apparatus and a definite nervous system.

2. Coral Polyps.-The majority of Anthozoa secrete a calcareous or horny frame-work called "coral." With few exceptions, they are fixed and composite, living in colonies formed by a continuous process of budding. Their

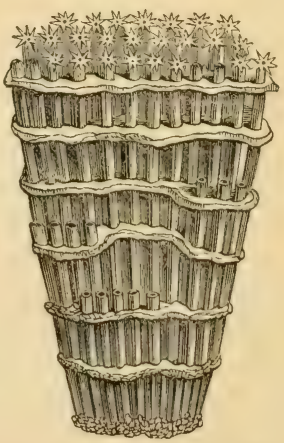

Frg. 196.-Organ-pipe Coral (Tubipora musica). Indian Ocean. structures take a variety of shapes: often dome-like, but more frequently imitating shrubbery and clusters of leares. 
The members of a coral community are organically connected; each feeds himself, yet is not independent of the rest. We can speak of the individual Corals, $a, b, c$, but we must write them down abc. The compound mass is "like a living sheet of animal matter, fed and nourished by numerons months and as many stomachs." Life and death go on together, the old Polyps dying below as new ones are developed above. The living part of an Astrece is only half an inch thick. The growth of the branching Madrepore is about three inches a year. The prevailing color of the Coral Polyps is green; and the usual size varies from that of a pin's head to half an inch, but the Mushroom-coral (which is a single individual) may be a foot in diameter.

Corals are of two kinds: those deposited within the tissues of the animal (sclerodermic), and those secreted by the onter surface at the foot of the Polyp (sclerobasic). The Polyps producing the former are Actinoid, resemb)ing the Actinia in structure. ${ }^{144}$ The skeleton of a single Polyp (called corallite, Fig. 95) is a copy of the animal, except the stomach and tentacles, the earthy matter being secreted within the onter wall and between each pair of partitions. So that a corallite is a short tube with rertical septa radiating toward the centre. ${ }^{145} \quad \mathrm{~A}$ sclerobasic coral is a true exoskeleton, and is distinguished by being smooth and solid. The Polyps, having eight fringed tentacles, are situated on the outside of this as a common axis, and are connected together by the fleshy canosare covering the coral.

(1) Sclerodermic Corals.-Astrcea is a hemispherical mass covered with large cells. Meandrina, or "Brain-coral," is also globular; but the mouths of the Polyps open into each other, forming furrows. Fungia, or "Mnshroomcoral," is disk-shaped, and differs from other kinds in being the secretion of a single gigantic Polyp, and in not 


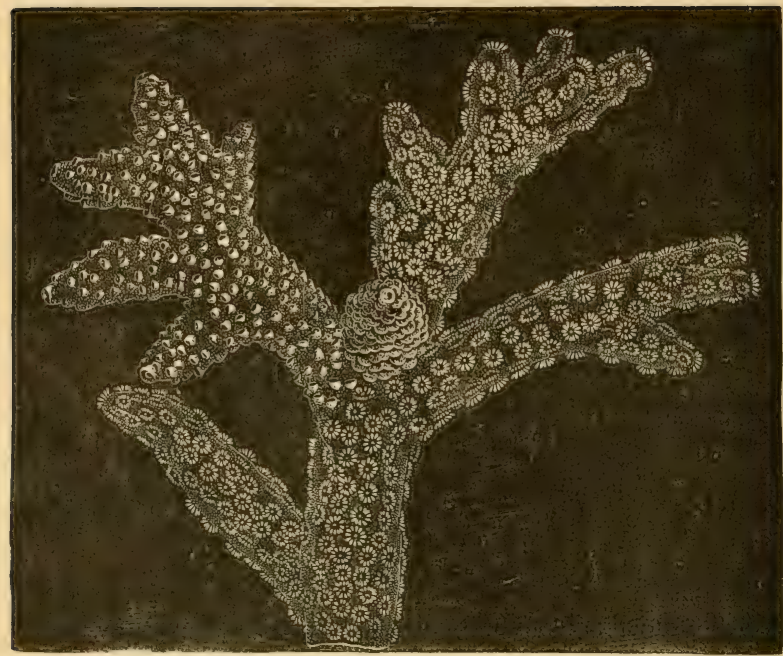

Fra. 197.-Hadrepora aspera, living aud expanded; uatural size. Pacitic.

being fixed. Mudrepore is neatly branched with pointed extrenities, each ending in a small cell abont a line in diameter. Porites, or "Sponge-coral," is also branching, but the ends are blunt, and the surface comparatively

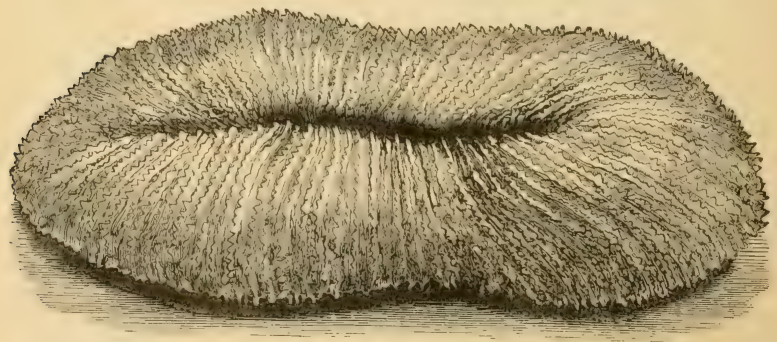

F16. 198,-Ctmactix celtinata, or "Nushroom-coral;" one-fourth natural size. Pacific. 


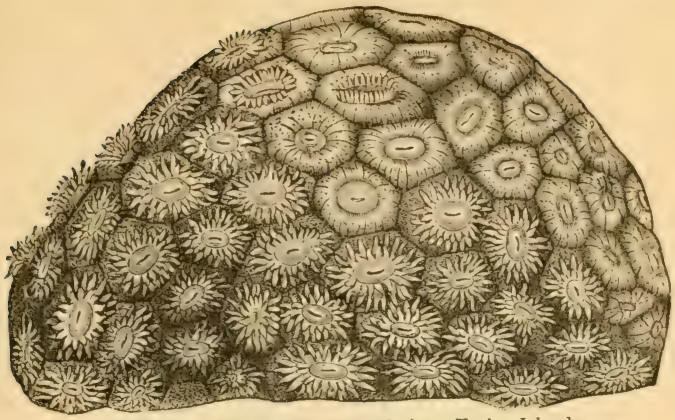

Fig. 199.-Astrae pallida; natural size. Feejee Islands.

smooth. Tutipora, or "Organ - pipe coral," consists of smooth red tubes comnected at intervals by cross plates.

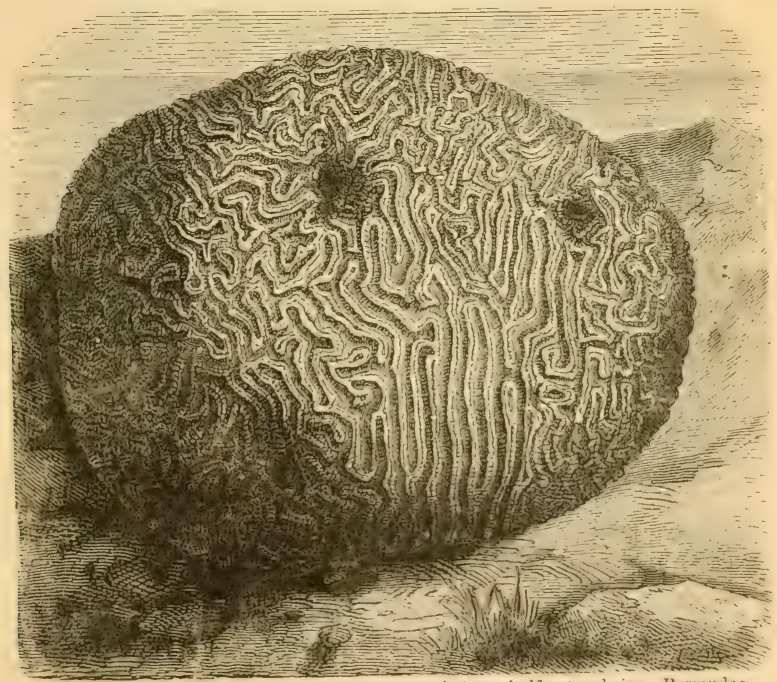

Fus. 2no. - Dipheriu cerebriformis, or "Brain-coral :" one-half uatural size. Bermulas. 


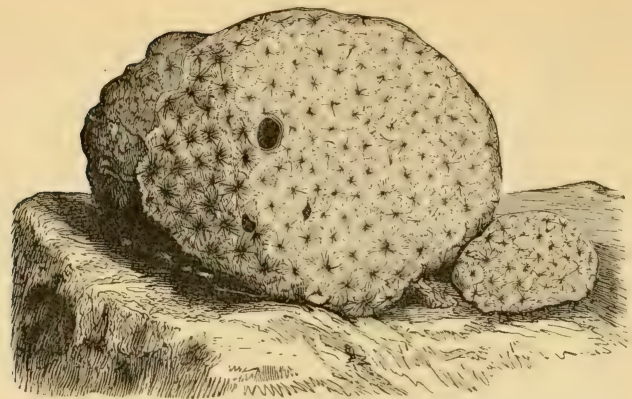

FIG. 201.-Astraea rotulosa. West Iadies.

The Astrea, Meandrina, Mradrepore, and Porites are the chief reef-forming corals. They will not live in waters the mean temperature of which is below $65^{\circ}$

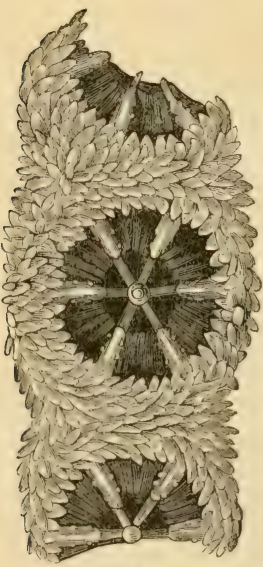

Fic. 202.-Cell of Madrepore Coral, magnified. The cup-like depression at the top of a coral skeleton is called calicle.

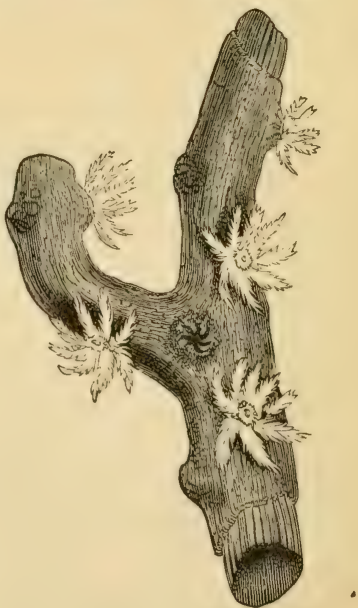

Fra. 203.-Fragment of Red Coral (Corallintm rubrum), showing living cortex and expauded Polyps. Mediterraueau. 
Fahr., nor at greater depth than twenty fathoms. The most luxuriant reefs are in the Central and Western Pacific and around the West Indies.

(2) Sclerobasic Corals-Curullizm rubrum, the precions coral of commerce, is shrub-like, about a foot high, solid throughout, taking a high polish, finely groosed on the

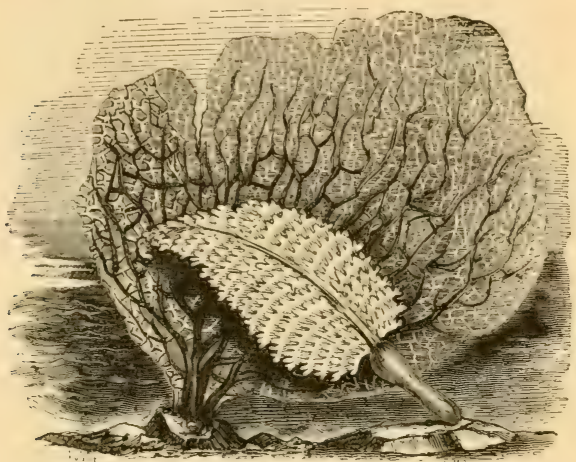

Fra. 204.-Sea-fin (Gorgonia) and Sea-pen (Pennatula).

surface, and of a crimson or rose-red color. In the living state the branches are covered with a red conosare studded with Polyps. Gorgonia, or "Sea-fin," differs from all the other representative forms in having a horny axis corered with calcareous spicules. The branches arise in the same rertical plane, and mite into a beautiful network.

\section{Subkingdom Echivoderinta.}

The Echinoderms, as Star-fishes and Sea-nrchins, are distingnished by the possession of a distinct nerrons srstem (a ring around the mouth); an alimentary canal, completely shut off from the body-earity, and having both oral and anal apertures; a peculiar system of circilar and radiat- 
ing canals, and a symmetrical arrangement of all the parts of the body around a central axis in multiples of five. ${ }^{1+6}$

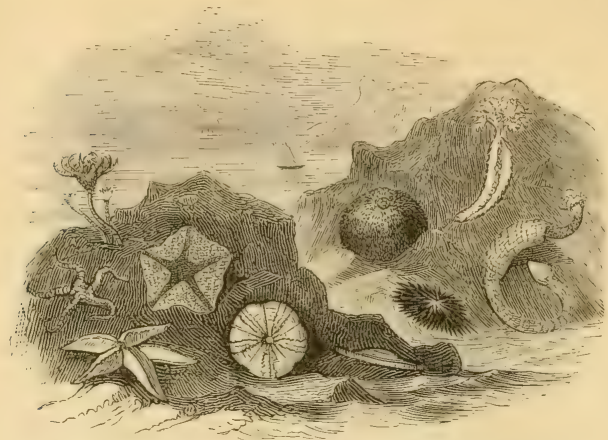

Frg. 205.-Forms of Echinoderms, from Radiate to Aunulose type.

There are four principal classes, all exclusively marine and solitary, and all having the power of secreting more or less calcareous matter.

\section{Class I.-Crinoidea.}

The Crinoids, or" "Sea-lilies," are fixed to the sea-lyottom by means of a hollow, jointed, flexible stem. On the tol of the stem is the body proper, resembling a bud or expanded flower, containing the digestive apparatus, with the surromding arms, or tentacles. The month looks npwarl. There is a complete internal slieleton for strength and support, the entire animal, boly, arms, and stem, consisting of thonsands of stellate pieces connected together by irritable matter. Crinoids were very abmolant in the old geologic scas, and many limestone strata were created out of their remains. They are now nearly extinct: drelging in the deep parts of the Caribbean Sea and Atlantic Ocean has brought to light two or three living representatives. 


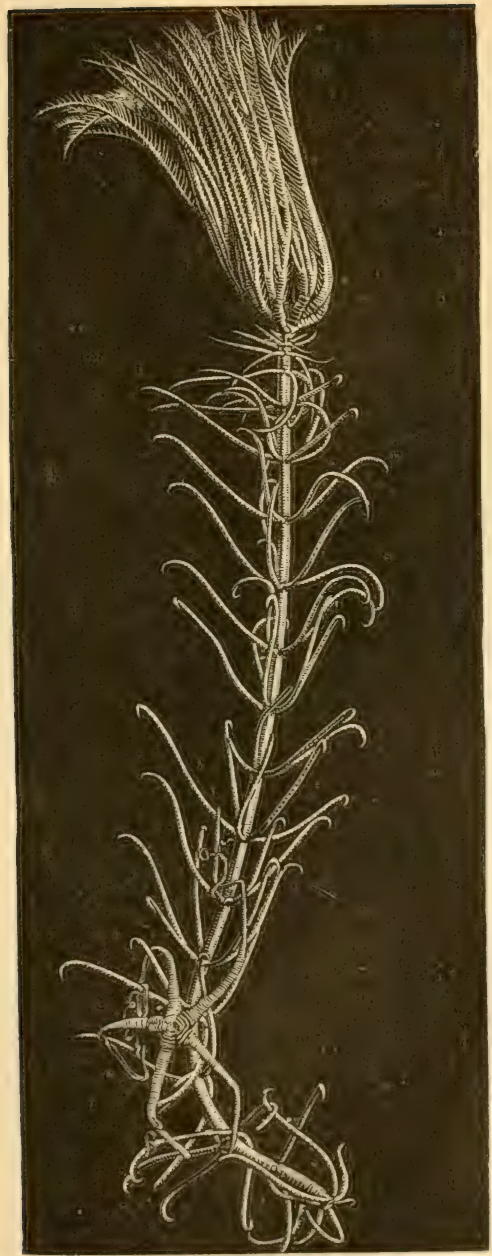

FIa. 206.-1 liviug Crinuid (Ientacinus asterin); une-fuurth natural size. West Indian Seas. 


\section{Class II.-Asteroidea.}

Ordinary Star-fishes consist of a flat central disk, with five or more arms, or lolses, radiating from it, and containing branches of the viscera. The skeleton is leathery, hardened by small calcareous plates (11,000 by calculation), but somewhat flexible. The mouth is below; and the rays are furrowed underneath, and piereed with numerous holes, through which pass the sucker-like tentacles-the organs of locomotion and prehension. The red spots at the ends of the rays are supposed to be eyes. The usual color of Star-fishes is yellow, orange, or red. They

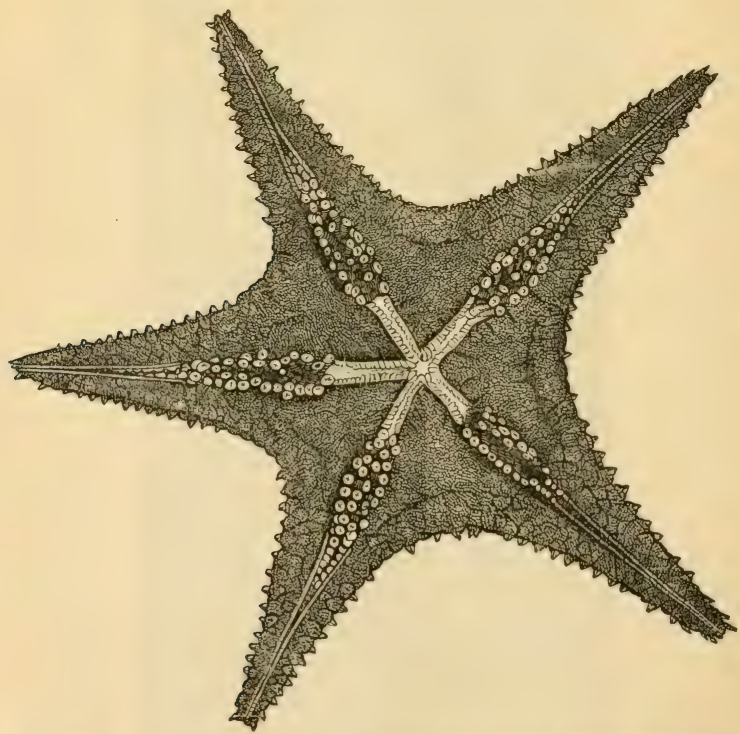

FIG. 207. - Under-surface of Star-fish (Goniaster reticulatus), showing ambulacral grooves and protruded suckers. 


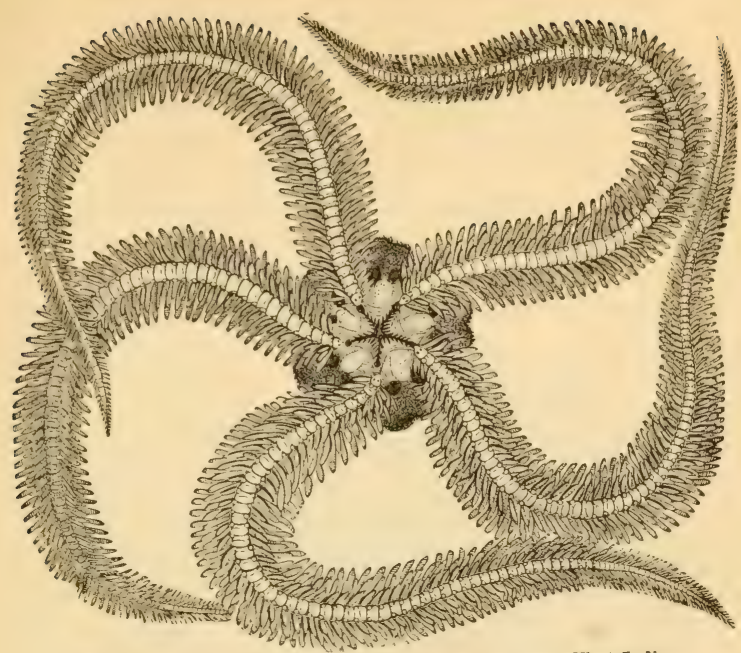

Fig. 20S.-Ophiocoma Russei, an Ophiura; natural size. West Indies.

abound on every shore, and are often seen at low tide half Inried in the sand, or slowly gliding orer the rocks. Cold fresh water is instant death to them. They have the power of reproducing lost parts to a high degree. They are very voracions, and are the worst enemies of the Oyster.

About 150 species are known. These may be divided into three gromps: (1) species liaving four rows of feet, represented by the common five-fingered Asterias; (2) species having two rows of feet, as the many-rayed Soluster, or "Sun-fish," and the pentagonal Gomiaster; (3) species having long slender arms, which are not prolongations of the body, and are not provided with suckers, as the Oplizura, or "Brittle-star," and Astropliyton, or "Basket-fisll." The last are of inferior rank, and resemble inverted stemless Crinoids. The digestive sac is confined to the disk; and the madreporic plate is underneath. 


\section{Cr.ass III.--Echinoidea.}

The Sea-urchin is encased in a thin hollow shell covered with spines, and rarving in shape from a sphere to a disk. ${ }^{47}$ The mouth is mderneath, and contains a dental apparatus more complicated than that of any other creature from the Sponge to Man. It leads to a digestive tube, which extends spirally to the summit of the body. The spines are for burrowing and locomotion, and are moved

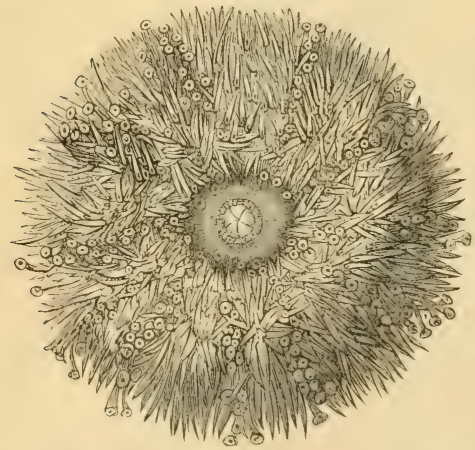

FIG. 209.-Under-surfice of a Sea-11rchin (Echimus escu(entus), showing rows of suckers among the spiues. British seas. by small muscles, each being articulated by ball-andsocket joint to a distinct tubercle. When stripped of its spines, the shell (or "test") is seen to be formed of a multitude of pentagonal plates, fitted together like a mosaic. ${ }^{148}$ Fire donble rows of plates, passing from pole to pole, like the ribs of a melon, alternate with five other double rows. In one set, called the ambulucru, the plates are perforated for the protrusion of tubular feet, or suckers, as in the Star-fish. So that altogether there are twenty series of plates - ten ambulacral, and ten interambulacral. The shell is not east, but glows by the enlargement of each individual plate, and the addition of new ones aromed the mouth and the opposite pole. Every part of an Echinns, even sections of the spines, show the principle of radiation. If the arms of a Star-fish were turned 
backward so as to meet, we wonld have a rery close imitation of a Sea-urchin, the rentral surface corresponding to the ambulatial areas. Echini live near the shore, in rocky holes or muler sea-weed. They are less active than Star-fishes, but, like them, feed on Shells and Crabs. They reproduce by minute red eggs.

Re'gulur Echini, as the common Ciduris, are nearly globular, and the oral and anal openings are oplosite. Irireyulur Echini, as the C'lypeaster, are flat, and the anal orifice is near the margin.

\section{Class IV.-Holothuroidea.}

These worm-like "Sea-slugs," as they are called, have a soft elongated body, with a tough contractile skin containing scattered gramules. One end, the hoad, is abruptly terminated, and has a simple aperture for a mouth, encircled with feathery tentacles. There are five longitudinal

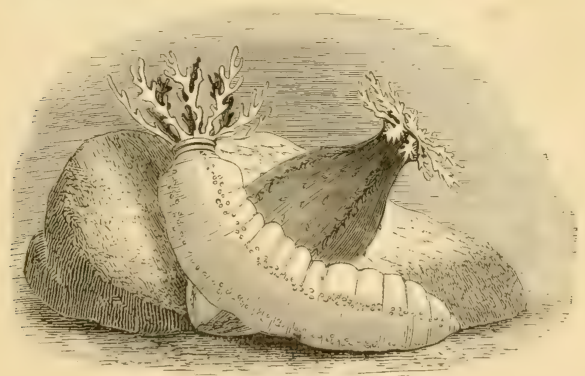

Fic. 210.-Sea-slugs (Holothuria).

rows of ambulacial suckers, but only one is used for locomotion. The muth opens into a pharynx leading to a long intestinal canal. Iolothurians have the singular power of ejecting all their internal organs, surviring for some time the loss of these essential parts, and afterward reproducing them. 'They oceur on nearly every const, 
especially in tropical waters, where they sometimes attain the length of three or four feet. As found on the beach after a storm, or when the tide is out, they are leathery lumps, of a reddish, brownish, or yellowish color. They may be likened to a Sea-urchin devoid of a shell, and long drawn ont, with the axis horizontal, instead of vertical.

\section{Subkingdom Mollusca.}

A Mollusk is a soft-bodied animal, without internal skeleton, and without joints, corered with a moist, sensitive, contractile skin, which loosely envelops the creature, like a mantle. In some cases the skin is naked; but generally it is protected by a calcareous covering (shell). The length of the body is less in proportion to its bulk than in other animals. The lower classes have no distinct head. The nervous system consists, in the true Mollusks, of three well-dereloped pairs of ganglia, which are principally concentrated around the entrance to the alimentary canal, forming a ring around the throat. The other ganglia are, in most cases, scattered irregularly through the body, and in such the body is unsymmetrical. The digestive system is greatly developed, especially the liver, as in most aquatic animals. Except in the Cephalopods, the muscles are attached to the skin. Only the higher Mollusks have a distinct heart (auricle and rentricle), and this is always on the arterial side. While in neighboring groups, as Foraminifers, Corals, Star-fishes, and Articulates, we find repetitions of similar parts, in Mollusks every part or organ is single. The total number of lixing species probably exceeds 20,000. The great majority are water-breathers, and marine; some are fluriatile or lacustrine; and a few are terrestrial air-breathers. All bivalves, and nearly all univalres, are aquatic Each zone of depth in the sea has its particular species. 
There are six classes of Mollusks. Of these, the first three form a group by themselves, called Molluscoideu, distinguished by having only one or two nervous ganglia, an imperfect circulatory apparatus, and generally no organs for prehension and locomotion. Of the other three, Lamellibranchs are headless, while Gasteropods and Cephalopods only have a distinct head, and an apparatus for mastication.

\section{Cluss I.-Polyzoa.}

These minnte Mollusks resemble the Polyps in appearance, living in clusters, each individual inhabiting a delicate cell, or tube, and having a simple month surrounded with ciliated tentacles. The colony often takes a plantlike form; sometimes spreads, like fairy-chains or lacework, over other bodies; or corers rocks and sea-weeds in

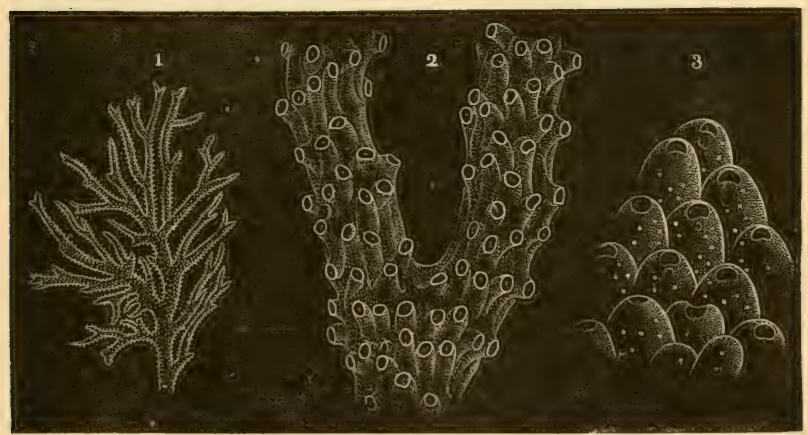

Fig. 211.--Polyzoans: 1. Hormera liehenoiles; natural size. 2. Branch of the same, magnified. 3. Discopora Skenei; greatly enlarged.

patches with a delicate film. The majority secrete carbonate of lime. Though an extremely low form of the Molluscan type, a Polyzoan shows its superiority to the Coral, which it imitates, in possessing a distinct alimentary canal 
and a well-defined nerrons system. The cells of a group never have comnection with a common tube, as in Culenterates. There are both marine and fresh-water species.

\section{CLASS II.-Tunicata.}

The Tumicates are either single or compound, and are found in all seas. The most common form (the solitary Ascicliuns) are inclosed in a leathery, elastic bag, one end of which is fastened to the rocks, while the other has two orifices, for the inlet and exit of a current of water $f(r)$ nutrition and respiration. They are withont head, feet, ar'ms, or shell. Indeed, few animals seem more helpless

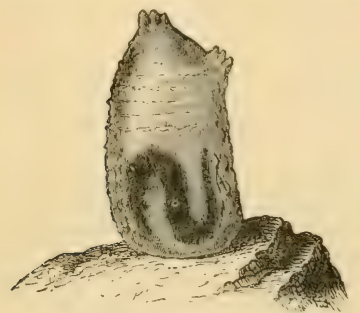

FIG. 212.-An Ascidiau. and apathetic than these apparently shapeless beings. The tubular heart exhibits the curious phenomenon of reversing its action at brief intervals, so that the blood oscillates backward and forward in the same ressels, as was supposed to be the case in the human system before the time of IIarvey. Another peculiarity is the presence of rellulose in the skin. While the Ascidians are fixed and single, the Sulprums are free, and alternately single and social. They are usually seen swimming in long (')ains (the offepring of one indiridual). Each member of this colony produces solitary yome, which are unlike their larents, and these again give birth to agrgregated forms.

\section{Cliss III.-Brachiopoda.}

These Mollusks have a bivalve shell, the valves being applied to the dorsal and rentral sides of the body. The valres are mequal, the rentral being nsually larger, and more convex; but they are symmetrical, i. e., a vertical 
line let fall from the hinge divides the shell into two equal parts. The rentral valve has, in the great majority, a prominent beak, perforated by a foramen, or hole, through which a tleshy foot protrudes to attach the animal to submarine rocks. The valves are opened and shut by means of muscles, and in some cases they are hinged, having teeth and sockets near the beak. The month faces the middle of the

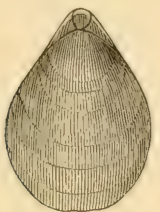

Frg. 213.-A Brachiopis (Terebratulina septentrionalis). Atlantic coast.

margin opposite the beak; and on either side of it is a long fringed "arm," generally coiled up, and supported by a bony frame-work. The animal, having no gills, respires either by the arms or the mantle. Brachiopods were once very abundant, orer 2000 extinct species liaving been described; but less than a hundred species are now living: ${ }^{143}$ They are all marine, and fixed; but of all Molluslis, they enjoy the greatest range of climate and depth.

\section{Class IV.-Lamellibranchiata.}

Lamellibranchs are all ordinary bivalves, as the Orster and Clam. The shells differ from those of Brachiopods in being placed on the right and left sides of the body, so that the linge is on the back of the animal, and in being mequilateral and equiralved. ${ }^{150}$ The umbo answers to the 
beak, but it is not perforated. It is the point from which the growth of the valve commences. Both Brachiopods and Lamellibranchs are headless; but in the latter, the

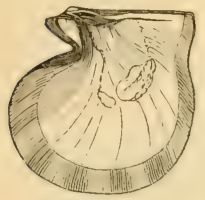

Fic. 215. - Pe:url Oyster (Mcleagrina margariti$f^{\prime} \cdot(a)$; one-fourth uatural size. Ceylon. mouth points the same way as the umbo, $i$. e., toward the anterior part. The length of the shell is measured from its anterior to its posterior margin, and its breadth from the dorsal side where the hinge is to the opposite, or ventral, edge. The ralves are mited to the animal by one muscle (as in the Oyster), or two (as in the Clam), and to each other by a hinge. In some species, as the Fresh-water Mussel, the hinge is simply an elastic ligament, passing on the outside from one valve to the other just behind the beak, so that it is on the stretch when the valves are closed, and another placed between the edges of the valves, so that it is squeezed as they shut, like the spring in a watch-case. Such bivalves are said to be edentulous. But in the majority, as the Clam, the ralves also articulate by interlocking parts called teeth. The valves are, therefore, opened by the ligaments, and elosed by the muscles.

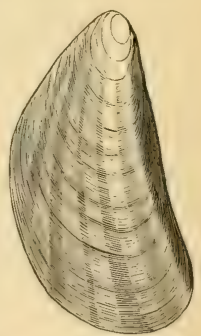

Fig. 216. - SaIt-water Mussel (Mytilus pellucielus). Atlantic consts.

The margin of the shell on which the ligament and teeth are situated is termed the linge-line.

Lamellibranchs breathe by four plate-like gills (whence the name), two on each side underneath the mantle (Fig. 78). In the higher forms, the mantle is rolled up into two tubes, or siphons, for the inhalation and exhalation of water. They feed on infusorial particles filtered from the water. A few are fixed, the Oyster, e.g., habitually lying on its left valve, and the Salt-water Mussel hanging to the 
rocks by a cord of threads called "lorssus;" but the rest hiwe a "foot," by which they creep about. L'nlike the Oyster, also, the majority live in an erect position, resting

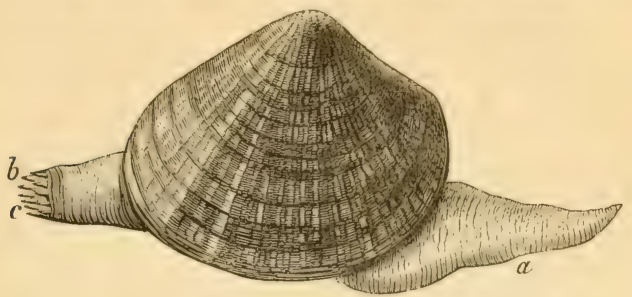

Fig. 217.-Lamellibranch (Hactra): $\alpha$, foot; $b, c$, siphons.

on the edges of their shells. Orer 4000 living species are known. These are fresh-water and marine, and range from the shore to a depth of a thousand feet.

The chief character's for distinguishing Lamellibranchs are the muscular impressions, ${ }^{151}$ whether one or two; the presence of a pallial sinns, which indicates the possession of siphons; the structure of the hinge; and the symmetry of the valves.

The following are the leading types of structure:

1. Mantle open; no siphon-tubes, and therefure no pallial simus; one muscular impression; foot wanting, or very small; shell mequivalve and edentulous: as the Oyster (Ostrea), Scallop (Pecten), and Pearl Oyster (Avicula). ${ }^{152}$

2. Mantle open in front, and closed behind, except one small aperture; no pallial sinus; two muscular impressions; foot large; shell equivalve: as the Sea MIussel (Mytilus), and Fresh-water Clam (Unio).

3. Mantle having three openings; tubes wanting, or very short; 10

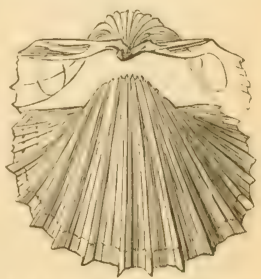

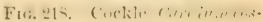
tatum) : one-third natural size. Chiul =c:ts. 
pallial sinus; two muscular impressions : as " the giant of the bivalve race" (Tridacne) and Cockle (Cardium). ${ }^{153}$

4. Mantle, with three openings; siphons large; pallial sinus and muscular impressions well marked: as the common Clam (Venus), ${ }^{154}$ and the burrowing Razor-shell (Solen).

\section{Class V.-Gasteropoda.}

The Snails are, with rare exceptions, all mivalres. ${ }^{155}$ The body is coiled up in a conical shell, which is usually spiral, the whorls passing obliquely (and generally from right to left) 150 $^{150}$ around a central axis, or "columella." When the columella is hollow (perforated), the end is called the "umbilicus." When the whorls are coiled around the axis in the same plane, we have a discoidal

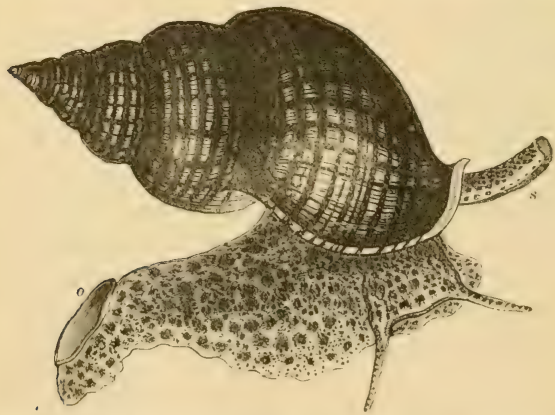

Frg. 219.-Whelk (Buccinum), showing operculum, o, and siphon, s.

shell, as the Planorbis. The month, or "aperture," of the shell is "entire" in most regetable-feeding Snails, and notched or produced into a canal for the siphons in the carnivorous species. The former are generally land and fresh-water forms, and the latter all marine. In some Gasteropods, as the River-snails, a horny or calcareous 
plate (operculum) is secreted on the foot, which closes the aperture when the animal withdraws into its shell. In locomotion, the shell is carried with the apex directed backward.

The body of most Gasteropods is unsymmetrical, the organs not being in pairs, but single, and on one side, instead of central. The mantle is continuons round the body, not bilobed, as in Lamellibranchs. $\Lambda$ few, as the common Garden-snail, have a lung; but the rast majority breathe by gills. The head is more or less distinct, and provided with two tentacles, with anditory sacs at their bases; two eves, which are often on stalks; and a straplike tongue corered with minute teeth. The heart is situated, in the majority, on the right side of the back. All, except the Pteropods, move by means of a ventral disk, or foot.

Gasteropods are now the reigning Mollusks, comprising three-fourths of all the living species, and are the types of the snbkingdom. They have an extraordinary range in latitude, altitude, and depth.

Omitting a few rare and alserrant forms, ${ }^{157}$ we may separate the class into the following orders:

1. Pteropods.-These are small, marine, floating Mollusks, whose main organs of motion resenble a pair of wings or fins coming out of the neek, whence the common name, "Sea-butterflies." Many have a delicate, transparent shell. The head has six appendages, armed with several hundred thonsand microscopic suckersa prehensile apparatus mecualed in complication. Pteropods oceur in

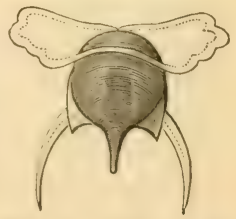

Fri, 220.-1 Pteropol $(I I y-$ aleu tribentutur). Atlantic. every latitude, but generally in mid-ocean, and in the arctic rewions are the food of Whales and sea-birds.

2. Opisthobrunchs.-These low Gasteropods are, for the 
most part, naked Sea-slugs, a few only having a small shell. The feathery gills are behind the heart (whence the name). They are found in all seas from the arctic to the torrid, generally on rocky coasts. When disturbed, most of them draw themselves up into a lump of jelly

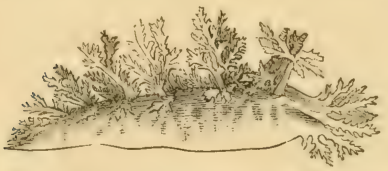

Frg. 221. - A Tritonian (Dendronotus arborescens). British seas.

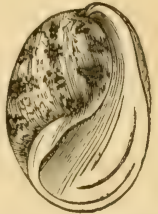

FIG. 222. - Bulla ampul$l \pi$, or "Bubble-shell;" three - fourths natural size. Indian Ocean.

or tough slin. Exmmples: Sea-lemon (Doris), the beauti. ful Tritonia, the painted EElis, the Sea-hare (Aplysia), which discharges a purple fluid, and the Bubble-shell (Bulla).

3. Putmonates. - These air-breathing Gasteropods, represented by the familiar. Snail, have the simplest form of lung - a cavity lined with a delicate net-work of bloodressels, which opens externally on the right side of the neck. This entrance is closed by a valve, to shut ont the water in the aquatic tribes, and the hot, dry air of summer days in the land species. They are all fond of moisture, and are more or less slimy. Their shells are lighter (being thimer, and containing less earthy matter) than those of marine Mollusks, having to be earried on the back without the support of the water. Their eggs are laid singly; while the eggs of other orders are laid in chains.

They are found in all zones, but most numerons where lime and moisture abound. All feed on vegetable matter. A few are naked, as the Slug; some are terrestrial; others live in fresh water. The Land-snails, represented by the common Ilelix, the gigantic Bulimus, and the Slug ( $\mathrm{Li}$ marc), are distinguished by their four "horns," the short 
front pair being the true tentacles, and the long hinder pair being the eye-stumps. They have a saw-lilie upper

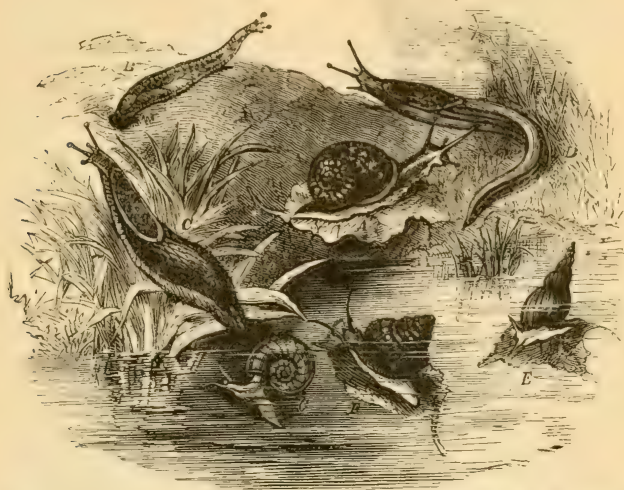

Fro. 223. - A, Land-suail (Helix); $D, C, D$, Slugs (Limex $) ; E, F, G$, Pond-snails (Limnoe, Paludina, and Planorbis).

jaw for biting leares, and a short tongue eorered with minute teeth. The Pond-snails, as Limnue and I'lanombis, differ in having no eye-stalks, the eyes being at the base of the tentacles. They are obliged to come frequently to the surface of the water to breathe.

4. Prosobranchs.-These are aquatic Gasteropods, breathing by gills situated in front of the heart. They are the most highly organized and the most abundant of the crawling Mollusks. Nearly all are marine, and all have a shell.

Among the lower forms are the sin-

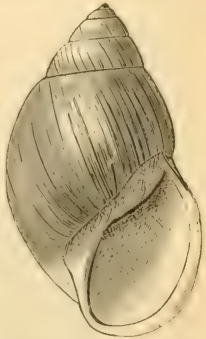

FIt. 224.-Dulimus oblen. gus; one-half natural size. Guiana. mular ('hiton, covered with eight shelly plates; Limpet (I'atella), well known to erery sea-side visitor; and the 


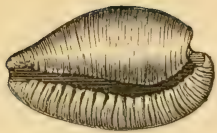

Fra. 225.-Cowry (Cumpea capensis) : twothirds natural size. South Africa.

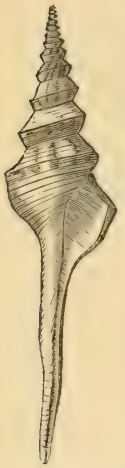

Fro. 227. - Spindleshell (Fusus colus); one-half natural size. Ceylon.

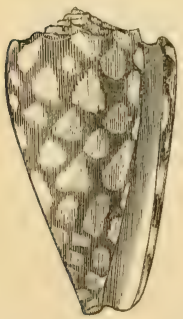

Fig. 230.-Cone-shell (Conus marmoreus); two-thirds natural size. China seas.

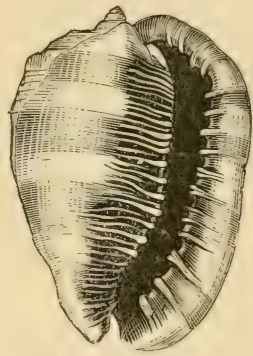

Frg. 228, - Cassis rufa, or "Helmet-shell:" one-fourth natural size. Indian Ocean.

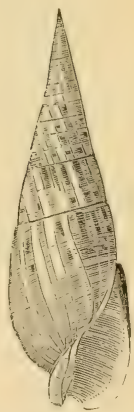

Fig. 229.-Anger-shel) (Terebra maculata): one-half natural size. China seas.

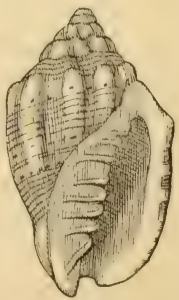

Fig. 231,-Chiton squamosne; one-balf natural size. West Iudies.
Fig. 232.-Volute (Voluta musica); one-half natural size. West Indies. 


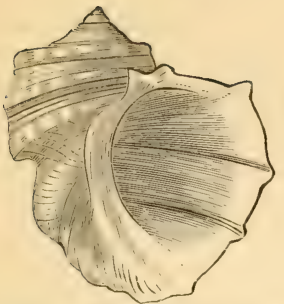

Fro. 233. - Top)-shell (Turbo marmoratus); one-fourth watural size. China seas.

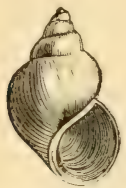

Frg. 235. - Paludind, a Fresh-water Snail.

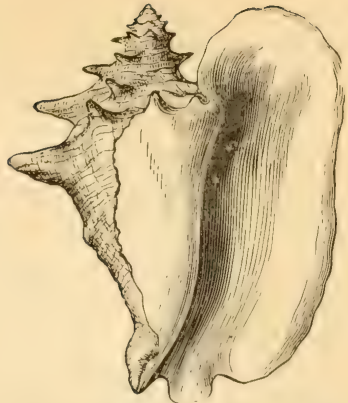

FIG. 234.-Strombus ginas, or "Wincedshell:" one-tifth natural size. West Indies.

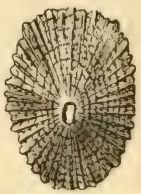

Fra. 236.-Key-hole Limpet (Fissurella listeri). West Iudies.

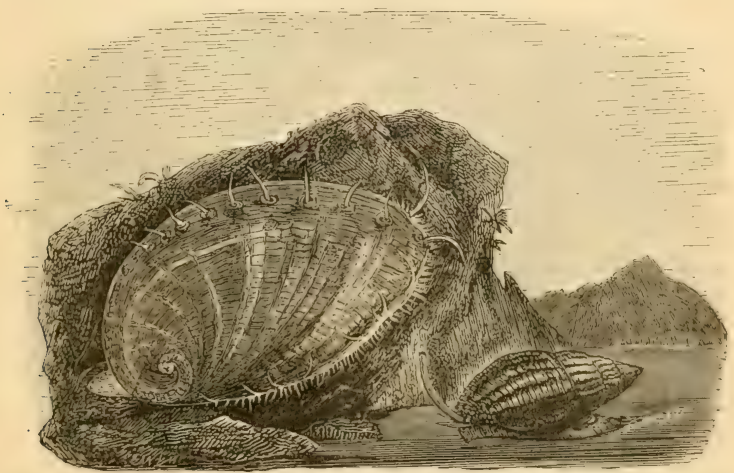

Fig 207.-Ear-shell $(H$. tuberculutu), and Dour-whelk (Nassa reticulutu). Eurgland. 
beautiful Ear-shell (Haliotis), frequently used for ornaments and inlaid-work.

In the higher Prosobranchs, the gills are comb-shaped and the sexes are distinct. The group includes all the spiral univalve sea-shells, and a few fresh-water shells. Many have the aperture entire, which is closed with an operculum: as the dull-colored P'alutina and Melania from fresh water, and the pyramidal Trochus, pearly Turbo, screw-like Turritella, common Periwinkle (Littorina), and globular Nuticu from the sea. Others, the highest of the race, have the margin of the aperture notched or produced into a canal, and are carnivorous and marine: such are nearly all the sea-shells, remarkable for their beautiful forms, enameled surfaces, and brilliant tints, as the Cowry (Cypraa), Volute, Olive, Cone, IIarp, Whelk (Buccinum), Cameo-shell (Cassis), Rock-shell (Murex), Trumpet-shell (Triton), Spindle-shell (Fusus), and Wing-shell (Strombus).

\section{Class VI.-Cephalopoda.}

The Cephalopods stand at the head of the subkingdom, some of them outranking the highest Articulates; but they are not so typical as the Gasteropods. The head is set off from the body by a slight constriction, and furnished with a pair of large, staring eyes, a mouth armed with a rasping tongue and a parrot-like beak, and eight or more tentacles or arms. The body is symmetrical, and wrapped in a muscular mantle.

The nervous system is more concentrated than in other Invertebrates; the cerebral ganglia are even inclosed in a cartilaginous craninm. All the five senses are present. The class is entirely marine (breathing by plume-like gills on the sides of the body), and carnirorous. The naked species are found in erery sea. Those with chambered shells (as Nuutilus, Ammonite, and Orthoceras) were once 
very abundant: more than 2000 fossil species are known, but only one living representative - the Pearly Nautilus.

1. Tetrubrunchs. - This order is characterized by the possession of four gills, forty or more short tentacles, and an external, chambered shell. The partitions, or septa, of the shell are united by a tube called "siphuncle," and the animal lives in the last and largest chamber. ${ }^{159}$ The living Nautilus has a smooth, pearly shell, a head retractile within the mantle or "lood," and calcareous mandibles well fitted for masticating Crabs, on which it feeds. This strag-

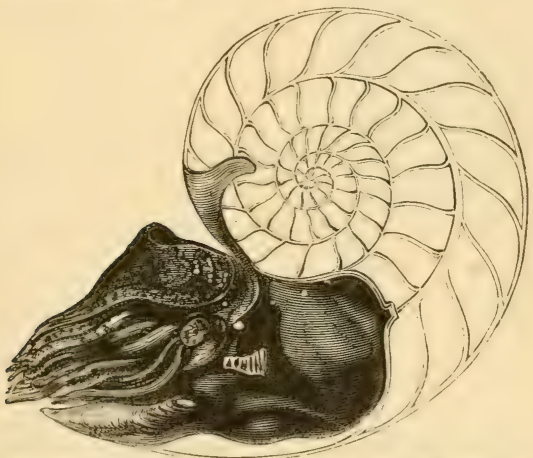

Frn. 239.-Pearly Nitutilus, with shell bisected: one-half natural size. Indian Ocenn. gler of a mighty race dwells in the deep parts of the Indian Ocean, crawling on the bottom; and while the shell is well known, only two or three specimens of the animal have ever been obtained.

2. Dibranchs.-These are the most active of Mollusks, and the trrants of the lower tribes. Among them are the largest of invertebrate animals. They are naked, having no external shell corering the boly, but usually a horny or calcareous part within. They have a distinct head, prominent eyes, horny mandibles, eight or ten arms furnished with suckers, ${ }^{150}$ two grills, a com- 


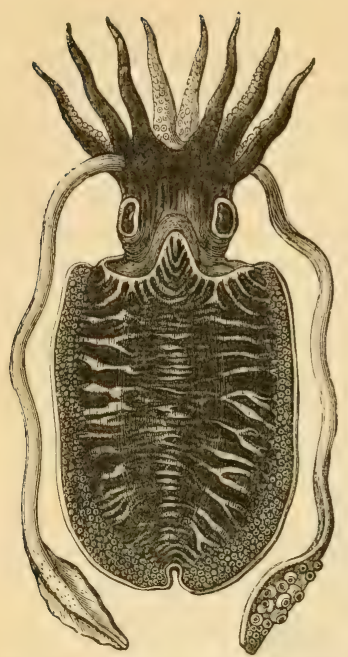

Fra. 239.-Cuttle-fish (Sepia officinalis); one-fifth natural size. Atlantic coasts. plete tubular funnel, and an ink-bag containing a peculiar fluid (sepia), of intense blackness, with which the water is darkened to facilitate escape. They have the power of changing color, like the Chameleon. They crawl with their arms on the bottom of the sea, head downward, and also swim backward or forward, usually with the back downward, by means of fins, or squirt themselves backward by forcing water forward through their breathing fumnels.

The Paper Nantilus (Argonauta) and the Ponlpe (Octopus) have eight arms. The female Argonant secretes a thin, unchambered shell for

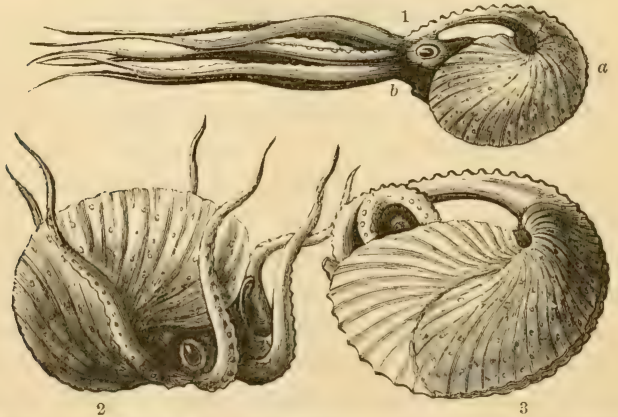

FIg. 240. - Paper Nantilus (Arqonauta argo): 1, swimming toward $a$ by ejecting water from funnel, $b ; 2$, crawling on the bottom; 3 , coiled within its shell, which is one-fourth natural size. Mediterrauean. 
carrying its ecgess. The Squid (Lotigo) and Cuttle-fish (Sepiu) have ten arms, the additional pair being much longer than the others. Their eyes are morable, while those of the Argonaut and Poulpe are fixed. The Squid, so much used for bait by cod-fishermen, has an internal horny "pen," and the Cuttle has a spongy - calcareous "bone." The extinct Belemnite had a similar structure.

\section{Subkingdom Articulata.}

This is larger than all the other sublingdoms put together, as it includes the jointed animals, such as Worms, Crabs, and Insects. These differ widely from the Molluscan type in having a symmetrical form, and in showing a repetition of similar parts, not only in the shelly exterior; but equally among the internal organs.

The skeleton is ontside, and consists of articulated segments or rings. The limbs, when present, are likewise jointed and hollow. The jaws more from side to side. The nervous system consists mainly of a donble chain of ganglia ruming along the ventral surface of the body under the alimentary canal. The brain is in the form of a ring encircling the gullet. The alimentary canal and the circulatory apparatus are nearly straight tubes lying lengthwise - the one through the centre, and the other along the back. There is a remarkable correspondence, especially in the lower forms, between the joints of the - body and the ganglia of the nerrous cord, the respiratory organs and the chambers of the dorsal heart. Each ring of a Worm has a complete circulatory, respiratory, and nervous apparatus. ${ }^{100}$

As we advance from the lowest forms (Worms), in which the body is elongated, the rings numerous, the skin soft, and the legs imperfect, we shall find the rings fewer, the skin firmer, and the legs more elaborately formed, as in the Centipede; till in the Bee, Spider, and 
Crab, we see an increasing consolidation of the exoskeleton, and more perfect limbs, and a tendency to concentrate the body in front, and thin ont behind. Along with these progressive steps, we notice the muscular powers becoming more energetic, and the nervous ganglia condensing into larger masses.

The subkingdom is divided into five classes: the aquatic Worms and Crustaceans, and the air-breathing Spiders, Myriapods, and Insects. ${ }^{161}$ The various forms of articulate life arise from the mequal development of the body-segments and rariation in the number and form of appendages.

\section{Class I.-Annelida.}

The Annelids, or Worms, are distinguished from all other Articulates by the absence of hollow articulated

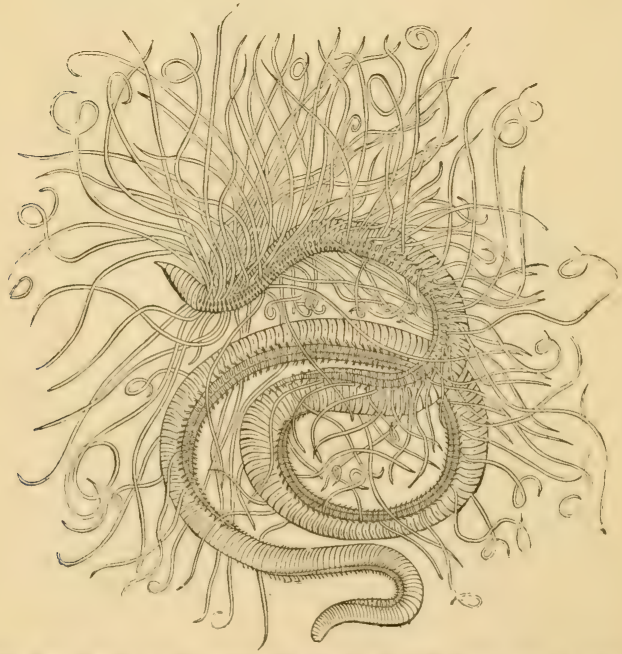

Fra. 241.-Marine Wurm (Cirratulus grandis), with extended cirri. Atlantic. 
limbs, and ly the fact that no one part of the body is highly honored abore the rest. The body is soft, and composed of a succession of rings (from 20 to 500 ), which are repetitions of each other. The first segment, called the head, differs little from the rest. The legs, when existing, are merely bunches of short, stiff bristles (sete), each terminating in a hook or blade. Many of the seaworms have tentacles. Touch is probably the only sense.

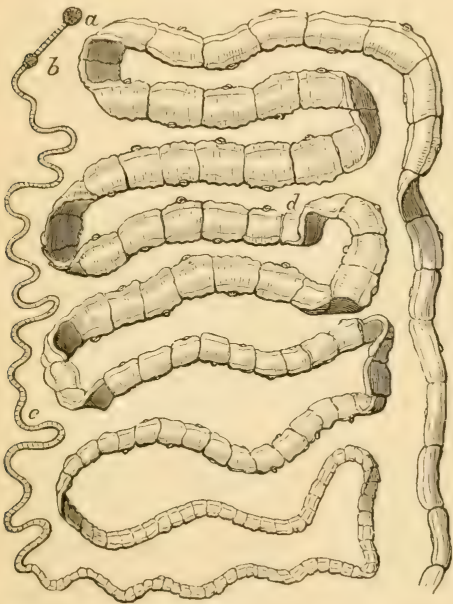

F1G. 242.-Tape-worm (Tania solium) : $a$, bead; $b, c$, $d$, segments of the body.

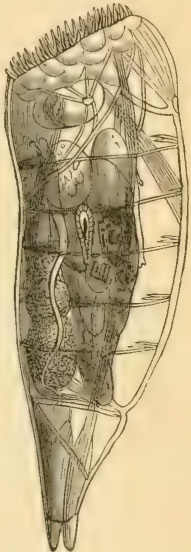

Fig. 243. - Rotifer, or "Wheel-animalcule" (Hydatina); highly magnified.

The blood is often reddish, but seldom contains corpuscles. Strange to say, the circulatory apparatus is closed, and more highly dereloped than in Insects. They are mostly marine, and carnivorons.

There are three representative orders: 1 . The low and abnormal Anmuloide, which are withont joints or setæ, and are mainly parasitic, as the Tape-worm (Twnia), IIair-worm (Gordiacea), and Trichina. ${ }^{102}$ 2. The Abran- 
chiates, which breathe by the skin. The majority are fresh-water, as the Leech (Sanguisuga) and Earth-worm (Lumbricus). 3. The Branchiates, whose organs of respiration are tuft-like gills on the back or head. Such are the sea-worms Arenicola, Nereis, and Serpula.

The Rotifers, or "Wheel-animaleules," are minute aquatic Articulates, whose exact position is doubtful, having some of the features of both Worms and Crustaceans. They resemble Infusoria externally, but have a complete alimentary canal and well-developed nervous system. At the head is a disk furnished with cilia for locomotion and prehension, and at the other end is a pair of "toes," which act like forceps. None are over $\frac{1}{36}$ of an inch long.

\section{CL $\Lambda$ SS II.-Crustacea.}

This class includes all Articulates having jointed legs and gills. ${ }^{163}$ Among them are the largest, strongest, and most voracious of the sublingdom, armed with powerful claws and a hard cuirass bristling with spines. Althongh constructed on a common type, Crustaceans exhibit a wonderful diversity of external form: contrast, for example, a Barnacle and a Crab. We will select the Lobster as illustrative of the entire group.

Every Crustacean consists of twenty-one segments, of which seren belong to the head, seven to the thorax, and seven to the abdomen. ${ }^{104}$ In the Lobster, howerer, as in all the higher forms, the joints of the head and thorax are welded together into a single crust, called the cephatothorax. On the front of this shield is a pointed process, or rostrum; and attached to the last joint of the abdomen (the so-called "tail") is the sole representative of a tail-the telson. This skeleton is a mixture of chitine and calcareous matter, and corresponds to our epidermis. ${ }^{165}$

On the under-side of the body we find numerous ap- 
pendages, feelers, jaws, claws, and legs beneath the cephalu-thorax, and flat swimmerets under the abdomen. In fact, as a rule, every segment carries a pair of movable appendinges. The seren segments of the head are compressed into a very small spare, yet have the following menibers: the eye-stalls; the short and long antenna; the mandibles, or jaws, between which the month opens; the two pairs of maxillæ; and a pair of modified limbs, called "footjaws." The thorax carries two more pairs of foot-jaws, and five pair's of legs. The foremost legs, "the great claws," are extraordinarily developed, and terminated by strong pincers (chelce). Of the four slender pairs succeeding, two are furnished with claws, and two are pointed. The last pair of swimmerets, together with the telson, form the candal fin-

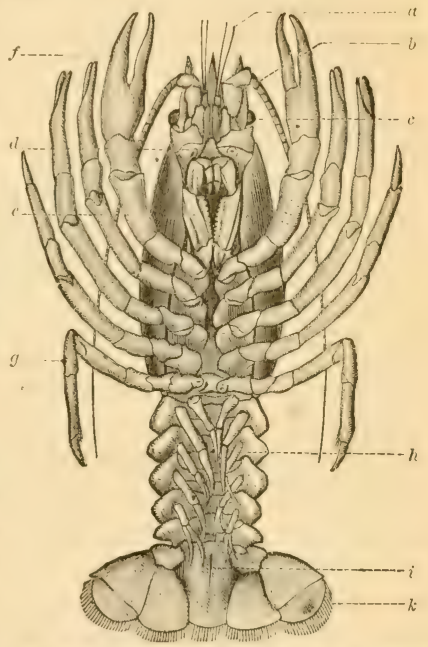

Fif. 241. - Tuder-xide of the Cray-1ish, or Freshwater Lobster (.1sfaces fiuriatilis): $a$, tirst pair of antemna: $b$, second pair; $c$, eyes: $d$, :militory tubercles; $c$, foot-jaws; $f, g$, tirst and tifth pair of thoracic less ; $l$, false abdominal feet ; $i$, anus ; $k$, caudal tin.

the main instrument of locomotion; the others (called "false feet") are used by the female for carrying her eggs. The eyes are raised on stalls so as to be movalle (since the liead is fixed to the thorax), and are (ompound, made up of about 2500 square facets. At the base of each small antenna is a minute sac, whose mouth is guarded by 
hairs: this is the organ of hearing. ${ }^{166}$ The gills, twenty on a side, are situated at the bases of the leg's and inclosed in two chambers, into which water is freely admitted, in fact, drawn by means of a curious valve at the outlet which works like the "screw" of a propeller. The heart is a single oval cavity, and drives arterial blood-a dusky fluid full of corpuscles. The alimentary canal consists of a short grullet, a gizzard-like stomach, and a straight intestine.

Crustaceans pass through a series of strange metamorphoses before reaching their adult form. They also periodically cast the shell, or molt, every part of the integument being renewed; and another remarkable endowment is the spontaneons rejection of limbs and their complete restoration. Many species are found in fresh water, but the class is essentially marine and camivorons.

No natural classification of this raried group has been discovered. It will be convenient to divide it into four order's :

1. Cimipeds, distinguished by being fixed, by having a shelly corering, and by their feathery arms (cirri). Such are Bamacles (Lepas) and Acorn-shells (Bulanus), so common on rocks and timbers by the sea-shore.

2. Entomostracans, which agree in having a horny shell and no abdominal limbs; represented by the little Waterfleas (Cyclops) of our pouds, the King-crabs (Limulus), ahounding on every sea-coast, and the extinct Trilobites. The abdomen of the King-crab is reduced to a mere spine, the appendages about the mouth are used for locomotion, and the eyes are smooth.

3. Tetradecapods, small, fourteen-footed species; as the Wond-louse, or Sow-bug (Oniscus), so common in damp places, and the Sand-flea (Gummarus), seen by the seaside in summer.

4. Decupods, having ten legs, as the Shrimp (Cran- 


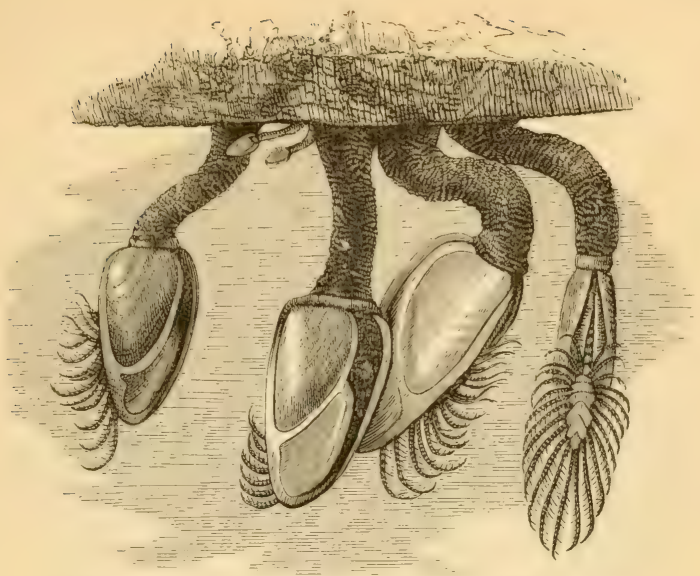

Fro. 245. -Baruacles, or Peluuculate Cirripedes (Lepas anatifera).

gon), Cray-fish and Lobster (Astacus), and Crab (C'ancer). Crabs differ from Lobsters chiefly in being formed for creeping at the bottom of the sea instead of swimming, and in the reduction of the abdomen or "tail" to a mere

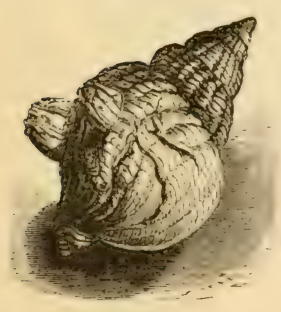

Fig. 246.-Acorn-shells (Balumes) on the shell of a Whelk (Buccinum).

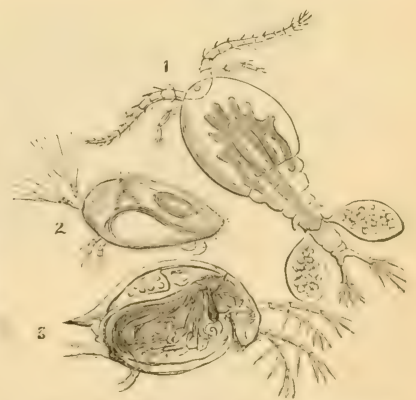

Fig. 247.-Watcr-fleas: 1, Cycloys emmmunis; 2, Copris unifusciuta; 3, Duphniu pulex. 
rudiment which folds into a groove under the enormons thorax. They are the highest and largest of Crustaceans: they have been found at Japan measuring ten feet between the tips of the claws.

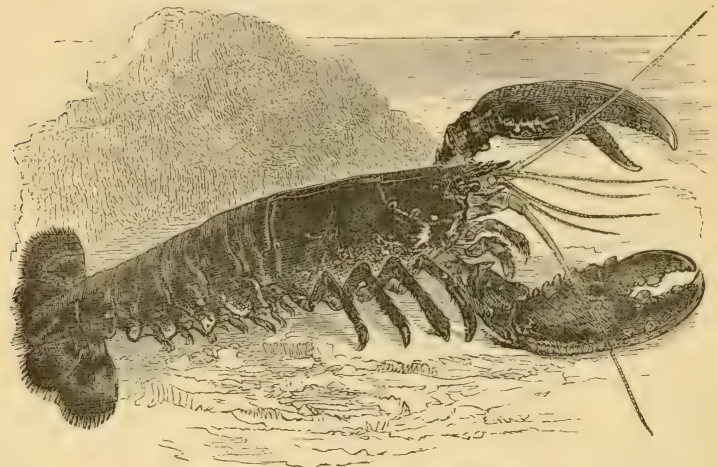

Fig. 245.-Lobster (Homarus A mericanus).

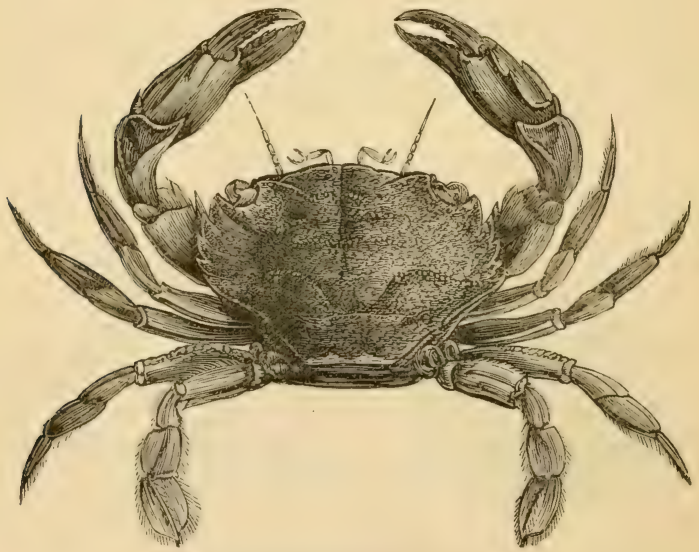

Fig. 249.-Swimming Crab. 


\section{Class III.-Arachnida.}

The Arachnids are clusely related to the Crustaceans, having the body divided into a cephalo-thorax and abdomen. ${ }^{167}$ To the former are attached eight legs of seren joints each; the latter has no locomotive appendages. The head carries two, six, or eight eyes, smooth and sessile (i. c., not fanceted and stalked, as in the Lobster), and approaching the eye of the Vertebrates in the completeness and perfection of their apparatus. The antema, if present, are only two, and these are not "feeler's" but modified to serve for the prehension of food. They are all airbreathers, having spiracles which open either into air-sacs or tracheie. The young of the higher forms undergo no metamorphosis after leaving the egg.

Arachnids number nearly 5000 species. The typical forms are divided into three groups :

1. Acarina, represented by the Mites and Ticks. They have an oral or rounded body, withont any marked articnlations, the head, thorax, and abdomen being apparently merged into one. They have no brain, only a single ganglion lodged in the abdomen. They breathe by trachex. The month is formed for suction, and they are generally parasitic. The Mites (Acarnes) are among the low-

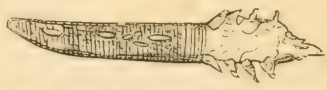

Ficr. 250, - A Mite (Demodex folliculurum), wne of the luwest Arachnids: a parasite ou human hair ; $\times 125$.

est of Articulates. The body is soft and minnte. The Tickis (Ixorles) hare a leathery skin, and are sometimes half an inch long. The month is furnished with a beak for piercing the animal it infests.

2. Perlipulpi, or Scorpiuns, characterized lyy very large maxillary palpi ending in forceps, and a prolonged, jointed abdomen. The nerrous and cirenlatery srstems are more highly organized than those of spiders; but the 
long, tail-like abdomen and the abnormal jaws place them in a luwer rank. The abdomen consists of twelve segments: the anterior half is as large as the thorax, with no well-marked division between; the other part is comparatively slender, and ends in a hooked sting, which is perforated by a tube leading to a poison-sac. The antennæ are transformed into small, nipping claws, and the eyes gen-

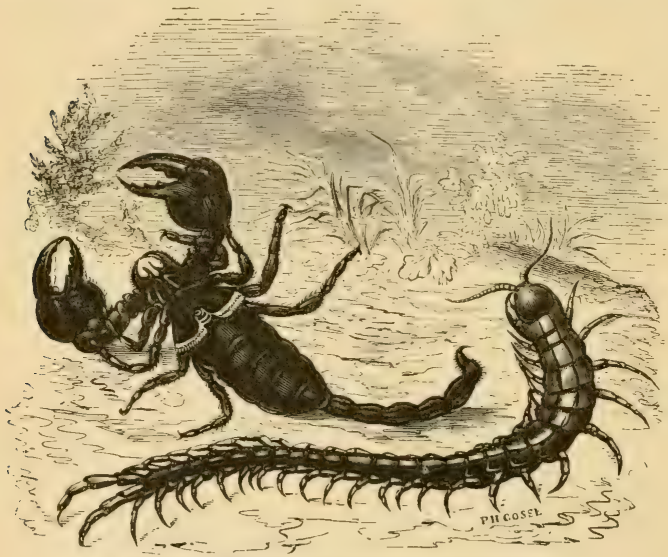

Fig. 251.-Scorpion (unter-surface) and Centipede.

erally number six. Respiration is carried on by four pairs of pulmonary sacs which open on the under-surface of the abdomen. The heart is a strong artery, extending along the middle of the back, and divided into eight separate chambers. Scorpions are confined to the warm-temperate and tropical regions, usually lurking in dark, damp places.

The Ilarvest-men (Phalangium), frequently seen about our houses, belong to this order. They have a short, thick body and extremely long legs, and breathe by trachex.

3. Araneina, or Spiders. They are distinguished by 
their soft, mjointed abdomen, separated from the thorax by a narrow constriction, and provided at the posterior end with two or three pairs of appendages, called "spinnerets," which are considered homologons with the legs. The oftice of the spinnerets is to reel out the silk from the silk-glands, the tip being perforated by a myriad of little

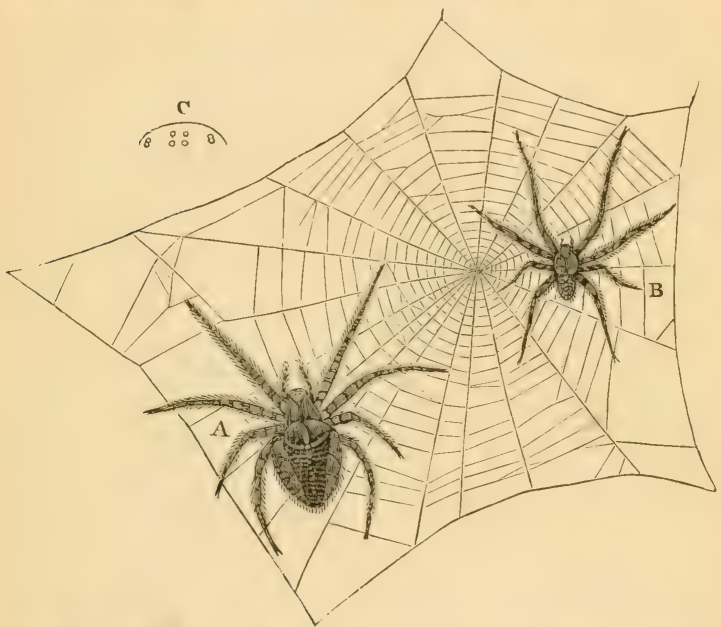

Frg. 252.-A, female Spider; B, male of same species; C, arrangement of the eyes.

tubes, through which the silk escapes in excessirely fine threads. An ordinary thread, just risible to the naked eve, is the mion of a thousand or more of these delicate streams of silk. ${ }^{168}$ These primary threads are drawn ont and united by the hind legs.

The mandibles are rertical, and end in a powerful hook, in the end of which opens a duct from a poison-gland in the head. The maxille, or "palpi," which in Scorpions are changed to formidable claws, in Spiders resemble the thoracic feet, and are often mistaken for a fifth pair. The 
brain is of larger size, and the whole nervons system more concentrated than in the preceding order. There are gen-

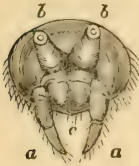

Ft(i. 253.-Spiunerets of the sipicler, $b, c ; a$, palpiform orgaus. erally eight simple eyes, rarely six. They breathe both by trachere and lung-like sacs, from two to four in number, sitnated under the abdomen. All the species are carnirorous.

The instincts of Spiders are of a high order. They are, perhaps, the most wily of Articulates. They display remarkable skill and industry in the construction of their webs; and some species (called "Mason Spiders") eren excarate a subterranean pit, line it with their silken tapestry, and close the entrance with a lid which moves upon a hinge. ${ }^{169}$

\section{Class IV.-Myriapoda.}

Myriapods differ from Crustaceans and Spiders in having the thorax merged in the abdomen, while the head is free. In other words, the body is divided into similar segments, so that thorax and alidomen are scarcely distinguishable. They resemble Worms in form and in the simplicity of their nervous and circulatory systems; but the skin is stiffened with chitine, and the legs (indefinite in number) are articulated. The legs resemble those of Insects, and the head appendages follow each other in the same order as in Insects-eres, antemne, mandibles, maxillie, and palpi. They breathe by trachea, and have two antennæ and a variable number of eyes.

There are two orders:

1. Chilognatha, having a eylindrical body, each segment furnished with two pairs of legs. They are of slow locomotion, harmless, and regetarian. The Thonsand-legged Worm (Julus) is a common representative.

2. Chilopode, characterized by haring a flattened body composed of about twenty segments, each carrying one 
prir of leos, of which the hindermost is converted into spines. They have longer antenne than the preceding, and the month is armed with two formidable fangs connected with poisonous glands. They are carnivorous and active. Such is the Centipede (Scolopendra).

\section{Class V.--Insecta.}

Insects are distinguished by having head, thorax, and aldomen distinct, three pairs of jointed legs, one pair of anteme, and generally two pairs of wings. The number of segments in the body nerer exceeds twenty. The head, apparently one, is formed by the union of seren pieces. The thorax consists of three, the prothorche, mesethorcex, and metuthorke, each bearing a pair of legs; the wings, if present, originate from the last two segments. The abdomen is normally composed of nine segments, more or less movable upon one another. The skin is hardened with chitine, and to it, as in all Articulates, the muscles are attached. The organs of sense are confined to the epphalic division of the body, the motor organs to the thoracic, and the regetative to the abdominal. All the appendages are hollow.

The antenna are inserted between or in front of the eves. There is a great rariety of forms, but all are tubular and jointed. They are supposed to be organs of touch, and also seem to be sensitive to sound. The eyes are usually compound, composed of a large number of hexagonal cornex, or facets (from fifty in the Ant to many thousands in the winged Insects). They are never placed on morable pillar's as the Lobster's. Besides these, there are three simple eyes, called ocelli. The month may be fitted for biting (masticutory), as in Ieetles, or for sucking (suctoricl), as in Buttertlies. The masticatory trpe, which is the more complete, and of which the other is but a moditication, consists of four horny jaws (mandib? 
illce) and an upper and an under lip (labrum and labium).

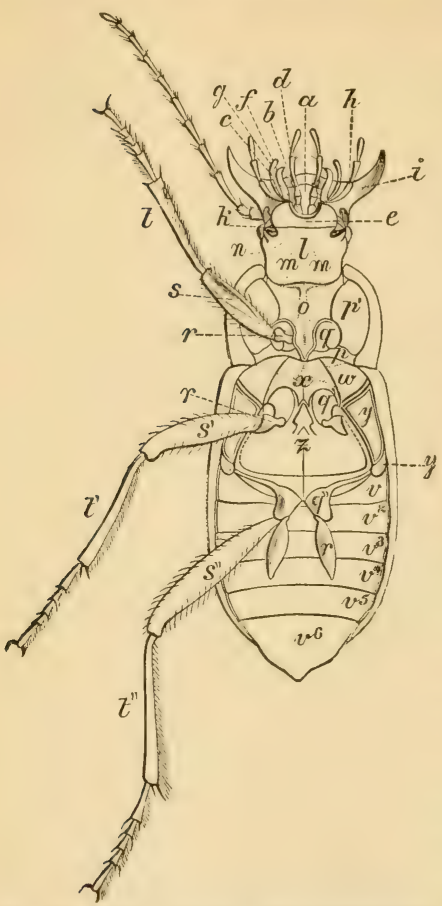

FIG. 254--Under-surface of a Beetle (Harpalus caliginosus): $a$, ligula; $b$, paraglossæ; $c$, supports of labial palpi; $d$, labial palpus; $e$, mentum ; $f$, inner lobe of maxilla; $g$, outer lobe; $h$, maxillary palpus; $i$, mandible; $k$, buccal opening; $l$, gula, or throat; $m$, buccal sutures; $n$, gular suture; $o$, prosternum; $p$, episternum of prothorax; $p^{\prime}$, epimeron; $q, q^{\prime}, q^{\prime \prime}, \operatorname{cox} \rightsquigarrow ; r, r^{\prime}, r^{\prime \prime}$, trochanters; $s$, $s^{\prime}, s^{\prime \prime}$, femora, or thighs ; $t, t^{\prime}, t^{\prime \prime}$, tibs; $v$, ventral abdominal segments; $v$, episterna of mesothorax; $x$, mesosternum; 1 , episterna of metathorax; $y^{\prime}$, epimeron; $z$, metusterunm.
Sensitive palpi (maxillary and labial) are developed from the lower jaw and lower lip. The labium is also prolonged into a ligula, or tongue.

The legs are invariably six in the adult, the fore-legs directed forward and the hinder pairs backward. Each consists of a hip, thigh, shank, and foot. ${ }^{170}$ The larvæ have also "false legs," withont joints, on the abdomen, upon which they chiefly rely in locomotion. The wings are expansions of the crust stretched over a network of horny tubes. The venation, or arrangement of these tubes (called veins and veinlets), particularly in the forewings, is peculiar in each genus. In many Insects, especially Hymenopters, the abdomen of the female ends in a tube which is the sheath 
of a sting, as in the Bee, or of an ovipositor, or "borer," as in the Ichnemmon, by means of which the eggs are deposited in suitable places.

Cephalization is carried to its maximum in this class, and we have animals of the highest instincts moler the articulate type. The "brain" is formed of several ganglia massed together, and lies across the upper side of the throat just behind the month. The main cord, which lies along the rentral side of the body, with a swelling for each segment, corresponds to the sympathetic system of Vertebrates. A true brain and spinal cord are umrepresented among invertebrated animals. The digestive apparatus consists of a pharynx, gullet (to which a crop is added in the Fly, Butterfly, and Bee tribes), gizzard, stomach, and intestine. There are no absorbent ressels, the chyme simply transuding through the walls of the canal. The blood, usmally a colorless liquid, is driven by a chain of hearts along the back, i. e., by a pulsating tube divided into valvular sacs, ordinarily eight, which allow the current to flow only toward the head. As it leares this main pipe (anta), it escapes into the cavities of the body, and thus bathes all the organs. Although the blood does not circulate in a closed system of blood-ressels, as in Vertebrates, yet it always takes one set of chammels in going from the heart, and another in returning. Respiration is carried on by trachese, a system of tubes opening at the surface by a row of apertures (spiracles), generally nine on each side of the body.

The sexes are distinct, and the larve are hatched from eggs. As a rule, an Insect, after reaching the adult, or imago, state, lives from six months to a few hours, and dies after the process of reproduction. Growth takes place only during larval life, and all metamorphoses oecur then. Among the social tribes, as Bees and Ants, the majority (called "workers") do not develop either sex. 
Insects (the six-fouted Articnlates) comprise four-fifths of the whole Animal Kingdom, or about 200,000 species. They are grouped into seven orders:

Lower series: body ustally flattened; prothorax large and squarish; mouth-parts usually adapted for biting; metamorphosis incomplete; pupa often inactive; Jarva flattened, often resembling the adult.

Higher series: body usually cylindrical; prothorax small; mouth-parts more generally formed for sucking; metamorphosis complete; pupa inactive; larva usually cylindrical, very unlike the adult.

Neuropters, Orthopters, Hemipters, Coleopters.

Dipters, Lepidopters, Hymenopters.

1. Neuropters have a comparatively long, slender body, and four large, transparent wings, nearly eçual in size, membranous and lace-like. Such are the brilliant Dragon-flies, or Devil's Darning-needles (Libellula), well known by the enormous head and thorax, large, prominent eyes

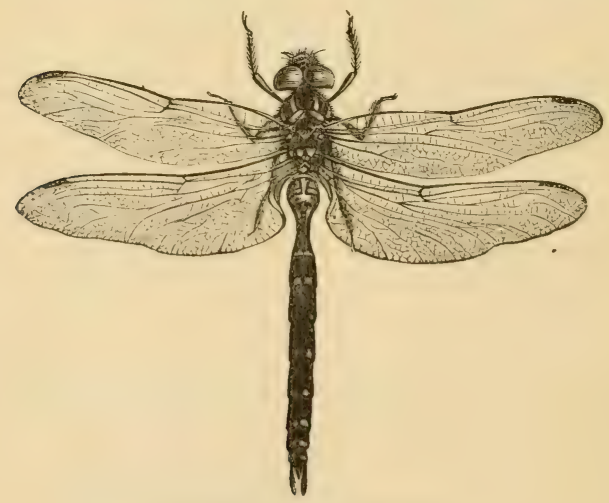

FiG. 255.-Dragon-fly (Libellula).

(each furnished with 12,000 polished lenses), and Scorpion-like abdomen; the delicate and short-lived May-flies (El)hemera); Caddis-flies (Phryganea), whose larra live in a tubular case made of minute stones, shells, or bits 
of wool; the IIorned Corydalis (Cormytulus), of which the male has formidable mandibles twice as long as the head; and the White Ants (Termes) of the tropics.

2. Orthopters have four wings: the front pair somewhat thickened, narrow, and overlapping along the back; the hind pair broad, net-veined, and folding up like a fan nyom the abdomen. The hind legs are usually large, and fitted for leaping, all the species being terrestrial, although some fly as well as leap. The eyes are small, the mouth

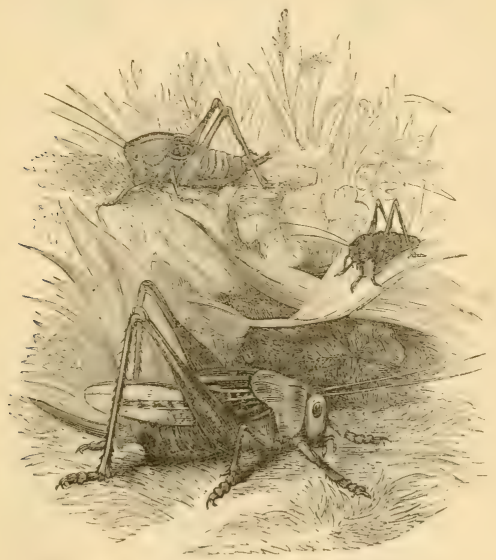

Fig. 256.-Metamorphosis of a Cricket (Gryllus).

remarkably dereloped for cutting and grinding. The larre and pupa are active, and resemble the imago. They are all regetarian. Each family produces characteristic sommls (stridulation). The representative forms are Crickets (Gimpllus), Locusts (Locustu), Grasshoppers (Acryılium), Walkingr-sticks (I'husma), and Cockroaches (Bluttu).

3. Hemipters, or "Bugs," are chiefly characterized by a suctorial month, which is produced into a long, hard 


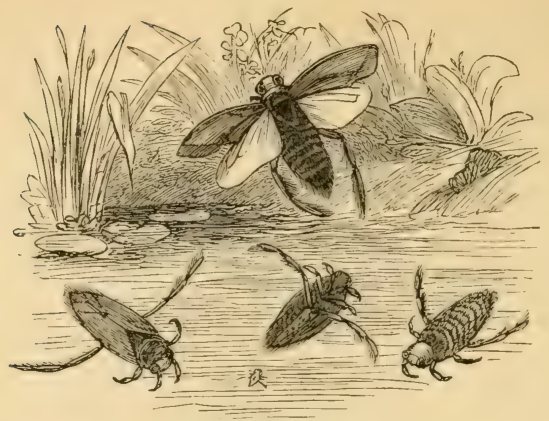

Frg. 257.-Metamorphosis of an Hemipter, Water-boatman (Notonecta).

beak. The four wings are irregularly and sparsely reined, sometimes wanting. The body is flat above, and the legs slender. The larra differs from the imago in wanting

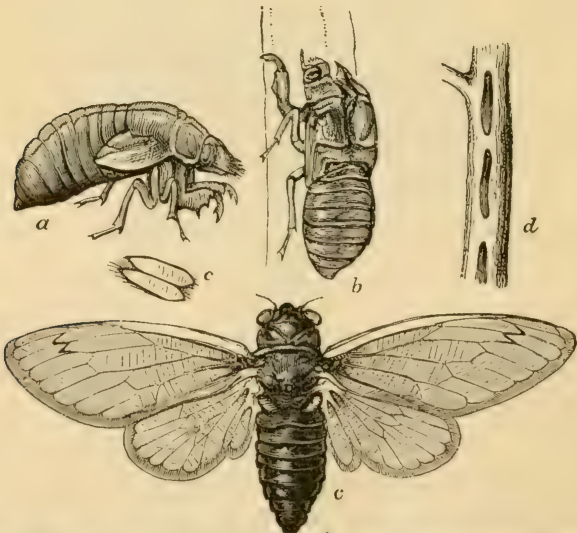

Fig. 25S,-Seventeen-rear Locust (Cicala septemdecim): $a$, pupa; $b$, the same, after the imago, $c$, has escaped through a rent in the back; $d$, holes in a twig, where the eggs, $e_{2}$ are inserted. 
wings. In some species, the fore-wings are opaque at the base, and transparent at the apex, whence the name of the order. Some feel on the juices of animals, others on plants. Ilere belong the wingless Bed-bug (C'imer) and Lonse (Péliculus), the Syuash-bug (Corezs), Water-boatman ( Fotonectu), Seventeen-year Locust (Ciculu), Cochineal (Coceus), and Plant-lice (Apliss).

4. Culeropters, or "Beetles." This is the largest of the orders, the species numbering about 90,000. They are easily recognized by the elytre, or thickened horny forewings, which are not used for flight, but serve to cover the hind pair. When in repose, these elytra are always mited by a straight edge along the whole length. The hind wings, when not in use, are folded transversely. The mandibles are well dereloped, and the integument general$\mathrm{l}_{\mathrm{y}}$ is hard. The legs are strong, for the Beetles are among
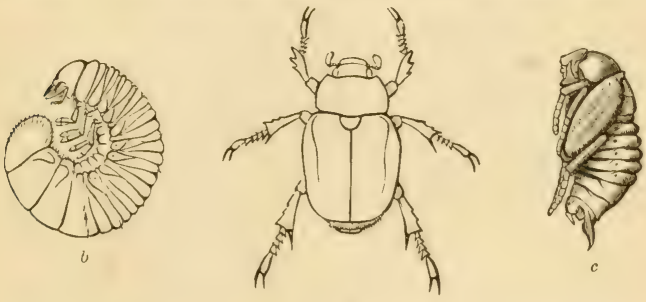

Fig. 259. - $a$, imago, and $b$, larva, of the Goldsmith Beetle (Cotalpa Ianigera); $c$, pupa of June-bug (Lachnosterna fusea).

the most powerful ruming Insects. The larve are wormlike, and the pupa is motionless. The highest tribes are carnirorums. 'The most prominent forms are the savage but beantiful Tiger Beetles (C'icintelu); the common Ground Beetles (C'aralus), whose hind wings are often absent; the Diving Iheetles (Dytisens), with boat-shined body, and hind lears changed into oars; the Carrion Beetles (Siljolea), distinguished by their black, flat bodies and 


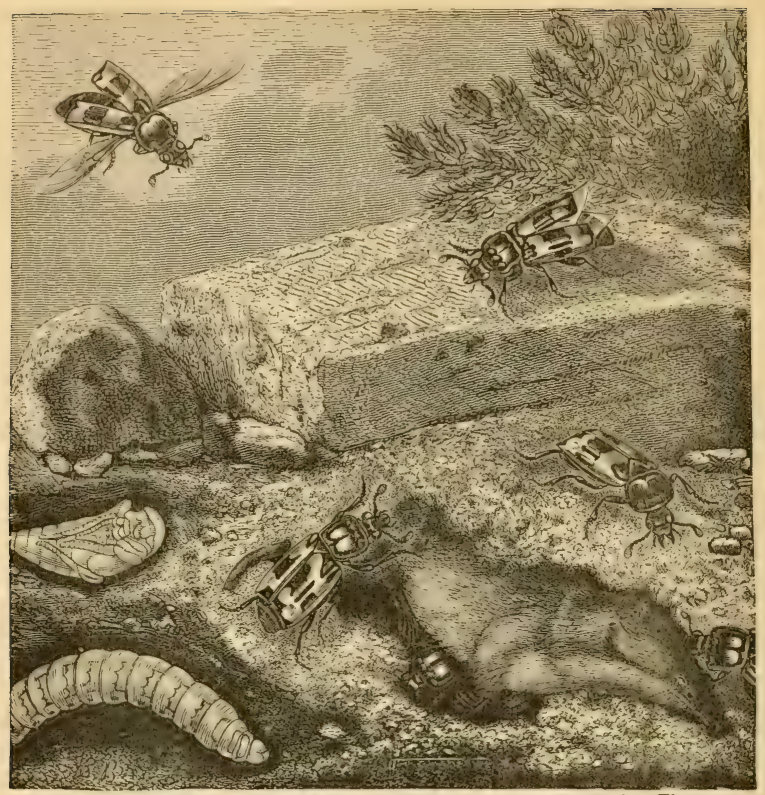

FIG. 260, - Sexton Bectles (Necrophorts vespillo), with liarva and nymph. They are burying a mouse, preparatory to laying their eggs in it.

club-shaped antennæ; the Goliath Beetles (Scarabous), the griants of the order; the Snapping-bugs (Elater); the Lightning-bugs (Pyrophomes); the spotted Lady-birds (Coccinella); the showy Long-horned Beetles (C'erambycidle); and the destructive Weevils (Curculionidu), with pointed suouts.

5. Dipters, or "Flies," are characterized by the rudimentary state of the hinder pair of wings. Although having, therefore, but one available pair, they are gifted with the power of rery rapid flight. While a Bee mores its wings 190 times a second, and a Butterfly 9 times, the 
IIonse-fly makes 330 strokes. A few species are wingless. The eves are lare, with numerous facets; the tongne terminates in a fleshy knoh, and the other parts of the mouth are fitted for suction, being generally converted into fine

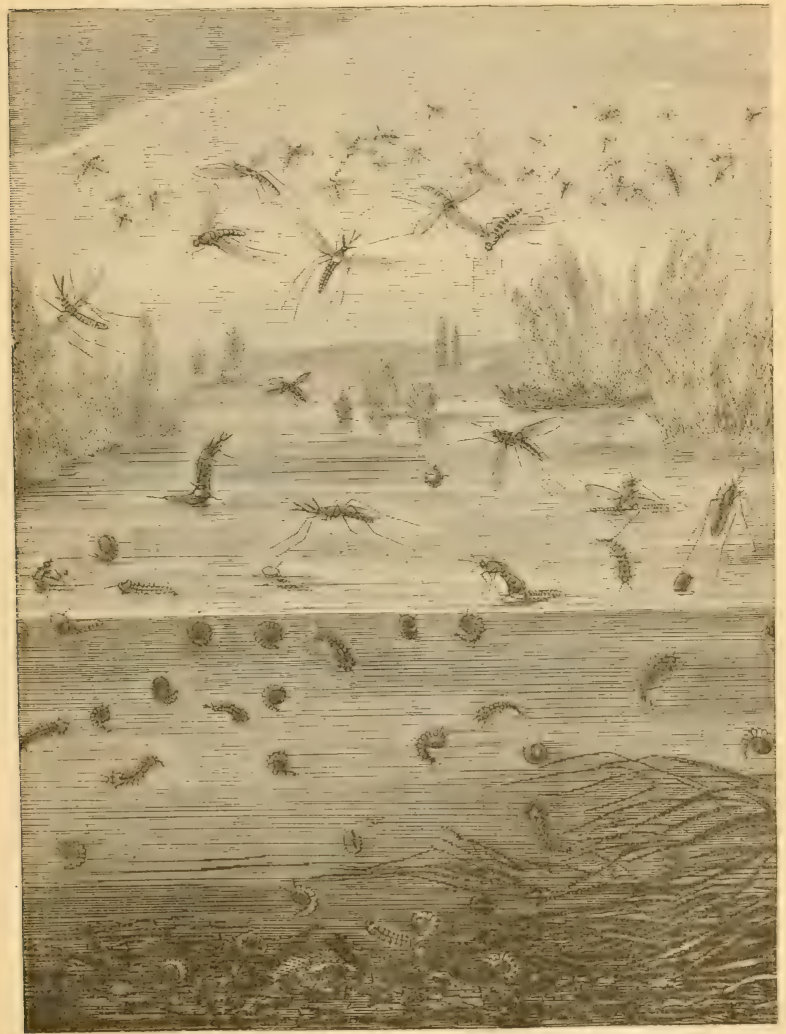

Fra. 261.-Jetamorphosis of the IIusquito (Culex pipiens). 
lancets; the thorax is globular; and the legs slender. The larre are footless gruls. The Dipters number about 2t,000. Among them are the Mosquitoes (C'ulex); Hes-
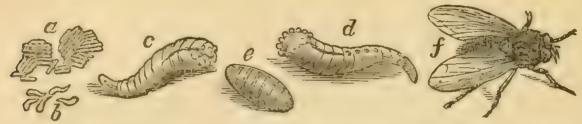

Fig. 262.-Metamorphosis of the Flesh-fly (Sarcop)haqa carmariu): $a$, egrs; $b$, young maggots just batched; $c, d$, full-grown maggots ; $e$, pupa ; $f$, imago.

sian-fly (Cecidomyiu), so destructive to wheat; Daddylong-legs (Tipulu), resembling a gigantic Mosquito; the wingless Flea (P'ulex); besides the immense fanilies rejresented by the IIouse-fly (ALuscre) and Bot-fly (Estrus).

6. Lepidopters, or "Butterflies" and "Moths," are

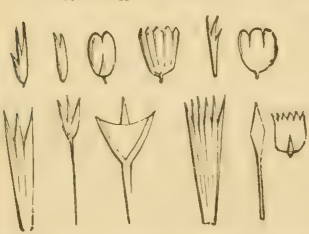

Fra. 263., Scales from the wimis of virious Lepilopters. known chiefly by their four large wings, which are thick. ly corered on both sides by minute, overlapping scales. The scales are of different colors, and are often arranged in patterns of exquisite beauty. They are in reality modified hairs, and every family has its particular form of scale. The head is small, and the body cylindrical. The legs are not used for locomotion. All the mouth parts are nearly obsolete except the maxillæ, which are fashioned into a "proboscis" for pumping up the nectar of flowers. The larræ,

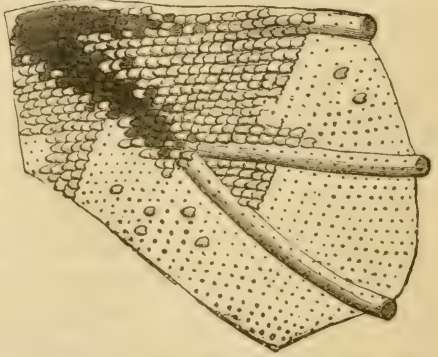

Frg. 264.-Part of the rring of a MIth (Saturnit), muguitied to show the arrangement of scales. 
called "caterpillars", have a worm-like form, and from one to five pairs of abdominal legs, in addition to the six on the thorax. The mouth is formed for mastication, and (except in the larræ of Butterflies) the lip has a spinneret connected with silk-glands.

There are three groups: the gay Fir. 265.-Vanessa polychloros, or "Tortoise-shell ButButterflies, having

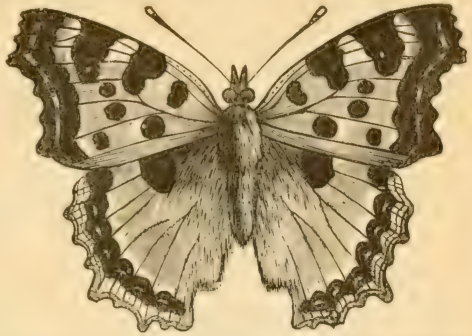
terfly." knobbed or hooked antennx, and flying in the sunshine only; the dull-colored Sphinges, with antennæe thickened

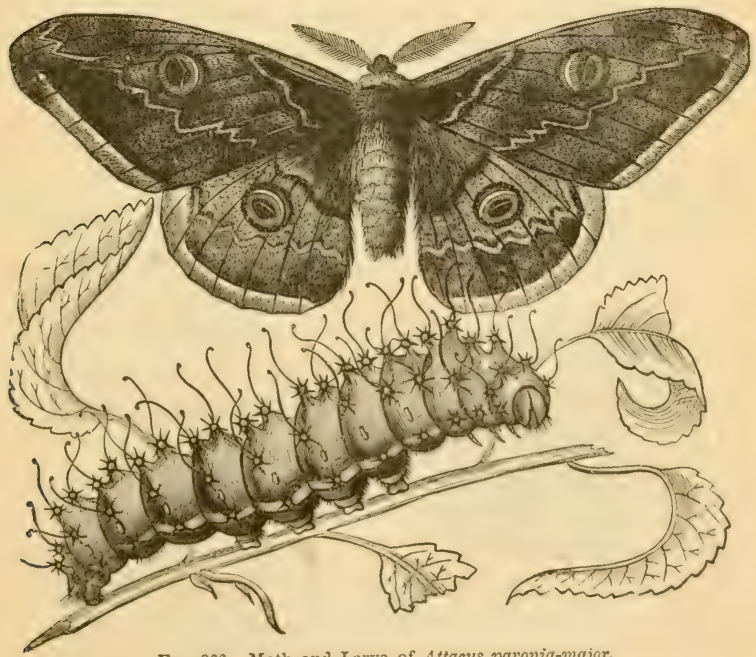

Fig. 266.-Moth and Larta of Attacus pavonic-major. 
in the middle, and flving at twilight; and the nocturnal Moths, which generally prefer the night, and whose antennæe are thread-like and often feathery. Generally, when

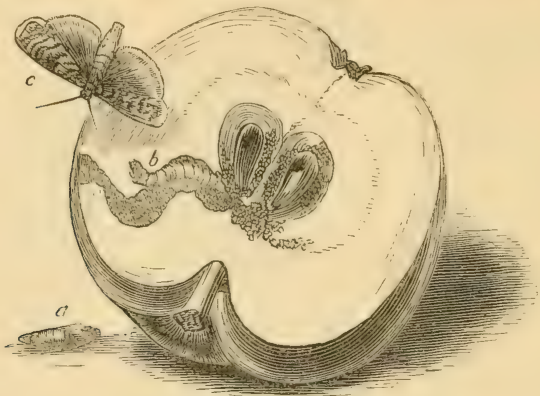

FIG. 267.-Fruit-moth (Pyralis pomona): $b$, larva ; $a$, chrysalis; $c$, imago.

at rest, the Butterflies lieep their wings raised vertically, while the others hold theirs horizontally. The pupa of the former is muprotected, and is nsmally suspended by

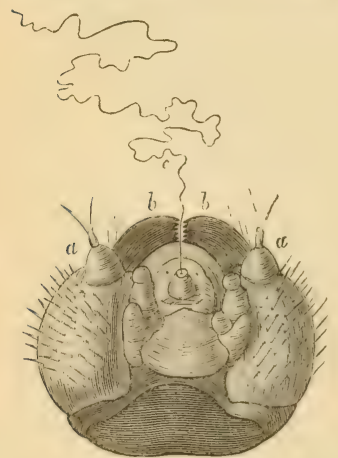

Fig. 26S. - IIend of a Caterpillar, from beneath: $a$, antennæ: $b$, horny jaws; $c$, thread of silk from the conical fusulus, on either side of which are rudimentary palpi. a lit of silk: ${ }^{171}$ the pupa of the Moths is inclosed in a cocoon.

From 22,000 to 24,000 Lepidopterons species have been identitied. Some of the most common Butterflies are the swallow-tail Papilio, the white Pieris, the sulphuryellow Colias; the Argynnis, with silver spots on the mder side of the hind wings; the Vanessa, with notched wings. The Sphinges exhibit little rariety. They have narrow, powerful wings, and 
are sometimes mistaken for Ifumming-birds. The "potato-worm" is the caterpillar of a Sphinx. The most conspicuons Moths are the large and beantiful Attacus, distinguished by a triangular, transparent spot in the centre of the wing; the white Bombyx, or "silk-worm;" the reddish-brown Clisiocanpa, whose larva, "the Ameriean Tent-caterpillar," spreads its web in many an apple and cherry tree; the pale, delicate Geometrids; and the small but destructive Tineids, represented by the Clothes-moth.

7. Hymenopters, comprising at least 25,000 species, include the highest, most social, and, we may add (if we except the Silk-worm), the most useful, of Insects. They have a large head, with compound eyes and three ocelli, mouth fitted both for biting and suction, ${ }^{172}$ legs formed for locomotion as well as support, and four wings equally transparent, and interlocking by small hooks during tlight. The females are nsually provided with a sting, or borer. The larva are footless, helpless grubs, and generally uurt-

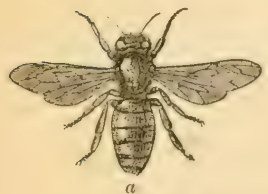

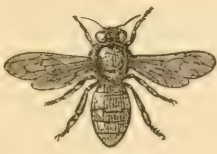

$b$

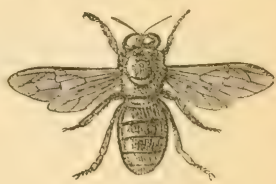

c.

FIG. 269,-Honey-bee (A pis mellifica) : $a$, female; $b$, worker; $c$, male.

mred in cells, or nests. Such are the IIoney-bees ( 1 pris), IImmble-bees (Bom7us), Wasps (Tespa), Ants (Fomniru), Ichnemmon-flies, and Gall-flies. Those living in societies exhibit three castes: females, or "queens;" males, or "drones;" and nenters, or sexless "workers." There is but one gueen in a hive, and she is treated with the greatest distinction, even when dead. She dwells in a large, pearshaped cell, opening downward. She lays three broods of egrgs: from the first come forth workers, the second pro- 
duces males, and the last females. The drones, of which there are about 800 in an ordinary hive, are marked by their great size, their large eyes meeting on the top of the head, and by being stingless. The workers, which number twenty to one drone, are small and active, and provided with stings and hollow pits in the thighs, called "baskets," in which they carry pollen. Their honey is nectar elaborated in the crop by an unknown process; while the wax is secreted from the sides of the abdlomen and mixed with saliva. There is a subdivision of extra labor: thus there are wax-workers, masons, and nurses. Ants (except the Saiiba) have but two classes of workers. While Ants live in hollow trees or subterranean chambers (called formi(arium), Honey-bees and Wasps construct hexagonal cells. The comb of the Bee is hung vertically, that of the Wasp is horizontal.

Such are the main divisions of the Invertebrates-creatures which are commonly regarded with arersion, and considered our foes rather than friends. Many of them are ummistakable nuisances, and it is difficnlt to see the purpose of their creation. Yet not a few have put us under obligations. Protozoans give us sponge and chalk; Radiates yield us coral; Mollusks contribute pearls; and Insects spin us silk. Nearly every grand group sends representatives to our tables: Oysters, Sea-slugs, and Lobsters are staple articles with many people; Bees gather honey; and Amazonian Indians make Auts into salad. 


\section{Subkingdom VertebratA.}

This grand division includes the most perfect animals, or such as have the most varied functions and the must numerous and complex organs. Besides the ummumbered lost of extinct forms, there are about 25,000 living species, widely differing among themselves in shape and habits, yet closely allied in the grand features of their organization, the general type being endlessly modified.

The fundamental distinctive character of Tertelrates is the separation of the main mass of the nervous system from the general carity of the body. A transverse section of the body exhibits two cavities, or tubes -- the dorsal, containing the cerebro-spinal nervous system; the rentral, inclosing the alimentary canal, heart, lungs, and a double chain of ganglia, or sympathetic system. This ventral, or hæmal, carity corresponds to the whole body of an Invertebrate; while the dorsal, or neural, is entirely extra.

Vertebrates are also distinguished by an in-
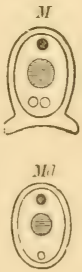
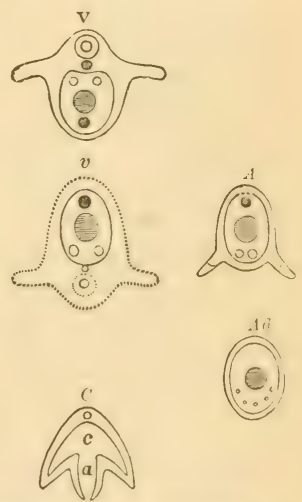

Fia. 270.-Iteal Plans of the suhkingtoms. I; transverse section of vertebrate type; $v$, the Eame, inverted. $M I$, trausverse section of mollu-cous type; ant .IFl, of mollnscuid. I anu Ad, trancrerse sections of articulate type, hith and low. $C$, Inngindinal section of cœlenterate type; $a$, alimentary canal; $c$, body-cavity. In the other figures, the alimentary canal is shaded, the heart is black, and the nerwous cords are open rings. ternal, jointed skeleton, endowed with vitality, and capable of growth and repair. During embryo-life it is represented by the notochord; but this is afterward replaced 


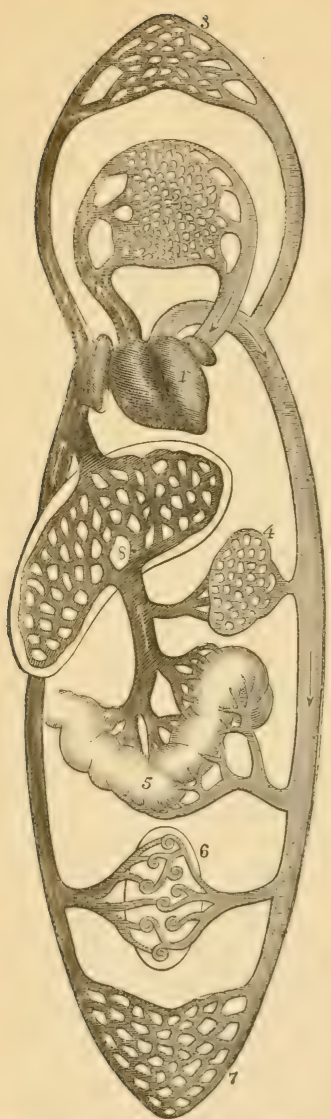

Frg. 271.-Diagram of Circulation in the higher Vertebrates: 1 , heart ; 2 , luugs: 3 , head and upper extremities; 4 , spleen ; 5 , intestine; 6 , kidney ; 7 , lower extremities; S, liver. (From Dalton's "Physiology.") by. a more lighlly dereloped vertebral column of cartilage or bone. ${ }^{173}$ The column and cranimin are never absent; other parts may be wanting, as the ribs in Frogs, limbs in Snakes, etc. The limbs are never more than four, and are always articulated to the hæmal side of the body, while the legs of Invertebrates are dereloped from the neural side. The muscles moving the limbs are attached to the endoskeleton.

The circulation of the blood is complete, the arteries being joined to the reins by eapillaries, so that the blood never escapes into the visceral cavity as in the Invertebrates. All have a portal vein, carrying blood through the liv$\mathrm{er}$; all have lacteals and lymphatics. The blood is red, and contains both kinds of corpuscles. ${ }^{174}$ The teeth are developed from the dermis, never from the cuticle, as in Mollusks and Articulates; the jaws move vertically, and are never modified limbs. The liver and kidneys are always present. The respiratory organs are either gills or lungs, 
or both. Tertebrates are the only animals which breathe through the month.

The nerrons system has two marked divisions: the cerebro-spinal, presiding over the functions of animal life (sensation and loconotion); and the sympathetic, which controls the organic functions (digestion, respiration, and circulation). In no case does the gullet pass throngh the nerrous system, as in Invertebrates, and the mouth opens on the side opposite to the brain. Probably none of the five senses are ever altogether absent. The form of the brain is modified by the relative derelopment of the rarions lubes. In the lower Vertebrates, the cerebral henispheres are small - in certain Fishes they are actually smaller than the optic lobes-in the higher, they nearly or quite overlap both olfactories and cerebellum. The hrain may be smooth, as in most of the cold-blooded animals, or richly convoluted, as in Man.

The skull is distinctly set apart from the spinal column, except in Fishes. It is bony in Mammals, mingled bone and cartilage in Birds and Reptiles, and in Amphibians and Fishes mainly or wholly cartilaginons. The human skull contains fewer bones than the skull of most animals, excepting Birds. The skull of all Tertebrates is divisible into two regions: the cranium, or brain-case, and the face. The size of the cranial capacity, compred with the area of the face, is generally the ratio of intelligence. In the lower orders, the facial part is enomonsly predominant, the eye-orbits are directed ontward, and the occipital condyles are nearly on a line with the axis of the body. In the higher orders, the face becomes subordinate to the cranium, the sensual to the mental, the eres look forward, and the condyles approach the base of the cranium. Compare the "snouty" skull of the Crocodile and the almost vertical profile of eivilized Man. A straight line drawn from the middle of the ear to the base of the nuse, and 
another from the forehead to the most prominent part of the upper jaw, will include what is called the facial angle, which roughly gives the relation between the two regions, and therefore the rank of the animal. ${ }^{175}$ In the cold-blooded Vertebrates the brains do not fill the cranium; while in Birds and Mammals a cast of the cranial cavity well exhibits the general features of the cerebral surfare.

The subkingdom is divided into five great classes: Fishes, Amphibiuns, Reptiles, Birds, and Hammals. The first three are "cold-blooded," the other two are "warmblooded." Fishes and Amphibians have gills during the whole or a part of their lives, while the rest never have gills. Fishes and Amphibians in embryo have neither ammion nor allantois, while the other three are prorided with both.

Fishes and Amphibians agree in having gills, in wanting ammion and allantois, and in possessing nucleated red blood-corpuseles.

Birds and Reptiles agree in having no gills, but both amnion and allantois, in the articulation of the skull with the spine by a single condyle, in the derelopment of the skin into feathers or scales, and in circulating oral, nucleated, red corpuscles.

Mammals differ from Birds and Reptiles in having two occipital condyles, and their blood-corpuscles are not nucleated. ${ }^{176}$

All Vertebrates are single and free. Mammals and a few Reptiles bring forth their young alive; the rest are oviparous.

\section{Class I.-Pisces.}

Fishes are the lowest of Vertebrates. 'They fall far hehind the rest in strength, intelligence, and sensibility. The eyes, though large, are almost immorable, bathed by 
no tears, and protected by no lids. Dwelling in the realm of silence, ears are little needed, and such as they have are without external parts, the somd being obliged to pass through the cranium. Taste and smell are blunted, and touch is nearly confined to the lips. Destitute of the means of social intercourse (being almost mute), their chief enjoyment is to eat, and to be eaten is the end of their existence.

But the class yields to no other in the number and variety of its forms. It includes nearly one-half of all the rertebrated species. So great is the range of rariation, it is difficult to frame a definition which will characterize all the finny tribes. ${ }^{177}$ It may be said, however, that Fishes are the only backboned animals having median fins (as dorsal and anal) supported by fin-rays, and whose limbs (pectoral and rentral fins) do not exhibit that three-fuld division (as thigh, leg, and foot) found in all other Vertebrates. ${ }^{178}$

The form of Fishes is admirably adapted to the element in which ther live and move. Indeed, Nature nowhere presents in one class such elegance of proportions with such variety of form and beauty of color. The lead is
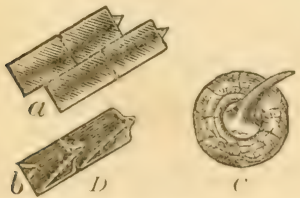

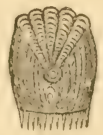

L

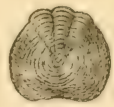

$\mathcal{A}$

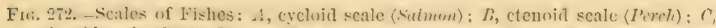

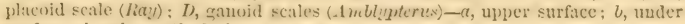
surface, showing articulating processes.

disproportionately large, but pointed to meet the resistance of the water. The neck is wanting, the head being a prolongation of the trunk. The viscera are closely: packed near the head, and the long, tapering trunk is lelt 
free for the derelopment of muscles which are to move the tail-the instrument of locomotion. The biconcare rertebræ, with intervening cavities filled with elastic gelatine, are designed for rapid and versatile movements. The body is either naked, as in the Eel, or covered with polished, overlapping scales, as in the Perch. Rarely, as in the Sturgeon, it is defended by bony plates, or by minute, hard spines, as in the Shark.

The rertical fins (dorsal, anal, and candal) are peculiar to Fishes. The dorsal vary in number, from one, as in the Ilerring, to three, as in the Cod; and it may be soft, as in the Tront, or spiny, as in the Perch. If the dorsals

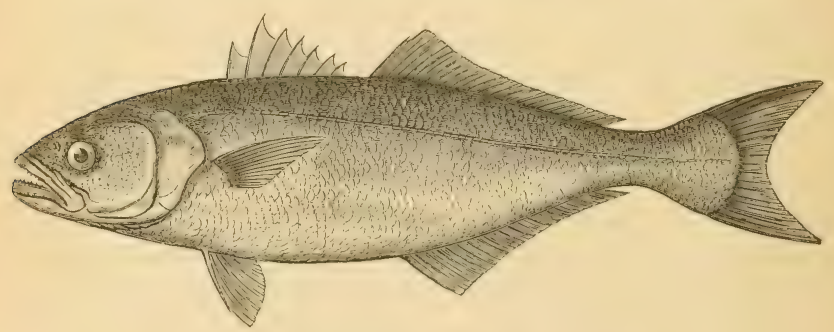

Frg. 273.-Blue-fish (Temnodon saltator). All seas.

be ent off, the Fish reels to and fro. The caudal may be homocercal, as in ordinary species; or heterocercal, as in Sharks. In ancient heterocercal Fishes, the tail was frequently vertebrated. The pectoral and rentral fins stand for the fore and hind limbs of other Vertebrates. As the specific gravity of the body is greater than that of the water, most Fishes are provided with an air-bladder, which is an outgrowth from the aesplagnus. This is absent in such as grovel at the bottom, as the Rays, and in those, like the Sharks, endored with compensating muscular power.

Fishes have no prehensile organ besides the mouth. 
Both jaws are alike movable. The teeth are numeroms, and are generally recurved spines, as in the Pike; flat and triangular, with serrated edges, in the Shark; and tessellated in the Ray. They feed principally on animal matter. The digestive tract is relatively shorter than in other. Vertebrates. ${ }^{153}$ With one exception (the Amplioxus), the blood is red, and the heart has rarely more than two (:ivities, an auricle and a ventricle, both on the venons side. Ordinary Fishes hare fom grills, the water escaping by one extermal aperture, or "gill-slit;" but in the Sliarks

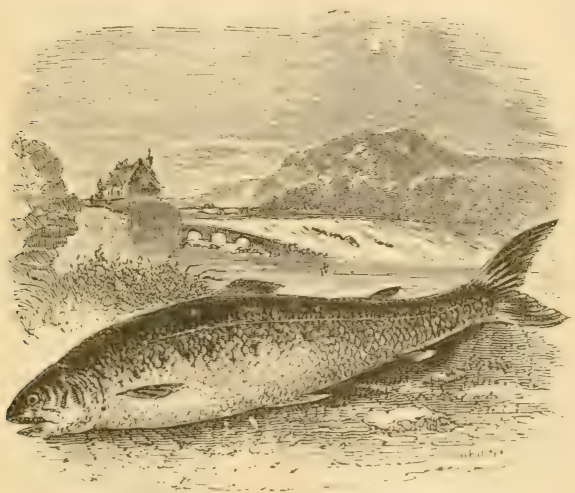

Frg. 2T..-Salmon (Salmo salar). Both hemispheres.

there is a separate opening for each gill. The brain consists of several ganglia placed one behind the other, and oceupres but a small part of the cranial cavity. Its arerage weight to the rest of the body is as low as 1 to 3000 . The egres of bony Fishes are nakel, and multitudinous. sometimes numbering millions in a single spawn; those of the Sharks are few, and protected by a horny shell.

There are six order's of Fishes:

1. Pharmngobranchs, represented by a single species, 
the Lancelei, or Amplizoxus. This lowest known Vertebrate is about two inches long, semi-transparent, and of worm-like form, and is found in the sandy bottom of many seas, especially the Mediterranean. ${ }^{173}$

2. Mursipobranchs, as the eel-like Lamprey and Hag. They have a cartilaginons skeleton and sac-like gills, but no scales, limbs, or lower jaw, and only one nasal organ, all other Vertebrates having two.

3. Teleosts, including all the common Fishes, haring a bony endoskeleton and a scaly exoskeleton. ${ }^{160}$ The skull is extremely complicated; the npper and lower jaws are complete (whence the name of the order), and the gills are comb-like or tufted. The tail is homocercal; the other fins are rariable in number and position. In the soft-finned Fishes, the rentrals are absent, as in the Eels; or attached to the abdomen, as in the Salmons, Herrings, Pikes, and Carps; or placed under the throat, as in the Cod, Haddock, and Flomder. In the spiny-finned Fishes, the rentrals are generally under or in front of the pectorals, and the scales ctenoid, as in the Perches, Mnnlets, and Mackerels.

4. Ganoids, distinguished by their enameled bony plates or scales. The endoskeleton is not completely ossified; the rentral fins are placed far back; and the tail is generally heterocercal. The gills are like those of the bony Fishes. This was one of the largest order's in old geological history. The few modem representatives, as the Sturgeon, Gar-pike, and Polypterus, are essentially freshwater.

5. Elasmotranchs, having a gristly skeleton, and a harsh skin, called "shagreen." The gill-openings are uncovered; and the mouth is generally under the head. The rentral fins are placed far back; the pectorals are large, in the Rays enormonsly developerl; and the tail is heterocercal. Such are the Sharks, Rays, and Chimæra. They are all 


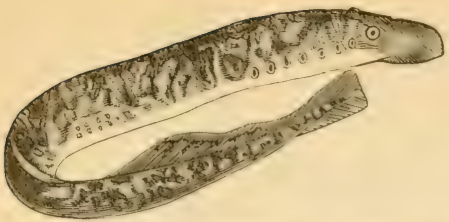

Fig, 275.-Lamprey (Petromyzon Americamus). Atlantic.

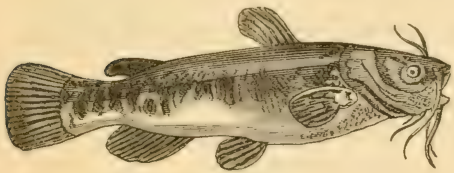

Frii. 276.-Cat-fish, or Horned Pout (Pimelodus catus). $A$ merican rivers.

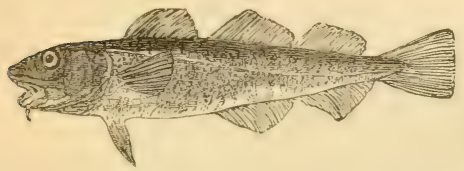

Fig. 2ii.-Cod (Jorrhua Americana). Atlantic const.

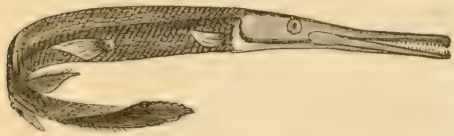

Fig. 2is.-Gar-pike (Lepidosteus bison). Lake Ontario.
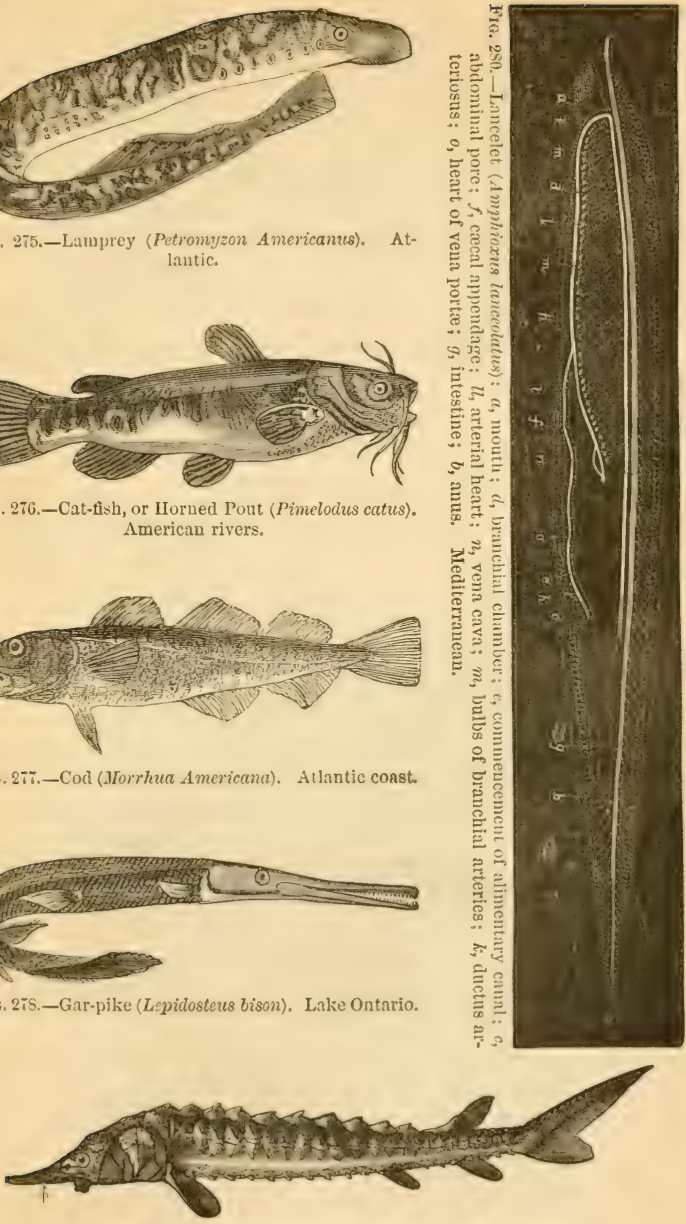

Fig. 279.-Sturgeon (Acipsnser sturio). Atlautic const. 


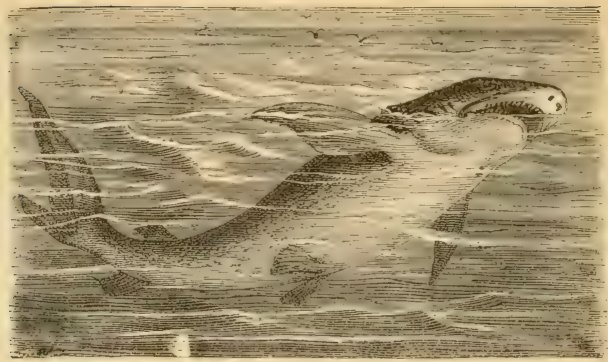

FIG. 2S1.-Shark (Carcharias vulgaris). Atlautic.

marine. The largest Shark found, and therefore the largest Fish, measured thirty-five feet.

6. Dipnoi, or Mud-iishes (Lepilosiren), of tropical civers. They form a link between the typical Fishes and

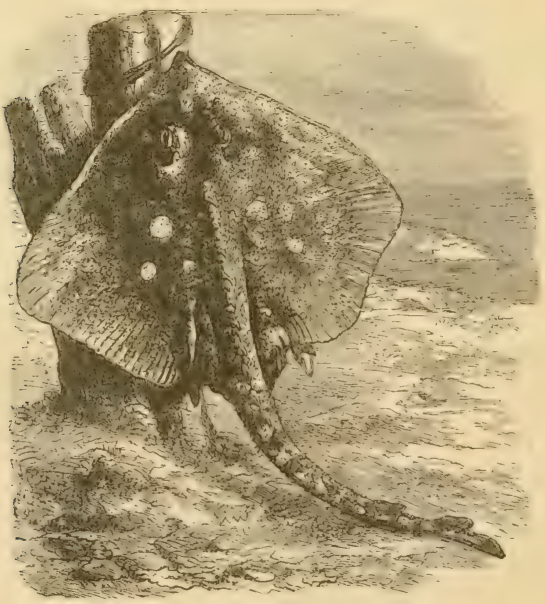

Fig. 2S2,-Thoruback (Raia clavata). Europenn seas. 
the Amphibians. They have an eel-like bedy corered with erceloid scales; an embryunic notochord for a hacli-

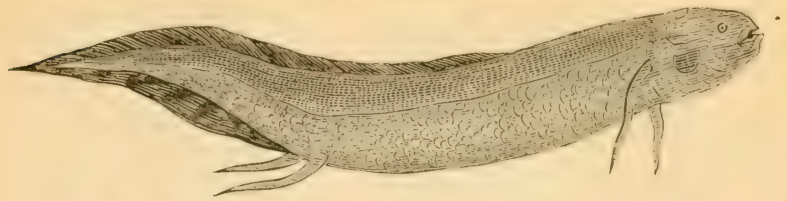

Fra. 253.-Lepidosiren annectens; one-fourth natural size. African rivers.

bone; long, ribbon-like pectoral and rentral fins, set far aprart; two auricles, and one ventricle; and, besides gills, a cellular air-bladder, which is used as a lung.

\section{Class II.-Amphibia.}

These cold-blooded Vertebrates are distinguished by having gills when young, and true lungs when adult. They have no fin-rays, and the limbs, when present, have the same divisions as those of higher animals. The skin is soft, and generally naked, and the skeleton is ossitied. The skull is flat, and articulates with the spinal column by two condyles. There is no distinct neck; and the ribs are usually small or wanting. The lieart consists of two auricles and one ventricle. All undergo metamorphosis upon leaving the egen, passing through the "tadpole" state. They commence as water-breathing larrae, when they resemble Fishes in their respiration, circulation, and locomotion. In the lowest forms, the gills are retained through life; but all other's have, when mature, lungs only, the gills disappearing. The cuticle is frequently shed, the mode varying with the halits of the species. ${ }^{1-1}$ The common Frog, the type of this class, stands intermediate between the two extremes of the vertelirate series; no fundamental part is excessirely developed.

There are four orders-the first two are tailed, the other two tailless: 
1. Urodetens have a nalied slin, a tail, and two or four limbs. Some retain their gills throngh life, as the Prote-

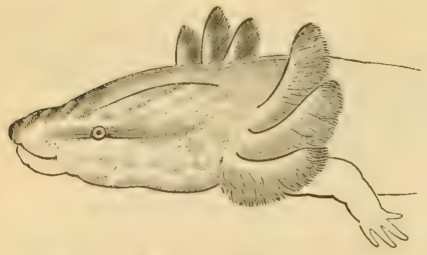

Frr. 2\$4,-Head and Gills of Menobranchus. Cayuga Lake. us of Austria, Axolotl (Siredon) of Mexico, and the two-legged Ind - eel (Siren) of South Carolina. Others drop their gills, and always have four limbs, as the aquatic Newts and land Salamanders. ${ }^{182}$ The fore limbs first make their appearance in the tadpole.

2. Labyrinthodonts, now extinct, resembled gigantic Salamanders, except in their complex teeth and exoskeleton of bony plates.

3. Cecilians have neither tail nor limbs, a snake-like

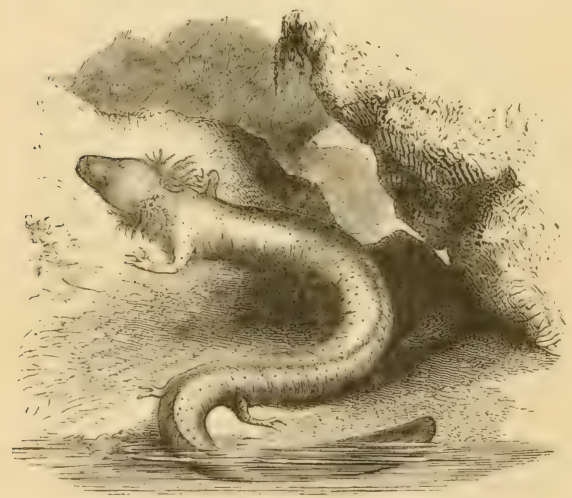

fis. ¿s5.-rroteus anguinus. Ëurope.

form, minute scales in the skin, and well-dereloped ribs. They are confined to the tropies. 
4. Butrachiens include all the well-known tailless $A \mathrm{~m}$ phibians, as Frogs and Toads. They have a moist, naked skin, ten vertebræ, and no ribs. As they breathe by swallowing the air, they can be suffocated by holding the mouth open.

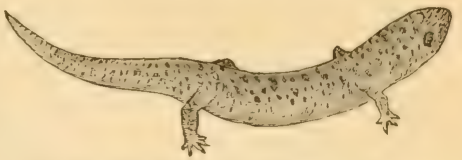

Fig. 2S6.-Red Salamander (Psezulotriton ruber). United States.

They have four limbs - the hinder the longer, and the first dereloped. They have four fingers and five toes.

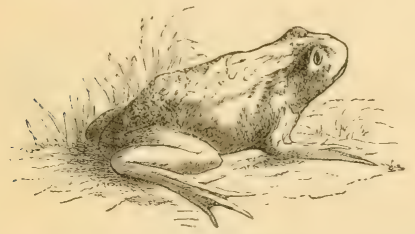

Frg. 2s7.-Frog (Rana).

The tongue is long, and, fixed by its anterior end, it cau be rapidly thrown out as 'an organ of prehension. ${ }^{183}$ The eggs are laid in the water enveloped in a glairy mass; and the tadpoles resemble the Urodelans, till buth grills and tail are absorbed. Frogs (Panu) have teeth in the upper jaw, and webbed feet; Toads (Bufo) are higher in rank, and have neither teeth nor fully webbed feet. The former have been known to live sixteen years, and the latter thirty-six.

\section{ClASS III.-Reptilia.}

These air-breathing, cold-blooded Vertelnates are distinguished from all Fishes and Amphibians by never having gills, and from Birds by being covered with horny scales or bony plates. The skeleton is never cartilaginous; and the skull has one occipital condyle. The rertebra are ordinarily concave in front; and the ribs are well developed. With few exceptions, all are carnivorous; and teeth are always present, except in the Turtles, where a horny 
sheath covers the jaws. The teeth are never fastened in sockets, except in Crocodiles. The jaws are usually very wide. The heart has three chambers, save in Crocodiles, where the rentricle is partitioned. ${ }^{1+4}$ But in all cases a mixtme of arterial and venous blood is circulated. The lungs are large, and coarsely cellular. The limbs, when present, are provided with three or more fingers as well as toes.

There are four orders of living Reptiles-the first two have horny scales, and two external nostrils; the others have bony plates combined with scales, and one external nostril :

1. Ophidians, or Snakes, are characterized by the absence of visible limbs $;^{185}$ by the great number of vertebræ, amounting to over 400 in the great Serpents; by a corresponding number of ribs, but no sternum; and immovable

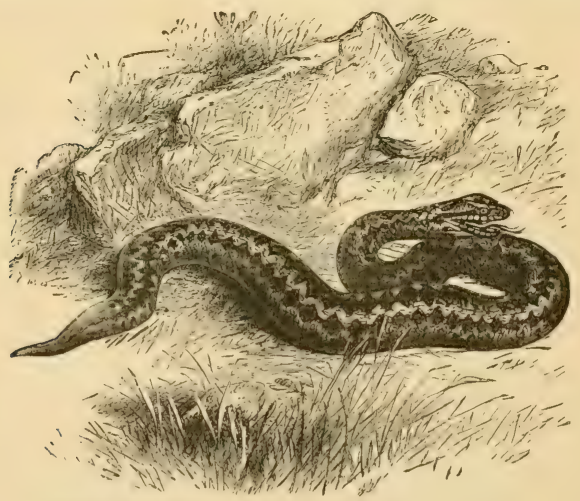

Fia. 25s.-Adder, or Viper (Vipera berus). England.

transparent eyelids. The tongue differs from that of nearly all other reptiles in being bifid and extensile. The mouth is very dilatable. The skin is frequently shed, and 
always by reversing it. Snakes make their way on land or in water with equal facility.

As a rule, the venomons Snakes, as Vipers and Rattlesnakes, are distinguished by a triangular head covered with small scales; a constriction behind the head; two or more fangs, and few teeth; small eyes, with vertical pupil; and

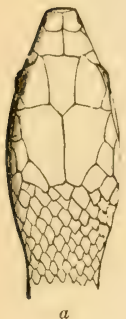

$a$
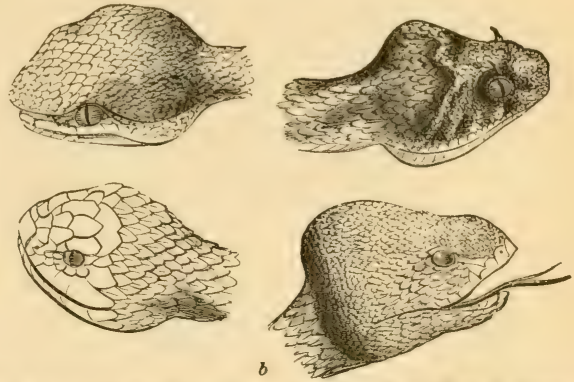

Fig. 2S9,-a, Head of a harmless Snake (upper view); $b$, heads of various venomous Snakes.

short, thick tail. In the harmless Snakes, the head gradwally blends with the neck, and is corered with plates; the teeth are comparatively numerous in both jaws; the pupil is round, and the tail tapering. This rule, however, has many exceptions.

2. Lizarls may be likened to Snakes provided with four limbs, each having five digits. ${ }^{1+6}$ The hody is covered with horny scales. All have teeth, which are simple in structure; and the halves of the lower jaw are firmly united in front, while those of Snakes are loosely tied together by ligaments. Nearly all have a breast-bone; and the eyes (save in the Gecko) are furnished with movable lids. In the common Lizards and Chameleon, the tongue is extensile. The tail is usmally long, and naturally snaps off at the twelfth caudal. The Chameleon has a prehensile tail. The Ignana is distinguished ly a dewlap on the 


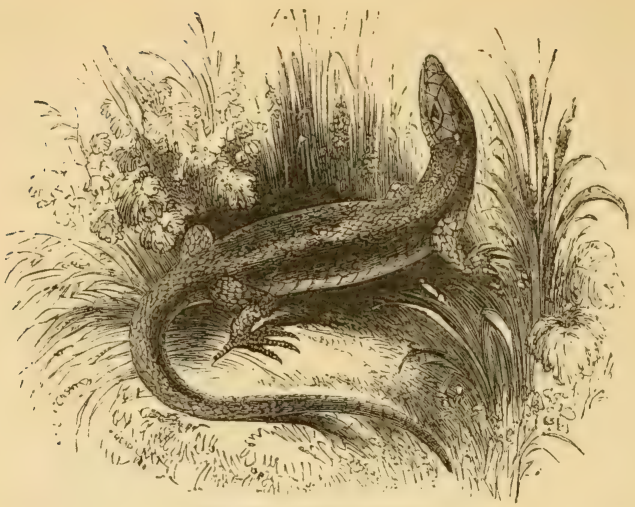

Frg. 290,-Lizard (Lacerta).

throat and a crest on the back. Except some of the Monitor's of the Old World, all the Lizards are terrestrial.

3. Chelonians, or Tortoises and Turtles, approach the Amphibians in some respects, but are of anomalous structure. The skeleton is external, so as to include not only

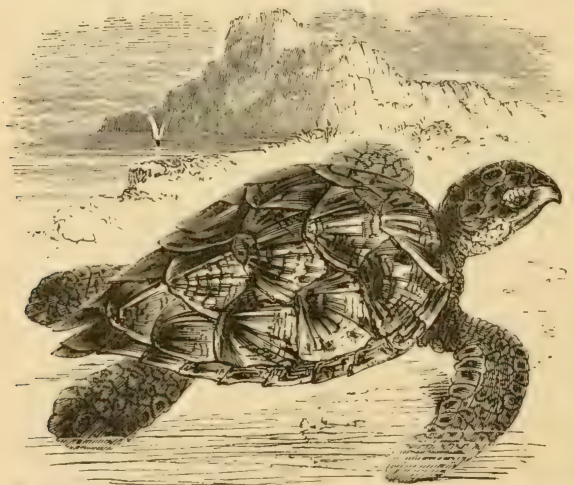

Fro. 291.-Hawk's-bill Turtle (Eretmochelys imbricata). Trupacal Atlatic. 
all the risecra, but also the whole muscular system, which is attached internally, as in Articulates; and even the limbs are inside, instead of ontside, the thorax. The exoskeleton unites with the endoskeleton, forming the carafur, or case, in which the body is inclosed. 'The exoskeleton consists of horny plates, known as "tortoise-shell;" in the soft Tortoises (Trionyx) this is wanting. The vertebrine of the back are soldered together, and the ribs are expanded, making the walls of the carapax. The ven-

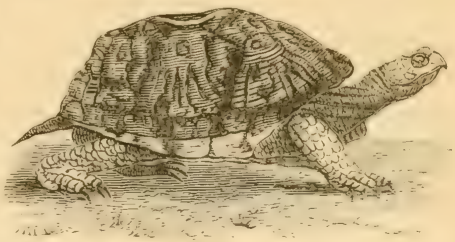

Fta. 292.-Box-tortoise (Cistuio virgineu). Lnited States.

tral piece is called the plustron, or sternum. ${ }^{167}$ All are toothless. There are always four stout legs; and the order furnishes the only examples of Vertebrates lower than Birds that really walk, for Lizards and Crocodiles wriggle and drag their body along. The eggs are covered with a calcareous shell.

The Sea-turtles, as the edible Green Turtle and the Irawk's-bill Turtle, which furnishes the "tortoise-shell" of commerce, have the limbs converted into paddles. The fresh - water forms, represented by the Snapping Turtle (Chelyclioe), are amplibions, and have palmated feet. Land Tortrises (Testudo) have short, clumsy limbs, fitted for sluw motion on the land; the plastron is very broad; and the carapax is arched (while it is flattened in the aquatic species), and head, legrs, and tail can be dram within it. The land and marine species are regetablefeeders; the others, carnivorous.

4. Crocoliles, the highest and largest of Reptiles, have two exoskeletons - one of horny scales (epidermic), and another of bony plates (demal). The bones of the skull 
are firmly united, and furnished with numerous teeth implanted in distinct sockets. The lower jaw extends back of the cranium. The heart has four cavities, but the pulmonary artery and aorta communicate with each other, so that there is a mixture of renous and arterial blood. They have external ear-openings, closed by a flap of the skin, and eyes with morable lids; a muscular gizzard; a long, compressed tail; and four legs, with feet more or less webbed, and having tive toes in front and four behind. The existing species are confined to tropical rivers, and are carnirorous. The eggs are covered with a hard shell.

There are three representative forms: the Gavial of the

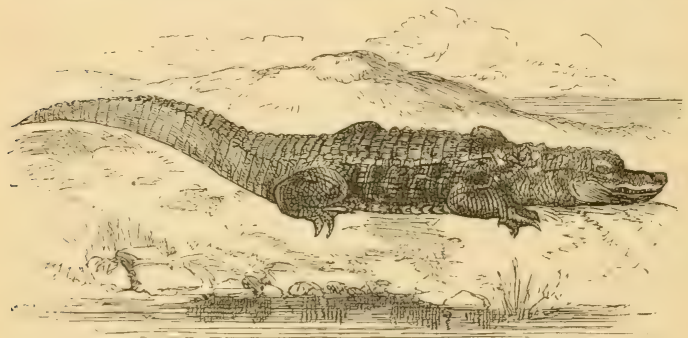

Frg. 293.-Alligator (A. Mississippiensis). Southern States.

Ganges, remarkable for its long snout and miform teeth; the Crocodile of the Nile, whose teeth are mequal, and the lower canines fit into a notch in the edge of the upper jaw, so that it is visible when the month is closed; and the Alligator of the Mississippi, whose canines, in shntting the month, are concealerl in a pit in the upper jaw. The toes of the (ravials and Crocodiles are webbed to the tip; those of the Allimators are not more than half-webbed.

In the mediaval ages of greological history, the class of Reptiles was far more abumlantly represented than now. Among the many forms which geologists have unearthed 
are numerous gigantic Saurians, which ean not be classified with any of the four living order's. Such are the Ichthyosumpr, Plesiosaurus, I'teroductyle, Megalosaurus, and Iguanodon.

\section{Class IV.-Aves.}

Birds form the most clearly defined class in the whole Animal Kingdom. The Eagle and IImmmer, the Ostrich and Duck, widely as they seem to be separated by size, form, and habits, still exhibit one common type of structure. On the whole, Birds are more closely allied to Reptiles than to Mammals. In number, they approach the Fishes, omithologists having determined 11,000 species.

A Bird is an air-breathing, egg-laying, warm-blooded, feathered Vertebrate, with two limbs (legs) for perching, walking, or swimming, and two limbs (wings) for flying or swimming. Organized for flight, it is gifted with a light skeleton, very contractile muscular fibre, and a respiratory function of the highest development.

The skeleton is more compact than those of Reptiles and Mammals, at the same time that it is lighter, and the bones are harder and whiter. It contains fewer bones than usual, many parts being anchylosed together, as the cranial, dorsal, and sacral. The lumbar vertebre are wanting; but the neck is remarkably long (containing from 9 to 24 rertebrae) and flexible, enabling the head to be a most perfect prehensile organ. The ribs grenerally are jointed in the middle, as well as with the backbone and sternum. The last, where the muscles of flight originate, is highly dereloped. ${ }^{1 n-}$ The skull articulates with the spinal column by a single condyle, and with the lower jaw, not directly, as in Mammals, but through the intervention of a separate bone, as in Reptiles.

All Birds always have four limbs, while every other vertebrate class shows exceptions. The fore-linbs are tit- 
ted for flight. They ordinarily consist of nine separate bones, and from the hand, fore-arm, and humerus are dereloped the primary, secondary, and tertiary feathers of the wing. The hind limbs are formed for progressionwalking, hopping, rumning, paddling, and also for perching and grasping. The modifications are more numerous and important than those of the bill, wing, or tail. There are trenty bones ordinarily, of which the tibia is the prin-

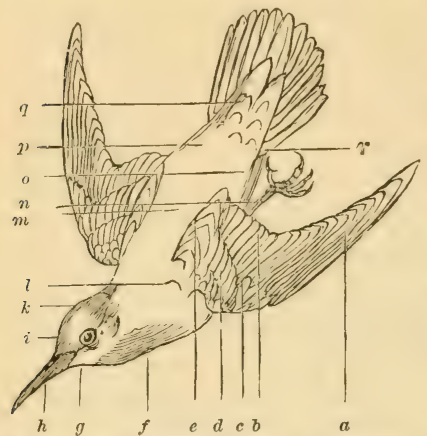

Fro. 294.-Principal Parts of a Bird: $\alpha$, primaries; $b$, secondaries; $c$, spurious wing; $d$, wing-coverts; $c$, tertiaries: $f$, throat, or jugulum; $g$, chin; $h$, bill; the meeting line between the two mandibles is the commissure; the ridge on the upper mandible is called culmen; that of the lower, gonys; the space between the base of the upper mandible and the eye is the lore; $i$, forehead; $k$, crown: $l$, scapular feathers: $m$, back: $n$, metatarsus, often called tarsus or tarso-metatarsus; 0 , abdomen ; $p$, rump ; $q$, upper tail-coverts ; $r$, lower tail-coverts. cipal; but the most characteristic is the tarso-metatarsus, which is a fusion of the lower part of the tarsins with the metatarsus. The thigh is so short, the knee is never seen ontside of the plumage; the first joint visible is the heel. ${ }^{180}$ Most Birds have four toes (the external or "little" toe is always wanting); many have three, the lallux, or "big" toe, lheing absent; while the Ostrich has but two, answering to the third and fourth. The normal number of phalanges, reckoning from the hallux, is $2,3,4,5$. The toes always end in claws.

Birds have neither lips nor teeth, epiglottis nor diaphragm. The teeth are wanting, because a heary masticating apparatus in the head would be unsuitable for flight. The beak, crop, and gizzard rary with the food. ${ }^{100}$ The sole organs of prehension are the beak and legs. The 
circulation is double, as in Mammals, starting from a fourchambered heart. Respiration is more complete than in other Vertebrates. The lungs are fixed, and communicate with air-saces in varions parts of the body, as along the vertebral column, and also with the interior of many bones, as the humerus and femur, which are usually hollow and marrowless. ${ }^{191}$ Both brain and eord are much larger relatively than in Reptiles; the cranium is larger in proportion to the face; and the parts are not situated in one plane, one behind the other. The cerebrum is round and smooth; and the cerebellum single-lobed. The ears resemble those of Crocodiles; but the eyes are well dereloped, and protected by three lids. They are placed on the sides of the head, and the pupil is always round. The sexes generally differ greatly in plumage, in some cases more widely than two distinct species. But the coloration of either sex of any one species is very constant.

A. Aquatio Brrds.-Specially organized for swimming; the body flattened, and covered with water-proof clothing -feathers and down; the legs short (the linees being whoily withdrawn within the skin of the body), and set far apart and far back; the feet webbed, and hind toe elevated or absent. The legs are always feathered to the heel at least. They are the only Birds whose neck is sometimes longer than the legs.

1. Pygopodes, or Divers.These lowest of the feathered tribe have very short wings and tail, and the legs are placed so far lack that they are obliged, when on

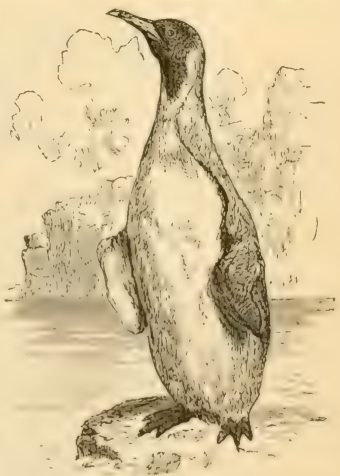

Fici. 295.-P'eneuin (.1ptemolytes Pennan. tii). Falkiand Islauds. 


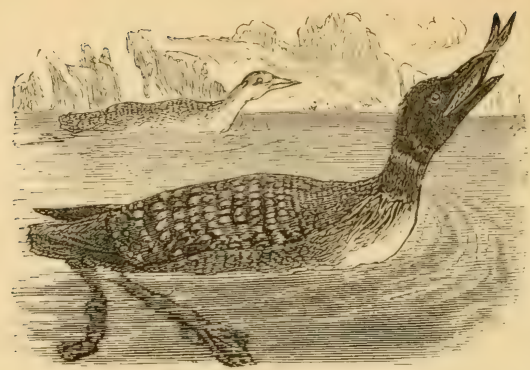

Fro. 296.-Loon (Colymbus torquatus). North America.

land, to stand nearly bolt upright. They are better fitted for diving than for flight or even swimming. They belong to the high latitudes, living on Fishes mainly, and are represented by the Penguins, Anks, Loons, and Grebes.

2. Longipennes, or Gulls.-Distinguished by their long, pointed wings, usually long tail, and by great powers of flight. They are all carnivorous. Such are the Gulls and

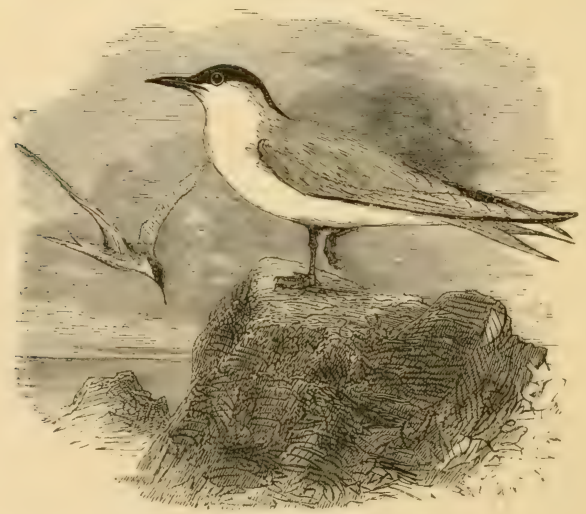

Fig. 2ji.-Tern (sternu). 


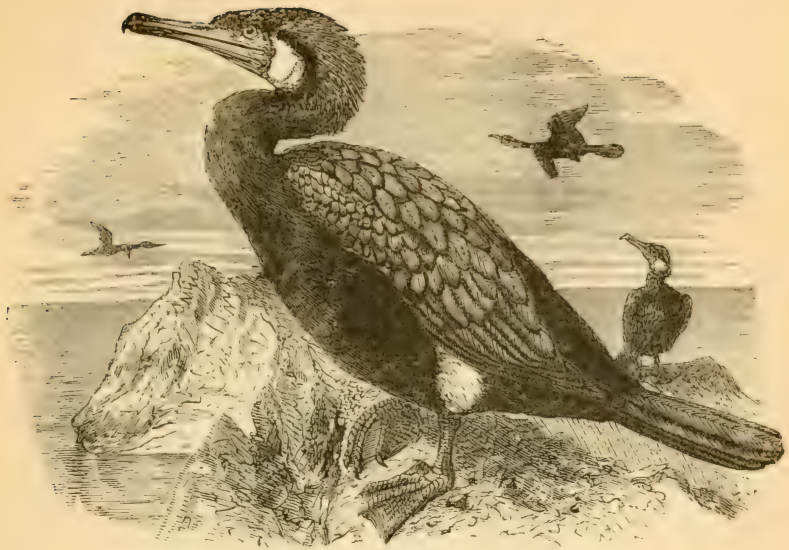

Fig. 29S,-Cormorant (Graculus).

Terns, which frequent the sea-coast, lakes, and rivers; and the Albatrosses and Petrels (the largest and smallest of web-footed Birds), which are oceanic.

3. Totipalmates, or Cormorants. - Characterized by a long bill, generally hooked; wings rather long; and toes long; and all four joined together by broad webs. Throat generally naked, and furnished with a sac. The majority are large sea-birds, and feed on Fishes, Mollusks, and Insects. Examples are the Cormorants, Pelicans, and Gannets.

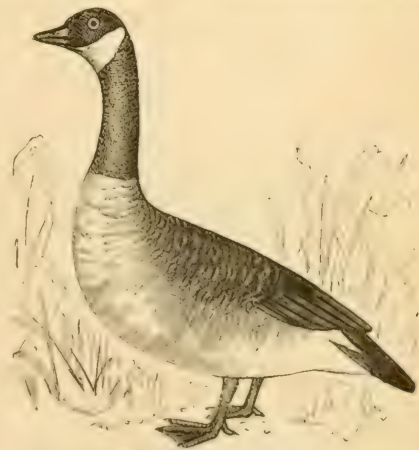

Frg. 299,-Wild Goose (Bernicla Canadensis). United States. 


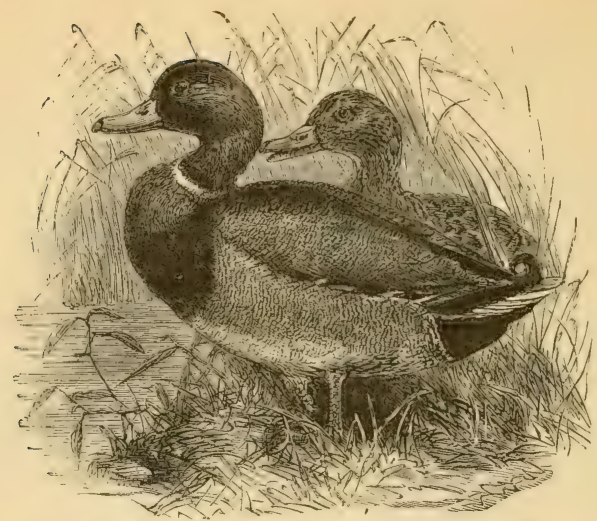

Fra. 300.-Wild Duck (Anas boschas). North America.

4. Lamellirostres, or Ducks, have a heary body, modcrate wings, short tail, flattened bill, corered by a soft skin, with ridges along the edges. Diet more commonly regetarian than animal. The majority inhabit fresh water-as the Ducks, Geese, Swans, and Flamingoes.

$B$. Terrestrial Birds. - This group exhibits great dirersity of structure; but all agree in being especially

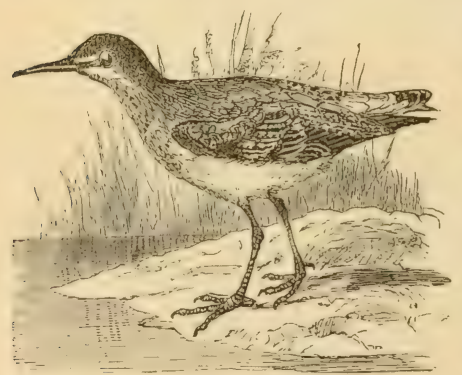

Fic. 301.-Sandpiper (Tringa hypoleuca). Eugland. terrestrial in habit, spending most of the time on the ground, not on trees or the water, although many of them fly and swim well. The legs are long or strong, and the knee is free from the body. The hind toe, when present, is small and elevated. 
5. Grullutores, or Waders. - These are readily distinguished by their long and bare legs. Generally, also, the toes, neek, and bill are of proportionate length, and the tail short. They feed on small animals, and, with a few exceptions, frequent the banks of rivers. In flying, their legs are stretched out behind, while in most other Birds they are folded under

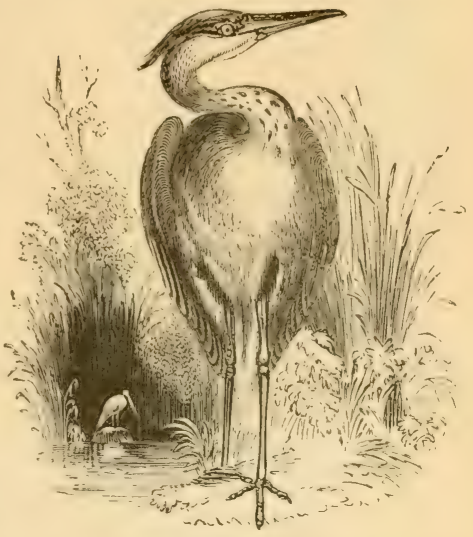

F1G. 302.-Heron (Ardea). the body. Such are the Rails, Cranes, Ilerons, Storks, Ilises, Stilts, Snipes, Sandpipers, and Plovers.

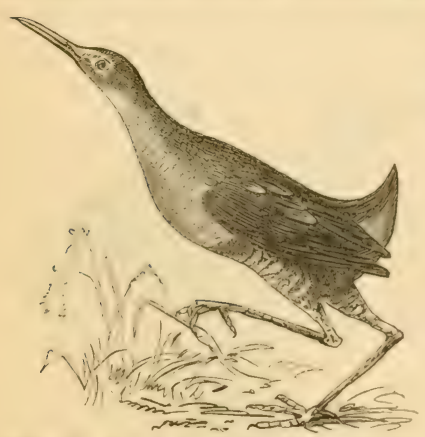

Fig. 303.-Rail, or Marsh Hen (Fullus elegens). United States.

6. Cursores, or Runners. - This small, aberrant order includes the Ostriches, Cassowaries, and Apteryx, well marked by their gigantic size, rudimentary wings, keelless breast-bone, and robust legs. The African Ostrich has two toes, the Cassowary three, and the Apteryx four. The barbs of the feathers are disconnected. They subsist chiefly on plants, sechls, 
and fruit, and, excepting the Rhea, or American Ostrich,

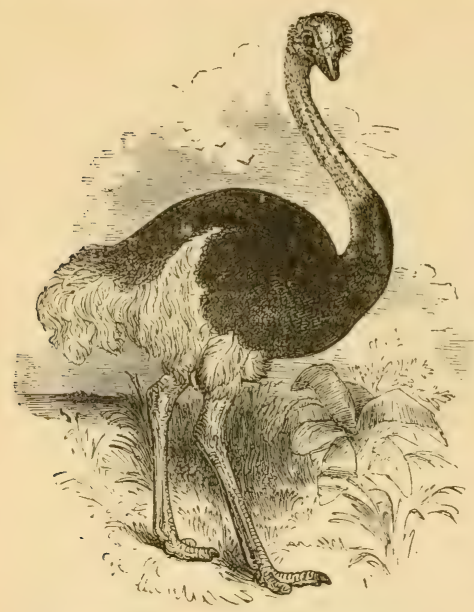

Fio. 304.-Africau Ostrich (Struthio camelus). belong to the Old World.

7. Rasores, or Scratchers. As a rule, this order, so valuable to Man, is characterized by a short, arched bill; short and concave wings, unfitted for protracted flight; stout legs, of medium length; and four toes, the three in front being united by a short web, and terminating in blunt claws. The legs are usually feathered to the heel, sometimes (as in Grouse) to the toes. The feathers of the body are large and coarse. The males generally have gay plumage, and some appendage to the head. The nostrils are covered by a scale or valve. Their main food is grain. Such are the Grouse, Partridges, Turkeys, Pheasants, Poultry, and Curassows. To these may be added

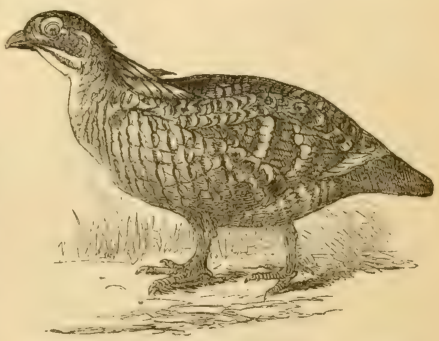

Fig. 305.-Prairie-chicken (Cupidonia cupido). Western prairies.

Pigeuns and Dores, although they stand intermediate be- 
tween the terrestrial and perehing Birds, as the Flamingoes link the aquatic and terrestrial. They differ from the typical Rasores in having wings for prolonged flight, and slender legs, fitted rather for an arboreal life, with toes not united, and the hind toe on a level with the rest.

C. AËrial Birds. - This highest and largest group includes all those Birds whose toes are fitted for grasping or perching, the hind toe being on a level

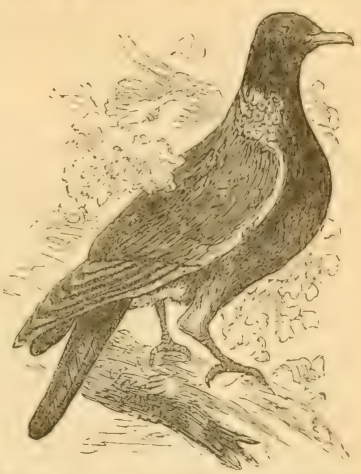

Fic. 306,-Ring-dove (Colunba palumbus). England.

with the rest. The linee is free from the body, and the $\operatorname{leg}$ is generally feathered to the heel. The wings are anlapted for rapid or long flight; and they hop, rather than walk, on the ground. ${ }^{102}$ They always live in pairs; and the young are hatched helpless.

8. Riuptores, or Birds of Prey, differ from all other

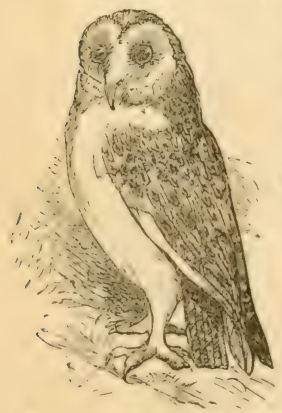

Fro. 30i.-Barn-owl (strix flume$m e a)$. Both hemispheres. Bircls, except Parrots, in having a strongly hooked bill and a waxy membrane (cere) at the base of the upper mandible; and from Parrots,

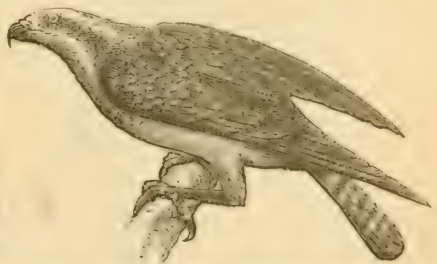

Fra. 3us.-Fish-hawli (Tumitun Curulinansas). United States. 
in having three toes in front and one behind. The toes are armed with long, strong, crooked talons; the legs are robust; and the wings are of considerable size, adapted

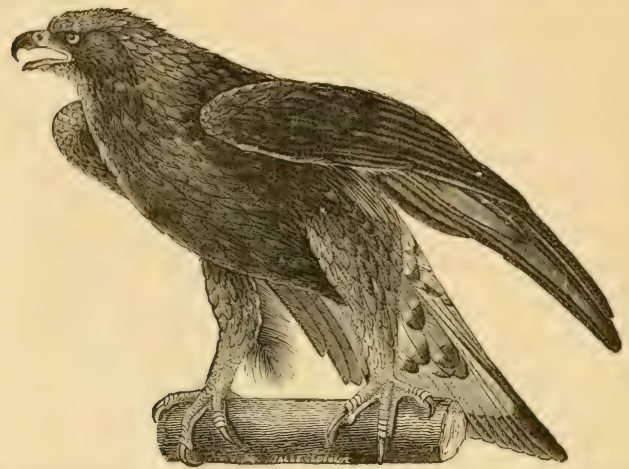

Fre. 309.-Golden Eagle (Aquila clirysaetos). North America and Europe.

for rapid and powerful flight. The bill is stont and sharp, and usually toothed. All are carnivorous. The female is larger than the male, except the Condor. There are two
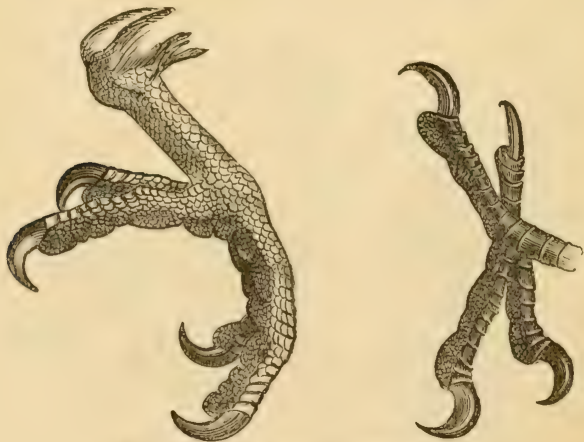

Fra. 310,-Foot of Parrot and Woodpecker. 
sections: the Diumal, whose eres are on the sides of the head, wings pointed, and metatarsus and toes covered over with seales, as the Vultures, Kites, Hawks, Falcons, and Eagles; the Nocturnal, whose large eyes are directed forward and surrounded by radiating feathers, metatarsus feathered, and plumage soft, as the Owls.

9. Scansores, or Climbers. ${ }^{103}$ — These Birds have no other exclusive peculiarity than the pairing of the toes, two being turned forward and two backward. Usually it is the outer toe which pairs with the hind toe; in the Trogons, it is the inner one. They are not musical, and only ordinary Hiers. They feed on Insects or fruit. The majority make nests in the hollows of old trees; but the Cuckoos lay in the nests of other Birds. In climbing, the Wood-

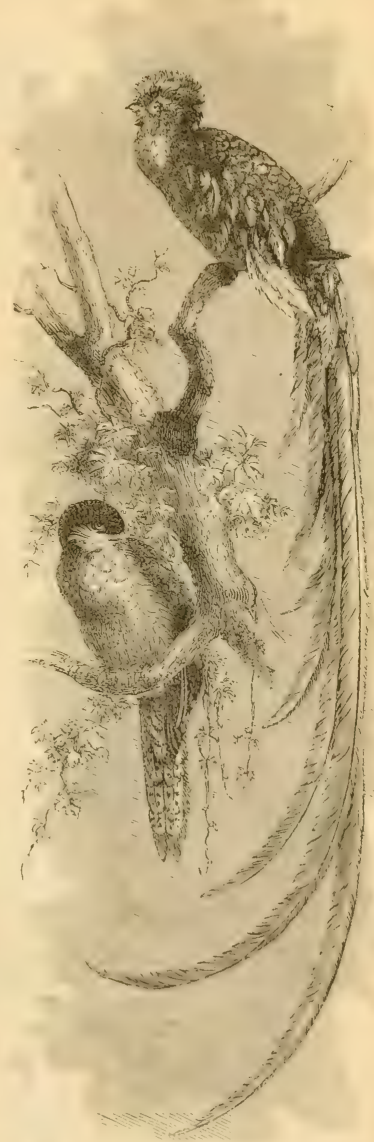

Fis. 311.-Tingon degens. Central America. 
peckers are assisted by their stiff tail, and the Parrots by their hooked bill. The important Scansores are the Par-

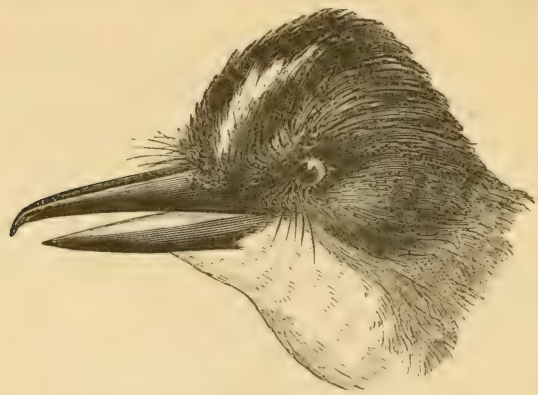

Fis. 312.-Head of a Fly-catcher (Tyrannus).

rots, Woodpeckers, Barbets, Toucans, Cuckoos, Jacamars, and Trogons.

10. Insessores, or Perchers.-This order is the most numerons and varied in the whole class. It comprehends all those tribes which live habitually among trees, excepting

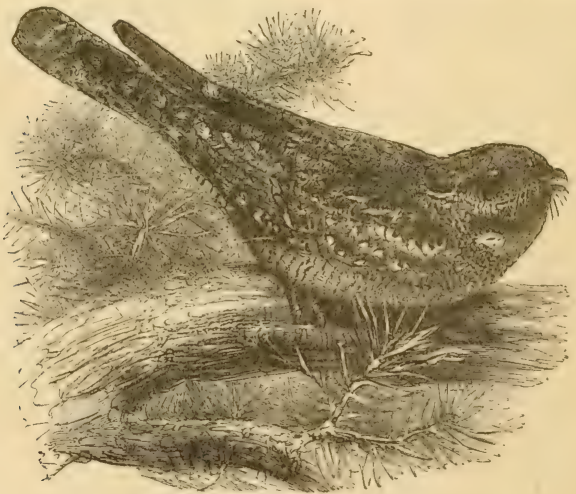

FIG. 313.-Guit-sucker (Caprimulgus). 
the Rapacions and Climbing Birds, and whose toes-three in front, and one behind-are eminently titted for perching only. The legs are slender, and seldom used for locomotion.

They are divisible into three sections: a. The Volitores, remarkable for their powers of flight. The wings are long and pointed, the roice is incapable of modulation, and the eggs are white. Such are the Hummers, having a long, slender bill; and the Swifts, Goat-suckers, and Kingfishers, having a short bill and wide gape. ${ }^{194}$ b. Clamatores, with nothing in common but a harsh voice. In most, the tarsus is enveloped in a row of plates, which meet behind in a groove, and the bill broad, and bent down abruptly at the tip.

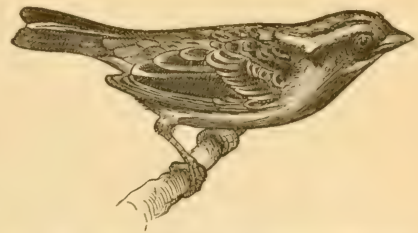

FIG. 314. - White-throated Sparrow (Zonotrichic albicollis). United States.

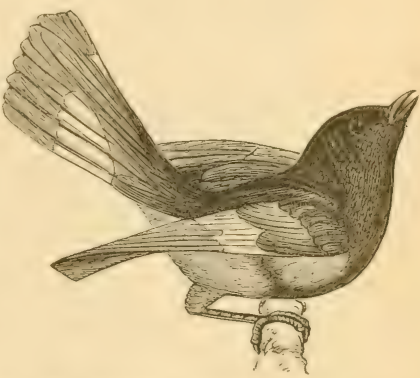

Fia. 315.-Redstart (Setophaga ruticilla). Unitea States.

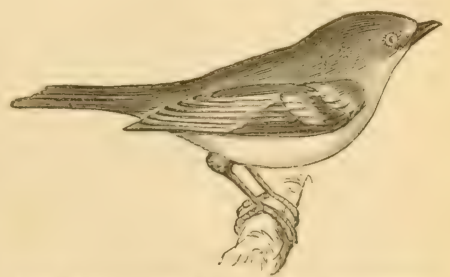

Fif. 316.- White-ered Viren (Virco Noveboracensis). United States. The typical representatives are the Tyrant Fly-catchers. c. Oscines, or Songsters, all of whom have a rocal ap- 
paratus, though all do not sing. The anterior face of the tarsus is one continuous plate, or divided transversely into

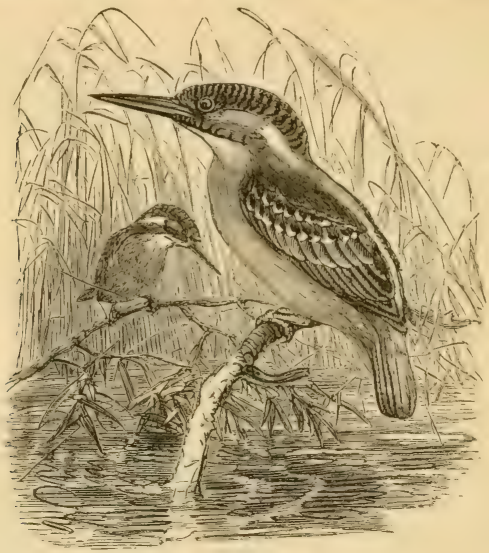

Fro. 317.-Kingfisher (Ceryle).

large scales; and the plates on the sides meet behind in a ridge. The toes, always three in front and one behind, are

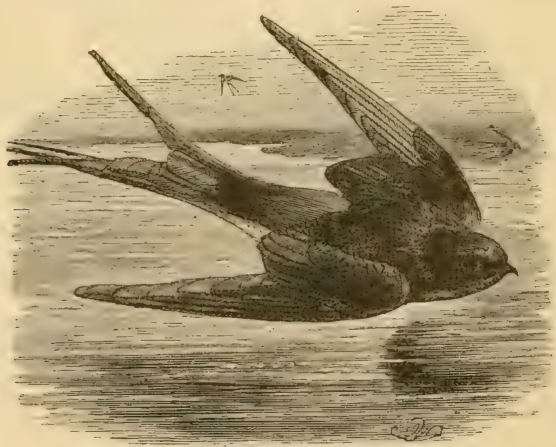

Fig. 310.-Swallow (Hirundo). 
on the same level. The eggs are usually colored. Here belong the Rarens, Crows, Jays, Birds of Paradise, Blackbirds, Orioles, Larks, Sparrows, Tanagers, Wax-wings, Swallows, Wrens, Warblers, Thrushes, etc.

\section{Chass V.-Mammalia.}

Mammals are distinguished from all other creatures by any one of the following characters: they suckle their young; the thorax and abdomen are separated by a perfect diaphragm; the red corpuscles of the blood have no nuclens, and are therefore double-concave; and either a part or whole of the body is hairy. ${ }^{195}$

They are all warm-blooded Vertebrates, breathing only by lungs, which are suspended freely in the thoracic carity; the heart is four-chambered, and the circulation is double, as in Birds; the aorta is single, and bends over the left bronchial tube; the large veins are furnished with valves; the red corpuscles differ from those of all other Vertebrates in being circular (except in the Camel); the entrance to the windpipe is always guarded by an epiglottis; the cerebrum is more highly developed than in any other class, containing a greater amount of gray matter and (in the higher orders) more convolutions; the cerebellum has lateral lobes, a mammalian peculiarity ; ${ }^{196}$ the cranial bones are mited by sutures, and they are ferer than in cold-blonded Tertebrates; the skull has two occipital condyles, a feature initated only by the Amphibians; the lower jaw consists of two pieces only (often united), and articulates directly with the cranimm; with two cxeeptions (Manatee and IIoffman's Sloth), there are always seren cerrical rertebre; the dorsals, and therefore the rils, vary from ten to twenty-four; the articulating surfaces of the vertebre are generally flat; the front limbs are never wanting, and the hind limbs only in a few aquatic forms; excepting the Whales, each digit car- 
ries a nail, claw, or hoof; the teeth (always present, save in certain low tribes) are planted in sockets; the mouth

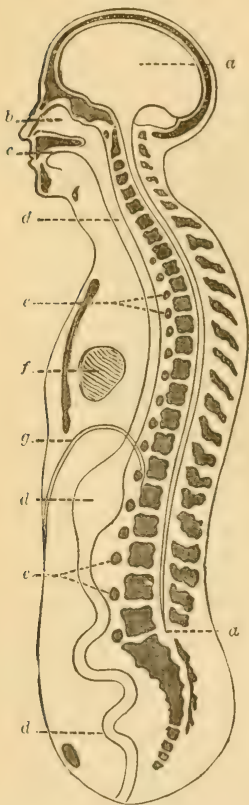

FrG. 319.-Longitudinal Section of Human Body (theoretical): $a$, cerebro-spinal nervous system; $b$, cavity of nose; $c$, cavity of mouth; $d$, alimentary canal ; $e$, chain of eympathetic ganglia; $f$, heart; $g$, diaphragm. is closed by flexible lips; an external ear is rarely absent $;^{197}$ the eyes are always present, though rudimentary in some burrowing animals; they are viviparous; and, finally, and perhaps above all, while in all other animals the embryo is developed from the nourishment laid up in the egg itself, in Mammals it draws its support, almost from the beginning, directly from the parent, and, after birth, it is sustained for a time by the milk secreted by the mammary glands. From the first, therefore, till it can care for itself, the young Mammal is in vital connection with the parent. ${ }^{198}$

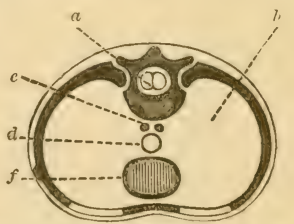

Fig. 320.-Transverse Section of Iruman Body (theoretical): $a$, cerebro-spinal nervons axis contained in nenral tube; $e$, chain of sympathetic ganglia ; $d$, alimentary canal $f$, heart; $h$, hremal tube.

1. Monotremes.-This order is created to include two singular forms, the Duck-mole (Omithorhynchus) and Spiny Ant-eater (Echichu), both confined to the Australian continent. The former has a covering of fur, a bill like 
that of a Duck, and webbed feet. The latter is covered with spines, has a long toothless snout, like the Ant-eater's, and the feet are not webbed. Both burrow, and feed upon

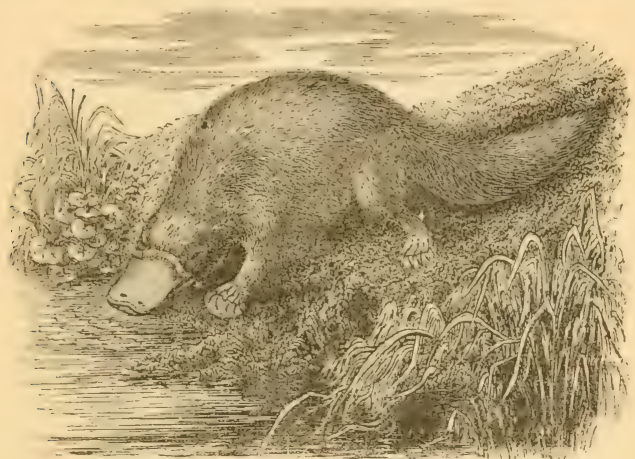

FIG. 321.-Ornithorhynchus.

Insects. The brain is smooth in the Ornithorhynchus, and folled in the Echidna. In both, the cerebral hemispheres are loosely united by transrerse fibres, and do not cover the cerebellum and olfactory lobes. ${ }^{199}$

2. Marsupials are distinguished by the fact that the young, always born premature, are transferred by the mother to a pouch on the abdomen, where they are attached to the nipples, and the milk is forced into their months by special muscles. ${ }^{300}$ They have "marsupial bones" projecting from the pelvis, which may serve to support the pouch; but as the Nonotremes have the same bones, but no pouch, they clunbtless have some other function. These bones are peculiar to animals having no placenta, namely, to Monotremes and Marsupials. The brains of Marsupials resemble those of the Munotremes, except that the cerebrum of the Kangaroo covers the olfatory lobes. All have the four kinds of teeth, and all are cor- 
ered with fur, never with spines or scales. Except the Opossums of America, all are restricted to Australia and

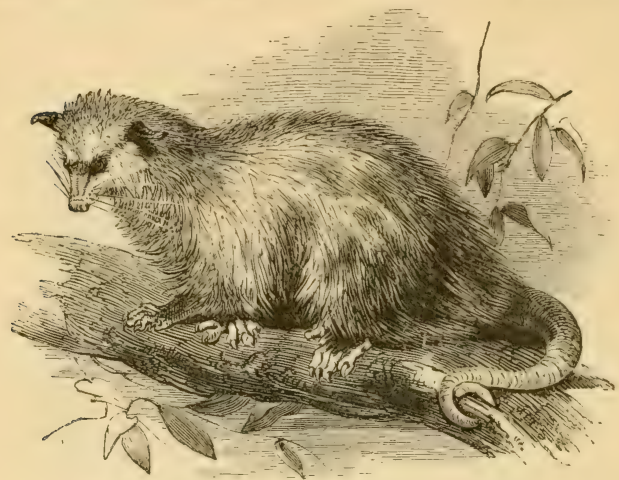

Fra. 322,-Virginian Opossum (Didelphys Virginiana).

adjacent islands. The Wombat, Kangaroo, and Plialanger are herbivorous; the Bandicoot, Opossum, IIylacinus, and Dasyurus are chiefly carnivorous.

3. Eilentates.-This strange order contains very diverse forms, as the leaf-eating Sloths and the insectivorous Anteaters and Armadillos of South America, and the Pangolin and Orycteropus of the Old World. The gigantic fos-

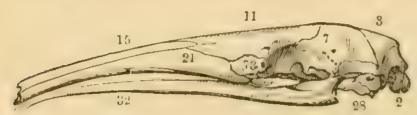

Fro. 323,-Skull of the Grent $\Lambda$ nt-eater (MIn'mecopherefe julute $)$ : 15 , nasal; 11, frontal: 7 , parietal ; 3 , superoccipital; 2 , occipital condyles; 2థ, tympanie: 73 , lachrymal; 32 , lower mandible. Teeth wanting. sils, Megatherium and Glyptodon, belong to this gromp. The Sloths and Ant-eaters are corered with coarse hair; the Armadillos and Pangolins, with an armor of plates or scales. The Ant-caters and Pangolins are strictly edentate, or toothless; the rest have molars, wanting, however, cnamel and roots. In general, it may be said that the order includes all quadrupeds having sep- 
arate, clawed toes and 110 incisors. The Sloths are arboreal; the others burrow. The brain is generally smooth;

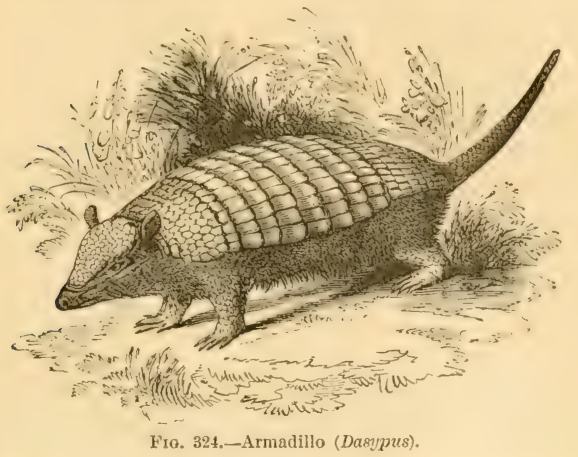

but that of the Ant-eater is convoluted, and has a large corpus callosum; but in all, the cerebellum and jart of the olfactories are exposed. ${ }^{201}$

4. Rodents, or Gnawers, are characterized by two long, curved incisors in each jaw, enameled in front, and perpetually growing; they are specially formed for nibbling. Separated from them by a wide space (for canines are wanting), are the flat molars, admirably fitted for grind-

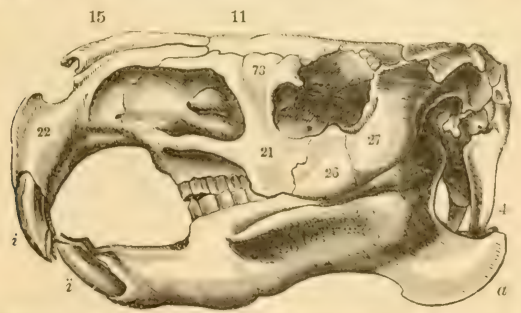

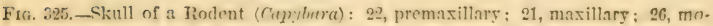
lar; 27 , squamosal ; 73 , lachrymal ; 15 , nasal : 11 , frontul; 4 , occipital procesecu, unusually developed ; $i$, incisors; $a$, angle of lower jaw. 
ing. The lower jaw has longitudinal condyles, which work freely backward and forward in longitudinal fur-

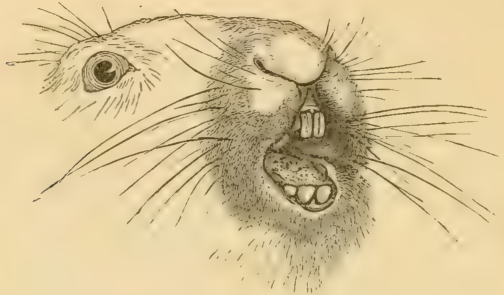

Fia. 326.-Incisor Teeth of the Hare.

rorrs. Nearly all have claricles; and the toes are clawed. The cerebrum is nearly or quite smooth, and covers but a small part of the cerebellum. All are regetarian.

About tro-thirds of all known Mammals are Rodents. They range from the equator to the poles, over every continent, over mountains and plains, deserts and woods. The

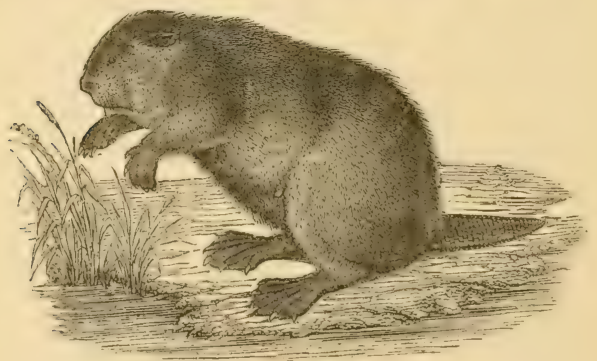

Fia. 327.-Beaver (Castor Canadensis), North America.

more important representatives are the Porcupines, Capybaras, Guinea-pigs, IIares, Mice, Rats, Squirrels, and Beavers. The Capybara and Beaver are the giants of the race. 
5. Insectivores are diminutive insect-eating animals, some, as the Shrew, heing the smallest of Mammals. They have small, smooth brains, which, as in the preceding orders, leave uncovered the cerebellum and olfactory lobes. The molar teeth bristle with sharp, pointed chrsps, and are associated with canines and incisors. They have a

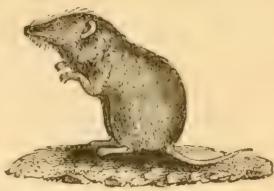

Fil, 32s,-Shrew Mlouse (Sorex). long muzzle, short legs, and clavicles. The feet are formed for walking or grasping, and are plantigrade, five-toed, and clawed. The Shrew, Hedgehog, and Mole are examples.

6. Cheiropters, or Bats, repeat the chief characters of the Insectirores; but some (as the Flying-fox) are fruiteaters, and have corresponding modifications of the teeth.

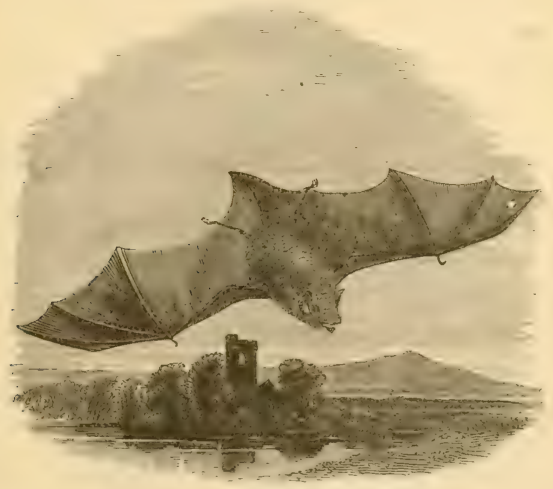

Fra. 329.-Bat (Vespertilio).

They are distinguished by their very long fore-limbs, which are adapted for flight, the fingers being immensely lengthened, and united by a membranous web. The 
toes, and one or two of the fingers, are armed with hooked nails. The clavicles are remarkably long, and the sternum is of great strength; but the whole skeleton is extremely light, though not filled with air, as in Birds. The

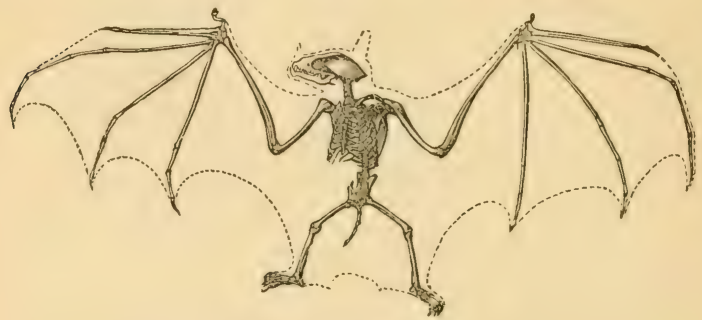

Fig. 330,-_skeleton of a Bat.

eyes are small, the ear's large, and the sense of touch is very acute. The favorite attitude of a Bat when at rest is that of suspension by the claws, with head downward. They are all nocturnal.

7. Cetaceans, or Whales, have the form and life of Fishes, yet they possess a higher organization than the preceding orders. They have a bruad brain, with many and deep foldings; the foramen magnum of the skull is entirely posterior; the whole head is disproportionately large, and the jaws greatly prolonged. The body is corered with a thick, smooth skin, with a layer of fat ("blub-

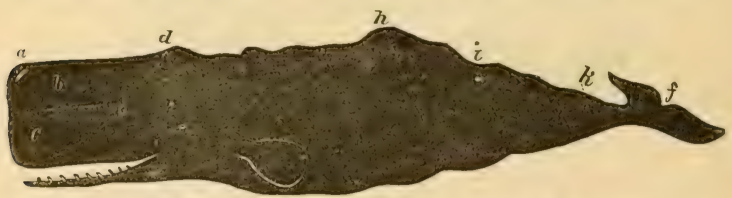

F1a. 331.-Outline of the Sperm-whale $(P h y / 2 t e r): a$, blow-hole; $b$, the case containing spermaceti; $c$, junk; $d$, bunch of the neck-between it and the corner of the mouth is the eye; $h$, hump; $i$, ridge; $k$, the small ; $f$, tail, or flukes. Between the dotted lines are the spiral strips of blubuer. Maximum length, sixty feet. South Atlantic. 
ber") underneath; there are no clavicles; the hind limbs are wanting, and the front pair changed to paddles; the tail expands into a powerful, horizontal fin; neck and ears are apparently wanting; the eyes small, with only two lids; the nostrils ("blow-holes")--double in the Whale, single in the Porpoise-are on the top of the head. All are carnivorous, and essentially marine, a few Dolphins only being found in the great rivers. In the Whalebone Whales, the teeth are absorbed, and disappear before birth, and their place is supplied by horny "baleen" plates. "The

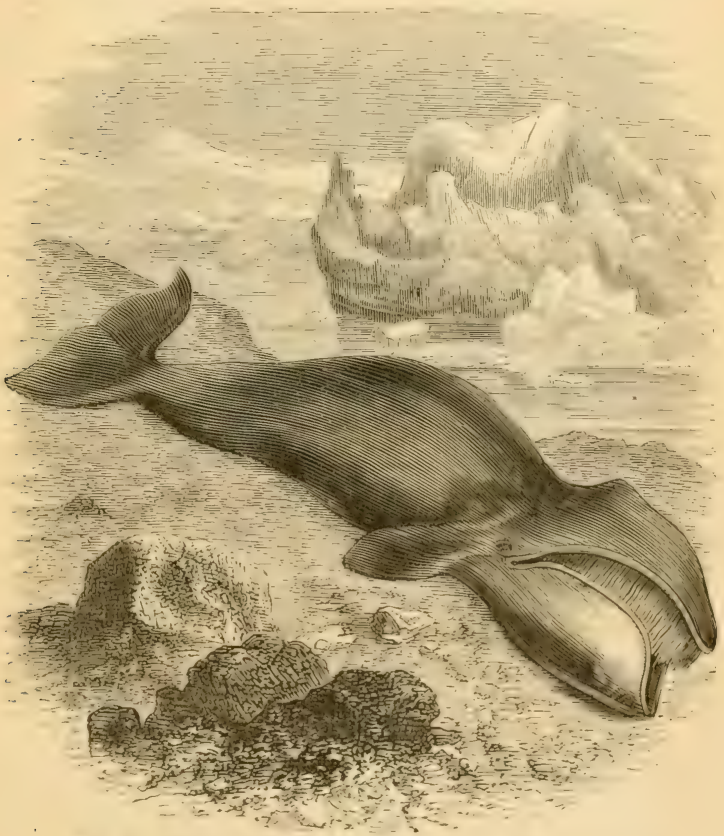

Fie. 332.-Greenland Whale (Balana mysticetus). North Atlantic. 
Whale feeds by putting this gigantic strainer into operation, as it swims through the shoals of minute Mollusks, Crustaceans, and Fishes, which are constantly found at the surface of the sea. Opening its capacious mouth, and allowing the sea-water, with its multitudinous tenants, to fill the oral cavity, the Whale shuts the lower jaw upon the

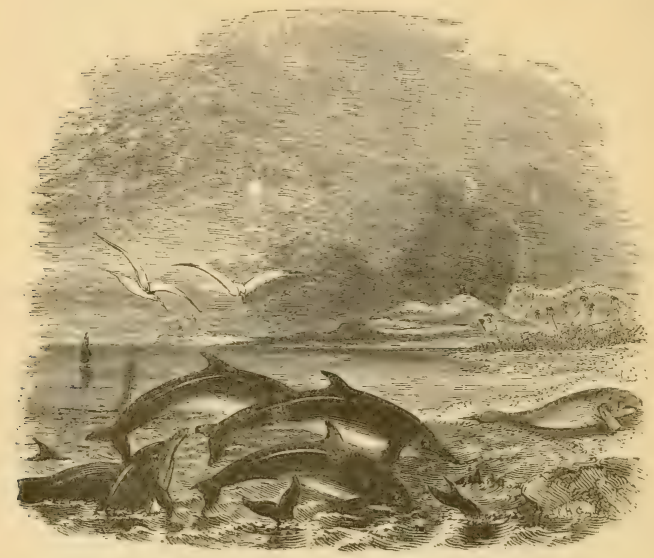

FIG. 333.-Troop of Dolphins, with Manatee in the distance.

baleen plates, and, straining out the water throngh them, swallows the prey stranded npon its rast tongue." In all other Cetaceans teeth are developed, especially in Dolphins and Porpoises; but the Sperm Whale has them only in the lower jaw, and the Narwhal can show but a single tusk. The Dolphins are the only Mammals having no organ of smell.

S. Sirenians resemble the Cetaceans in shape, but are closely allied to the hoofed animals in organization. They hare the limbs of the Whales, and are aquatic; but they are herbivorous, and frequent great rivers and estuaries. 
They have two sets of teeth, the Cetaceans nerer having but one. They have a narrow brain; bristles scantily corering the body; and nostrils placed on the snont, which is large and Heslyy. Such are the Manatee and Dugong.

9. Proboscidiens.-This race of giants, now nearly extinct, is characterized by two upper incisors in the form of tusks, mainly composed of dentine (irory). In the extinct Dinotherium the tusks projected from the lower jaw; and in the Mastodon, from both jaws. Canines are wanting. The molars are few and large, with transverse ridges (Elephant) or tubercles (Mastodon). The cerebrum is large and convoluted, but does not cover the cerebellum. The skull is enormons, the size arising in great measure from the development of air-cavities between the inner and outer plates. The nose is prolonged into a flexible trunk, which is a strong and delicate organ of prehension. There are four massive limbs, each with five toes incased in broad, shallow hoofs, and also with a thick, tegmentary pad. The knee is below and free from the body, as in Monkeys and Men. Clavicles are wanting. The body of the Elephant is nearly naked; but the Mammoth, an extinct species, had a covering of long woolly hair. Elefhants live in large herds, and subsist on foliage and grrass. There are but two living species: the Asiatic, with long head, concave forehead, small ears, and short tusks: and the $A$ frican, with round heal, convex foreheat, large ears, and long tusks. ${ }^{202}$

10. Ungulutes, or IIoofed Quadrupeds.-This large order, comprehending many animals most useful to Man, is distinguished by four woll-developed limbs, each furnished with not more than four complete toes, and each toe incased in a hoof. The leag, therefore, has no prehensile power; it is only for support and locomotion. Clavicles are wanting; and the radius and uhna are so mited as to prevent rotation. There are always two sets of teetl, i.e., 
milk-teeth are succeded by a permanent set. The grinders have broad crowns. As a rule, all are herbivorons. The brain is always consoluted, but the cerebellum is largely uncovered.

Ungulates are dirided into the odd and even toed. $a$. The Odd-toed, as the three-toed Rhinoceros and Tapir, ${ }^{203}$ and the one-toed IIorse. ${ }^{204}$ The first is distinguished by its very thick skin, the absence of canines, and one or two horns on the nose. The tapir has the four kinds of teeth, and a short proboscis. The dental formula of the Horse is-

$$
i \frac{3-3}{3-3}, c \frac{1-1}{1-1}, p m \frac{3-3}{3-3}, m \frac{3-3}{3-3}=40 .
$$

The canines are often wanting in the mare. The IIorse walks on the third finger and toe. The metacarpals and metatarsals are greatly elongated, so that the wrist and heel are raised to the middle of the leg. $\quad$. The Even-toed Ungulates - Ilog, Hippopotamus, and Ruminants-have

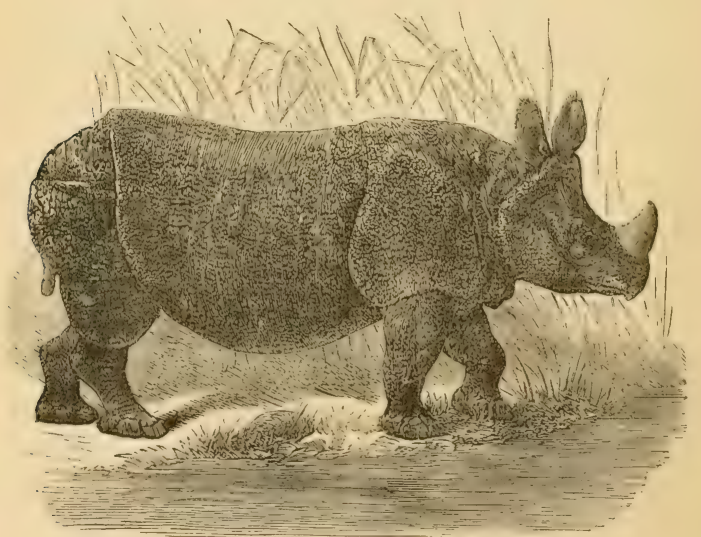

F10. 334,-Indian Rhinoceros ( $R$, unicornis). 
two or four toes. ${ }^{205}$ The IFog and Hippopotamus have the four kinds of teeth, and, in the wild state, are vegetarian. The Rumninants have two toes on each foot, enveloped in hoofs which face each other by a flat side, so that they appear to be a single hoof split or "cloven." L sually there are also two supplementary hoofs behind, but they do not ordinarily tonch the gromd. All chew the end, and have a complicated stomach. They have incisors in the lower jaw only, and these are apparently eight; but the two outer ones are canines. ${ }^{206}$ The molar's are flat typical grinders. The dental formula of the $\mathrm{Ox}$ is-

$$
i \frac{0-0}{3-3}, c \frac{0-0}{1-1}, p m \frac{3-3}{3-3}, m \frac{3-3}{3-3}=32 .
$$

With few exceptions, as the Camel, all Ruminants have horns, which are always in pairs. Those of the Deer are sulid, bony, and decidnons; those of the Giraffe and An-

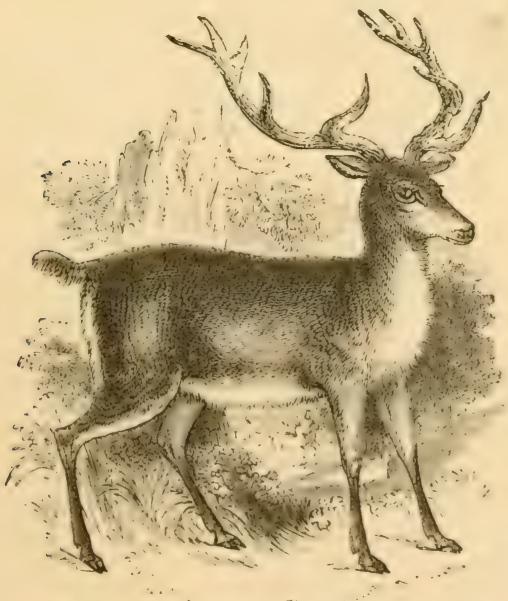

รo. 335.-Stag, or lied Deer (Cercus elaphus). Enrope. 
telope are solid, horny, and permament; in the Goat, Sheep, and Ox they are hollow, horny, and permanent.

11. Camivores, or Beasts of Prey, may be recognized ly their four long, curred, acute, canine teeth, the gap

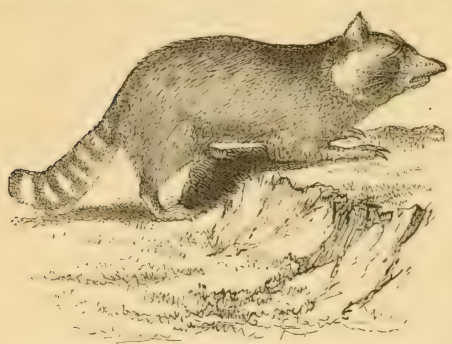

F1G. 336,-Raccoon (Procyon lotor). United States.

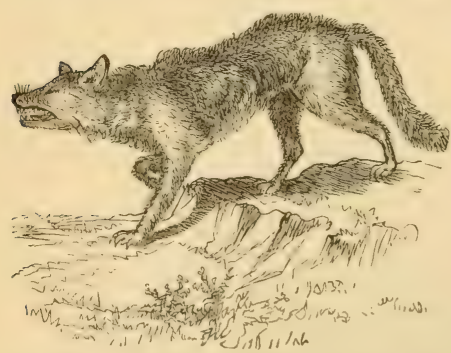

Fra. 337.-Wolf (Lupus occidentalis). Uniter Sitates.

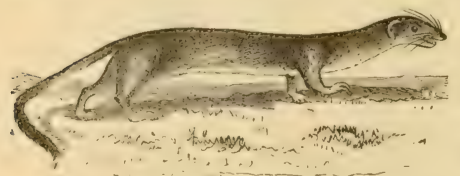

Fig. 335.-Ermine-weasel (Putorius Noveboracensis). United States.

between the incisors and canines in the upper jaw for the reception of the lower canine, and molars graduating from a tuberculate to a trenchant form in proportion as the diet deviates from a miscellaneons kind to one strictly of flesh. The incisors, with rare exceptions, number six in each jaw. The teeth are lodged in distinct sockets, and corered with enamel. There are always two sets. The skull is comparatively small, the jaws are shorter and deeper than in Ungulates, and there are numerous bony ridges on the inside and ontside of the cranium - the high occipital crest being specially characteristic. The cerebral hemispheres are joined by a large corpus callosum, but the 
cerebellum is never completely covered. Both pairs of limbs are well dereloped, the front being prehensile; but the clavicles are rudimentary. The humerus and femur are mainly inclosed in the body. The digits, never less than four, always have sharp and pointed claws. ${ }^{207}$ The body is covered with abundant hair.

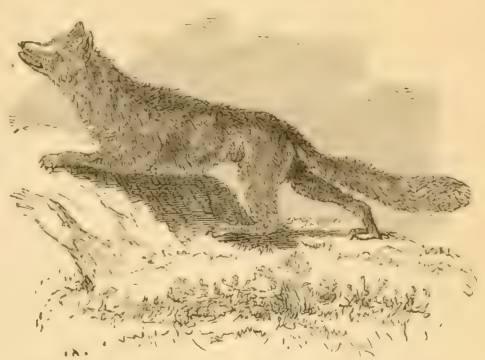

Fig. 339.-Red Fox (Vulpes fulvus). United St:tes.

Carnivores are divided according to the modifications of the limbs: $a$. Pinnigrades, having short feet expanded into webbed paddles for swimming, the hinder ones heing bound in with the skin of the tail. Such are the Seals, Walrus, and Eared Seals, or Sea-lions. 6. Plantigrades, in which the whole, or nearly the whole, of the hind foot forms a sole, and rests on the ground. The claws are not

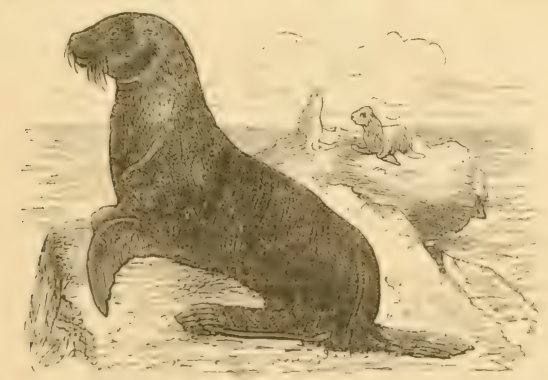

Fra. 340.-Southern Sea-lion (Otaria jubata). Antarctic Ocean.

retractile; the ears are small, and tail short. Bears, Badgers, and Raceoons are well-known examples. c. Digriti- 
grades keep the heel raised abuve the gromnd, walking on the tips of the toes. The majority have long tails. Such are the Weasels, Otters, Civets, Iyenas, Foxes, Jackals, Wolves, Dogs, Cats, Panthers, Leopards, Tigers, and Lions. The last five differ from all others in liaving retractile claws, and the radius rotating freely on the ulna. The Cats have thirty teeth; the Dogs, forty-two, or twelve more molars. In the former, the tongue is prickly; in the latter, smooth.

12. Primates, the head of the linglom, are characterized by the possession of two hands and a pair of feet, the thigh free from the body, and all the digits furnished with nails, the first on the foot enlarged to a "great toe." Throughout the order, the hand is eminently or wholly prehensile, and the foot, however prehensile it may be, is always locomotive. ${ }^{208}$ The clavicles are perfect. The eyes are situated in a complete bony cavity, and look forward.

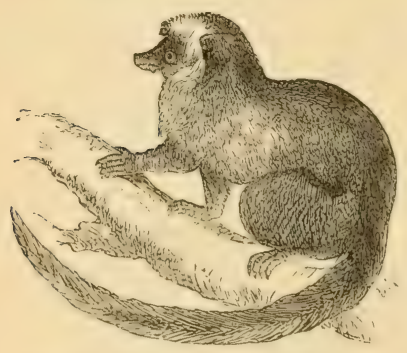

Fig. 341.-Lemur (L, ruber). Madagascar. There are two sets of teeth, all enameled; and the incisors, numbering four in each jaw. They are divided into Lemurs, Monkeys and Apes, and Man.

a. Lemurs, or "Madagascar Cats," are covered with soft fur, have usually a long tail, pointed ears, fox-like muzzle, and curved nostrils. They walk on all fours, and the thumb and great toe are generally opposable to the digits. The second toe has a long, pointed claw instead of a nail. The cerebrum is relatively small, and flattened, and does not corer the cerebellum and olfactory lobes. ${ }^{203}$

乙. The Monkeys of tropical America have, generally, a 
long, prehensile tail $;^{210}$ the nostrils are placed far apart, so that the nose is wide and flat; the thumbs and great toes are fitted for grasping, but are not opposable to the other digits; and they have four molars more than the Apes or Aran-that is, thirty-six teeth in all. In the Apes of the Old Workl the tail is never prehensile, and is sometimes wanting; the nostrils are close together; both thumbs and great toes are opposable; and the teeth, thongh numbering the same as Man's, are uneren (the incisors being

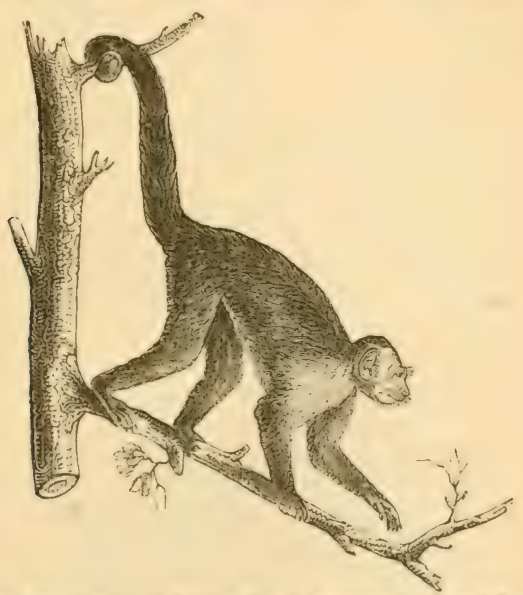

Fro. 342.-White-throated Sapajou (Cebus hyjoleucus). (entral America.

prominent, and the canines large), and the series is interrupted by a gap on one side or other of the canines. Their average size is much grreater than that of the Lemurs or MLonkeys, and they are not so strictly arboreal. In both Monkeys and Apes, the cerebrum eorers the cerebellum. ${ }^{211}$ While in the Lemurs and Monkeys the skull is rounded and smooth, that of the $\Lambda$ pes, especially those coming nearest to Man - the anthropoid, or long-armed, 
Apes, as Gorilla, Chimpanzee, Orang, and Gibbon - is characterized by strong crests. Lemurs and Monkeys

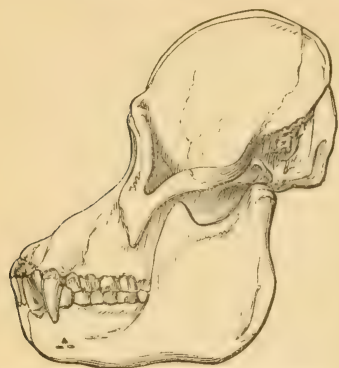

Fro. 343._Sknll of Ot:merg-utim (Simia satyrus). take a horizontal position; but the Apes assume a semierect attitude, the legs being

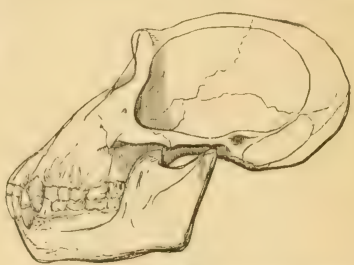

Fıg. 34. - Skull of Chimpanze (Troglodytes niger).

shorter than the arms. In all the Primates but Man, the body is clothed with hair, which is generally longest on the back. Sereral Monkeys and Apes have a beard, as the Howler and Orang.

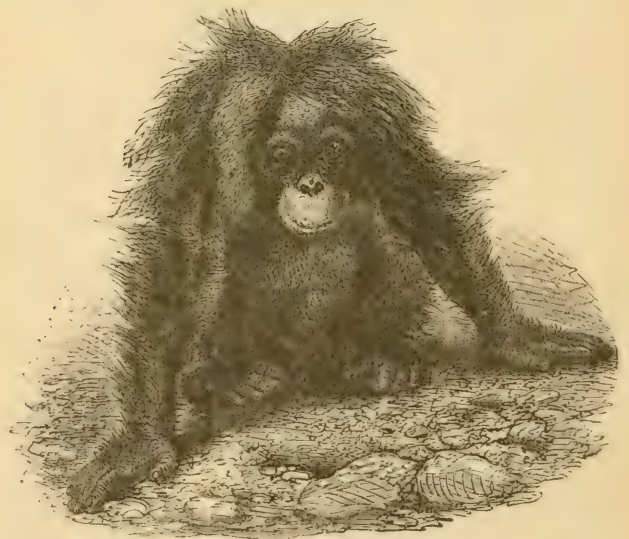

Frc. 345.-Female Orang-utan (from photograph). Bornco. 
The Orang is the least human of all the anthropoid $\Lambda$ pes as regards the slieleton, but comes nearest to Man in the form of the brain. The Climpanzee approaches Man most closely in the character of its cranium and teeth, and the proportional size of the arms. The Gorilla is most

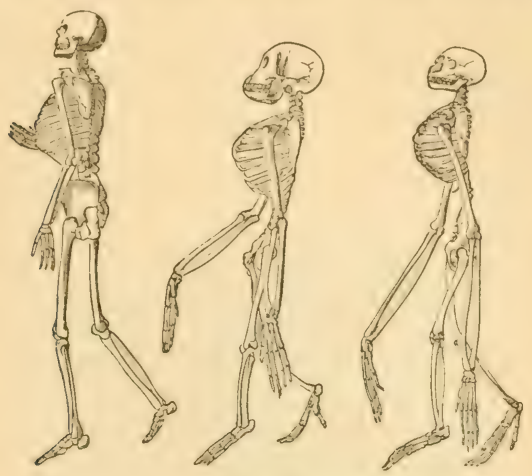

Fra. 346.-Skeletons of Man, Chimpanzee, and Orang.

Man-like in bulk (sometimes reaching the height of fire feet six inches), in the proportions of the leg to the body and of the foot to the hand, in the size of the heel, the form of the pelvis and shoulder-blade, and volume of brain..$^{212}$

c. Man differs from the $\Lambda_{\text {pes }}$ in being an erect biped. In him, the vertebrate type, which hegan in the horizontal Fish, finally became rertical. No other animal habitually stands ereet; in no other are the fore-limbs used exclusively for head-purposes, and the hind pair solely for locomotion.

Man alone can stand, walk, run, jump, climb, swim, ride, drive, sit, or lie on his back for any length of time.

II limbs are naturally parallel to the axis of his body, not perpendicular. They have a near equality of length, 
but the arms are always somewhat shorter than the legs. In all the great $\Lambda$ pes the arms reach below the knee, and the legs of the Chimpanzee and Gorilla are relatively shorter than Man's.

Man only has a finished hand, most perfect as an organ of touch, and most versatile. Both hand and foot are relatively shorter than in the $\Lambda$ pes. The foot is plantigrade; the leg bears vertically upon it; the heel and great toe are longer than in other Primates; and the great toe is not
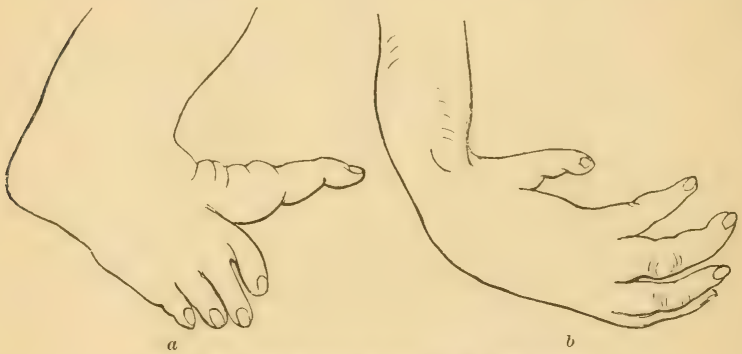

FIG. 347.-Foot $(a)$ and Hand $(b)$ of the Gorilla.

opposable, but is used only as a fulcrum in locomotion. The Gorilla has both an inferior hand and inferior foot. The hand is clumsier, and with a shorter thumb than Man's; and the foot is prehensile, and is not applied flat to the ground. ${ }^{213}$

The scapular and pelvic bones are extremely broad, and the neck of the femur remarkably long. Man is also singular in the double curve of the spine: the Baboon comes nearest to Man in this respect.

The human skull has a smooth, rounded outline, elerated in front, and devoid of crests. The cranium greatly predominates orer the face, being four to one $;^{214}$ and no other animal (except the Siamang Gibbon) has a chin.

Man stands alone in the peculiarity of his dentition : his 
teeth are vertical, of nearly miform height, and close together. In every other animal the incisors and canines are more or less inclined, the canines project, and there are vacant spaces. ${ }^{216}$

Man has a longer lobule to his ear than any $A$ pe, and no muzzle. The bridge of his nose is decidedly convex; in the Apes generally it is flat.

Man has been called the only naked terrestrial Mammal. His hair is most abundant on the scalp; never on the back, as in the Apes.

Man has a more pliable constitution than the Ipes, as

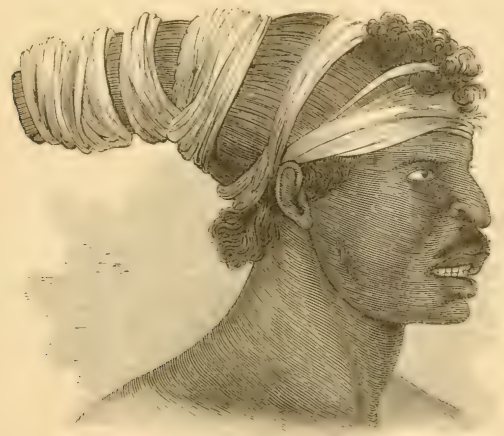

Fic. 348.-Australian Savage.

shown by his world - wide distribution. The animals nearest him soon perish when removed from their native places.

Though Man is excelled by some animals in the acuteness of some senses, there is no other animal in which all the senses are eapable of equal development. IIe only has the power of expressing his thoughts by articulate speech, and the porrer of forming alstract ideas.

Man differs from the Apes in the absolute size of brain, 
and in the greater complexity and less symmetrical disposition of its convolutions. The cerebrum is larger in proportion to the cerebellum (being as $S_{\frac{1}{2}}$ to 1 ), and the former not only covers the latter, but projects beyond it. The brain of the Gorilla scarcely amounts to one-third in

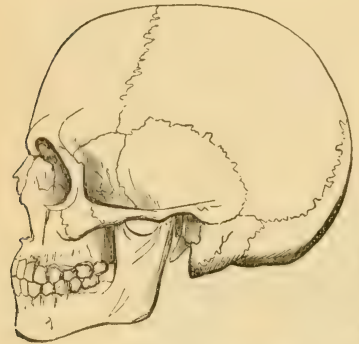

Fig. 349,-Skull of European.

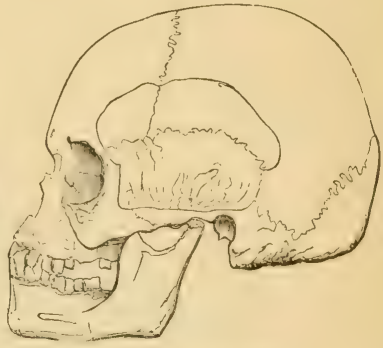

Fig. 350.,Skull of Negro.

rolume or one-half in weight of that of Man. Tet, so far as cerebral structure goes, Man differs less from the Apes than they do from the Monkeys and Lemurs. The great gulf between Man and the brute is not physical, but psychical. ${ }^{210}$ 


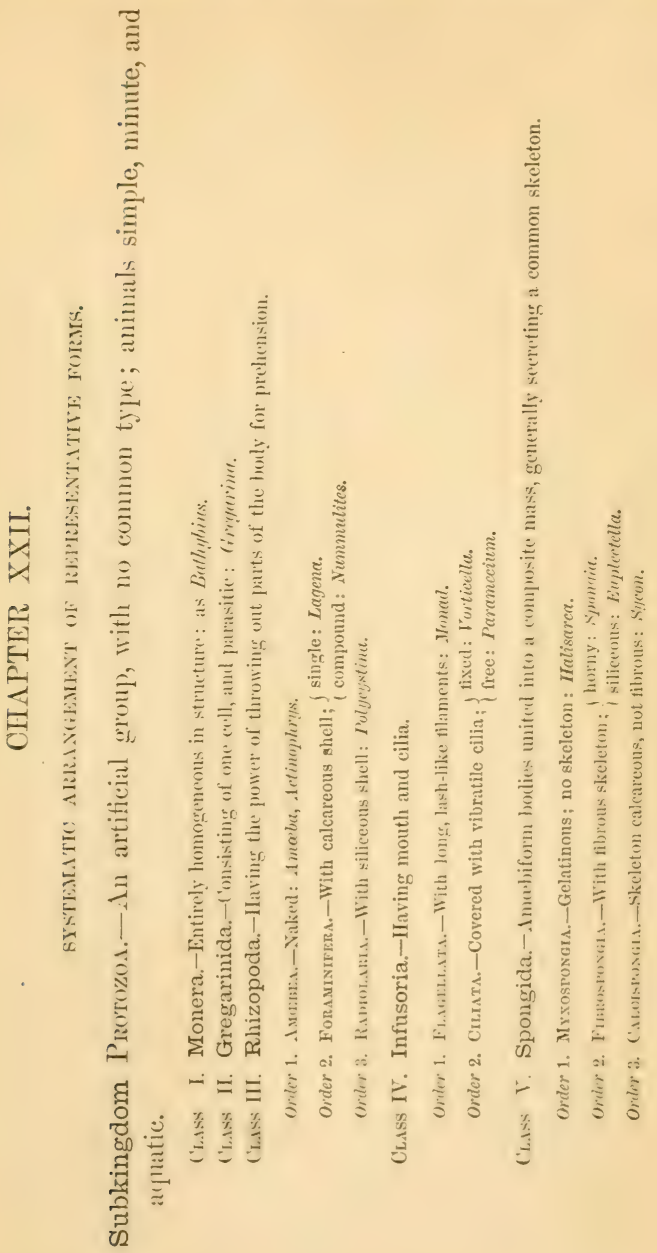



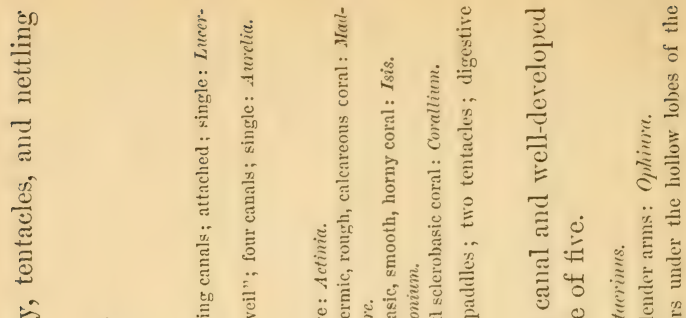

$\overbrace{0}^{\infty}$

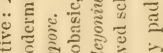

डु छ ह छ

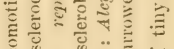

๖ुँ

¿

प छ ङ

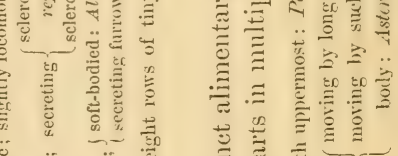

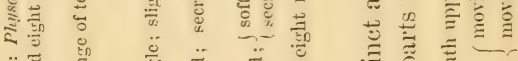

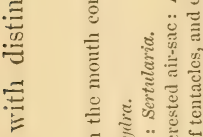

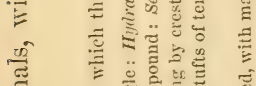

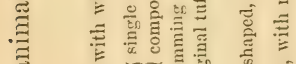
胥

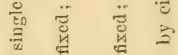

ङ

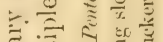

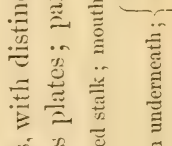

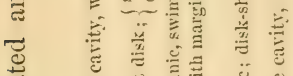
莺

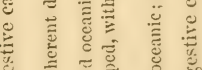

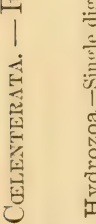

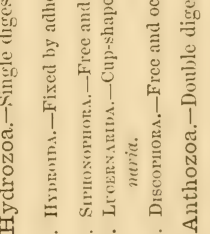

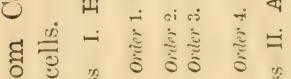
党

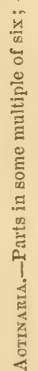
崖 
ARTANGEMLNT OF REIRESLNTATIE FORMS.

351

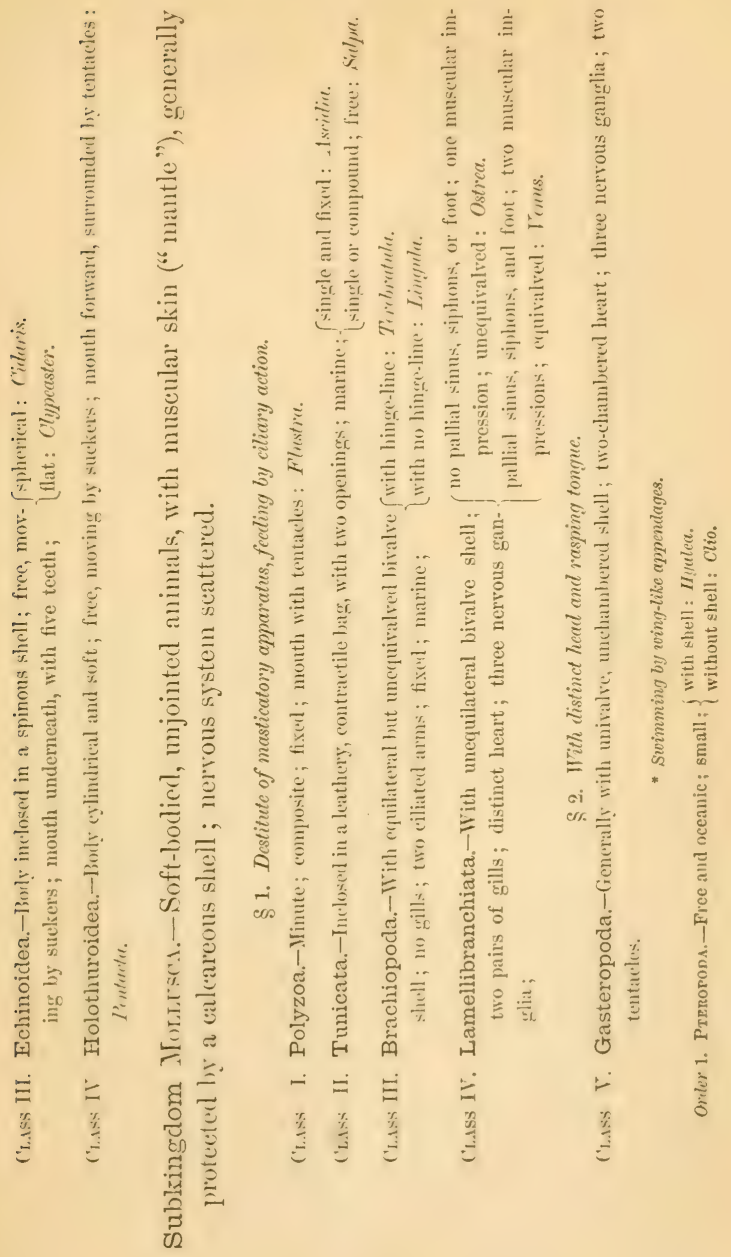


告

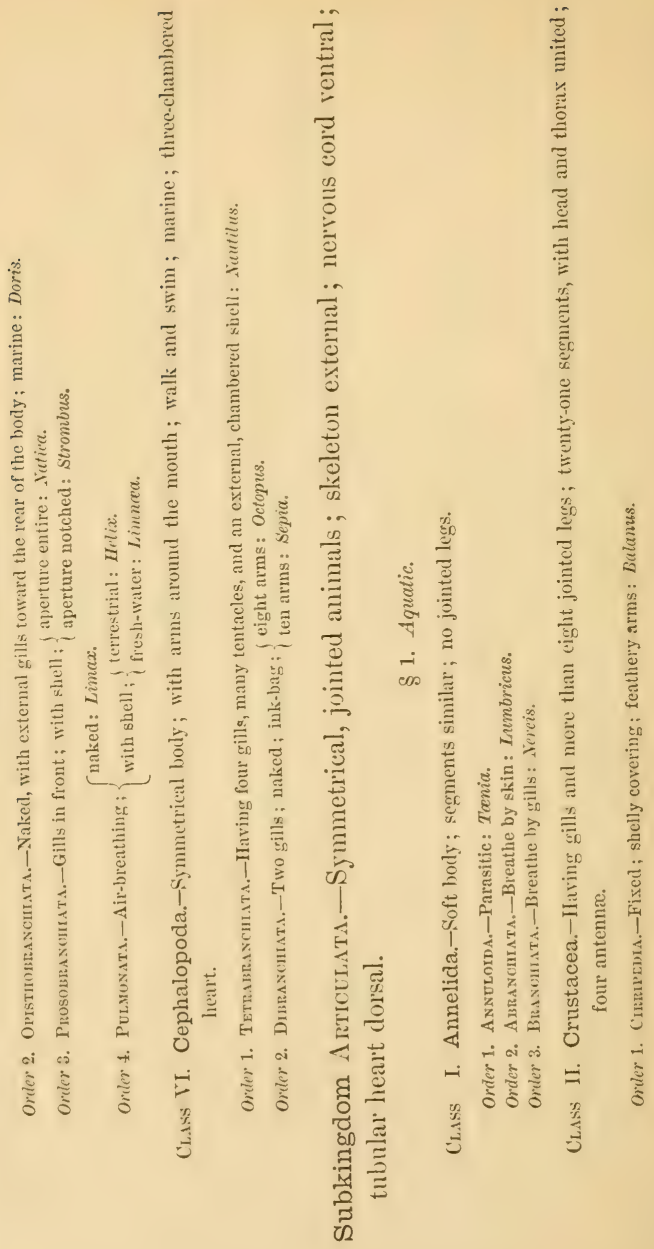



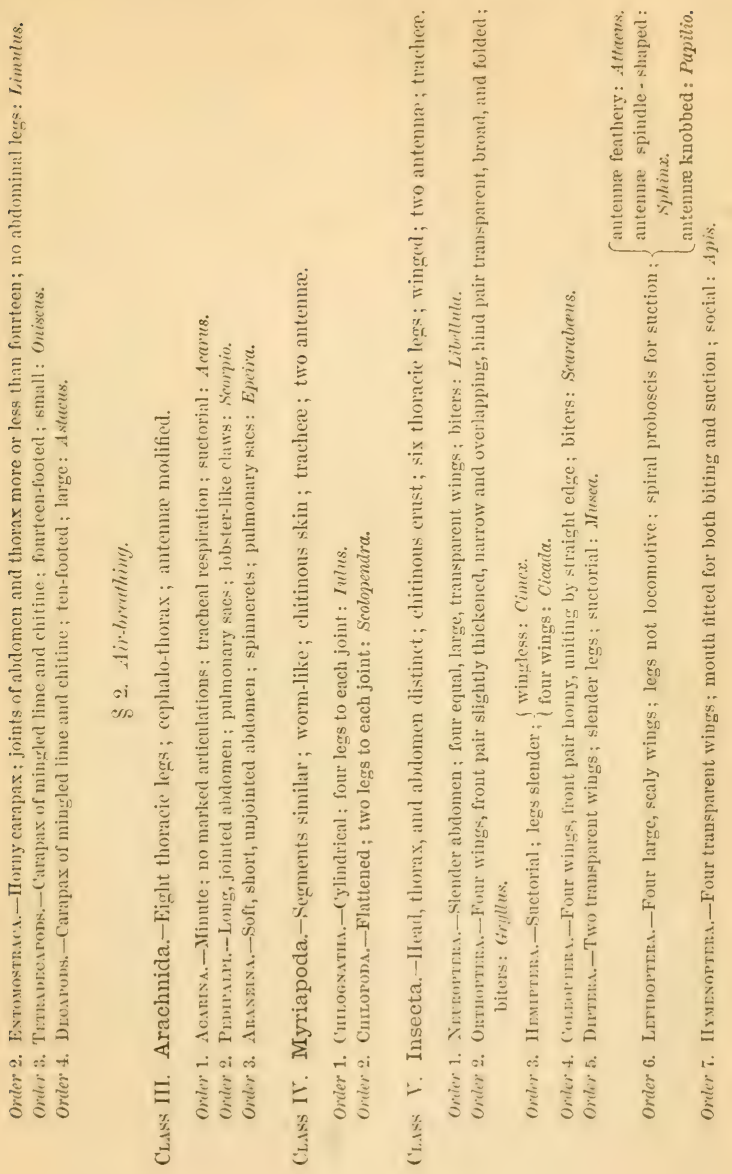


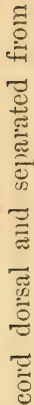

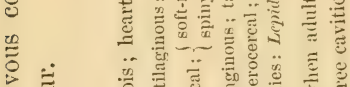

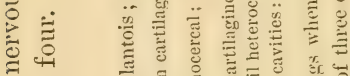

$\ldots$ 灵

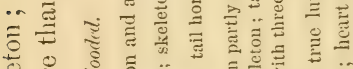

to 0 ๖

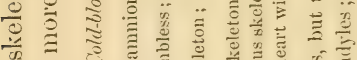

品

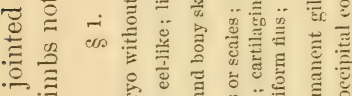

-

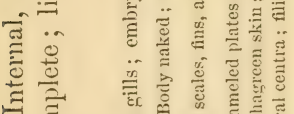

$\because$ छ

$\dot{\xi} \approx$

空

द⿱乛龰

可

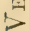

a मि
き

ฮี

E

ह

छ

.. E

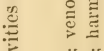

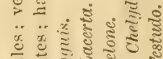
¿ ए

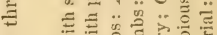

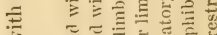

E छ छ छ

$\rightleftarrows \cong \Xi \cong$

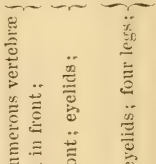

总芯苛

苑芯

‥

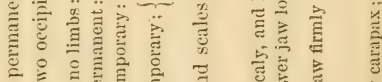

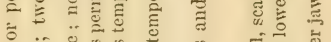

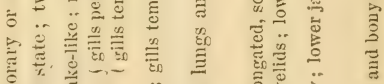

$\therefore \quad \bar{\Xi} \ddot{D}$

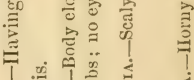

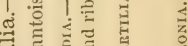

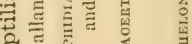

Q

氙

द्व $:$ का

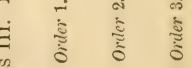




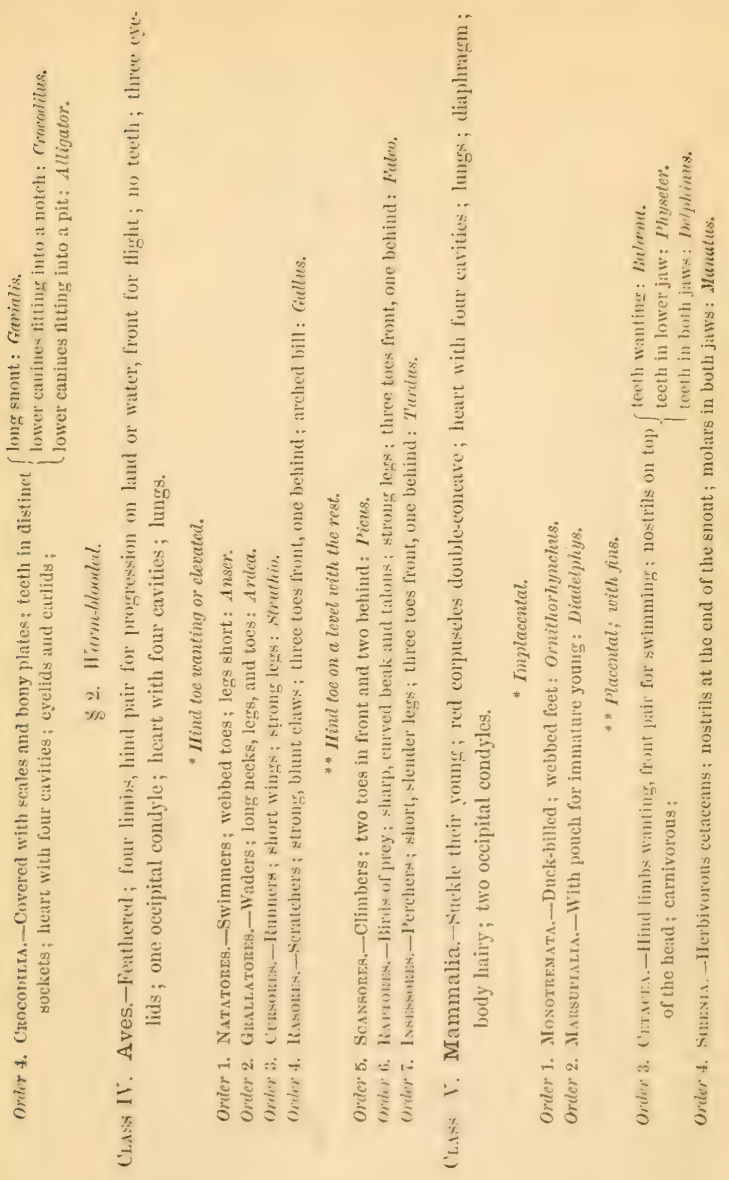




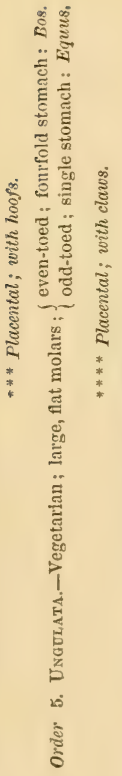

을

\&

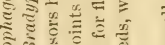

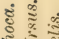

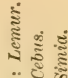

ฮ...

产芯芯

क

○웛

.. 3 छँ

芯芯芯

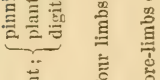

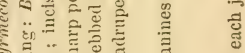

ड.

$\approx \equiv \equiv$ 品

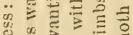

0 क

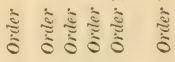




\section{CHAPTER XXIII.}

TIE DISTRIBUTION OF ANIMALS.

LIFE is everywhere. In the air above, the earth beneath, and the waters under the earth, we are surrounded with life. Nature lives: every pore is bursting with life; every death is only a new birth, every grave a cradle. The air swarms with Birds, Insects, and invisible animalcules. The waters are peopled with immmerable forms, from the Protozoan, millions of which would not weigh a grain, to the Whale, so large that it seems an island as it sleeps upon the waves. The bed of the sea is alive with Crabs, Shells, Polyps, Star-fishes, and Foraminifera. Life everywhere-on the earth, in the earth, crawling, creeping, burrowing, boring, leaping, ruming.

Nor does the rast procession end here. The earth we tread is largely formed of the déloris of life. The quarry of limestone, the flints which struck the fire of the old Revolutionary muskets, are the remains of countless skeletons. The major part of the Alps, the Rocky MIomtains, and the chalk cliffs of England are the monmmental relics of by-gone generations. From the ruins of this living architecture we build our Parthenons and Pyramids, on St. Peters and Lourres. So generation follows generation. But we have not yet exhansted the survey. Life cralles within life. The bodies of animals are little worlds having their own famma and flora. In the fluids and tissues, in the eye, liver, stomach, brain, and muscles, parasites are found; and these parasites often have their parasites living on them. 
"Great fleas have little fleas and smaller fleas to bite 'em;

And these again have other fleas, and so ad infinitum."

Thus the ocean of life is inexhaustible. It spreads in every direction, into time past and present, flowing everywhere, eagerly surging into every nook and corner of creation. On the momntain-top, in the abysses of the Atlantic, in the deepest crevice of the earth's crust, we find traces of animal life. Nature is prodigal of space, but economical in filling it. ${ }^{217}$

Animals are distributed over the globe according to definite laws, and with remarkable regularity.

Each of the three great provinces, Earth, Air, and $\mathrm{Wa}$ ter, as also every continent, contains representatives of all the classes; but the various classes are unequally represented. Every great climatal regrion contains some species not found elsewhere, to the exclusion of some other forms. Every grand division of the globe, whether of land or sea, each zone of climate and altitude, has its own fama. And, in spite of the many canses tending to disperse animals berond their natnral limits, each country preserves its peculiar zoological physiognomy.

The space oceupied by the different groups of animals is inversely as the size of the individuals. Compare the Coral and Elephant.

Fauma now oceupying a separate area is closely allied to the fauma which existed in greologic times. Thus, Australia has always been the home of Marsupials, and South America of Edentates.

It is a general rule that gromps of distinct species are circumscribed witlin definite, and often narrow, limits. Man is the only cosmopolitan; yet even he comprises several marked races, whose distribution corresponds with the great zoological regions. The natives of $\Lambda$ ustralia are as grotesque as the animals. Certain brutes likewise have a great range: thus, the Puma ranges from Canada to Pata- 
gonia; the Mnsk-rat, from the Aretie Ocean to Florida; the Emine, from Behring's Straits to the Inimalityas; and the IIippopotamus, from the Nile and Niger to the Orange River. ${ }^{2-y}$

Frequently species of the same genus, living side by side, are widely different, while there is a close resemblance between forms which are antipudes. The Mnd-eel of South Carolina and Axolotl of Mexico have their connecting links in Japan and Austria. The American Tapir has its mate in Sumatra the Llama is related to the Camel, and the Opossum to the Kangaroo.

The chief canses modifying distribution are temperature, topography, ocean and wind currents, humidity and light. To these may be added the fact that animals are ever intruding on each other's spheres of existence. High momntain-ranges, wide deserts, and cold currents in the neean are impassable barriers to the migration of most species. Thus, river-fish on opposite sides of the Andes differ widely, and the cold Perurian current prevents the growth of coral at the Galapagos Islands. So a broad river, like the Amazons, or a deep, narrow chamnel in the sea, is an effectual barrier to some tribes. Thus, Borneo belongs to the Indian region, while Celebes, though but a few miles distant, is Australian in its life. The faune of North America, on the east coast, west coast, and the open plains between, are very different.

Animals dwelling at ligh elevations resemble those of colder latitudes. The same species of Insects are found on Momnt Washington, and in Laburador and Greenland.

The range does not depend npon the powers of locomotion. The Oyster extends from IIalifax to Charleston, and the Snapping-turtle from Canada to the equator; while many Quadrupeds and Birds have narrow hal. itats.

The distribution of any gronp is qualified by the nature 
of the food. Carnivores have a wider range than herbivores.

Life diminishes as we depart from the equator north or sonth, and likewise as we descend or ascend from the level of the sea.

The zones of geography have been divided by zoologists into narrower provinces. Five rertical regions in the sea have been recognized: the Littoral, extending between tide-marks; the Laminarian, from low water to 15 fathoms; the Coralline, from 15 to 20 fathoms; the deep-sea Coral, from 50 to 100 fathoms; and the Bathybian, from 100 fathoms down. Every marine species has its own limits of depth. It would be quite as difficult, said Agassiz, for a Fish or a Mollusk to cross from the coast of Europe to the coast of America as for a Reindeer to pass from the arctic to the antaretic regions across the torrid zone. Narine animals congregate mainly along the coasts of continents and on soundings. The meeting-place of two maritime currents of different temperatures, as on the Banks of Newfoundland, favors the development of a great diversity of Fishes.

Every great province of the ocean contains some representatives of all the subkingdoms. Deep-sea life is diversified, thongh comparatively sparse. Examples of all the five invertebrate divisions were found in the Bay of IBiscay, at the depth of 2435 fathoms. ${ }^{219}$

Distribution in the sea is influenced by the temperature and composition of the water, and the character of the bottom. The depth acts indirectly by modifying the temperature. Northern animals approach nearer to the equator in the sea than on the land, on accoment of cold currents. The heary aquatic Mammals, as Whales, Walruses, Seals, and Porpoises, are mainly polar.

The land consists of the following somewhat distinct areas: the Neotropie, comprising Sonth America, Mexi- 
co, and Wrest Indies; the Teoaretic, including the rest of America; the I'aladeretic, composed of the eastern continent north of the Tropic of Cancer; the Africano-Inclian, or Ifrica south of Sahara, Southern isia, and the western half of the Malay Arehipelago; and the Australian, or the eastern half of the Malay Islands and A Instralia.

Life in the polar regions is characterized by great uniformity, the species being few in number, thongh the number of individuals is immense. The same animals inhabit the aretic portions of the three continents; while the antarctic ends of the continents, Australia, Cape of Good IIope, and Cape IIorn exhibit strong contrasts. Thuse three continental peninsulas are, zoologically, seprarate worlds. In fact, the whole southern hemisphere is peculiar. Its fam is antique. Australia possesses a strange mixtme of the old and new. South America, with newer Mammals, has older Reptiles; while Africa has a rich vertebrate life, with a striking uniformity in its distribution.:-

In the tropies, diversity is the law. Life is more raried and crowded than elsewhere, and attains its highest derelopment.

The New-rorld fama is old-faslioned, and inferior in rank and size, compared with those of the eastern continents.

is a rule, the more isolated a region, the sreater the rariety. Oceanic islands have comparatively few species, lut a large proportion of endemic or peenliar forms. Batrachians are generally absent, and there are no indigenous terrestrial Mammals. The productions are related to those of the nearest continent. Wrhen an island, as Britain, is separated from the main-land by a shallow chamel, the mammalian life is the same on both side-:

Protozonns, C'xlenterates, and Echinoderms are limited to the waters, and nearly all are marine. Sponges are 
mostly obtained from the Grecian Archipelagro and Baha. mas. Corals abound thronghout the Indian Ocean and Polynesia, east coast of Africa, Red Sea and Persian Gulf, West Indies and around Florida. True Crinoids are found only in the Caribbean Sea and on the coast of Norway. The other Echinoderms abound in almost erery sea, the Star-fishes chiefly along the shore, the Seaurchins in the Laminarian zone, and the Sea-slugs around coral-reefs.

Mollusks have a world-wide distribution over land and sea. The land forms are restricted by climate and food, the marine by shallows or depths, by cold currents, by a sandy, gravelly, or mud bottom. Living Brachiopods, though few in number, occur in tropical, temperate, and arctic seas, and from the shore to the greatest depths. The rest of the Bivalves are also found on every coast and in every climate, as well as in rivers and lakes, lut do not flourish at the depth of much more than 200 fathoms. The fresh-water Mussels are more numerous in the United States than in Europe, and west of the Alleghanies than east. The sea-shells along the Pacific coast of America are unlike those of the Atlantic, and are arranged in five distinct groups--Alentian, Californian, Panamic, Peruvian, and Magellanic. On the Atlantic coast, Cape Cod and Cape IIatteras separate distinct provinces. Of land-snails, IIilir has an almost miversal range, but is characteristic of North America, as Butimus is of South America, and Achetine of Africa. The Old World and America have no species in common, except a few in the extreme north.

The limits of Insects are determined by temperature and regetation, by oceans and mountains. There is an insect-fauna for each continent, and zone, and altitude. The Insects near the snow-line on the sides of mountains in the temperate region are similar to those in polar lands. The Insects on our Pacific slope resemble those of Europe, 
while those near the Atlantic coast are more like those of Asia. Not half a dozen Insects live in the sea.

The distribution of Fishes is bounded by narrower limits than that of other animals. I few tribes may be called cosmopolitan, as the Sharks and Ilerrings; but the species are local. Size does not appear to bear any relation to latitude. The marine forms are three times as numerons as the fresh-water. The migratory Fishes of the northern hemisphere pass to a more southern region in the spring, while Birds migrate in the antumn.

Living Reptiles form but a fragment of the immense number which prevailed in the Middle $\mathrm{Ages}$ of Geology. Being less under the influence of Man, they have not been forced from their original habitats. None are arctic. America is the most favored spot for Frogs and Salaminders, and India for Snakes. Australia has no Batrachians, and two-thirds of its Snakes are renomons. In the United States, only 22 ont of 176 are renomons. Frogs, Snakes, and Lizards ocenr at elerations of orer 15,000 feet. Crocodiles, and most Lizards and Turtles, are tropical.

Swimming Birds, which constitute alout one-fourteentlı of the entire class, form one-half of the whole number in Greenland. As we approach the tropies, the variety and number of land Birds increase. Those of the torrid zone are noted for their brilliant plumage, and the temperate forms for their more sober hues, but sweeter roices. India and Sonth America are the richest regions. Birds with rudimentary wings, as Penguins and ()striches, prevail in the sonthern hemisphere. IIummers, Tanagers, Orioles, and Toncans are restricted to the New World. Parrots are found in erery continent, except Europe; and Woolpeekers oceur ererywhere, save in Australia.

The rast majority of Mammals are terrestrial; but Cetaceans and Seals take to the sea, Otters and Bearers du- 
light in lakes and rivers, and Moles are subterranean. As of Birds, the aquatic species abound in the polar regions. Marsupials inhabit two widely separated areas-America and Australia. In the latter continent, they constitute three-fourths of the fauna; while Edentates, Ruminants,

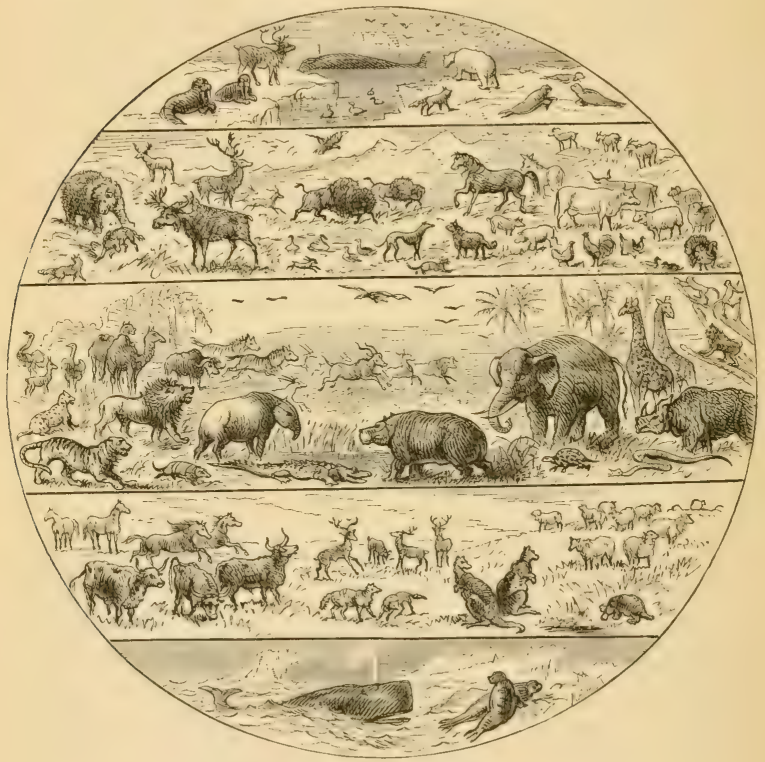

Fre. 351,-Zones of Animal Life.

IIorses, Elephants, Hogs, Squirrels, Moles, Carnivores, Monkeys, and Apes are wanting. Excepting a few species in Sonth Africa and South Asia, Edentates are confined to tropical South America. The equine family is indigenous to Sonth and East Africa and Sonthern Asia. In North America, Rodents form abont one-half the num- 
ber of Mammals; they are entirely wanting in Madagascar. Ruminants are sparingly represented in America. Carnivores flourish in every zone and continent. The prehensile-tailed Monkeys are strictly South American; while the anthropoid Apes belong to the west coast of Africa, and to Borneo and Sumatra. Both Monkeys and Apes are most abundant near the equator; in fact, their range is limited by the distribution of palms. 



\section{NOTES.}

1 The eomplete and elaborate natural history of a single species or limited

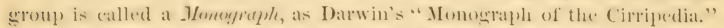
A. Memeri, is not so formal or exhauntive, giving mainly original investigations of a special subject, as Owen's "Memoir on the Gorilla."

${ }^{2}$ Before the time of Linneus, the Lady-bug, e.g., was ealled "the Coceinellat with red coleopters having seven black spots." He called it ciecinelle septem-punctata.

${ }^{3}$ Matudino (1:315) and Berenger (1515), of Bologna, and Vesalius, of Brussels $(15.50)$, were the tirst anatomists. Circulation of the blood discovered by Harver, 1616. The lacteals discovered by Asellius, 16:2, and the lymphaties by liudbel, 16.0. Willis male the first minute anatomy of the bratin and nerves, 166t. The red blond-corpuseles were discovered by Leenwenlook and Malpighi, 16\%i). Infusoria first observed by Lecuwenhoek, 16;is; the name given by Mïller, 17s6. Swammerdam was the founder of Entomology, 16\%5. Comparative anatomy was tirst eultivated by Perrault, Peequet, Duverney, and Mery, of the Acatemy of Paris, the latter part of the serenteenth eentury. Malpighi, the founder of structural anatomy, was the first to demonstrate the structure of the lumgs and skin, 1690. Ahout the same time, Ray and Willoughhy first classified Fishes on structural ereunds. Foraminifers were seen by Becearius one humeled and fifty years acos; lut their true structure was not demonstrated till 1895, hy Dujardin. Peyssonel published the first elaborate treatise on Corals, 17:2 . Haller was the first to distinguish between contractility and sensibility, 175\%. White bloot-eorpuscles discovered by Hewson in 17\%. Spallanzani was the first to demonstrate the true nature of the digestive process, 1\%so. Cuvier and Geoffroy, in $1 \% 9 \%$, proposed the fir-t natural clas-ifieation of amimals. Before that, all Invertebrates were divided into Insects and Worms. Lamarek was the first to study Mollusks, 1soo; before him, attention was confined to the sluell. He separated spiders from Insects in 1s1:2. The law of errelation emunciated by Cuvier, 1s:21. Von Bare wats the founder of Embryolegr, establishing the

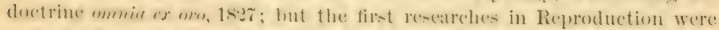
male by Fabricius about 1600, ame hy llarvey in 1651. Woltl, early in this coutury, was the pioneer in ols-erving the phenomena of Development. sars first observed alternate Generation, 1s:3). Inmeril is considered the father of IIerpetologs, and Owen of Odontolesy. Sehleiden and Schwann published their celehrated researehes in eell-structure, 1s+1; hut Bichat, who died 1s(1), was the founder of Histology. Protoplasm was discovered by Dujardin. 
4 This twofold division is arhitrary. No essential distinction, founded on the nature of the elements concerned, or the laws of their combination, can be mate ; and so many so-called organic substances, as urea, ammonia, alcohol, tartaric and oxalie acids, have been prepared by inorganic methods, that the boundiary-line is daily beeoming fanter, and may in time vanish altogether. It should be added, however, that "those organic compounds which hate been artificially formed are invariably products of decompusition, or, in other words, the excretions or secretions of organized bodies; and are far less cenmplex in their constitution than organized structures. "-Gregony's Oryanic Clermistry. "Chemical synthesis has in reality reproduced only matters untitted for life; that is to say, mineral matters." -M. Deans. We would lere utter our protest against the introduction of any more terms like inorganic, invertebrate, acephalous, etc., which express no qualities.

${ }^{5}$ Even the works of nearly all animals proceed in circles or segments of circles.

${ }^{6}$ Lomione Qnurerly Pevieu, January, 1869, p. 142. It is true of any great primary group of animals, as of a tree, that it is much more easy to define the summit than the base.

7 De Bary on "Mysornyectre;" Darwin on "Carnivorous Plants."

8 This, of course, is not universally true. If we regard a tree as an association of phytons, or plants, instead of an individual, then each leaf and petal when developed is perfect and abiding, like the separate Polyps of a compound Coral. Some consider every organ a distinct individual existence; in this view, an animal, like a tree, is a compact community.

${ }^{9}$ It should be noted that plants erolve carbonic acid only when in a state of decomposition or exhanstive process, not during normal, vigrorous growth. Both animals and plants in decay consume oxygen. "There is every reason to believe that carbonic acid is continually sriven off from the inteim of plants, while oxygen is absorbed." -C.nnpexter. It is interesting to compare the temporary respiratory organ of plants, the cotyledon, with the gills of a tadpole: both disappearing when the evolution of the permanent apparatus renders them unnecessary.

10 There are eertain phenomena, even among the higher plants, connected with the habits of elimbing plants and with the functions of fertilization, which it is very diflicult to explain without admitting some low form of a seneral harmonizing and regulating function, comparable to such an obseure manifestation of reflex nervous action as we have in Sponges and in other animals in which a distinet nerrous system is absent.-Prof. Wrville Tromson's Introductory Lecture at Edimburgh.

11 If nature had endowed us with microscopic powers of rision, and the integuments of plants had been rendered perfectly transparent to our eres, the vegetable world would present a very different aspect from the apparent immohility and repose in which it is now manifested to our senses.-HurBOLDT's Cosmos, i., 311.

12 Sie Gray's "Structural Botany," p. 350; Rolleston's "Forms of Animal Life," p. 143.

${ }_{13}$ We may safely say that there is no plant which may not serve as food for some animal. 
14 Life has heen ealled the vital foree, and it has been sugerested that it maly be found to belong to the sane category as the convertible forces, heat and light. Life seems, however, to be more a property of matter in a certain state of combination than a foree. It does no work, in the ordinary sense. - Prof. Wrilie Thomsox. The recent experiments of Rolert Hamiltom tend to prove the existenee, in every highly developed organism, of two lives: a lifie resident in every atom of the structure, howerer complex, and mother life for which we fail to find an expression. But the latter is the life which lieeps together the strueture as a whole: it is the life that seleets the mutrition best suited to its individual self; it is the life that has to do with the continuation of the species; lastly, it is the life to which the molecular lives, which make up the structure, are subordinated; and when this nameless life departs, these myriad lives, no longer co-operating, start on an independent course.

15 There was a time in onr history when a single membrame discharged all the functions of life-digesting, respiring, secreting. The selaration of a heart, lung, stomach, liver, ete., for special duty, was an after-eonsideration.

16 The vegetable cell has usually two concentric coverings : cell-wall and primorlial utricle. In animal cells the former is wanting, the nembrame representing the utricle. As a general fact, animal eclls are smaller than regetable cells.

1: Cells are not the sourees of life, as once thought, but are the products of protoplasm. "They are no more the producers of vital phenomena than the shells scattered in orderiy lines along the sea-beach are the instruments by which the gravitation-force of the moon acts upon the ocean. Lilie these, the cells mak only where the vital tides have been and how they liave acted." -Prof. HuxLey.

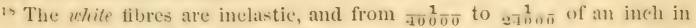
diameter. They are best seen in the tendons. The yellom tibres are elastie,

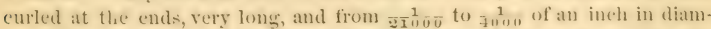
eter. They are shown in the hinge-ligament of an Oyster. Connective tisste appears areolar, $i$. e., shows interspaces, only under the microsenpe.

19 Certain benes, as those of the face and forehead, are preceded by membranes instead of cartilage.

${ }^{20}$ In the heart, the muscular fibres are striated, yet involuntary; but the sarcolemma is wanting.

21 Other names are melullary she:ath and white suhstance of sehwamm.

2s $\mathrm{We}$ max, howerer, infer that the amimal functions are not alsolutely (cosential to the vecretative, from the facts that plants digest without muscles or nerves, and that nutrition takes place in the embryo lone before the nerves have been developed.

sa This is not -trictly true, for the Elm and Oak, the Trout and Alligator, do reach a maximum size.

24 The suetorial Insects always sulsist ujou one and the same lind of food.

s sempioms and spiders properly feed upon the juices of their rictims after lacerating them with their claws; but fragments of Insects have been found in their stomachs. 
26 At one end of the Tape-worm is a minute pore, by some considered the mouth, with a circlet of spines and four suckers.

23 The real tongue forms the floor of the mouth, and is found as a distinct part in a few Insects, as the Crickets.

${ }^{28}$ In a few Fishes, it is circular or oval.

29 The mouth of the Whale is exeeptional, the walls not being dilatable. The act of sucking is characteristic of all young Mammals, hence the need of lips.

30 The Ant-eater has two callous ridges in the mouth, against which the insects are crushed by the action of the tongue.

as strictly spealing, the baleen plates do not represent tecth; for in the cmbryo of the Whale we find minute calcareous teeth in both jaws, which never ent the gum. The whalebone is probably a peculiar development of hair in the palate, and under the microscope it is seen to be mate up of fibres which are hollow tubes.

3: The "tusks" of the Narwhal and Elephant are prolonged incisors; those of the Walrus and Wild Boar are canines.

33 "I was one day talking with Professor Owen in the Hunterian Museum, when a grentleman approached, with a request to be informed respecting the nature of a curious fossil which had been dug up by one of his workmen. As he drew the fossil from a small bag, and was about to hand it for examination, Owen quietly remarked, "That is the third molar of the under jaw of an extinet species of rhinoceros." "-LEwes's Studies in Arimel Life.

${ }^{34}$ This gap or interspace, so characteristic of the inferior Mammals, is called diusteme. It is wanting in the extinct Anoplotherium, and is hardly perceptible in one of the Lemurs.

${ }^{35}$ In the Spermaceti-whale, the teeth are fixed to the gum.

${ }_{36}$ The Iguma among Reptiles, and Fishes with pavement-teeth, approach the Mammals in this respect.

${ }^{37}$ This movement is ealled peristultic or vermiculer, and characterizes all the succeeding movements of the alimentary canal.

${ }^{38}$ Fishe's and Amphibians have no saliva, but a short gullet. Birds are aided by a sudden upward jerk of the head.

${ }^{39}$ Fishes and Reptiles have no pharynx proper, the nostrils and glottis opening into the mouth.

40 This movement of the pharynx and nesopharus is wholly involuntary. Liquids are swallowed in exactly the same way as solids.

41 The few animals in which the digestive cavity is wanting are ealled ugustric, and agree in having a very simple structure, and in being parasitic. Such are some Entozon (as Tape-worm), and unicellular Protozoa (as Gregarina). They absorb the juices, already prepared, by the physical process of endosmose. There are other minute organisms which seem to be able to extract the necessary elements, $\mathrm{CHON}$, from the medium in which they live.

${ }_{42}$ Moreover, as a Sponge is an agregation of animals, these canals are for a community, not for a single individual. According to Alexander Agasiz, the: Ctenophore have a true alimentary canal, passing through the bodycavity. 
43 "Xothing is more curious and entertaining than to watch the neat ness and acenracy with which this prexes is performet. One may sere the rejected hits of fored pats-ing rapidly along the lines upon which these pediecllarie oceme in ereate-t number, as if they were so many little roats for the eonvering away of the refuse matters ; nor do the forks eease from their labor till the surtace of the animal is eompletely chean and free from any foreign substance."-AGAssiz's Sict-side Studies.

4t In the larva of the Bee, the anal orifice is wanting.

4. The loneth of the (anal in Inscets is not so inclieative of the habits as in Mammals. Thus, it is nearly as lome and more enmplicated in the carnivorous Bectles than in the honey-sipping Buttertlies.

46 The object of this is unknown. It does not occur in the Oyster.

${ }^{47}$ In the Nautilus, this is preceded by a capacious crop.

4. In the shark, this is impossible, owing to at great number of firinges in the gullet hanging down toward the stomach.

$4^{*}$ At the herimning of the large intestine in the Lizards (aud in many Vertebrates above them, esectially the regetarian orders), there is a blind sac, called corem. The worm-like appendage to the caecum is almo-t peenliar to Man and the Apes.

so The Crocodile is said to swallow stones sometimes, like Birds, to aic the gastric mill.

51 In the erop of the eommon Fowl, vegetable food is detained sixteen hours, or twice as long as animal food. The Dormonse, amony Mammals, has an approach to a crop.

52 In Mollusks, the gizzard, when present, is situated between the crop) and the true stomach; in Birds, it comes after the stomach.

${ }^{53}$ The fourth stomach of Ruminants is the largest so long as the animal sucks.

54 The Tape-Trorm has no digestive aplaratus, and "Hesh whith is deeomposed by decay into a semi-fluid mass is absorbed by the -ponge-like bodies of certain animals which live in stagnant pools" ( ( L.Lnis); hut these are not real exceptions to the rule. In both eases, transmutation goes before absorption.

5.5 As starch is a recectahle product, we would look for the mo-t abundant saliva in those mammals that feed on herhs and grain; and such is the fact. Morenver, as sugar is heat-producing, in cold-bluoded Peptiles, Fishes, Mollusks, and other like carnivores, a fluid to convert starch into susar would be out of place.

66 These substances are only dissolved and chemically modified (being comverted into what are termed pystomes), not "ormanized" or "vitalized."

s: It is probable that the digestive purt of the alimentary ("anal in all animals manifests a similar mechanieal movement. It is most remarkable in the cizzard of a fowl, which corresponds to the pylorie end of the human stomach. This muscular organ, supplyine the want of a ma-ticatory :upparatus in the head, is powerful enough to pulverize, not only arain, hut even

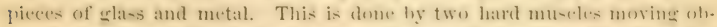

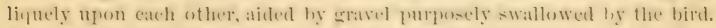
The grinding mas be heard by means of the stethoseope. 
ss Chyle is opaque in carnivores; more or less transparent in all other Tertebrates, as in Birds, sinee the food does not contain fatty matter.

5n In Fishes, the villi are few or wanting. In Man, they number about 10,000 to the square inch.

${ }^{6}$ Exeept, probably, the brain, spinal-marrow, bones, tendons, ligaments, epidermis, etc.

6. The lacteals also carry lymph when the intestine is empty and they have nothing else to do.

62 The phenomenon produeed by these properties conjointly, eapillary attraction and diffusion, is ealled endosmosis.

${ }^{63}$ The blood is colorless also in the muscular part of all Fishes. That of Birds is of the deepest red. The eoloring matter of the red blood in Worms is not in the corpuscles, but in the plasma.

64 Coagulation in the living body is mainly prevented by being liept in constant motion. It may be artificially arrested by common salt. Arterial blood eoagulates more rapidly than venous. The disposition of the red corpuscles in chains, or roulcuux, does not occur within the blood-vessels. The cause has not been discovered.

${ }_{65}$ The corpuseles of Invertebrates are usually colorless, eren when the plood is tinged. It should be observed that those animals whose blood resembles chyle or lymph have no lacteals or lymphatics.

${ }^{66}$ Exeept during foctal life. The corpuscles of the Camel are non-nucleated, as in other Mammals. - If the transparent fluid from a boil be exam. ined with a microscope, it will be seen to be almost composed of colorless corpuscles, showing their use in repairing iujuries.

67 There are no valves in the veins of Fisues, Reptiles, and Whales, and few in Birds.

6t Capillaries are wanting in the epidernis, nails, hair, teeth, and cartilages. Hence, the epidermis, for example, when worn out by use, is not remored by the blood, like other tissues, but is shed.

69 A part of the blood, however, in going from the capillaries to the heart, is turned aside and made to pass through the liver and kidueys for purification. This is called the portul circulation, and exists in all Vertebrates, except that in Birds and Mammals it is confined to the liver.

70 Two in the higher Mammals, three in the lower Mammals, Birds, and Reptiles. They are ealled vence cavce.

71 Tricuspid in Mammals, triangular in Birds.

72 The pulse of a Hen is 140 ; of a Cat, 110 to 120 ; of a Dog, 90 to 100 ; and of an $\mathrm{Ox}, 25$ to 43 .

is The bivalve Brachiopods, having no gills, breathe by delicate arms about the mouth, or by the "mantle."

is The air-bladler, found in most Fishes, is another rudiment of a lung, although it is used, not for respiration, but for altering the specific gravity of the Fish. In the Gar-pike of our Northern lakes, it very closely resembles a lung, having a cellular structure, a tracheal tube, and a glottis. The gills represent lungs only in function; they are totally distinct parts of the organism. (See Huxley, "Anatomy of Vertebrated Animals," p. 92.)

is Well seen in Tadpoles, or young of the Frog. 
:6 In the human lungs, they number $600,000,000$, each about -11 , of an inch in cliameter, with an acroregate area of $1: 3$ square feet. The thickness of the membrane between the blood and the air is so fino of an inch. The lungs of Camivores are more highly developed than those of Iferbivores. In the Innatee, they are not contined to the thorax, but extend down nearly to the tail.

7 Crocodiles are the only Reptiles whose nostrils open in the throat behind the palate, instead of directly into the mouth-avity. This cnables the Crocolile to drown its vietim without drowning itself; for, by keeping its snout above water, it can breathe while its mouth is wide open.

is A rudimentary diaphragm is seen in the Crocodile and Ostrich.

${ }^{79}$ The poison-glands of venomous Serpents and the silk-vessels of Caterpillars are considered to be modified salirary glands. Birds, snakes, and Cartilaginous Fishes have no urinary bladder.

so since the weight of a full-urown animal remains nearly uniform, it must lose as much as it receives; that is, the excretions, including the solid residum ejected from the intestinal canal, equal the food and drink.

si Other names for derm are, crutis, corium, endrom, and true skin; and for epilermis, cutirle, ecterm, and serof-skin. The derm is often so intimately blended with the museles, that its existence as a distinct layer is not easily made out. Even in Infusoria, we find the tunic double, an outside cuticulu lined hy a soft cortical layer; and in Jelly-fishes, naturalists distinguish an ectoderm and endoderm.

s2 See Fig. 146. Papilla are searcely visible in the skin of Reptiles and Birds.

${ }^{8}$ The animal basis of this structure is chitime, a peculiar substance found in the hard parts of all the articulated animals.

of The large elaws within the old crust are soft, and hence are able to be drawn through the small joints.

is The shell is always an epidermal structure, eren when apparently internal. The horny "pen" of the Squid, the "bone" of the Cuttle-fish, and the ealeareous spot on the back of the slue, are only concealed under a fold of the mantle. So the shell of the common Lnio, or Fresh-water Clam, is corered with a brownish or areenish membrane, which is the outer layer of the epidermis. Where the mantle eovers the lips of a slell, as in most of the larese sea-snails, or where its folds cover the whole exterior, as in the polished Cowry, the epidermis is wanting, or eovered up hy an additiomal layer.

${ }_{-\infty}$ The pearls of commerce, found in the mantle of some Mollusks, are similar in structure to the shell; but what is the innermost layer in the shell, is plated on the outside in the pearl, and is much fincr and more compact. The pearl is formed around some nuclens, as an oreanic particle, or grain of sand.

$\because$ When the centrum is concave on both sides, as in Fishes, it is said to be

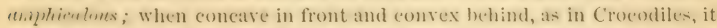
is called momlous; when concave behind and convex in front, as in the neckvertehre of the $0 \mathrm{x}$, it is apistlemelens. In the last two eares, the vertebrie unite by ball-and-socket joints.

s: A few have but one pair, the Whale and siren wanting the hind pair: while some hare none at all, as the snakes and lowest Fishes. In land ani- 
mals, the po-terior limbs are generally most developed; in aquatic animals, the anterior. Dr. Wyman contends that the limbs are tegumentary organs, and ittached to the vertebral column in the same sense that the tecth are attached to the jaws.

89 The muscles of some Invertebrates, as Spiders, are yellow.

90 The muscles of the heart and gullet are striped. In the lowest animals, there distinctions of voluntary and involuntary, striated aud smooth, solid and hollow, muscles can seldom be made.

91 The skcleton of the Carrion-crow, for example, weighs, when dry, only 23 grains.

62 The Dragon-fly can outstrip the swallow, nay, it can do in the air more than any bird-it can fly backward and sidelong, to right or left, as well as forward, and alter its course on the instant without turning. It makes ss heats per second with its wings; while the Bee makes 190, and the House1ly :3:30. The swiftest Race-horse can double the rate of the Salmon. So that Insect, Bird, Quadruped, and Fish would be the order according to velocity of movement.

93 Thuse suckers ( pulvilli) have a deliente fringe of hairs, each hair being a minute tube containing a viscid fluid by which the Fly adheres.

24 The cilia of Infusoria appear to act independently of any nervous power.

95 More precisely, the term brain, or brains, applies only to the cerebrum, while the total contents of the cranium are called encephalon.

${ }_{96}$ The exact functions of the eeretrum are not yet clearly understood. If we remove it from Fishes, or even Birels, their voluntary movements are little aflected; while the Amphioxns, the lowest of Fishes, has no brain at all, but its life is regulated by the spinal cord. Such mutilated animals, howerer, make no intelligent efforts. The substance of the cerebrum, as aloo the cerebellum, is insensible, and may be cut away without pain to the animal; and when hoth are thus remored, the animal still retains sensation.

9: Part- destitute of blood-ressels, as hair, teeth, nails, eartilage, ete, are not sensitire. The impresibility of the nerves is proportioned to the activity of cireulation. According to the reent investigations of Dr. Bowditeh, the chamuels of motor and sensitive impressions lie in the lateral, and not in the anterior and posterior, columns of the spinal cord.

98 "Tentacles" and "horns" are more or less retractile, while antenna are not, but all are hollow. Antenne alone are jointed.

95 In Man, the soft palate and tonsils also have the power of tasting.

${ }^{160}$ No organ of hearing has been discovered with certainty in the Radiates and Spiders.

101 It is wanting in the aquatic mammals. Crocodiles have the first representative of an ontside ear in the form of two folds of skin.

112 This, like the definition of smell and hearing, is loose language. There is 110 such thing as sound till the vibrations strilic the tympanum, nor eren then, for it is the work of the brin, not of the anditory nerve. Sound is the sensation of the wave-norement of the air, and learing is that sensation. So without eyes the workd would be wrapped in clarkness; light is nothing.

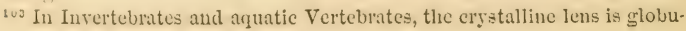


lar: ur, in other words, it is round in short-sighted animals, and flattish in the lome-sighted. The lens of the Invertebrate is not exactly the same as the lens of the Vertebrate eye, though it performs the same function; it is really a part of the cornea.

1.4 The - Int has 50 in ach eye, the House-fly solo0, the Dragon-1ly $12,500$.

3.6 'The pigment, therefore, while apluarently in front of the retina, is really behind it, as in Vertebrates. The layer beneath the eornea, serving as an "iris," is wanting in noctmmal inscets, since they need every ray of light. The optic nerve alone is insensible to the strongest lisht.

:ar It should be notiend that this corresponds with another pereuliar fact alrealy mentioned, that either hemisplere of the brain controls the muscles on the opposite side of the body. In Invertebrates the motor apparatus is governed on its own side.

10: Sharks have eyelids, while Snakes have none. The third eyelid (ealled nictitating membrane) is rudimentary in Mammals.

in In infint would doubtless leam to walli if brought up by a wild heast, since it was made to walls. Just ats an infusorium moves its cilia, not because it has any object, but because it cun move them. New-bom puplies, deprived of brains, have suckled; and decapitated centipedes run rapidly. Sueh physical instincts exist without mind, and may be termed "blind impulses."

109 We say "apparently," because it may be a fixed halit, first learned hy experience, trankmitted from generation to tneneration. A duckling may gूo to the water, and a hound maty follow game in some sense, as Sir John Herselnel takes to antronomy, inleriting a taste from his father. Breeders talie adrantage of this power of inheritance.

11... Thus, while the human oryanism may he likened to a keyed instrument, from which any music it is capathle of producing ean be called forth at the will of the performer, we may compare a Bee, or any other Insect, to a barrel-orean, which plays with the greatest exactuess a certain number of tumes that are set upon it, but ean do nothing use."-Cineseren's If netel Plysioleng!, p. 61. This constancy maly be largely due to the uniformity of conditions under which Insects live.

111 We may say, as a rule, that the proportion of instinet and intelligenee in an animal corresponds to the rehtive development of the spinal (o)rd and cerebrum. As a rule, also, the addition of the power to reaton comes in with the addition of a cerelorum, and is proportioned to its develonment. B3-tween the lowest Vertehrate and Man, therefore, we olserre suceessive types of intedligence. Intelligenee, however, is not aceoreling to the size of the brain (else Whales and Eliphants would be wisest), but rather to the amount of eraty matter in it. A luneg-eomb and an () riole's nest are constructed with more care and art than the hut of the savage. It is true, thi- is no te-s of the enpability of the animal in any other direetion; but when they are fastrioned to suit circumstanees, there is proof of intelligenee in me direction. Physiolorists now hold that the cerebram is not essential to eonsciousness.

112 Air-breathing Vertubates, as the Manates and Sata-lion, are exceptions. There are, doubtless, many sounds we c:m not hear. The notre of a spider 
may be terrific to a Fly; and while Flies hear one another, they take no notice of the human voice.

${ }^{113}$ An exception to the general rule that the smaller animals have more acute voices.

${ }^{214} \mathrm{It}$ is wanting in a few, as the Storks.

215 The Nightingale and Crow have vocal organs similarly constructed, yet one sings, and the other croaks.

116 The three methods are substantially alike; for an egr is only a separated lud. In the lower organisms, the parent is completely broken up into new individuals; in the higher, new individuals form but an infinitesimal part (cerm) of the parent. Under any form, reproduction is a process of disintegration. Some Protozoa do not appear to produce hy equs.

117 These cells are detached portions, or buds, of the parental organisms. Generally, these two kinds of cells are produced by separate sexes; but in a few eases, as the Snail, they originate in the same individual. Such an animal, in whom the two sexes are combined, is called an hemultrudite.

118 If an egg be violently shaken, this comuection is lroken; and this is the secret of making an egg stand on end without breaking it, as Columbus is said to have done.

119 The egrss of Mammals are of nearly uniform size; those of Birds, Insects, and most other animals are proportioned to the size of the adult. Thus, the egre of the Epyornis, the great extinet bird of Madagasear, has the capacity of 50,000 Humming-birds' eggs.

${ }^{120}$ As a general rule, when both sexes are of gay and eonspicuous colors, the mest is such as to conceal the sitting Bird; while, whenerer there is a striking contrast of colors, the male being gay and the female dull, the nest is open. Such as form no nest are many of the Waders, Swimmers, Scratehers, and Goatsuckers.

${ }^{121}$ As the Croeodile, by its gizzard and its rude nest, looks forward, so the ponched Kangaroo looks backward, to the true ornithic type.

122 This rudiment lies transversely to the long axis of the ege; and as the chick derelops, it turns upon its side, so that the forepart of the head usually faces the narrow end of the egg.

${ }_{123}$ The blood comes into being before the blood-ressels, and reins befure arteries; i. e., the very first motion is toward the heart. The hood is first yellowish. The red corpuseles are supposed to be lerived from the nuelei of the white corpuseles: the origin of the latter is undetermined.

${ }^{124}$ Fxactly as the blood in the eapillarics of the skin is aërated by the external atmosphere.

is Thus, the hollow wing-bone was first solid, next a marrow-bone, and fimally a thin-walled air-cell. The solid bones of the Penguin are examples of arrested development.

12i The thigh-bone of the child consists of five distinct parts; in the adult, they are united into one.

127 Muscle is mainly fibrine, while nerve is chiefly albumen.

12s This generalization nust not he confounded with the old statement, which is not true, that the higher animals pass through all the phases of the lower life. See Spencer's "Principles of Biology," i., 143; Clark's "Mind in Nature," 159. 
$129 \mathrm{For}$ this reason, Mammals are ealled rivipurons: but, strictly speakiner, they are as wriparous as Birds. The process of reproduction is the same, whether the enge is hatehed within the parent or without. The engers of Birds emontain whatever is wanted for the development of the embryo, exeept heat, which must come from without. Manmals, having no foodyolk, obtain their nutrition from the blood of the parent, and after birth from milk. Most of the sliarks are viviparous.

150 The larre of Butterflies and Ifoths are ealled enterpillets; those of

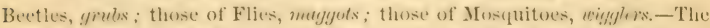
terms letra, pupu, and imety are relative only; for, while the grub and eaterpillar are quite diflerent from the pupn, the bee-state is reached by a rery gradual change of form, so that it is ditlieult to say where the pupa ends and the imago begins. In fact, a large number of Insects reach maturity through an indefinite number of slight elimges. The Inumble-bee molts at least ten times before arriving at the winged state.

131 Every tissue of the caterpillar disalyears before the development of the new tissues of the imago is commenced. The organs do not ehange from one into the other; but the new set is dereloped out of formless matter.-The pupa of the Moth is protected by a silken cocoon, the spimning of which was the last act of the larva; that of the Butterfly is simply inclosed in the dried skin of the larra, which is ealled cliryalis because of its grolden spots. The pupa of the Honey-bee is called nymph; it is kept in a wax-cell lined with silk, spun by the nursing-bee, not by the larva. The time required to pass from the egg to the imago varies greatly: the Bee consumes less than twenty days, while the Cieada requires seventeen years.

132 Compare the amount of food repuired in proportion to the liulk of the body, and also with the amount of work done, in youth, manhood, and old age.

${ }^{133}$ Excepting, perhaps, that the new tail of a Lizard is cartilaginous.

134 The patella, or knee-pan, has no representative in the fore-limb, and, strictly, it belongs to the muscular system rather than to the skeleton. Some anatomists contend that the great toe is homologous with the little finger, instead of the thumb.

135 It is doubtful whether the dorsal tube of Inserets and the heart of Mammals are homologous, as the cirenlatory orwans of Invertebrates may prove to be homologous with the lymphatic system of Vertebrates. The jawbones and limb-bones of Vertebrates are homologous, according to some naturalists.

t5o Polarity becins, as we have alrealy seen, in the very first change of an exg.

137 The structure of the highest plants is more complex than is that of the lowest animals; hut, for all that. powers are possessed hy jelly-fishes of which oaks and cedars are devoid.-Mrvart.

135 It is, fowever, true that the number of eress latid is proportioned to the risk in derelopment.

139 Areording to $\mathbf{M r}$. Darwin, the eharacters which maturalists consider as showing true allinity between any two or more slecies are those which have been inherited from a common parent, and, in $=0$ far, all true chassiti- 
ention is genealngieal; i.e., it is not a mere grouping of like with like, but it includes like deseent, the cause of similarity. In the existing state of s.ience, a perfect classitication is impossible, for it involves a perfect knowlellge of all animal structure and life's history. As it is, it is only a provisional attempt to express the real order of nature, and it eomes as near to it as our laws do in explaining phenomena. It simply states what we now know about comparative anatomy and physiology. As science grows, its language will become more precise and its classitication more natural.

${ }^{140}$ The term type is also used to signify that form which presents all the characters of the group most completely. Each genus has its typical species, each order its typical genus, etc. The word is also applied to the specimen on which a new speeies is founded. A persistent type is one which has continued with very little change through a great range of time. The family of Oysters has existed through many geological ages.

141 The Calenterata and Echinodermata together make up the Radiatr, the old subkingdom of Cuvier. Echinoderma is probably more correct than Echinodermata; but we retain the old orthography.

142 Strictly speaking, no individual is independent. Such is the division of labor in a hive, that a single Bee, removed from the community, will soon die, for its life is bound up with the whole. In a philosophical sense, M:m is a composite being, every organ being an individual, though not an independent, existence. An individual repeats the type of its lingdom, sublingdom, elass, order, family, genus, and species, through its whole line of descent.

143 The Millepore coral, so abundant in the West Indian Sea, is the work of IIydroids. The surfice is nearly smooth, with minute punctures. Gegenbaner, Haeckel, and others hold that the Acalcphs have no body-eavity at all, the internal system of eanals being homologous with the intestinal eavity of other animals.

144 Among the exceptions are Tubiport, which have eight tentacles and no septa, and the extinet Cyathophylla, whose septa are eight or more.

145 The longest septa (ealled prinary) are the oldest: the shorter, secondary ones, are developed afterward. As a rule, sclerodermic corals are cal(areous, and a section is star-like; the selerobasic are horny and solid. The latter are considered higher in rank.

${ }^{146}$ Some Star-fishes ( Sultester) have twelve rafs. In all Echinoderms, probably, sea-water is freely admitted into the body-cavity around the visceral. The canals likewise contain water, which enters through a porous tuberele, the madreproriform plate, or "dorsal wart," best seen on the back of the Starfish and Sea-urchin.-By some, Echinoderms are regarded as Worms.

147 The shell is not strictly external, like the crust of a Lobster, but is coated with the soft substance of the animal.

14s Six hundred piees have been counted in the shell alone, and twelre hundred spines. The feet number about three thousand. They ean be protruded beyond the longest spines.

${ }^{149}$ The most important genera are Terburatula, Rhynchonclla, Discina, Linsylu, Orthis, spirifer, and Procluctus. The first four have representatives in existing seas. Professor Morse, indorsed by Kowalensky, maintains the 
aftinity of Brachiopods to the Worms. Davidson, howerer, retains them in their ohd position, as a class independent of, hut related te, the Mfollu-cat. By many, the Tunieates are joined to the Brachiopods; by others, they are called Worms in disguise.

1.n There are some exceptions: the oyster is unequivalved, and the Peden equilateral.

131 The ehief impressions left on the shell are those made by the musches -the dark spots called "eges" hy oyster-men; the pallial bine made lyy the marein of the mantle; and the bend in the pallial line, called pellial sines, which exists in those shells having retractile siphons, as the Clam.

15: The Pearl Oyster lats a small, anterior muscle in the umbo, and the Sponclylus has teeth.

153 The muscular impressions in Tridacne are blended into one. It is conjectured that this is the case in the Oyster.

154 The Clam is the himhest of Lamellibranehs, and the Oyster one of the. lowest. The Vimus ameuriu, or "Suft Clam," has its mouth always open a little; while V. mercenaria, or "Hard Clam," keeps its mouth closed.

1s5 The slug has ne shell to speak of, and the Chiton is corered with cight fieces. It may be remembered, as a ruke, that all univalve shells in and around the United States are Gasteropods, and that all bivalves in our rivers and lakes, and along our sea-coasts (save a few Brachiopods), ate Lamellibranchs.

${ }^{156}$ That is, if viewed with the aperture facing the obserrer. Shells twist. ed in the opposite direction are called "left-handed."

15: Such as Dentuline, which maty be a Pteropod, and the swimuing Nucleobranch, as Carinaria.

15s Instead of a strong breathing tube with a valve, answering for a forcepump and propeller, as in the Cuttle-fish, it hals only an open gutter made ly a fold in the mantle, like the siphons of the Gasteropods. The back chambers are filled with nitrogen gas.

159 The common Poulpe has two thousand suckers, each a wonclerful little air-pump, under the control of the animal's will.

160 Ifence the theory of Spencer, favored by Wallace and Clark, that Artieulates are compound animals, each serment representing an indivilual. The dorsal tube is probably homologous with the right ventricle.

161 The order is one of relation rather than of rank. The elasses ean not le arranged serially. The Myriapods have a worm-like multiplication of farts, decrading them, and their nervous system is simpler than that of (aterpillars; yet their heads -how a chose relationship to Insects. The Arach. nids include some lower forms than Myriaquels; on the other hand, for their wonderful instincts, Owen places them above the Insects. They are chesly allied to Crustateans, and stand more marly between C'rustaceans and Insects than between Myriapud- and Insects. The hierher Artieulates herin life as worm-like enbryos. None of the air-breathers hate two pairs of antemen, while the aruatic classes may have-Articulates with jointed appendages articulated to the body are ealled Arthropode.

1r: The joints of the T:ure-worm are not true segment<, only sueces-in growths containing ova. The thac animal is the so called "ireal." Tise 
inte-tinal Worms are, hy some eminent naturalists, separated under the dis. tinct name of Helminthozoa.

${ }^{103}$ Apparent exceptions: Some lower forms have no branchie, but respire ly the skin, usually of the legs, but this is substantially a gill; certain Crabs, also, live on dry land, but they manage to keep their gills wet.

16: The student should remember that this threefold division is not equivalent to the like division of a vertebrate body.

${ }_{165}$ Each ring (called somite) is divisible into two ares, a dorsal and ventral, and each arc consists of four pieces.

${ }^{166}$ Sight and hearing are the only senses discovered in this class.

16: The four pairs of leus in Arachnids answer to the two pairs of maxille, the great claws, and the first pair of legs of the Lobster.

165 Compare the single thread of the Silk-worm and other caterpillars.

${ }^{169}$ The common Spider, Elxire, which constructs with almost geometrical precision its net of spirals and radiating threads, will finish one in forty minutes, and just as regularly if confined in a perfectly dark place.

1:0 These parts do not correspond to the parts so uamed in human anat. omy.

$1>1$ The pupa-case is generally ormamented with golden spots; lience the common name chrysalis.

1:2 More properly, at least in the Bee, the lip is not converted into a suetorial tube, but into an extensible tougue, with which the liquid food is lapped up.

173 All Vertebrates have a notochord, but not all have a rertebral column, as the fimplioxus. This eecentric ereature, without skeleton, limbs, brain, heart, lrmphatics, or red blood, we leave out of account. It is not fairly a member of the subkingdom, but rather a link between the Mollusks and Fishes. In aquatic animals the posterior limbs are the ones aborted or reducet, if any; in land animals the fore-limbs are usually sacrificed. The rertehre correspond with and are dependent on the nerrons centres. This is shown by the fact that the tail, which is reproduced by Lizards in ease of loss, is a single bone, berause although bone may be reproduced, the spinal cord can not be.

174 The smallest corpuscles are found in Ruminants; the largest in Amfhilians with permanent grills. The arerage size in Birds is double that of Man's, and about equal to that of the Elephant. Those of Monkeys are a trifle smaller than the human. In the embryo they are larger than in the adult. Camels only among Mammals have oral disks.

${ }^{175}$ Olblong skulls, whose diameter from the frontal to the oceipital greatly exceeds the transverse diameter, are ealled dolichocpholie; and such are usually frenguthous, i. e., have projecting jats, as the negro's. Round sliulls, whose extreme leneth does not exceed the extreme breadth by a greater fropurtion than 100 to so, are brachyecpleutie; and such are generally orthorgnathous, or straight-jawed.

15. The chasses are variously grouped into the Hematoerya, or Cold-bloodret. and the Ifemetotherme, or Warm-blooded; into the Brancliata and

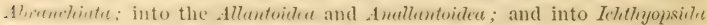
Eislies and Amphibian-), Souropside (Reptiles and Birds), and Ifommalict. 
According to Owen, the only character which absolutely distincuishes Fishes and Reptile's is whether or not there is an open passage from the nostrils to the mouth.

177 some Ichthyologists, as Agas-iz, Hatekel, Cope, and Gill, divide the Vertebrates beluw the Amplibians into three or four distinct clarses. See "Smitlısonian Mise. Coll.," vol. xi.

1:4 It would be safe to saty that any living Vertehrate with sile fins sup. ported by fin rays is a Fish; but the extinct Amplibian Iehllygoseures also had them.

179 The eapacity for growing as long as life lasts, which some Fi-hes are satid to possess, may be explained by the facts that their boties are, firstly, of very nearly the same specitic gravity as the water in which they live, and, secondly, of a temperature which is but a very little higher than that which they are there exposed to. Thus the force which in other animats is expended in the way of opposition to that of eratrity and in the waty of pro. ducing heat is available for sustaining eontinuous growth.-RoLls-tox.

1so scales with smooth, circular outline are called ryelroil; those with notehed or spiny margins are cteroid. A few Teleosts are without scales or osseous sheleton. The ventral fins are often wanting, and the pectoral occasionally. There are about 9000 speeies of bony fishes.

181 Amphibians with a moist skin are also remarkable for their cutaneous respiration. They will live many days after the lungs are removed. Their vertebre vary in form: in the lowest they are biconcave, like those of Fishes; in Salamanders they are opisthocelian: in the Frogs and Tuads they are usually procœlian.

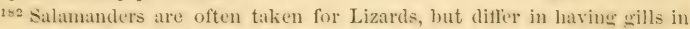
early life and a naked skin. The Proteus and sireu resemble a tadpole arrested in its development.

${ }^{143}$ The Surinam Toad has no tongue.

${ }^{194}$ The Reptilian heart may be likened to a persistent fortal heart of the higher animals.

185 The posterior pair of limbs is sometimes represented hy a pair of small hones: and there is one Ophidian which shows traces of external limbs.

156 There are some notable exceptions. The slow-worm is legless, and the Chameleon has a soft skin.

197 Aceording to Owen; but IIuxley insists that the plastron belones to the exoskeleton.

${ }^{189}$ Knees always bend forward, and heels always bend backward.

${ }^{199}$ It is a peculiarity of all Birds, thomen not eonfined to them, that the generation products and the refuse of disestion are all discharged flumugh one common outlet.

190 Existing Birds have been divided into two primary groups, aceording to the develofument of the brea-t-lume: (1) liutiter, or Rummers, as the ()strich, without a keel; and (2) Carimete, or Fliers, (comprisinge the erand majority of Birels, having a prominent keel. The for-il .1,clamptery/s, a lizard-like Birel, is placed in a separate division, Smmoner. Birds have also been divided aceordins to their degree of development at birth into (1) IIesterymums, as Fowls, Ostriches, Plovers, suiges, Ratils, 
Dirers, and Ducks, whose chick is hatehed completely elothed, has perfect senses, rums about, and feeds itself. When full grown, it uses its feet rather than wings, flying with a rapid, labored stroke, and taking the first opportunity to settle on land or water, not on trees; the male is polygamous and pugnarious; the female makes little or no nest; and neither sex sings. This uroup is of the best use to man, and approaches more nearly to Mammals, the habitual use of the legs and preference for land or water degrading it as a Bird and raising it in the list of animals; (2) Gymneyfenores, ats Gulls, Pelieans, Birds of Prey, Herons, Sparrows, Woodpeckers, and Pigeons, whose chick comes helpless, blind, and naked; it cau neither walk nor feed itself, but gapes for food; the adult is monogamous, and builds chaborate nests in trees and perches; many sing; all are habitual fliers. These are birds par excellence, gifted with higher intelligence than the others, and are never domesticated for food.

:91 We ean not elaim that this airy skcleton is neecssary for flight. The bones of the Bat are free from air, yet it is able to keep longer on the wing than the Sparrow. The common Fowl has a hollow humerus; while some Birds of long flight, as the Snipe and Curlew, have airless bones.

${ }^{192}$ Hopping is characteristic of and confined to the Perchers; but many of them, as the Meadow-lark, Blackbird, and Crow, walk.

${ }_{193}$ This order, founded on the disposition of the toes, is purely artificial. But it is better to retain it until ornithologists agree upon some natural arrangement.

${ }^{194}$ In the Swifts and Goatsuckers, the hind toe is rersatile, being turned sideways, or even forward; while the third and fourth toes of the Kingfisher are united, and its wings are short.

${ }^{195}$ The Whales are hairy during fotal life only.

${ }^{196}$ The brain of Mammals differs also from that of lower Vertebrates in that the lobes of the cerebrum are connected by a band called corinus callosum, and the lobes of the cerebellum by the pons Tarolii.

${ }^{197}$ As in the Whale, Porpoise, Seal, and Mole. Teeth are wanting in the Whalebone Whales, Ant-eaters, Manis, and Echidna.

${ }^{19 y}$ An acceptable classification of Mammals is still a desideratum. Owen's subclasses, founded on the structure of the brain, and De Blainville's (adopted by Huxley and Gill), founded on the nature of the reproductive organs, are unsuitable for a text-book. It is suflicient to state here that the two lowest orders are implacentul, and their young are born in a very imperfect condition; while all the rest are plecentul, whose embryos are more completely formed before birth, being connected with the blood of the mother by means of the placenta, a development of the allantois.

199 The Monotremes resemble Birds and Reptiles in having but one outlet for the rectum, genital, and urinary organs. They resemble Marsupials in latving marsupial bones, but have no pouch. They differ from all other Mammals in having no distinct nipples.

${ }^{200}$ The pouch is wanting in some Opossums and the Dasyurus.

2n1 The Edentates are allied to the Reptiles, especially the Tortoises: (emmare the caralax of the Armadillo, the broad ribs, tonthless mouth, and gizzard-like stomach of the Ant-eater, and the great size of the blood-corpuseles in the Sloth. 
s: For the best aceount of the Elephant, see Temunt's "Cirlon."

$=3$ The forrefeet of the Tapir latve four toes, but one does not touch the erround.

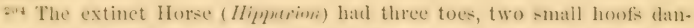
rling behind. The foot of the Horse is of wonderful structure. The bones are comstructed and placed with a view $t)$ speed, lightness, and strength, and houmd together hy liganents of marvelous tenacity. There are chatic pads and cartilages to prevent jarring ; and all the parts are essered by a living memhrane which is exquisitely sensitive, and endows the forot with the sense of tonch, without which the animal could not be sure-footed. The houf itself is at world of wonders, being mate of parallel filires, each a tube compered of thousands of minute cells, the tubular form giving strength. There are three parts, "wall," "sole," and "fioge"-the triangular, elastic piece in the middle, which atets ats a cushion to prevent concussion and alsoo slipping.

205 The American Peceary has three toes on the hind foot.

206 The Camel and Llana are exceptional, having two upper incisors and canines, are not strictly cloven-footed, and are hornless.

20: The Hyena alone of the Carnivores has only four toes on all the limbs, and the Dog has four hind toes. - The Lion is the king of beats in majesty, but nut in strength. Five men ean casily hold down a Lion, while it requires nine to control a Tiger.

2ns The old term (fundrumum is rejected beeause it misleads, for Apes, as well as Men, lave two feet and two hands. There is as much anatomieal difference hetween the feet and hands of an Ale as between the feet and hands of Man. Owen, however, with Cuvier, conxiders the Apes truly "fourhanded."

20: The ere-orthits of the Lenurs are open behind. The Flying Lemur (Galcopithecus) is considered an Insectivore.

210 The little Marmosets are not typical Monkess, having a nom-prehensile tail and only 32 teeth.

${ }^{211}$ It fats to eover in the Howline Monkey and Siamang (riblon; but in the Squirrel Monkey it more than corers, overlappine more than in Man. As to the convolutions, there is every eracle from the almost smooth hrain of the Marmoset to that of the Chimpanzee or Orang, which falls but little below Man's.

212 The tailed Ipes of the Old World have Ionger legs than arms, and generally have "cheek-pouches," which serve as pockets for the temporary stowage of food.

s13 In the hum:m infint, the sole naturally turns inward; and the arms of the embryo are longer than the legs.

214 The Aye-aye, the lowest of the Lemurs, is remarkable for the larece proportion of the eranium to the fuce.

215 This feature was shared he the extinet . Anophotherium, and now to some extent by one of the Lemurs (Tursius).

216 We have treated Man zonlogically only. His place in Nature is a wider questinn than his pusition in Zenleng: hut it involves metaphysical and psychological considerations, which do not belong here. 
217 See Lewes's charming "Studies in Animal Life." Doubtless an examination of all the strata of the earth's crust would disclose forms immensely outumbering all those at present known. And even had we every fossil, we would have but a fraction of the whole, for many deposits have been so altered by heat that all traces have been wiped out. Animal life is much more dirersitied now than it was in the old geologic ages; for several new types have come into existence, and fer have dropped out.

${ }^{218}$ Among the types characteristic of Ameriea are the Gar-pike, Snappingturtle, Hummers, Sloths, and Musk-rat. Many of our most common animals are importations from the Old World, and therefore are not reckoned with the American fama; such as the Horse, Ox, Dog and Sheep, Rats and Miee, Hone-bee, House-fly, Weevil, Currant-worm, Meal-worm, Cheese-magrot, Cockroach, Croton-bug, Carpet-moth and Fur-moth.-Distribution is complicated by the voluntary migration of some animals, as well as by Man's intervention. Besides Birds, the Bison and Seals, some Rats, certain Fishes, as Salmon and Herring, and Locusts and Dragon-flies among Insects, are migratory.

219 When the cable between France and Algiers was taken up from a deptl of eighteen hundred fathoms, there came with it an Oyster, Cockle-shells, Annelid tubes, Polyzoa, and Sea-fans. Ooze brought up from the Atlantic plateau (two thousand fathoms) consisted of ninety-seven per cent. of Foraminifers.

220 Only around the shores of the Aretic Sea are the same animals and plants found through every meridian; and in passing southward, along the three principal lines of land, speeific identities give way to mere identity of genera; these are replaced by fumily resemblances, and at last eren the families beeome in a measure distinct, not only on the great continents, but on the islauds, till every little rock in the ocean has its peculiar inlabitants. 


\section{TIIE NATURALIST'S LIBRARY.}

TrE following works of reference, accessible to the American student, are recommended:

AgAssiz, Methods of Study in Natural
History.

Carpenter, Comparative Physiology.

Marsund, Outlines of Physiology.

Hexher, Lessons in Elementary Physiology.

Mrvart, Lessons in Elementary Anatomy.

Agassiz and Gould, Principles of Zoology.

Rolleston, Forms of Animal Life.

LEWEs, Studies of Animal Life.

Jones, General Outline of the Organization of the Animal Kingdom.

Clark, Mind in Nature.

Huxcer and Martin, Elementary Biology.

Owes, Comparative Anatomy of Invertebrates and Vertebrates.

Srrnor.D, Anatomy of Invertebrates.

HexLex, Auatomy of Vertebrated Auimals.

Hexhex and Hawniss, Atlas of Comparative Osteology.

Frower, Osteology of Mammalia.

Crauvent, Comparative Auatomy of Domesticated Animals.

Grax, Auatomy, Descriptive and Surgical.

Foster and Batfour, Elements of Embryology.

Paoknno, Life Historics of Animals.

Striorre, Handbook of Human aud Comparative Histology.

LANkfster, Half-hours with the Microscope.

Owex, Paleontology.

KNIGIT, English Cyclopredin (Niatural History).

YAN nFR Iforven, Handbook of Zoolngy.
Cuvier, Animal Kingdom.

Woos, Illustrated Natural History.

Mrine-Edwaris, Mautal of Zoology.

Nicuorson, Manual of Zoology.

Tenney, Elements of Zoology.

Morse, First Book of Zoology.

JoNes, Animal Creation.

Agassiz, Sea-side Studies in Natural History.

TAYLOR, Half-hours at the Sea-side.

Greenf, Manuals of Sponges aud Coeleuterata.

Dana, Corals and Coral Islands.

Verrily and Surti, Invertebrates of Vineyard Sound.

Gould and Brwnex, Invertebrata of Massachusetts.

IVoOHWARi, Manual of Mollusca.

Packard, Guide to the Study of Insects.

Duscas, Transformations of Insects.

Sroner, Fishes and Reptiles of Massachusetts.

De KAr, Natural History of New York.

Cours, Key to North American Birds.

Jomas, Manual of the Vertebrates, etc. of Northeru United States.

Batri, Brewre, and Rrogwar, Birds of North America.

Barrd, Mammals of North America.

Ar.r.s, Mammalia of Massachusetts.

Sonmmos, Marine Mammals of North $\mathrm{Pa}$ citic.

Br.toe, Manual of Ethnology.

Darwin, Animals and Plants under Domestication.

WAt.ACE, Geographical Distribution of Animals.

Merrax, Geographical Distribution of Mammals. 
Of serial publications, the student should have aceess to the Ameriertn Nuturatist, American Joumal of Sichec, Popular Science. Ionthly, Smithsoniun Contributions and Miscelluneous Collections, Bulletins and Proceedings of the various societies, Popular Seience Revieu, Intellectual Observer, and Aunals and Magazine of Natural History. *

* Perfect specimens are invaluable in the study of Zoology. A few hundred choice objects are the best illustrations to accompany a text-book, or course of lectures. In fact, they are iudispensable to the clear comprehension of the forms of life. Many specimens are easily obtained; but many others come from distant lands or seas, and must be carefully prepared for preservation and use. It is well for teachers and students to know that there is one establishment in America where it is possible to secure those type-collections so important for educational purposes. Professor H. A. Ward, of Rochester, New York, has the largest facilities in the country for furnishing skeletons and special preparations for schools and museums. The leading museums in America are indebted to him for some of their choicest materia!. Every effort is made to supply select and perfect specimens. His collection is especially rich in Invertebrates, and his osteological preparations are remarkable for the elegance of their monnting. 


\section{N D E X.}

Amtanomite Worms, 272, 352.

Absorbent System, 93.

Acaleph, alternate generation of, $20 \pi$. " structure of, 238,375 .

Acarina, 277, 353.

Acarns, 353.

Acipenser, 303, 354 .

Acorn-shells, 274.

Actinaria, 350 .

Actiuia, anatomy of, 74 .

“ described, 241, 350 .

"development of, 200 .

Actinophrys, 349 .

Adder, 308.

Adipose Tissne, 36 .

Eolis, 262.

Agastric Animals, $3 \overline{0} 0$.

Air-bladder of Fishes, 116, 372 .

Air-breathers, 111, 113.

Albatross, 317 .

Alcyonaria, 350.

Alcyonium, 350.

Alimentary Canal, 73.

Allantoidea, $3 S_{0}$.

Allautois, 198.

Alligator, 312, 355 .

Altermate Geueration, 206, 239.

Ambulacra, 129, 252.

Ammonite, 260.

Amuion, 197.

Amciba feeding, $50, \pi$.

" locomotion of, 155 .

“ structure of, 232, 3.19.

American Types, 354.

Amphibians, described, 305, 354, 381.

Amphiccelous, $3 \pi 3$. eggrs of, 193.

Amphioxus, 50, 302, 374, 350 .

Anallantoidea, 350 .

Auslogy, 211.

Anchylosis, 142.
Anguis, 354.

Animaicules, month of, 54 .

Animals and Plauts, 21, 365 .

Anuelids, 270, 352 .

Anuuloida, 271, 352.

Anoura, 354 .

Anser, 355.

Ant-enter, 330, 3 īo.

Anteune, 17t, 3it.

Anthozoa, 211, 350 .

Ants, 293.

Aorta, 103.

Ape, $151,343,353$.

$\Lambda$ pis, 353.

Aplysia, 262.

$\Lambda$ pteryx, 319.

Arachuid, $277,353$.

Araneina, 27s, 353.

Archetype, 137.

Arclea, 319,355 .

Areolar 'Tissue, 35.

Argonauta, 268.

Armadillo, 133, 330.

Arteries, 103.

Arthropoda, 379.

Articulates, circulation in, 105.

" described, 226, 269, 352.

"digestion in, 77,91 .

Ascidian, circulation in, 106.

" describet, 256, 350.

" mouth of, 55 .

Astacus, 273, 352.

Asterias, 251, 350 .

Asteroidea, 55, 75, 91, 111, 129, 159, 250, 350 .

Astrea, 243.

Atavism, 210.

Attacus, 291, 353.

Ank, 316.

Aurelia, $239,350$.

Aves, 313, 355. 
Axolotl, 306.

A ye-aye, 353 .

BABIRUSA-HOG, 68 .

Baboon, 346.

Balana, 147, 355 .

Balauus, 274, 352.

Bandicoot, 330 .

Barbet, 324.

Barnacle, 57, 275.

Basket-tish, 251.

Bathybius, 349 .

Batrachiaus, 307.

Buts, 187, 333.

Beaver, 332.

Bed-bug, 287.

Bee, anatomy of, 114 .

"described, 293.

"s egrs of, 192.

" eye of, 178.

"instinct of, 183 .

(6) mouth of, $5 \mathrm{~s}$.

6t muscles of, 154.

Beetles, described, 282, 257.

" eyes of, 179.
" mouth of, 55 .
" prehension of, 53.

Belemnite, 269.

Beroë, 242.

Birds, anatomy of, S4.

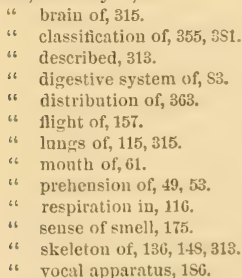

Bird of Paradise, 327.

Bivalve Shells, 131, 258.

Blackbird, 327.

Blastema, 33 .

Blastoderm, 194.

Blood, circulation of, 102 .

4 color of, 97,372 .

" constitution of, 9S.

"current, 110,372.

"development of, 376 .

" oftice of, 101.

"vessels, 102.

Blubber, 334.

Blue-tish, 300 .

Bua constrictor, skull of, 72 .
Bones, 36, 136, 145.

Bos, 150, 356.

Brachiopods, 256, 351, 378.

Brachycephalic \$kull, 3s0.

Bradypus, 356.

Brain-case, 141.

"6 development of, 199.

"6 functions of, 170 .

" size of, 345 .

"structure of, 166, 352 .

Brauchiate Vertebrates, 350. "Worms, 272.

Bronchial T'ubes, 118.

Bryozoa, 255.

Bubble-shell, 262.

Buccinum, 260.

Budding, 189.

Bufo, 307, 354 .

Bugs, described, 285.

" mouth of, 59 .

Bulimus, 262.

Bulla, 262.

Butterfly, described, 290.

. 6 mouth of, 59 .

Candis-rLT, 254.

Crecilians, 306, 354 .

Crecum, 371.

Calcispongia, 349.

Camel, 353.

Cameo-shell, 266.

Canaliculi, 35.

Capillaries, 103.

Capybara, 331.

Carapix, 133.

Cardium, 259.

Carinatre, 381.

Caruivores, 340, 356.

Cartilaginous Tissue, 36 .

Cassis, 264.

Cassowary, 319 .

Castor, 332.

Cat, brain of, $167,171$.

Cat-tribe, 342 .

Caterpillar, anatomy of, 77.

" circulation in, 104.

" head of, 292.

" nervous system of, 165 .

Cebus, 356.

Cells, 31, 98, 369 .

Centipede, 52, 114, 159, 166, 281.

Cephalization, 218.

Cephalopods, anatomy of, $S 1$. " described, 266, 352.

Cephalo-thorax, 130, 272.

Cerebellnm, 169.

Cerebram, 165, 374.

Cestum, 242. 
Cetricen, 334, 355 .

Chameleun, 309 .

Cheiropters, 333, 356.

Cheloniaus, 310, 354 .

Chelydra, 354 .

Chilognatha, 250, 353.

Chilopoda, 250, 353.

Chimera, 302.

Enimpanzee, $69,151,345$.

Chitine, 3 T3. $^{3}$

Chiton, 263.

Chorion, 195.

Chrysalis, 377, 350.

Chyle, 92, 372.

Chyme, 92.

Cicada, 286, 353.

Cicatricula, 190.

Cidaris, 253, 351.

Cilia, 50, 374 .

Cilinta, 349 .

Cimex, 353.

Cirripeds, 274, 352.

Clam, described, 260,379 .

" digestive system, 79.

"t locomotion of, 158 .

"6 respiration in, 112.

Clamatores, 325.

Class, 227.

Classification, $223,349,378$.

Clawe, 134.

Clio, 55, 351.

Cloaca, 84.

Clypenster, 351.

Coagulation, 37 .

Cochineal, 287.

Cockle-shell, 259.

Cockroaches, 255.

Cod-fish, 167, 303.

Colenterata, 225, 237, 349.

Cold-blooded Animals, 119, 354.

Coleopters, 287, 353.

Coluber, $35 \%$.

Condor, 322.

Cone-shell, 264.

Connective Tisste, $3 \sharp, 369$.

Coral, 128, 242.

Corallium, 247, 352 .

Corium, $3 \pi 3$.

Cormorant, 317.

Corpuscles, 97, 372, 350.

Correlation of Growth, 212.

Corydalis, 285.

Cowry, 264.

Crab, described, 275.
" legs of, 159.
" mouth of, 56.
"s skeleton of, 130.
Crane, 319 .

Cranitum, 139, 141.

Craly-tish, 273.

Cricket, $2 \$ 5$.

Crinoid, 248, 350.

Crocodile, described, $147,311,355,373$.

" digestive system, $81,83,371$.

" exoskeleton of, 133.

" heart of, 107.

" locomotion of, 160 .

" mouth of, 61 .

Crotalus, 354.

Crow, 327 .

Crustaceans, described, 272,352 .

" digestive system, 76 .

" skeleton of, 130 .

Ctenophora, 242, 350, 370.

Cuckoo, 323.

Curassow, 320 .

Cursores, 319, 355.

C'nticle, 373.

Cutis, 373 .

Cuttle-bone, 373.

Cuttle-fish, brain and eyes of, 176, 179 .

" circnlation in, 106.

" described, 268.

" digestive system, 79 .

" mouth of, 56 .

" prehension of, 51 .

"6 skeleton of, 132, 135, 373 .

Cypræa, 266.

DAUDY-LONG-LEGS, 290.

Dasspus, 331.

Dasyurus, 330 .

Decapods, 274, 353.

Deep-sea Forms, 359, 354.

Deer, 339.

Deglutition, 71 .

Delphinus, 355.

Dental Formula, 69.

"Tissue, 33.

Dermis, 126, 373 .

Development, 193, 199, 376.

Diadelphys, 330, 355.

Diaphragm, 85, 119, 373.

Diastema, 370 .

Dibranchs, 267, 352.

Differentiation, 31.

Digestion, 90.

Digitigrades, 161, 312.

Dipnoi, 304, 354.

Dipters, '25s, 353.

Discophori, 210, 350 .

Distribution, 357, 3S4.

Divers, 315.

Dog, 342 .

" brain of, 167 .

“ digestiun in, 123. 
Dog, skull of, 140.

Dolichocephalic Skull, 380.

Dolphin, 335, 355.

Doris, 262, 352 .

Duve, 320 .

Dragon-11y, 251, 374.

Duck, 318.

Duck-mole, 323.

Dugong, 108, 337.

Duodelium, 89.

EAGLe, 322.

Ear, 176.

Ear-shell, 264.

Earth-worm, 272.

$\begin{array}{ll}\text { " } & \text { circulation in, } 105 . \\ \text { " } & \text { Jocomotion of, } 159 . \\ \text { " nervous system, } 166 . \\ \text { respiration in, } 112 .\end{array}$

Eicieron, 373.

Échidna, 328.

Echinoderms, 226, 247, 350, 378 .

Échinus, 91, 104, 129, 252, 350, 378.

Ectoderm, 237, 373.

Edentates, 330, 356, 352.

Eirgs, geveration by, 189,376 .

" kinds of, 191, 376 .

" structure of, 189.

Elasmobranchs, 302, 35t.

Elephant, 337, 356.

" brain of, 167,168 .

" skeleton of, 150 .

" teeth of, 70 .

" voice of, 187.

Elytra of Beetles, 297.

Embryology, 12, 193.

Embryos, likeness of, 201.

Encephalon, 172, 374.

Enderon, 373.

Endoderm, 237, 373.

Eudoskeleton, 126, 128, 135.

Endosmosis, 372.

Entomostracaus, 274, 353.

Epeira, 353.

Epidermis, 34, 126, 128, 373 .

Epiglottis, 118.

Epithelium, 33.

Equns, 142, 149, 356.

Euplectella, 237, 349 .

Excretion, 119.

Exoskeleton, 125.

Eyes, compound, 178, 375.

" simple, 178 .

" structure of, 1 so.

Faotal ANgle, 298.

Fulcon, 323, 355.
Family, 227.

Fang8, 67.

Feathers, 135.

Felis, 137, 356.

Fibrospongia, 349 .

Fishes, anatomy of, 82.

" brains of, $168,301$.

" circulation in, 106, 109.

" described, 295, 381.

" digestive system, 79 .

" distribution of, 363 .

" gills of, $113,301$.

" heart of, 107.

" locomotion of, 156,300 .

" mouth and teeth, 60,66 .

" muscles of, 154 .

" prehension of, 53 .

" scales and skeleton, $133,146,299$.

Fish-hawk, 321.

Flagellata, 235, 349.

Flamingo, 158, 318.

Flea, 290.

Flight, 157.

Flustra, 351.

Fly, described, 288.

" feet of, 160 .

" mouth of, 59.

Fly-catcher, 324.

Flying-fox, 333 .

Follicles, 121.

Food, kinds of, 47.

" necessity of, 45.

" prehension of, 49 .

Foraminifers, 50, 128, 233, 349.

Forms of Animals, 215.

Fox, 341 .

Frog, blood-cells of, 98 .

" brain of, 170 .

" described, 307.

" metamorphosis of, 205

" prehension of, 53.

" skeleton of, 118.

Fungia, 243.

Fusus, 26t, 266.

Galt-Bt,ADnfr, 122.

Gall-1lies, 293.

Gallus, 355 .

Ganglia, nervous, 163.

Gamnet, 317.

Ganoids, 302, 354.

Gar-pike, 302.

Gasteropods, 260, 351 .

Gastric Follicles, 121.

"Teeth, 63.

Gavial, 312, 355 .

Genus, 227.

Germinal Dot, 191. 
Gibbon, 344.

Gills, 112, 113.

Giraffe, 339.

Gizzard, 63, 83, 371.

Glands, 121.

Glottis, 117.

Glyptodon, 330.

Gnawers, s31.

Goatsucker, 324 .

Guose, 318 .

Gorgonia, 247.

Gorilla, 345.

Grallatores, 319, 355.

Grasshopper, 285.

Grebe, 310 .

Gregariuida, 231, 349 .

Grouse, 320.

Growth and Repair, 207, 381.

Grubs, 377.

Gryllus, 353.

Guinea-pig, 332.

Gulls, 316.

Gymuogenous Birds, 352.

Hematooris, 380 .

Hrematotherma, 350 .

Hag-fish, 302 .

Hair, 134.

Hair-worm, 271.

IIaliotis, 264.

Halisarca, 349 .

Hand, 346 .

Hare, 332 .

Harvest-men, 278.

Haversian Cauals, 37 .

Hawk, 323.

Hearing, 175.

Heart of Fishes, 107.

“I Man, 108, 195.

“ Oyster, 105.

Heat, animal, 119.

Hedgehog, 333 .

Helix, 262, 352.

Hemipters, 255, 353.

Hen's Egg, development of, 194.

" parts of, 190.

Hermaphrodite, 376 .

Herou, 319.

Hesthogenous Birds, 391.

Heterocercal Tail, 156.

Hippopotamus, 338 .

Histology, 12.

History of Zoology, 14, 367.

Ifog, 338 .

IIolothurinns, 253, 351.

Homo, 345, 356.

Homocercal Tail, 156.

Homology, 211.
Ifoofs compared, 102.

Horns, 134 .

Horse, brain of, 168.

" described, 13, 33S.

“ foot of, 134, 161, 353 .

“ skull and skeleton, 142, 149.

"s stomach of, 86 .

Horseshoe Crab, 52.

Hummer, 325.

Hyalea, 351 .

Hydra, 75, 159, 237, 350.

Hydroida, 350 .

Hydrozoa, 237, 350.

Hyena, 383.

Hylacinus, 330.

Hymenopters, 293, 353.

Ints, 319 .

Ichneumon, 293, -

Ichthyopsida, 350 .

Ich thyosaurus, 313.

Iguana, 309.

Individual, 227.

İnfusoria, 50, 1S8, 234, 349.

Insectivores, 333,356 .

Insects, circulation in, 104, $2 S 3$.

" classification of, $284,353$.

"described, 281, 353.

"development of, 200.

"dicestive system in, 78 .

" distribution of, 362 .

" eyes of, 178 .

" legs of, $160,163,252$.

" metamorphosis of, 203.

" mouth of, 53, 57, 282.

"nervous system, 283.

" noise of, 185.

" respiration in, 113, 114, 233.

"skeleton of, $130,252$.

" wings of, $157,252$.

Insessores, 324,355 .

Inspiration, modes of, 118 .

Instinct, 181, 375 .

Intelligence, 183, 375.

Intestinal Canal, 89.

Invertebrates, 15t, 294.

Isis, 350 .

Iulus, 250, 353.

J NOANAR, 324.

Jaws, 53.

Jay, 327.

Jelly-fish, described, 238. "digestive system, 54,75 .

Kangaroo, 330.

Kiduey, 123.

King-crab, 274. 
Kingflsher, 325.

Kite, 323.

LamidM and Labron, 59.

Libyrinthodonts, 306.

Lacerta, 310, 354.

Lacertilia, 354 .

Lacteals, 94.

Lacunz, 38 .

Lagena, 349.

Lamellibranchs, 112, 257, 351.

Lamellirostres, 318 .

Lamprey, 302.

Lancelet, 302.

Land-suails, 263.

Lark, 327.

Laryux, 1 s7.

Leech, 272.

" locomotion of, 159.

" mouth of, $49,56,63$.

Legs of Animals, 155, 199, 213.

Lemur, 312, 356.

Lepidopter8, 290, 353.

Lepidosiren, 304, 354 .

Libellula, 284, 354 .

Life, distribution of, 357 .

" duration of, 219.

" wature of, 28,369 .

" phenomena of, 29, 43.

" struggle for, 219.

Lightning-bug, 288.

Ligula, 58.

Likeness and Variation, 209.

Limax, 262, 352.

Limbs of Vertebrates, 144, 374.

Limura, 263, 352.

Limpet, 263.

Limulns, 274, 353.

Linguln, 351.

Lion, $87,137,383$.

Liver, 121.

Lizards, 160, 170, 309.

Lobster, 272.

$\begin{array}{ll}\text { " } & \text { egrenlation in, } 105 . \\ \text { " } & \text { gills of, } 113 . \\ \text { " Jocomotion of, } 155 . \\ \text { " mouth of, } 56 . \\ \text { " muscles of, } 154 . \\ \text { prehension of, } 52 . \\ \text { skeleton of, } 130 .\end{array}$

Locomotion, 155.

Locust, 285.

Lolign, 209.

Lougipennes, 316 .

Loon, 316.

Louse, 257.

Lucernaria, 240, 350 .
Lumbricus, 272, 352.

Lungs, 115, 123, 373.

Lymphatics, 94.

M..DLETone, 214, 350.

Madreporiform Plate, $37 \mathrm{~s}$.

Maggots, 377.

Mammals, anatomy of, 86 .

" brain of, 382 .

" circulation in, 109.

" described, $327,355$.

" distribution of, 364 .

" locomotion of, 161.

" month and teeth of, 61,67 .

“ respiration in, 116.

" skull of, 141 .

" vical apparatus, 1 S6.

Mammoth, 337.

Mau, 85, 171, 213, 345, 383 .

Mauatee, 327, 337, 355 .

Mandibles, 58, 143.

Mantis, 53.

Mantle, 126.

Marsipobranchs, 302, 354.

Marsupinls, 329, 355.

Mastodon, 337.

May-fly, 294.

Meaudrina, 243.

Medulla oblongata, 169.

Medusil, 75, 23 .

Megatherium, 330.

Melauia, 266.

Memirane Bunes, 19s, 369.

Meuobranchus, 306 .

Mesentery, 82, 94.

Metamorphosis, 203, 377.

Millepede, 56, 114 .

Millepore, 378.

Mimicry, 210, 376.

Minerals and Organisms, 19.

Mites, 277.

Mole, 333.

Molluscoidea, 255.

Mollusks, anatomy of, 80.

" circulation in, 105.

“ described, 226, 254, 351.

" digestion in, 91 .

" distribution of, 362 .

" locomotion of, 158 .

" mouths of, 55 .

" nervous system of, 165 .

" respiration in, 112 .

" shells of, 131.

Monad, 234, 349.

Monera, 349.

Monkeys, 342.

Monotreme, 32S, 355, 8 S2.

IIosquito, 49, 20-4, 2S9. 
Mnth, 291.

Monlting, 12S, 130, 205.

Monse, 332 .

Mouths of Animals, 54 .

Mucl-eel, 306.

IInd-1ish, 304.

Murex, 260.

Ifus, 356 .

Jusca, 290, 353.

Iuscle, 152.

Mnscular Tissue, 38, 152, 199.

Mlussels, 259.

Myriapods, $76,250,353$.

Myrmecophaga, $330,356$.

Iytilus, 259.

Myxospongia, 349 .

Narr., 134.

Natatores, 315, 355.

Natica, 266, 352.

Natural Selection, 220.

Nautilus, 267, 352.

Nereis, 272, 352.

Nerve-cells, 163.

Nerves, 163, 172.

Nervous Tissue, 40, 161, 199 .

Neurilemma, 40 .

Neuropters, 284, 353.

Yewt, 306.

Nictitating Membrane, 375.

Notochord, 195.

Nucleolus, 191.

Number of Animals, 214.

Nummulite, 349.

Nutrition, 4.

Nymph, 377.

Ooflut, 17s.

Octopus, 269, 352.

Esophagus, 85.

Olfactory Nerves, 175.

Olive-shell, 266.

Oniscus, 353.

Ophidians, 308, 354.

Ophiomorpha, 354 .

Ophiura, 251, 350.

Opisthobranchs, 261, 352.

Opisthoccelous, 3 i3.

Opossum, 330.

Orang-utan, 171, 344.

Order, 227.

Organization, 30.

Organ-pipe Coral, 242.

Organs, 41 .

Oriole, 327.

Ornithorhynchus, 329, 355.

Orthoceras, 266.

Orthopters, 255, 353.
Orfcteropus, 330.

Oscines, 325 .

Osseous Tissue, 36 .

Ossification, 36, 19s.

Ostrea, 259, 351.

Ostrich, 319.

Otoliths, 175.

Ovipositor, 283.

Owls, 323.

Ox, 150,340 .

Oyster, circulation in, 105.

" described, 259.

" development of, 200.

" digestion in, 79.

" mouth of, 54 .

"i muscles of, 154.

" prehension of, 50 .

" respiration in, 112.

"s shell of, 131, 208.

Patate, 62, 85.

Pallial Siuus, $3 \pi 9$.

Paipi, 5S.

Paludina, 265.

Pancreas, 121.

Pangolin, 330.

Paper Nautilus, 26 S.

Papillæ, 62, 126, 174, 373.

Papilio, 353.

Paramecium, 234, 349 .

Parrot, 322, 324.

Partridge, 320 .

Patella, 263, 377.

Pavement-teeth, 66.

Peurl-oyster, 25s, 373, 379.

Peccary, 353.

Pectoral Arch, 14.

Pedicellarixe, 76, 371.

Pedipalpi, 27ī, 353.

Pelican, 317.

Penguiu, 315.

Pennatula, 247.

Pen of the Squid, 373.

Pentacta, 351.

Pentacrinus, 249, 350.

Perch, 146, 170, 354.

Perchers, 324.

Periosteum, 136.

Peristaltic Movement, 370.

Periwiukle, 266.

Petrel, 317.

Petromyzon, 303, 354.

Phalanger, 330.

Pharyngobrauchs, 301.

Pharynx, 72, S4, 370.

Pheasant, 320.

Phoca, 356.

Physalia, 239, 350. 
Physeter, $334,355$.

Picus, 355.

Pigenn, 320.

Pinnigrades, 161, 341.

Pisces, 354.

Placental, 199.

Placental Auimals, 355, 3S2.

Plauorbis, 263.

Plantigrades, 161, 341.

Plant-lice, 2 s7.

Plastron, 311.

Platypus, 328.

Pleurobrachia, 242, 350.

Plover, 319.

Poison-fang, 52, 67, 373.

Polycistines, 128, 234, 349.

Polyps, 50, 54, 75 .

Polyzoa, 255, 351.

Pond-suails, 263.

Porcupine, 332.

Porites, 244.

Porpoise, $57,335$.

Portal Circulation, 372.

Portuguese Man-of-war, 239.

Poulpe, 268, 379.

Prairie-chicken, 320.

Primates, 342, 356.

Primitive Streak, 195.

Proboscideans, 337, 356.

Proboscis of Butterfly, 58 . " Elephant, 62, 150.

Procelous, 373.

Proguathous Skull, 3 So.

Prosobranchs, 263, 352.

Proteus, 306, 354.

Protozoa, 200, 231, 349.

Psendopodia, 50, 232.

Pteropods, 55, 261.

Pulmonates, 262, 352.

Pygropodes, 315.

Quadrumana, $3 S 3$.

Rroooon, 340.

liadiates, 237.

IRadislarians, 233, 349 .

Ratils, 319 .

Rana, 307, 354.

Range of Animals, 358 .

Rank of Animals, 216.

Raptores, 321, 355.

Rinsores, 320, 355 .

Rat, 332.

IRatitæ, 3S1.

Rattlesuake's Fangs, 67 .

Raven, 327.

Ray, 302 .

Razor-shell, 260.
Redstart, 325 .

Reproduction, 188, 208, 376.

Reptiles, circulation in, 107, 109, 308.

" corpuscles of, 99 .

" described, 307.

" digestion in, 81 .

" distribution of, 363 .

" lungs of, 116.

" mouth of, 60 .

" prehension of, 53.

" scales of, 134.

" teeth of, 66 ,

"v voiceless, 186 .

Respiration, 111.

Rete mucosum, 127.

Retina, 180.

Rhea, 320 .

Rhinoceros, 338.

Rhizopods, 232, 349 .

Rodents, 331, 356.

Rotifers, 63, 272.

Rudimentary Parts, 202.

Ruminants, 87, 339.

SALAMANDER, 306, 354, 381.

Salivary Glands, 121, 373.

Salmon, 301, 354.

Silpians, 256, 351 .

Saud-flea, 274.

Sandpiper, 318.

Sarcolemma, 39, 199.

Saurians, 313 .

Sauropsida, 380 .

Saururæ, 381.

Scales of Butterflies, 290.

"Fishes and Reptiles, 193, 299, 351.

Scallop-shell, 259.

Scalops, 356.

Scausores, 323, 355.

Scapular Arch, 144.

Scarabrus, 353.

Scarf-skin, 373 .

Sclerobasic Coral, 123, 247.

Sclerodermic Coral, 128, 243.

Scolopendra, 2s1, 353.

Scorpion, describer, $277,353$.

" digestion in, 78 .

" mouth of, 52,59 .

" spiracles of, 115.

Sea-anemone, $200,241$.

Sea-blubber, 238.

Sen-butterfly, 260.

Sea-fan, 247.

Sen-hare, 262.

Seal, 341 .

Sea-lemou, 262.

Sea-lily, 2ts. 
Sea-lion, 341.

Sea-slug, 253 .

Sea-urchin, circulation in, 104.

" described, 25\%,

"di:estion in, 75,91.

" mouth of, 55 .

" respiratiou in, 111.

“ shell of, $129,378$.

" spines of, $129,37 \mathrm{~s}$.

" teeth of, 63 .

Sea-worms, 272 .

Secretion, 120.

Self-division, 158.

Senses, 173 .

Sepia, $268,352$.

Serpeuts, skulls of, 73 .

Serpula, 272 .

Sertularians, 23s, 350 .

Setre, 271.

Setophaga, 325.

Shark, described, 302.

"6 eggs of, 191.

"6 skeleton of, 135 .

Shells of Crustaceans, 130,272 .

"s Mrollusks, 131, 257, 260.

، Sen-urchius, 129, 375.

Shrew, 333.

Shrimp, 274 .

Sight, 177.

Silli-worm, 293.

Simia, 356.

Siphonophora, 350.

Siphuncle, 267.

Siredon, 306.

Siren, 306.

Sirenians, 336, 355 .

Size of Animals, 214.

Skeleton, 125.

Skin, 125, 126.

Skull, 142, 350.

Sloth, 330.

Slug, 262.

Smell, 175.

Suail, circulation in, 105.

" described, 260 .

" digestion in, 79 .

" month aud teeth of, 56,64 .

" prehension of, 51 .

" shell of, 132 .

" tentacles of, 175 .

Snakes, described, 308,354 .

"4 locomotion of, 155, 159.

" prehension of, 53 .

Snapping-bugs, 257.

Snipe, 319.

Somite, 350 .

Songsters, 325 .

Sorex, 333 .
Sow-bug, 274.

Sparrow, 35, 327.

Species, $22 \pi$.

Sperm-whale, 334.

Sphinx-moth, 291, 353.

Spider, described, 305, 354.

" digestion in, 78 .

" legs of, 159.

" mouth of, 59 .

“ prehension of, 52.

" spiracles of, 115 .

Spinal Column, 143.

"Cord, 166, 169, 172.

Spinnerets of Caterpillar, 292.

$$
\text { " Spider, } 250 .
$$

Spiracles, 113.

Sponge, 49, 128, 235, 349, 370.

Squalus, 354 .

Siquid, 155, 269.

Squirtel, 332.

Star-fish, anatomy of, 159.

" circulation in, 104.

" described, 250.

" digestion in, 91.

“ feeding, 51 .

" locomotion of, $15 \mathrm{~S}$.

"nervous system, 165 .

" respiration in, 111.

Stilt, 319.

Stomachs, \$3, 86, 85 .

Stork, 319.

Stridulation, 185.

Strombus, 205, 352 .

Struthio, 355 .

Sturgeou, 53, 302.

Subkingdiom, 227.

Sun-fish, 251.

Survival of the Fittest, 220 .

Suture, 145.

Swallow, 326.

Swan, 318.

Swift, 325 .

Sycon, 349.

Symmetry, 215.

Synovia, 145.

TÆEIム, 271, 352

Tanagers, 327 .

Tapetum, 181.

Tape-worm, 49, 271, 379.

Tapir, 213, 33s, 383.

Taste, 174.

Teeth, 38, 62, 65, 66, 68, 70 .

Teleosts, 302, 354 .

Temperature of Animals, 119.

Tendons, 154 .

Tentacles, 50.

Terebra, 264. 
Terebratuln, 257, 351.

Termites, 285.

Teru, 316 .

'Testudo, 354.

Tetrabranchs, 267, 352.

T'etradecapods, 274, 352.

'thorax, 118, 281.

'Thornback, 304.

'T'housand-legged Worm, 280.

Throat of Mammals, 72.

T'brush, 327.

Thyroid Cartilage, 186.

Ticks, 277.

Tissues, 32.

Toad, 307 .

Tongue, 53, 54, 61, 62

Top-shell, 265.

Tortuise-shell, 311.

Totipalmates, 317 .

Toucan, 324.

'Touch, 173.

Tracheæ, 113.

Trichina, 271.

Trilobite, 274.

Triton, 266.

Tritonia, 262.

Trochus, 266.

Trrogon, 323.

T'ubipora, 242, 245.

Tunicates, 126, 256, 351, 379.

Turbo, 265.

Turdus, 355.

Turkey, 170, 320 .

Turritella, 266.

Turtle, 134, 148, 160, 192, 310.

Tukks, 370 .

Types, 225, 378 .

Tyrant Fly-catcher, 325 .

UneUlates, 161, 337, 356.

Unio, 259.

Univalves, 131, 260.

Urodelans, 306, 354 .

Ursus, 356.

VATration, 209.

Variety, 227.

Veius, 94, 102, 103.

Vera cava, 103, 372.

Venus, 260, 351.

Venus-basket, 237.

Vertebræ, 13s, 143, 199.

Vertebrates, 226, 295.

" circulation in, 108, 296.

" classification of, 298.

") development of, 201.
Vertebrates, digestion in, 91.

" mouths of, 60 .

" nervous system of, 297.

" preheusion of, 53.

Vespertilio, 333, 356 .

Villi, 89, 94, 372.

Vireo, 325 .

Vitelline Membrane, 190.

Viviparous, 377.

Voices of Animals, 185.

Volitores, 325.

Volute, 264.

Vorticella, 349 .

Vulture, 148, 323 .

WALKING-STIOK, 285.

Warblers, 327.

Warm-blooded Animals, 119, 355。

Wasps, 293.

Water-boatmen, 286.

Water-breathers, 111.

Water-Hleas, 274.

Wax-wing, 327.

Weasel, 340 .

Weevil, 2 s7.

Whale, baleen of, 64, 134, 370.

"6 brain of, 167,168 .

"described, 334.

" feeding, 50,336 .

" locumotion of, 156 .

" skeleton of, 147 .

Whelk, 55, 260, 265.

White Ants, 255 .

Wigglers, 377.

Windpipe, 117.

Wings of Bats, 15 .

"1 Birds, 157.

"Iusects, 157.

Wolf, 340 .

Wombat, 330 .

Woodpecker, 322, 324.

Worms, described, 270.

" digestive system, 76 .

" locomotion of, 155.

"s mouth of, 56 .

" respiration of, 112 .

Wren, 327 .

YoLK, 189, 194.

ZoNOTRIOHIA, 325.

Zoological aualysis, 228.

" barriers, 359.

" provinces, 360 .

Zoology defined, 11.

" history of, 14, 367 . 


\section{V.LLLABLE AND INTERESTING WORKS}

\section{FOI \\ PUBLIC \& PRIVATE LIBRARIES,}

Publismed by HARPer \& BROTHERS, New York.

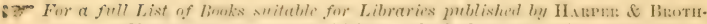
ERs, see HaRren's CaтAlogue, which may be had gratuitously on applications to the publishers personally, or by letter enclosing Nine Cents in Postage stamps.

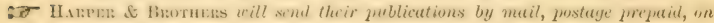
receipt of the price.

M.ACACLAYX EN(iLAND. The History of England from the Aecession of James II. By Thomas Bannaton Maratay. New Edition, from new Electrotype Plates. Sro, Cloth, with Paper Labels, Lneut Edders and Gilt Tops, 5 vols. in a Box, $\$ 1000$ per set. Sold only in Sets. Cheap Edition, 5 rolk, in a Bux, $12 m 0$, ('loth, s.2 50) sheep, $8: 375$.

MACALLAYS LIFE AND LETTERS. The Life and Letters of Lom

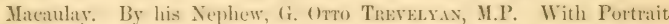
on steel. Complete in 2 rols., svo, Cloth, Uneut Eilges and (rilt Tops, 85 (10); Sheep, 86 (6); Half (alf, \$9 50. Popular Edition, two vols. in one, 12 mo, Cloth, $\$ 175$.

HCIES ENGLAND. The Hixtory of England, from the Invasion of Julius Casar to the Abdication of James II,, 1688. By Davin Hume. New and Elenant Lilnary Edition, from new Electrotype Platess. fi vols, in a Box, 8vo, Cloth, with Paper Lathels, Cnent Edges and (iilt Tops, \$12010. Sold only in sets. Popular Lithtion, 6 vols. in a Box, 12mo, ('loth, 83 (0); Sheep, \$4 50,

GIBBON'S ROME. The IIistory of the Deeline and Fall of the Roman Empire. By Enwan Grmbos. With Votes hy Dean Mamas, M. Gotzor, and Dr. Wrimim Surm. Xow Eilition, from new Electrotype Plates.

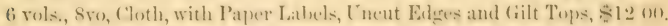

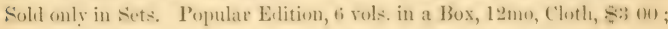
Sheep, \$ 50.

IILIDRETII ' CNITEI) ST.ITES. IIistory of the United States. Finst Sharrs: From the Discosery of the ('ontinent to the (1) ramization of the

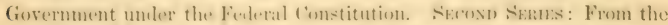
Alloption of the Ferleral constitution to the Fud of the Sixternth Con-

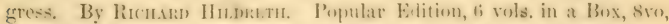
Cloth, with l'ituer Labels, l'nent biges and (iilt Tops, $\$ 12$ (n). Sold onlr in Sets. 
MOTLEYT DETCII REPLBLIC. The Rise of the Dutch Republic. A History. Byy Jomx Lotmop Motley, LL.D., D.C.L. With a Portrait of William of Orange. Cheap Edition, 3 vols, in a Box, $8 \mathrm{vo}$, Cloth, with Paper Labels, Lnent Eitges and Gilt Topss, \$ 600 . Siold only in Sets. Original Librany Edition, 3 vols., 8vo, Cloth, \$10 50; Sheep, \$1200; Half Calf, $\$ 1725$.

MOTLEI'S CNITED NETIERLANDS. Ilistory of the Lnited Netherlands: from the Death of William the Silent to the Twelve Years' Truee -158-1609. With a full View of the English-Dutch Struggele against Spain and of the Urigin and Destruction of the Spanish Amada. Iy John Lotinop Motrex, LL.D., D.C.L. Portraits. Cheap Edition, 4 vols. in a Box, 8vo, Cloth, with Paper Labels, Uncut Edges and Gilt Tops, $\$ 800$. Fold only in Sets. Original Library Edition, 4 vols., Sro, Cloth, $\$ 1400$; Sheep, $\$ 1600 ;$ Half Calf, $\$ 2300$.

MOTLEY' LFE AND DEATH OF JOIN OF BARNEVELD. The Life and Death of John of Barneveld, Adrocate of Holland: with a View of the Primary Causes and Movements of "The Thirty Years" War." By John Lotirop Motley, LL.D., D.C.L. Illustrated. Cheap Edition, 22 vols, in a Box, 8vo, Cloth, with Paper Labels, Uneut Edges and Gilt Tops, s. (0). Sold only in sets. Original Library Edition, 2 rols., 8 vo, Cloth, $\$ 700$; Sheep, $\$ 800 ;$ Half Calf, $\$ 1150$.

GEDDES'S IISTORY OF JOHN DE WITT. History of the Administration of John De Witt, Grand Pensionary of Holland. By JAMes Geddes. Vol. I.-1623-1654. With a Portrait. 8vo, Cloth, \$2 50.

SIETCHES AND STLDIES IN SOLTHERN ELROPE. BY JOHN AnDington Symonds. In Two Volumes. Post 8vo, Cloth, $\$ 400$.

SYMONDS'S GREEK POETS. Studies of the freek Pocts. By Jonn ADDington Srmonds. 2 vols., Square $16 \mathrm{mo}$, Cloth, $\$ 350$.

BENJAMINS CONTEIPORARY ART. Contemporary Art in Europe. By S. G. W. Benjanis. Illustrated. 8vo, Cloth, $\$ 350$.

BENJAMIN'S ART IN AMERICA. Art in America. By S. G. W. BENJAMIN. Illustrated. 8ro, Cloth, $\$ 400$.

HIDSON'S HISTORY OF JOLRNALISM. Joumalism in the United States, from 1690 to 1872 . By Fredenc IItusos. 8ro, Cloth, $\$ 500$; Half Calf, \$725.

KINGLAKE'S CRIMFAN WAR. The Invasion of the Crimea: its Origin, and an Aecomint of its Progress down to the Death of Lord Raglan. By Arexanele Whlidu Kinglake. With Maps and Plans. Three Tolumes now ready. $12 \mathrm{mo}$, Cloth, $\$ 200$ per vol. 


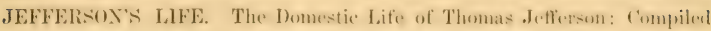

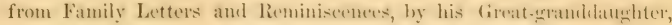
Sirah N. Raxdolir. Illustrated. Crown 8vo, Cloth, $\$ 250$.

LAMB't complete Woliks. The Works of Charles Lamb. Comprising his Letters, Poems, Essays of Elia, Exays upon Shakspeare, Iogarth, ete., and a Sketch of his Life, with the Final Memorials, by T. Noos Talfound. With Portrait. 2 vols., 12 mo, Cloth, $\$ 300$.

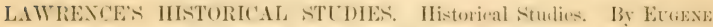
L.Awatare. Containing the following Exsays: The Bishops of Rome.Leo and Lather.-Loyela and the Jesuits-Eomenical foumeils.-The Vatulois.-The Huguenots.-The ('hureh of Jernsalem.-Dominic and the Inquisition.-The Conquest of Ireland.-The Greek Chureh. Sro, Cloth, Uncut Edges and Gilt Tops, $\$ 300$.

LOSEING'S FIELD-BOOK OF TIIE REVOLCTIOS. Pietorial FieldBook of the Revolution: or, Illustrations hy Pen amb P'encil of the History, Biograpley, Secenery, Relies, and Traditions of the Witr for Independence. By Brisson J. Lossing. 2 rols., 8 vo, Cloth, $\$ 1400$; Sheep or Roan, \$1500; Half Calf, \$18 00 .

LOSAING' FIELD-BOOK OF THE WAR OF 1sl:. Pictorial FiehlBook of the War of 1812; or, Illustrations by Pen and Pencil of the Ilistory, Biography, Seenery, lielies, and Traditions of the last War for American Independenee. By Bexson J. Lossixg. With several hundred Engravings on Wood hy Lassing and Barritt, chiefly fonn (triginal

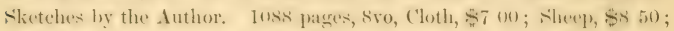
Roan, $\$ 900$; Half Calf, $\$ 1000$.

FORATER' LIFE OF DE.LY SIFHT. The Farly Life of Jonathan Swift (1667-1711). By Jorn Fonster. With Portrait. 8vo, Cloth, Uncut Edges and Gilt Tops, \$2 50.

GREENA E.NGISAI PEOPLE. IIistory of the English People. By Joms

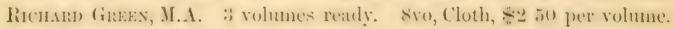

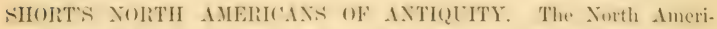
eans of Antiquity. Their Origin, Migrations, and Type of Civilization Considered. By Jonx T. Snort. Illustrated. 8vo, Cloth, \$3 00.

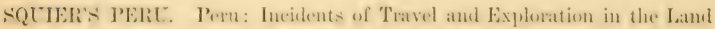

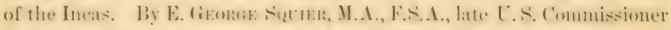
to Peru. With Illustrations. 8vo, Cloth, $\$ 500$.

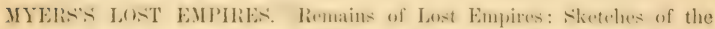
Ruins of Palmyra, Nineveh, Babylon; and Persepolis. By P. V. N. Myers. Illustrated. 8vo, Cloth, $\$ 350$. 
MAURY'S PIYSICAL GEOGRAPIIY OF THE SEA. The Physical Geography of the Sea, and its Meteorology. By M. F. Maunx, LL.D. Sro, Cloth, $\$ 400$.

SCIIWEINFURTH'S HEART OF AFRICA. The Пleart of Africa. Three Fears' Travels and Adventures in the Unexplored Regions of the Centre of Africa-from 1868 to 1871. By Dr. Geora Schweinfurti. Translated by ElLex E. Frewer. With an Introduction by Winwoop RE.aDe. Illustrated by about 130 Wood-euts from Drawings made by the Author, and with two Maps. 2 vols., 8 vo, Cloth, $\$ 800$.

M'CLINTOCK \& STRONG'S CYCLOP EDIA. Cyclopedia of Biblical, Theologieal, and Ecclesiastical Literature. Prepared by the Rev. JoHn M'Clintock, D.D., and Jimes Strong, S.T.D. 9 vols. non reuly. Royal 8vo. Price per vol., Cloth, \$500; Sheep, \$6 00; Half Horoeco, \$8 00 . (Sold by Subscription.)

MOHAMMED AND MOHAMMEDANISM: Lectures Delirered at the Royal Institution of Great Britain in February and March, 1874. By R. Bosworti Smin, M.A., Assistant Master in Harrow Sehool; late Fellow of Trinity College, Oxford. With an Appendix containing Emanuel Deutsch's Article on "Islam." 12mo, Cloth, \$1 50.

MOSHEIY'S CHURCH HISTORY. Ecclesiastical History, Ancient and Modern; in which the Rise, Progress, and Variation of Church Power are considered in their connection with the State of Learning and Philosophy, and the Political History of Europe during that Period. Translated, with Notes, ete., by A. Maclaine, D.D. Continued to 1826 by C. Coote, LL.D. 2 vols., 8vo, Cloth, $\$ 400$; Sheep, $\$ 500$.

IIARPER'S NEW CLASSICAL LIBRARY. Literal Translations.

The following rolumes are now ready. $12 \mathrm{mo}$, Cloth, $\$ 150$ each.

CæSAr.-Virgil. - Sillest - Horace. - Cichro's Orations - Cicfro's Offices, ete-Cicfro on Oratori and Orators.-Tacites ( 2 vols.). - Terence. - Sophocles. - Jutenal. Xenorhon. - Homer's Iliad. - Homer's Odyssey. - Herodotus. - Demosthenes ( 2 vols.). - Thucrdides.-Escirlus.-Euripides (2 vols.).-Liry (2 vols.).-Plato [Select Dialogues].

FINCENT'S LAND OF THE WHITE ELEPIANT. The Land of the White Elephant: Sights and Scenes in Southeastern $\Lambda$ sia. A Personal Narrative of Travel and Adventure in Farther India, embracing the Countries of Burma, Siam, Cambodia, and Cochin-China (1871-2). By Frisk Vincent, Jr. Illustrated with Maps, Plans, and Wood-cuts. Cromn 8ro, Cloth, $\$ 350$. 



. 

